Hans-Joachim Alscher

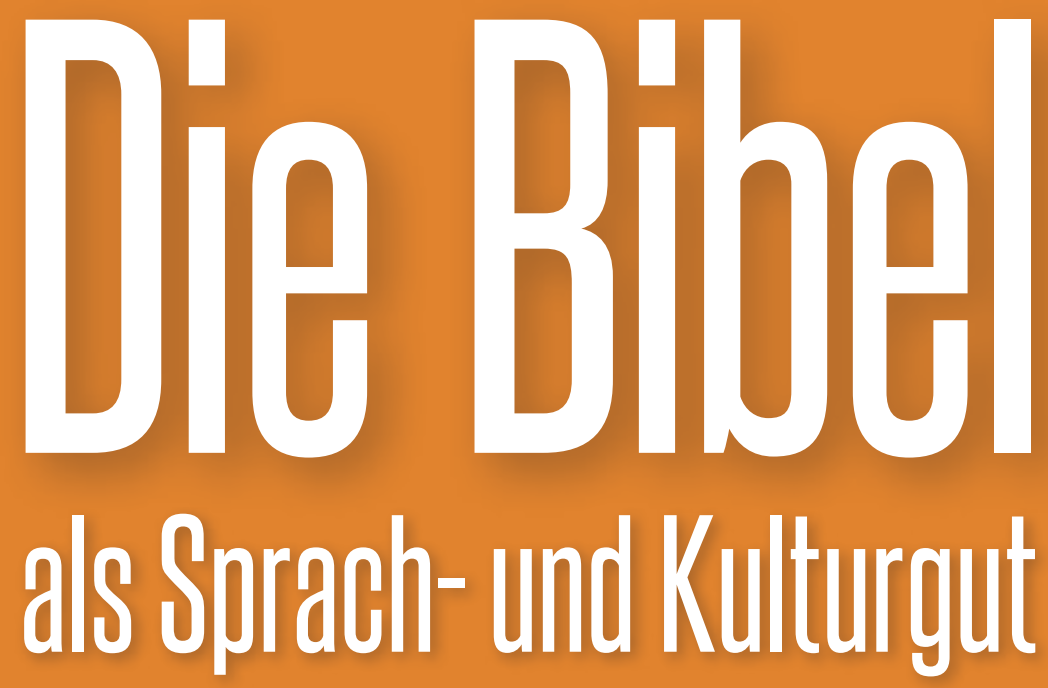

Katalog zur Ausstellung in der Niederösterreichischen Landesbibliothek 25. September bis 30. Oktober 2020

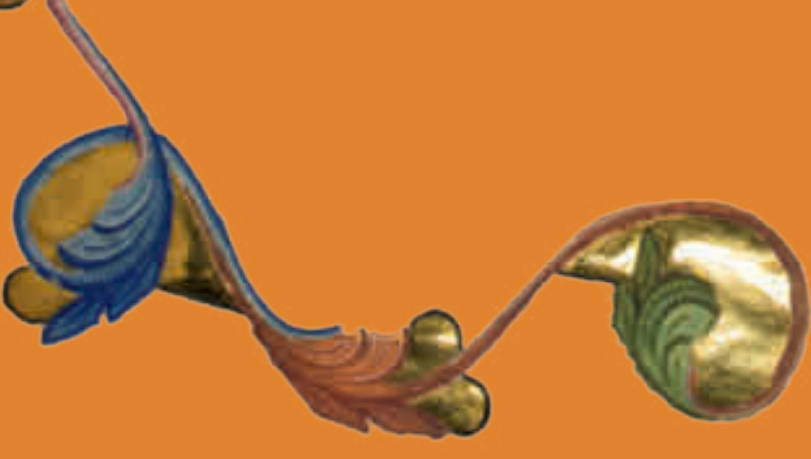

NÖ LANDESBIBLIOTHEK 
NÖ LANDESBIBLIOTHEK 
Sonder- und Wechselausstellungen der NÖ Landesbibliothek 45

\section{Die Bibel als Sprach- und Kulturgut}

25. September bis 30. Oktober 2020

\section{Ausstellung}

Kurator: Hans-Joachim Alscher

Ausstellungsgestaltung und -grafik: Sascha Windholz

Fotografien: Wolfgang Kunerth

Restaurierung und Ausstellungsaufbau: Ilse Entlesberger, Christa Gattringer, Johannes Haslhofer, Martin Havranek, Sebastian Steininger, Monika Zuba

Öffentlichkeitsarbeit: Herbert Schuster

Exponate: NÖ Landesarchiv und NÖ Landesbibliothek, Diözesanbibliothek St. Pölten, Gerhard Sarman, Kloster Heiligenkreuz, SLUB Dresden - Deutsche Fotothek, Stiftsbibliothek Klosterneuburg

\section{Begleitbuch}

Medieninhaber (Verleger und Herausgeber):

NÖ Institut für Landeskunde, 3109 St. Pölten, Kulturbezirk 4

Verlagsleitung: Elisabeth Loinig

Redaktion: Heidemarie Bachhofer

Grafik und Layout: Martin Spiegelhofer

Fotos: Wolfgang Kunerth (soweit nicht anders angegeben)

Umschlag: Sascha Windholz / Martin Spiegelhofer

Hersteller: Gugler GmbH, 3390 Melk, Auf der Schön 2

Land Niederösterreich

Gruppe Kultur, Wissenschaft und Unterricht

Abteilung NÖ Landesarchiv und NÖ Landesbibliothek

NÖ Institut für Landeskunde

www.noe.gv.at/landeskunde

(C) NÖ Institut für Landeskunde

ISBN 978-3-903127-22-7

St. Pölten 2020

Das Werk ist urheberrechtlich geschützt. Die dadurch begründeten Rechte, insbesondere die der Übersetzung, des Nachdrucks, der Entnahme von Abbildungen, der Rundfunk- oder Fernsehsendung, der Wiedergabe auf fotomechanischem oder ähnlichem Weg und der Speicherung in Datenverarbeitungsanlagen bleiben, auch bei nur auszugsweiser Verwendung, vorbehalten. 
Hans-Joachim Alscher

Die Bibel als Sprach- und Kulturgut Katalog zur Ausstellung in der Niederösterreichischen Landesbibliothek, 25. September bis 30 . Oktober 2020 
Bewohnte Initiale mit dem Evangelisten Johannes und seinem Adler, Stiftsbibliothek Klosterneuburg, Codex 4, fol. 10r, um 1410 (vgl. Abb. 2 und Katalog Nr. 2) 


\section{INHALTSVERZEICHNIS}

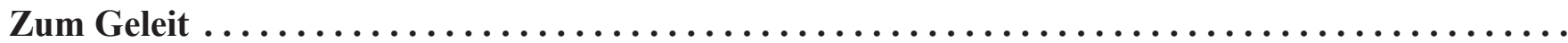

Landeshauptfrau Johanna Mikl-Leitner und Landesrat Ludwig Schleritzko

Diözesanbischof Dr. Alois Schwarz

Vorwort . .

Archivdirektor Priv. Doz. wHR Mag. Dr. Roman Zehetmayer, MAS

Einleitung .

1. Einführung und Begrifflichkeiten $\ldots \ldots \ldots \ldots \ldots \ldots \ldots \ldots \ldots \ldots \ldots \ldots \ldots \ldots \ldots \ldots \ldots \ldots$

1.1 Die Herkunft des Wortes Bibel. . . . . . . . . . . . . . . . . . . . . . . . . . . . . . . 21

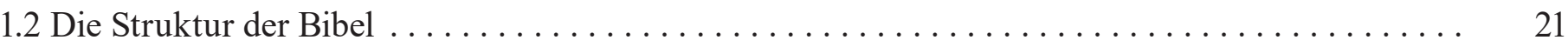

1.2.1 Apokryphen (Pseudepigraphen) . . . . . . . . . . . . . . . . . . . 24

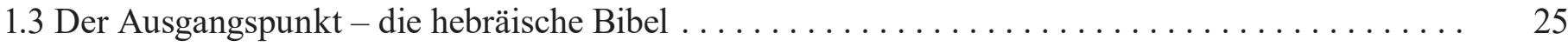

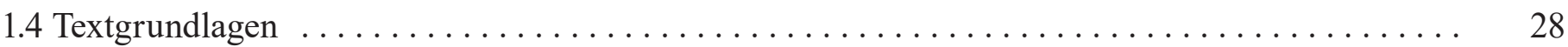

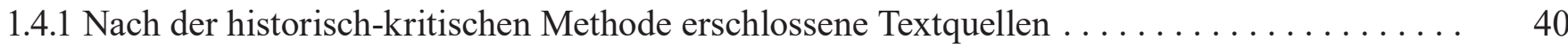

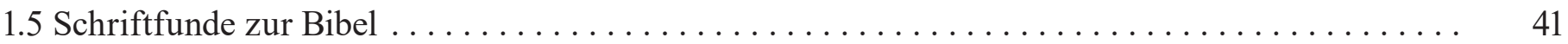

1.6 Textgattungen von Übersetzungen in Auswahl $\ldots \ldots \ldots \ldots \ldots \ldots \ldots \ldots \ldots \ldots \ldots \ldots \ldots$

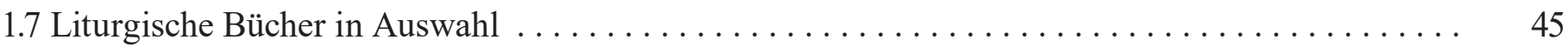

2. Die Bibel aus deutschsprachiger und aus niederösterreichischer Sicht $\ldots \ldots \ldots \ldots \ldots \ldots \ldots$

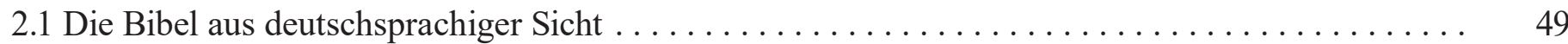

2.1 .1 Gotisch . . . . . . . . . . . . . . . . . . . . . . . . . . . . . . . 49

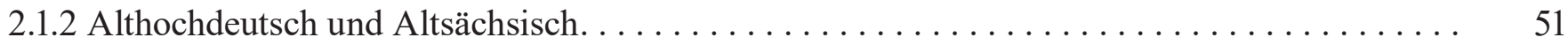

2.1.3 Gutenberg-Bibel und deutschsprachige Bibeldrucke in Auswahl $\ldots \ldots \ldots \ldots \ldots \ldots \ldots . \quad 52$

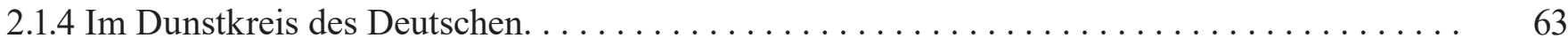




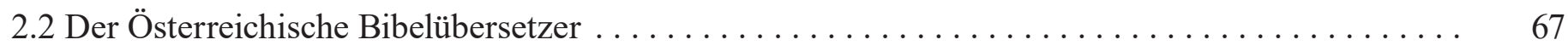

2.3 Ein niederösterreichischer Bibelübersetzer auf dem Index librorum prohibitorum. . . . . . . 68

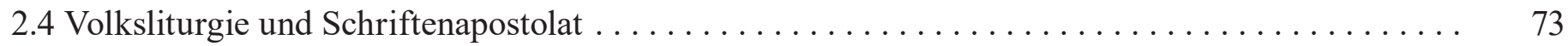

2.5 Das Missionshaus St. Gabriel der Steyler Missionare (SVD) in Maria Enzersdorf $\ldots \ldots \ldots \ldots .80$

3. Sprachfamilien und Schriftsysteme $\ldots \ldots \ldots \ldots \ldots \ldots \ldots \ldots \ldots \ldots \ldots \ldots \ldots \ldots \ldots \ldots \ldots$

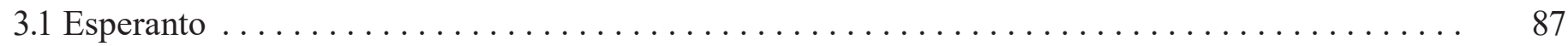

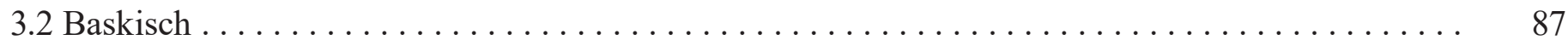

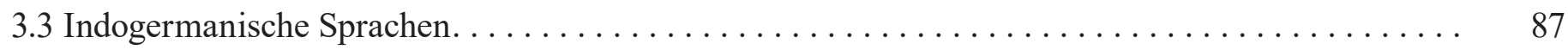

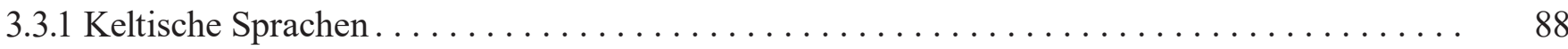

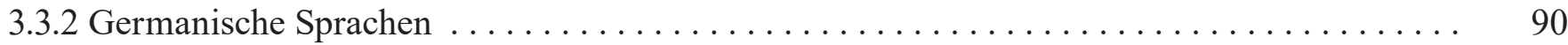

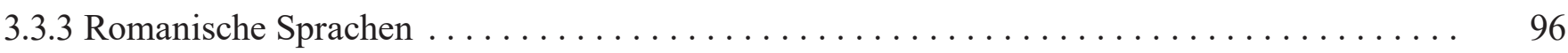

3.3.4 Baltische Sprachen............................................. 99

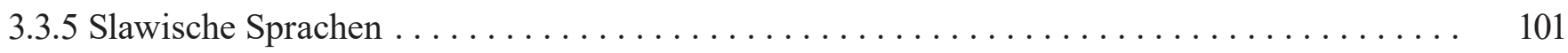

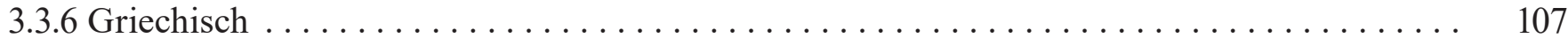

3.3 .7 Albanisch . . . . . . . . . . . . . . . . . . . . . . . . . . . . . . 109

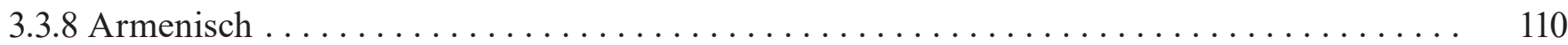

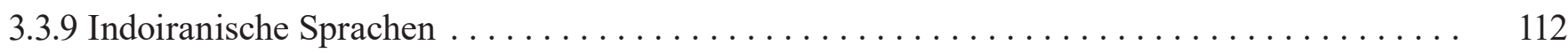

3.3.9.1 Iranische Sprachen . . . . . . . . . . . . . . . . . . . . . . . . 112

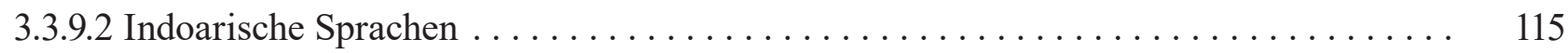

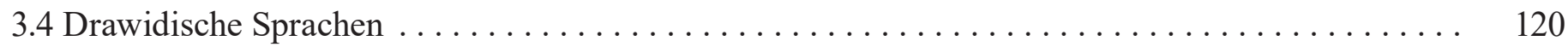

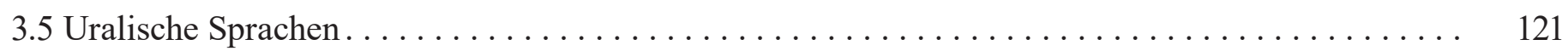

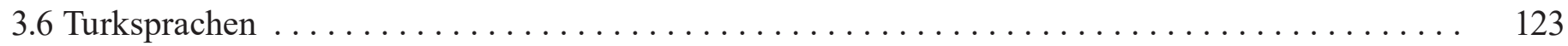

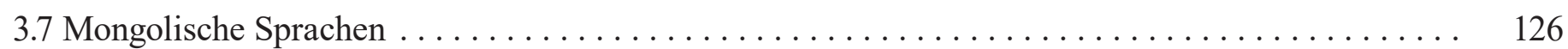

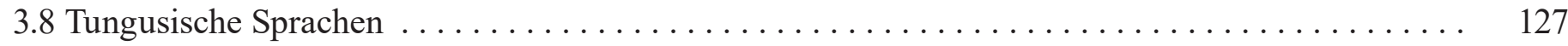

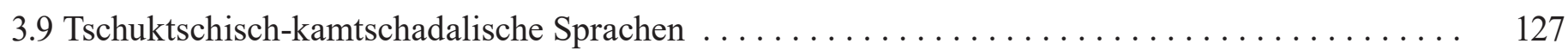

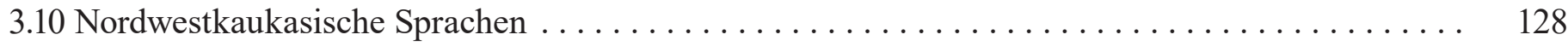

3.11 Nordostkaukasische Sprachen. . . . . . . . . . . . . . . . . . . . . . . . 128

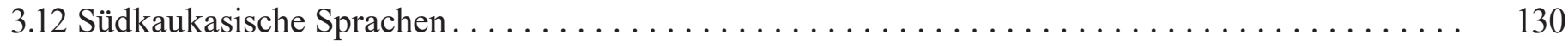




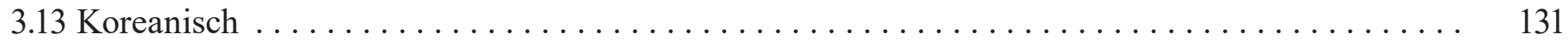

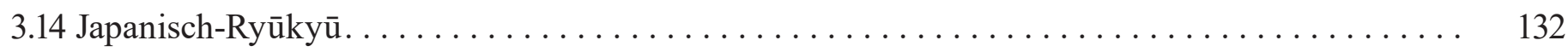

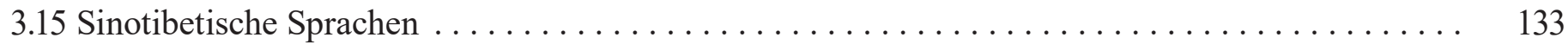

3.16 Hmong-Mien-Sprachen. . . . . . . . . . . . . . . . . . . . . . . . . . . . . . . 136

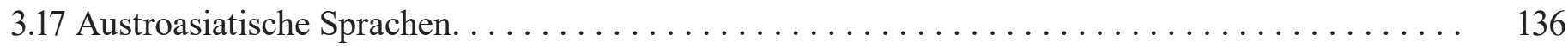

3.18 Tai-Kadai-Sprachen. . . . . . . . . . . . . . . . . . . . . . . . . . . . . . . . . . 137

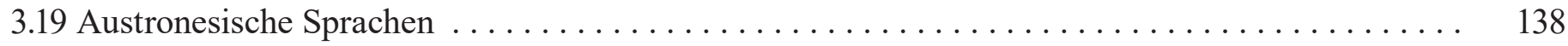

3.20 Afroasiatische Sprachen . . . . . . . . . . . . . . . . . . . . . . . . . . . . . 140

3.20 .1 Semitische Sprachen . . . . . . . . . . . . . . . . . . . . . . . . . . . . 141

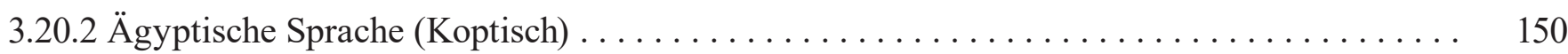

3.20 .3 Kuschitische Sprachen . . . . . . . . . . . . . . . . . . . . . . . . . 153

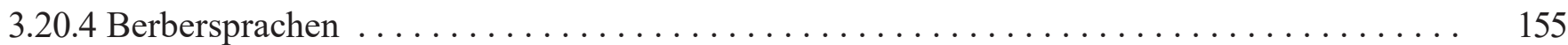

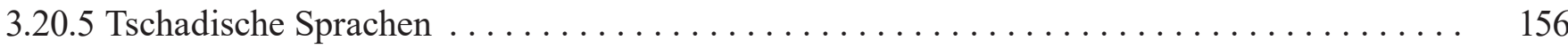

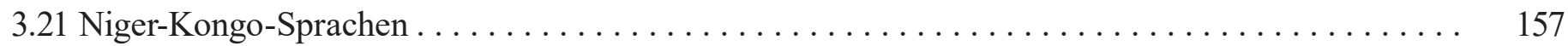

3.21 .1 Atlantische Sprachen ... . . . . . . . . . . . . . . . . . . . . . . . . . 159

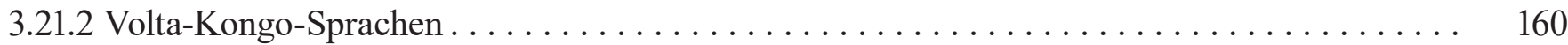

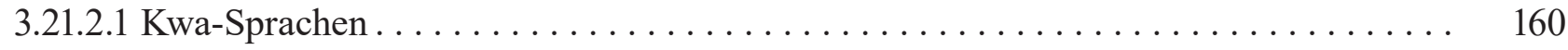

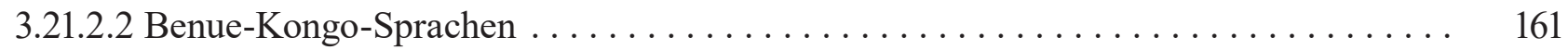

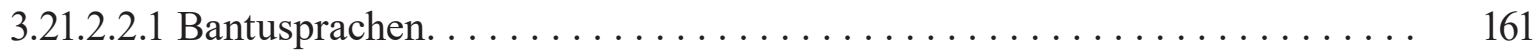

3.22 Nilosaharanische Sprachen (Ostsudanische Sprachen, Nilotische Sprachen) . . . . . . . . . . . 161

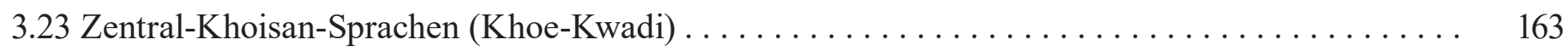

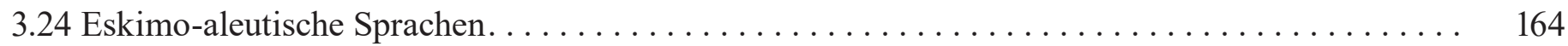

3.25 Haida. . . . . . . . . . . . . . . . . . . . . . . . . . . . . . . . . . 165

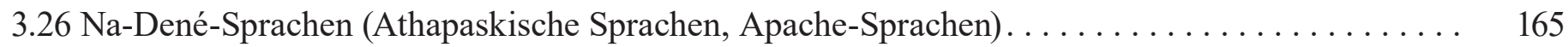

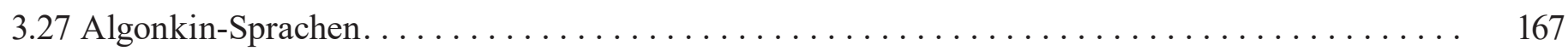

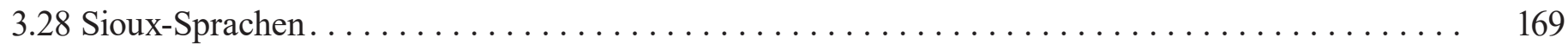

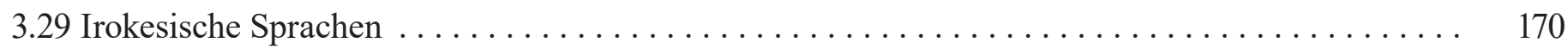

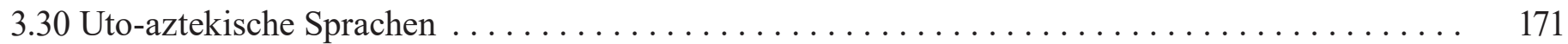




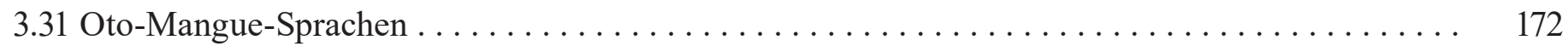

3.32 Maya-Sprachen . . . . . . . . . . . . . . . . . . . . . . . . . . . . . . . 174

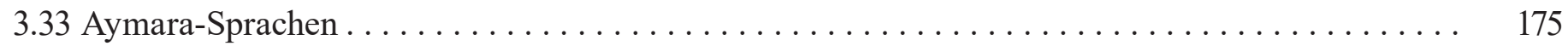

3.34 Quechua-Sprachen . . . . . . . . . . . . . . . . . . . . . . . . . . . . . 175

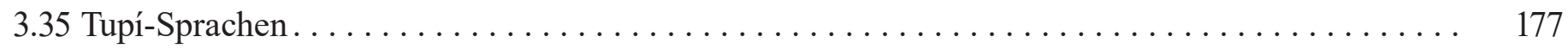

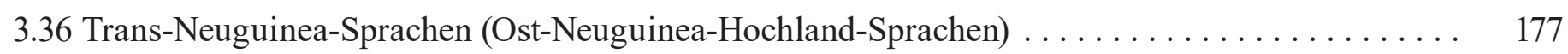

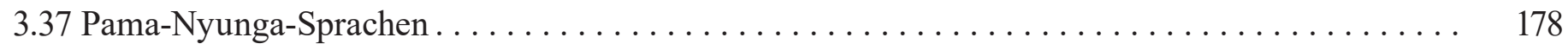

3.38 Braille-Schrift. . . . . . . . . . . . . . . . . . . . . . . . . . . . . . 180

Register der vertretenen Sprachen und Schriften $\ldots \ldots \ldots \ldots \ldots \ldots \ldots \ldots \ldots \ldots \ldots \ldots \ldots$

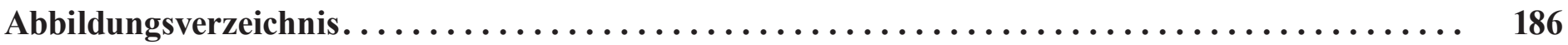

Bildnachweis............................................. 190 


\section{ZUM GELEIT}

Kein anderes Buch wurde öfter gelesen, übersetzt oder verkauft als die Bibel. Die Sammlung der heiligen Schriften hat nicht nur für die Christen auf aller Welt eine ganz besondere Bedeutung. Die Bibel hatte auch als Kulturgut über alle Zeiten hinweg einen hohen Stellenwert und ohne sie ist unsere europäische Kulturgeschichte nicht zu verstehen. Das gilt sowohl für die Verbreitung und das Erlernen von Sprache und Schrift wie auch für die bildenden Künste und die Philosophie. Nicht zuletzt hat der Disput um die Bibel bzw. deren Übersetzung und Interpretation das religiöse und politische Zusammenleben in Europa grundlegend verändert und auch entscheidend zur Ausbildung eines deutsch-

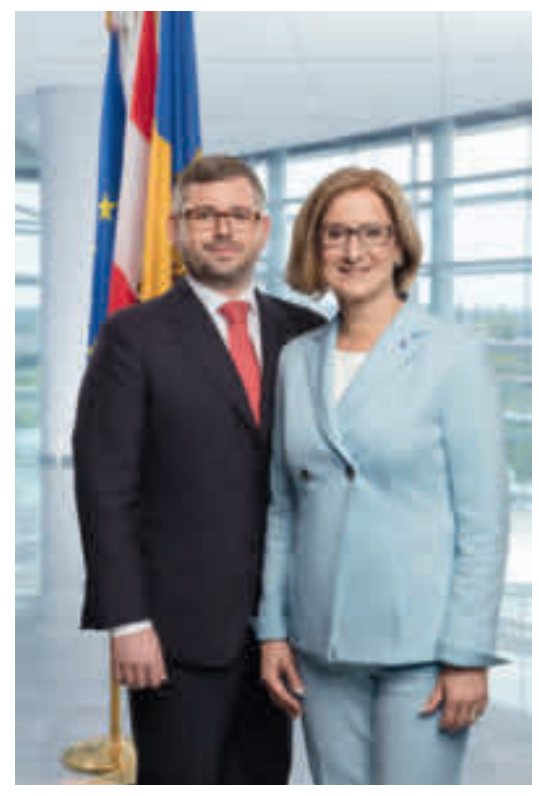
sprachigen Kulturraums auf unserem Kontinent beigetragen.

Die Niederösterreichische Landesbibliothek hütet in ihrem Bestand seit Jahrzehnten eine Vielzahl an Bibeln in verschiedensten Arten, Sprachen und Schriften. Dass man sich jetzt, in Zeiten der Diskussionen um eine gemeinsame europäische Identität, mit der Bedeutung dieses zentralen Schriftgutes auseinandersetzt und in den von der Österreichischen Bischofskonferenz ausgerufenen „Jahren der Bibel“ diese Sammlung vor den Vorhang holt, ist daher sehr naheliegend.

Aus diesem Grund wünschen wir Ihnen beim Besuch der Ausstellung in der Landesbibliothek und bei der Lektüre des begleitenden Katalogs viele spannende Einblicke in die christliche und europäische Kulturgeschichte.

Landeshauptfrau Johanna Mikl-Leitner

Landesrat Ludwig Schleritzko 


\section{ZUM GELEIT}

Die Bibel ist mein Lieblingsbuch. In der Bibel lese ich von Menschen, die Gott suchen, nach Gott fragen, Gott fürchten, an Gott zweifeln und schließlich Gott begegnen, Gott erfahren, eine Freundschaft und Beziehung aufbauen, mit allen Höhen und Tiefen, mit Jesus dem Christus. Oft höre ich davon, dass es zu jeder Lebenssituation eine Geschichte in der Bibel gibt. Umgekehrt ist es genauso: Es gibt zu jeder Bibelstelle einen Aspekt der persönlichen Lebenssituation. Es ist doch oft so, dass die Lesungen des Tages, der Sonntage, das Evangelium des Tages immer etwas mit meinem Leben zu tun haben - manchmal auch erst auf einen zweiten oder dritten Blick.

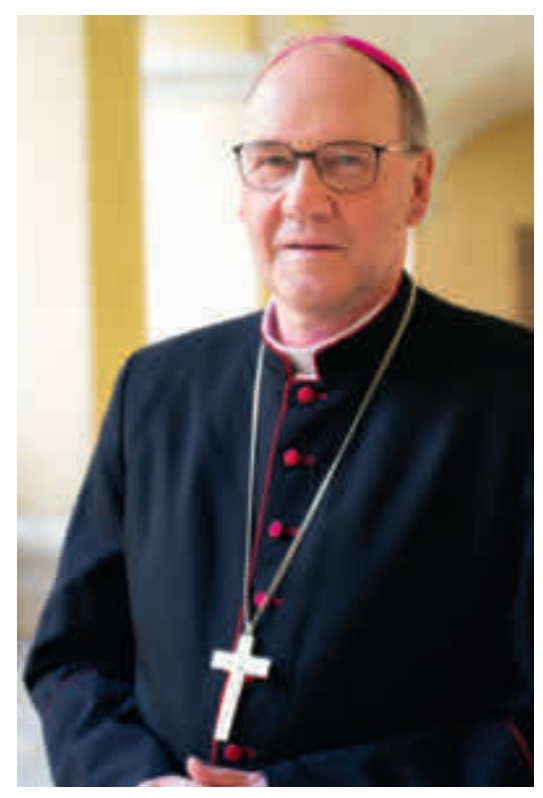

Gerade weil ich in der Bibel vom Leid und von der Sorge und der Angst der Menschen lese, finde ich in ihr auch Kraft und Mut und Hoffnung und Liebe. Die Bibel erzählt uns vom Leben in Fülle, vom Leben der Menschen in all seinen Schattierungen und Beziehungen, im Geflecht von richtig und falsch, von wahr und unwahr.

Die Bibel als meistübersetztes Buch ist nun das Thema der Bibelausstellung in der NÖ Landesbibliothek. Es fasziniert mich immer wieder aufs Neue, das Wort Gottes in so unterschiedlichen „Gewändern“ zu wissen: von den großen handgemalten Schriften und klösterlichen Lebenswerken zu den versteckten und getarnten Schriften der verfolgten Christinnen und Christen weltweit, von der Kinderbibel bis zu den Familienbibeln, mit Geburtstagen und einer Chronik, oder auch als App auf dem Handy, in so vielen Sprachen der Menschheit. Das Wort Gottes bleibt ein Haltegriff für die Welt.

Ich wünsche den Besucherinnen und Besuchern eine Begegnung, eine Neuentdeckung und eine spannende Auseinandersetzung mit dem Weltbuch Bibel.

Diözesanbischof Dr. Alois Schwarz 


\section{VORWORT}

Mangels Quellen ist es müßig, darüber zu spekulieren, wann und wo die ersten Bibeln im heute niederösterreichischen Raum aufbewahrt oder hergestellt worden sind. Nichtsdestotrotz ist davon auszugehen, dass bereits in der Antike hier befindliche Klerikergemeinschaften, wie etwa jene um den heiligen Severin in Mautern, oder Priester Bibeln besessen haben. Im Frühmittelalter ist dies jedenfalls für die kleine Klosterzelle zu St. Pölten oder für die in Niederösterreich wirkenden Passauer Chorbischöfe anzunehmen, wofür sich in einer Urkunde des Jahres 903 mit einer Auflistung etlicher Handschriften des Chorbischofs Madalwin sogar ein deutlicher Hinweis findet, werden hier doch auch die vier Evangelien erwähnt. Freilich gibt es gerade aus dieser Zeit auch Berichte über sehr ungebildete Kleriker, die zum Teil vermutlich nicht einmal lesen konnten. Dies könnte auch auf den einen oder anderen Priester der adeligen Eigenkirchen im Hochmittelalter zutreffen. Nichtsdestotrotz waren spätestens damals Bibeln nicht nur in den in großer Zahl gegründeten Klöstern, sondern wohl auch in den meisten Landpfarren und Burgkapellen Niederösterreichs vorhanden. Aus einer Urkunde des Jahres 1136 erfahren wir, dass Markgraf Leopold III. und seine Frau Agnes eine Bibel in drei Bänden und ein Missale vom Passauer Stift St. Nikola erhalten haben, die anschließend wohl in der Bibliothek zu Klosterneuburg aufbewahrt worden sind.

Allein aus diesen skizzenhaften Andeutungen lässt sich vielleicht erahnen, welch große Bedeutung Bibeln auch für die Geistes- und Kulturgeschichte Niederösterreichs gehabt haben und haben. Deshalb freut es mich sehr, dass einige damit in Verbindung stehende Aspekte - vor allem jener der Bedeutung von Bibelübersetzungen und darüber hinaus ganz allgemeine Fragen zum Thema Bibel und Sprache in einer eigenen Ausstellung in der Niederösterreichischen Landesbibliothek ausführlich behandelt werden. Bei allen, die zum Gelingen beigetragen haben, besonders aber beim Kurator und Autor des vorliegenden Begleitbandes, Bibliotheksdirektor wHR Mag. Hans-Joachim Alscher, dem das Thema sichtlich zu einer Herzensangelegenheit geworden ist, möchte ich mich recht herzlich bedanken und der Ausstellung jene große Resonanz wünschen, die sie verdient.

Archivdirektor Priv. Doz. wHR Mag. Dr. Roman Zehetmayer, MAS Leiter der Abteilung NÖ Landesarchiv und NÖ Landesbibliothek 



\section{EINLEITUNG}

Die Österreichische Bischofskonferenz hat die „Jahre der Bibel“" vom 1. Dezember 2018 bis 3. Oktober 2021 unter dem Motto „BIBEL - Hören. Lesen. Leben“ ausgerufen. Grund dafür bietet das Erscheinen der neuen Mess-Lektionare (Sonn- und Festtage Lesejahr C 2018, Lesejahr A 2019, Lesejahr B 2020) nach der „Einheitsübersetzung 2016“. In der Diözese St. Pölten sind dem Thema „10 Tage für die Bibel“ vom 25. September bis 4. Oktober 2020 gewidmet. $^{1}$

Die Niederösterreichische Landesbibliothek beteiligt sich an den entsprechenden Aktivitäten mit einer eigenen Ausstellung zum Thema Bibel. Dabei sollen nicht theologische Fragen im Zentrum stehen, sondern die Bibel in ihrer Bedeutung als Sprach- und Kulturgut vorgestellt werden. Den Hintergrund dazu bildet der Umstand, dass im Laufe der Jahre ein ansehnlicher Bestand an Bibeln in verschiedenen Sprachen und Schriften angewachsen ist, der hiermit der Öffentlichkeit vorgestellt werden soll.

Häufig wird an Übersetzungsliteratur, mithin auch an christlicher Übersetzungsliteratur, bemängelt, dass die Sprache des Ausgangstextes Einfluss auf die Sprache der Übersetzung nimmt, sie also gewissermaßen verfälscht, weshalb originärer Literatur der jeweiligen Sprache der Vorzug zu geben sei, soweit das möglich ist. Allerdings wird auch bei solcher originärer Literatur oft die Frage nach Spuren christlichen Einflusses aufgeworfen. Ohne dieses Argument entkräften zu wollen, sei darauf hingewiesen, dass christliche Übersetzungsliteratur oft den Beginn der Schriftlichkeit, gelegentlich auch deren bisher einziges oder im Falle des Sprachtodes auf Dauer deren einziges Ergebnis darstellt. Kein anderes Werk ist in so viele Sprachen übersetzt worden wie die Bibel und ihre Teile. In der Bemühung um theologische Angemessenheit wurde häufig um die bestmögliche Übersetzung gerungen, sodass eine Bibelübersetzung in der Regel eine weit höhere literarische Qualität aufweist als die häufigen Schnellübersetzungen von Trivialliteratur. Gerade das Argument der Rückwirkung des Ausgangstextes kann man auch als Stärke der Bibelübersetzungen ansehen: das Hervorbringen eines auch wegen seiner Bekanntheit gut vergleichbaren Textes in verschiedenen Sprachen.

1 Vgl. https://bibel.dsp.at/einrichtungen/bibelweg/jahre-der-bibel, https://bibel.dsp.at/10-tage-bibel, http://www.jahrederbibel.at/ und https://presse.dsp.at/ einrichtungen/kommunikation/artikel/2020/bibelwoche-der-dioezese-st-poelten-findet-statt (23.6.2020). 
Ganz sicher kann eine Ausstellung zur Bibel und ihren Teilen in verschiedenen Sprachen und Schriften die Buntheit des Themas Bibel und Sprache näherbringen.

Zuletzt möchte ich mich noch bei folgenden Personen und Institutionen bedanken, die zum Gelingen von Ausstellung und Katalog beigetragen haben.

Besonderer Dank gebührt zunächst der Stiftsbibliothek Klosterneuburg, namentlich Dr. Martin Haltrich, als Leihgeber des Codex Claustroneoburgensis 4, dem Diözesanarchiv und der Diözesanbibliothek St. Pölten, namentlich Dr. Thomas Aigner und dessen Stellvertreter Mag. Karl Kollermann, als Leihgeber des Codex Sanhippolytensis 54 sowie Mag. Gerhard Sarman, Leiter des kirchlichen Bibliothekswesens der Erzdiözese Wien, für die privaten Leihgaben der Dietenberger-Bibel von 1534 sowie der Froschauer-Bibel von 1538 und manchen wertvollen Ratschlag. Dem Heiligenkreuzer Stiftsarchivar P. DDr. Alkuin Schachenmayr ist die Zurverfügungstellung von zwei Porträtfotos von P. Nivard Schlögl, dem Klosterneuburger Stiftsarchivar Dr. Karl Holubar die Zurverfügungstellung eines Porträtfotos von Pius Parsch und der SLUB Dresden / Deutsche Fotothek / Hans Loos die Zurverfügungstellung einer Reproduktion von Albrecht Dürers Kupferstich „Hieronymus im Gehäus“ zu danken.

Für die Ausstellungsgestaltung und -grafik konnte Sascha Windholz, für die Redaktion des Katalogs Mag. Heidemarie Bachhofer, für Grafik und Layout des Katalogs Martin Spiegelhofer, für den Druck des Katalogs die Gugler GmbH und als Verleger das NÖ Institut für Landeskunde, namentlich die Institutsleiterin Mag. Elisabeth Loinig, gewonnen werden, die Fotografien besorgte Wolfgang Kunerth, für die Öffentlichkeitsarbeit zeichnet Mag. Herbert Schuster verantwortlich. Für Restaurierung und Ausstellungsaufbau standen Mag. Ilse Entlesberger, Dr. Christa Gattringer, Johannes Haslhofer, BA BA MA, Martin Havranek, Sebastian Steininger und Monika Zuba zur Verfügung. Bedanken möchte ich mich auch bei Dr. Ralph Andraschek-Holzer, Dr. Achim Doppler und Dr. Peter Gretzel für die kritische Durchsicht der Erstfassung des Manuskripts.

Schlussendlich sei Gerlinde Falkensteiner und Mag. H. Leopold Klenkhart von der Bibliotheksfachstelle der Diözese St. Pölten und Mag. Karin Hintersteiner, der Referentin für Bibelpastoral der Diözese St. Pölten, für die fruchtbringende Zusammenarbeit gedankt. Ohne ihre Initiative und weitere Beharrlichkeit wäre das Projekt weder angedacht noch weiter verfolgt und ohne die wohlwollende Unterstützung des Leiters der Abteilung NÖ Landesarchiv und NÖ Landesbibliothek, Archivdirektor Priv. Doz. wHR Mag. Dr. Roman Zehetmayer, MAS, auch nicht verwirklicht worden. 


\section{EINFÜHRUNG UND BEGRIFFLICHKEITEN}

\section{In principio ...}

In principio creavit Deus caelum et terram. In principio erat verbum et verbum erat apud Deum et Deus erat verbum. ${ }^{2}$ So lautet der Anfang der Bücher Genesis ${ }^{3}$ bzw. Johannes ${ }^{4}$ in der lateinischen Bibel und gibt dabei mit In principio das hebräische neutestamentliche Text greift bewusst auf den alttestamentlichen zurück; der Anklang ist also kein Zufall. Die beiden Schlüsselstellen wurden auch häufig entsprechend prunkvoll gestaltet und zeigen in illuminierten Handschriften oft Prunkinitialen. Neben dem Wortwitz, diese beiden Bibelstellen zusammen an den Anfang zu stellen, werden damit zugleich zwei Zimelien präsentiert: der Beginn der Genesis anhand Blatt $5 \mathrm{r}$ der Handschrift 54 der Diözesanbibliothek St. Pölten, einer um 1230 entstandenen Pergamenthandschrift aus Paris mit dem Text der Vulgata, ${ }^{5}$ und der Beginn des Johannesevangeliums anhand Blatt 10r des Codex 4 der Stiftsbibliothek Klosterneuburg, einer um 1410 entstandenen Pergamenthandschrift mit dem um 1330 abgefassten mittelhochdeutschen „(Klosterneuburger) Evangelienwerk“ des sogenannten Österreichischen Bibelübersetzers. ${ }^{6}$

Das Thema der Bibelübersetzung bildet den Fokus dieser Zusammenstellung und wird daher gleich zu Beginn durch den heiligen Hieronymus (347-420) anhand des berühmten Kupferstiches von 1514 „Hieronymus im Gehäus“" von Albrecht Dürer (1471-1528) verkörpert. Hieronymus ist als Übersetzer der als Vulgata bezeichneten lateinischen Bibel, die in der katholischen Kirche in der Version Sixto-Clementina von 1592 bis zum Zweiten Vatikanum als Grundlage aller anderen Übersetzungen diente, gewissermaßen der Archetyp des Bibelübersetzers.

2 „Im Anfang erschuf Gott Himmel und Erde. Im Anfang war das Wort und das Wort war bei Gott und das Wort war Gott.“ (Wiedergabe nach der „Einheitsübersetzung 2016“)

3 Gen $1,1$.

4 Joh 1,1

5 Die auf den heiligen Hieronymus (347-420) zurückgehende lateinische Bibelübersetzung vom Ende des vierten Jahrhunderts. Die vorliegende Handschrift beinhaltet außer der Vulgata mit Schmuckinitialen (Blatt 1r-274v) ab Blatt 276r Werke von Stephen Langton (ca. 1150-1228) wie die ,Interpretationes nominum hebraicorum“; am Schluss der Handschrift ist ein F. Gentiloltus Caesar und das Ende des dreizehnten Jahrhunderts erwähnt. Die belebte Initiale I am Beginn der Genesis zeigt das „Hexaemeron“ (Sechstagewerk der Schöpfung).

6 Näheres dazu in Kapitel 2.2. 


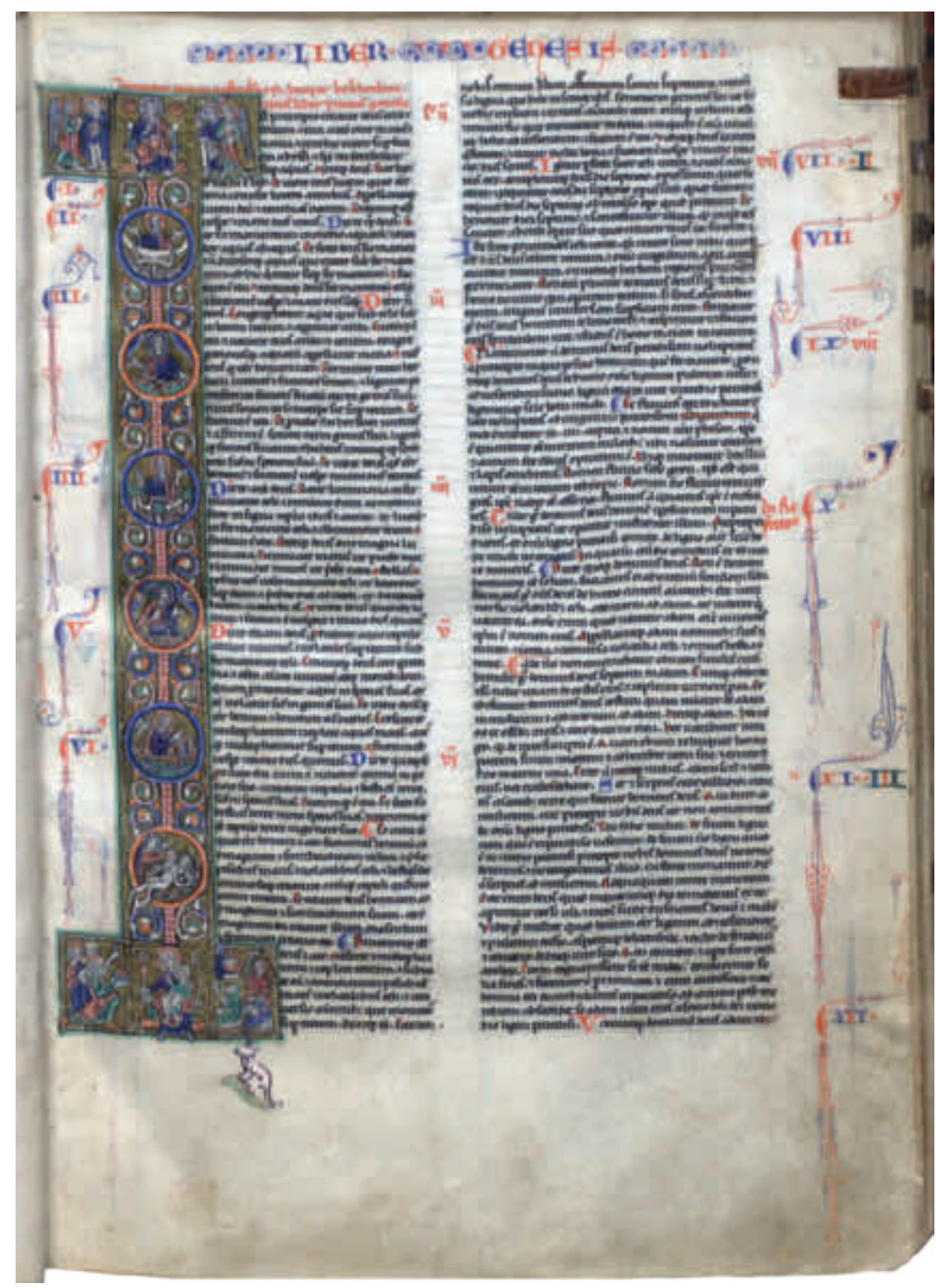

Abb. 1 / Katalog Nr. 1: Handschrift 54 der Diözesanbibliothek St. Pölten (um 1230), Blatt 5r, bewohnte Initiale mit dem Hexaemeron
Als Zimelien sind auch die Handschriftenfragmente aus Landesarchiv und Landesbibliothek $\mathrm{zu}$ werten: Hinter Signatur Varia 012 des Niederösterreichischen Landesarchivs verbirgt sich das Fragment einer jüdischen Ester-Rolle (Megilla) aus der Zeit um $1400{ }^{7}$ Zwei Inkunabeln im Zusammenhang mit der 1485 erfolgten Heiligsprechung von Markgraf Leopold III. (1073-1136) aus der Niederösterreichischen Landesbibliothek, die „Historia Sancti Leopoldi“, Passau, um 1489 (Signatur 139.392 B), und die „Oratio in laudem Leopoldi Marchionis Austriae“ des 1486 verstorbenen Johannes Franciscus de Pavinis, Passau, um 1485 (Signatur 139.394 B), besitzen jeweils einen Einband aus Pergamentmakulatur mit Textstellen aus der Vulgata.

\section{1}

\section{Handschrift. Diözesanbibliothek}

St. Pölten, Hs. 54

Paris, um 1230. - 314 Blätter;

$24,5 \times 16,5 \mathrm{~cm}$

Pergament

Blatt 1a-274b (aufgeschlagen: Blatt 5r):

Bibel. Lateinisch (Vulgata). Lateinische Schrift

Abb. 1

$7 \quad$ Vgl.https://www.noela.findbuch.net/php/main.php?be kurz $=5661726961 \&$ ve_vnum $=12 \# 5661726961 \times 1 \overline{2}$ (23.6.2020). 
2

Handschrift. Stiftsbibliothek Klosterneuburg, Cod. 4

Niederösterreich [?], um 1410. 365 Blätter; $42,5 \times 32 \mathrm{~cm}$

Pergament

aufgeschlagen: Blatt 10r:

Österreichischer Bibelübersetzer.

Klosterneuburger Evangelienwerk.

Mittelhochdeutsch. Lateinische

\section{Schrift}

Abb. 2

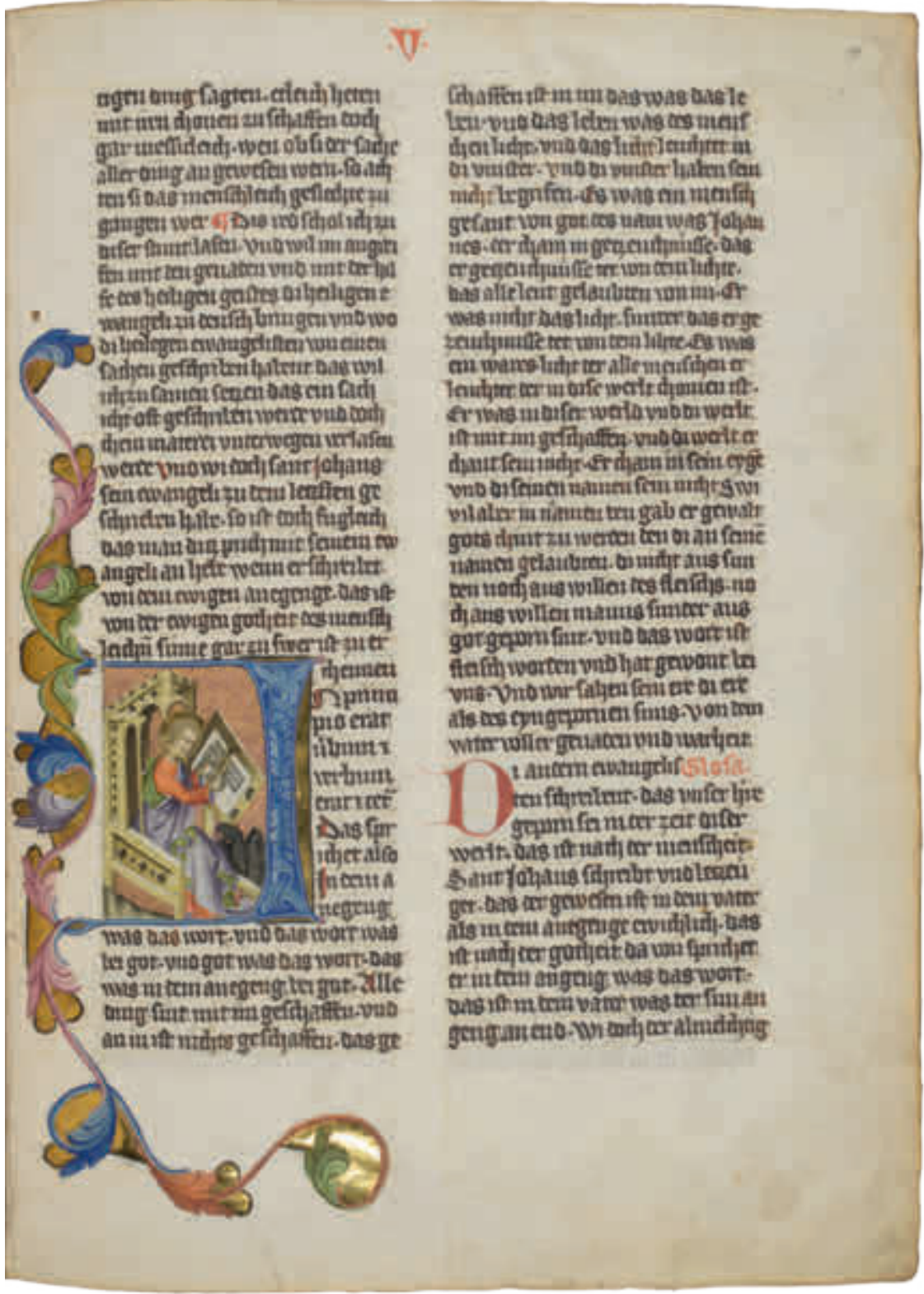

Abb. 2 / Katalog Nr. 2: Codex 4 der Stiftsbibliothek Klosterneuburg (um 1410), Blatt 10r, bewohnte Initiale mit dem Evangelisten Johannes und seinem Adler (siehe auch Umschlagbild). 


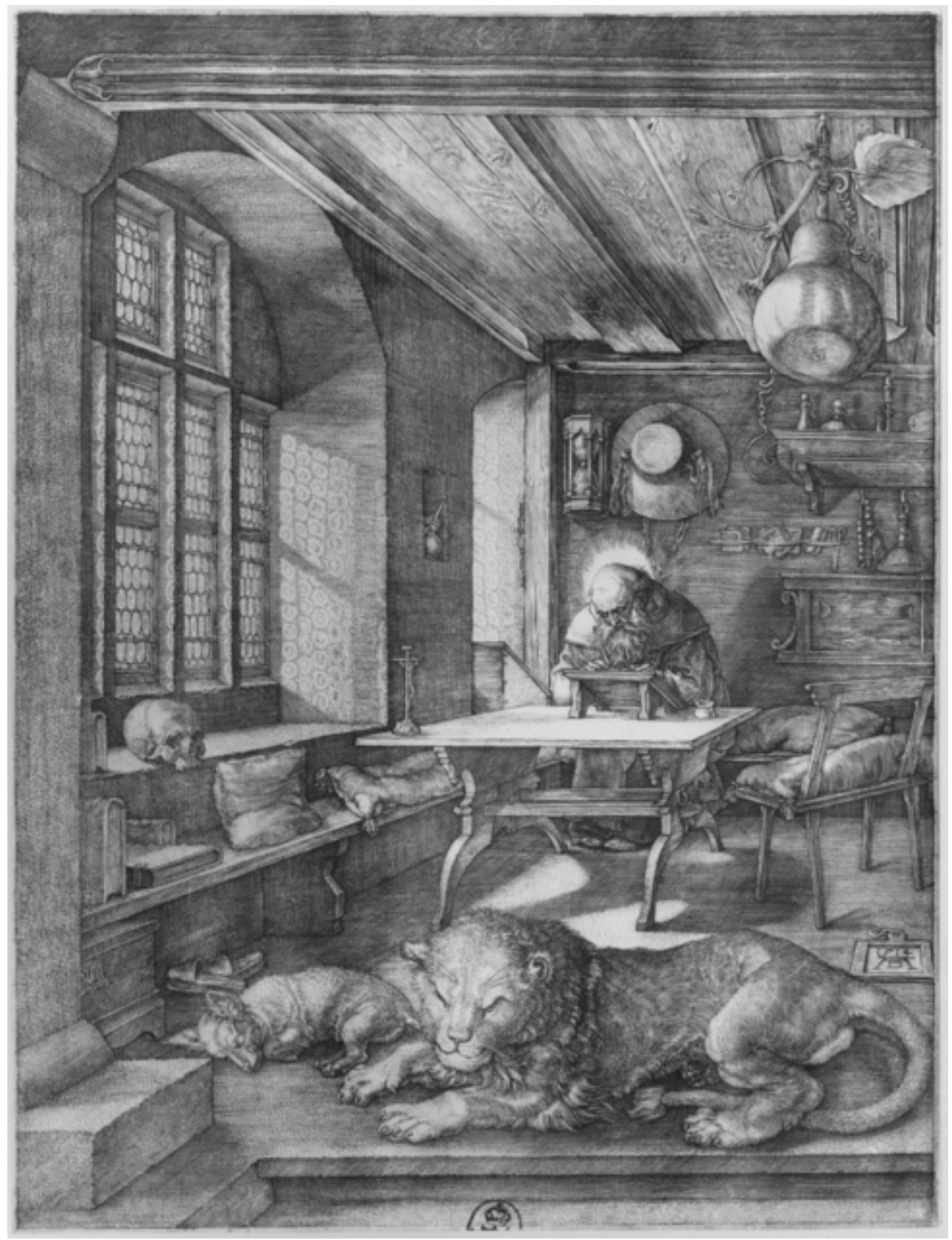

I8
3

Dürer, Albrecht, 1471-1528.

Hieronymus im Gehäus

1514. -1 Blatt; $24,5 \times 18,7 \mathrm{~cm}$

Kupferstich

Staatliche Kunstsammlungen

Dresden, Kupferstich-Kabinett,

B 60

Faksimile

Abb. 3 
Fragmente. NÖ

Landesbibliothek, Signatur

139.392 $B$ und 139.394 $B$

Pergamentmakulatur

Bibel. Lateinisch (Vulgata).

Lateinische Schrift

Faksimile

Abb. 4

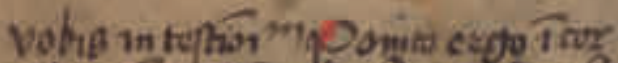

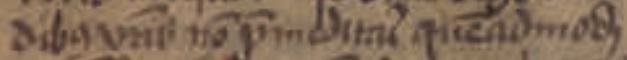

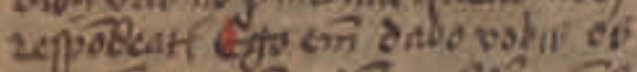

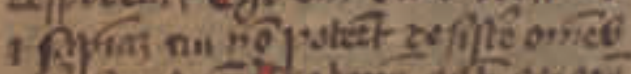

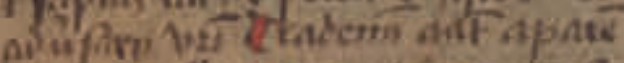

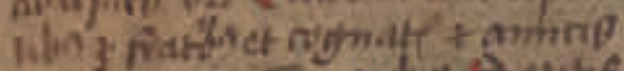

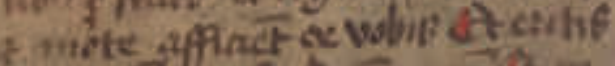

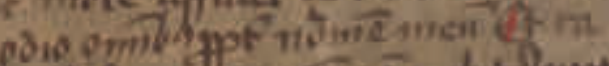

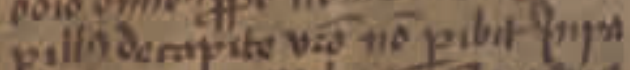

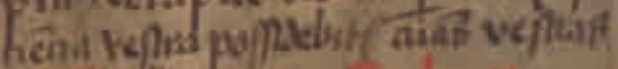
nillo tomin Doplendents thic stmank

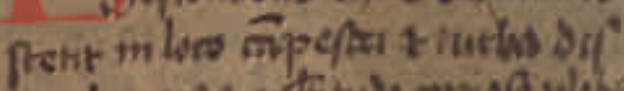

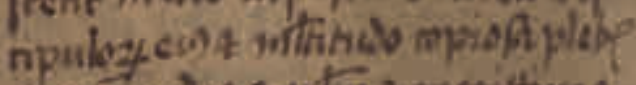

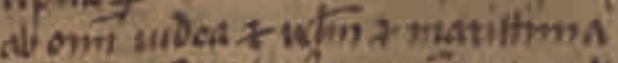

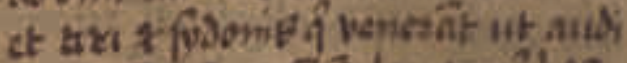

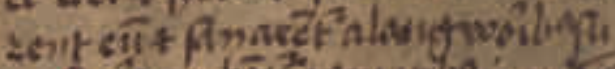

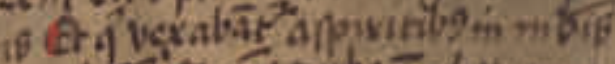

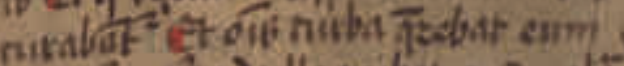

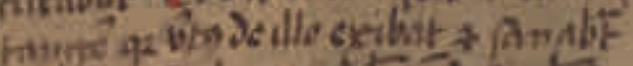

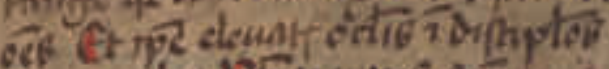

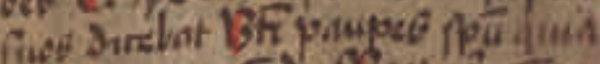

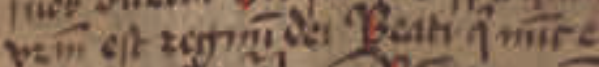

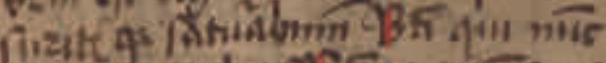

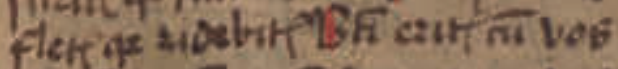

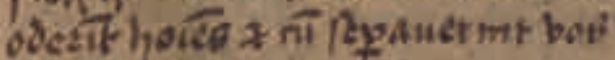

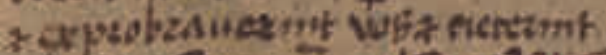

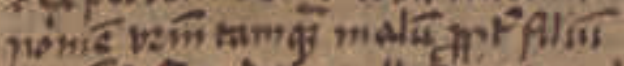

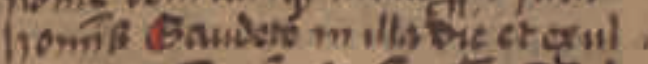

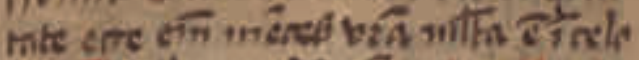

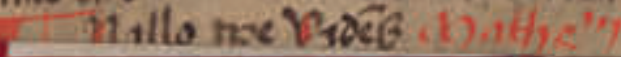

giा यf foplabirt aiif + finit iufhin Thialut 20 fin

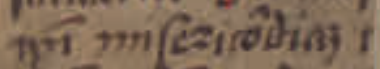
bु mos arde 4 vidclint Bfiparif Jsi veralimt $13 \frac{6}{4}$ fonmt fyptivita

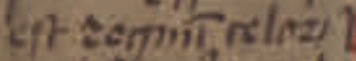
halobueint vdr fienits wol fictint one aduizfizls distine Baiben +cxieltake 4 मा wiva ep in reh

71 Atropमre afo:

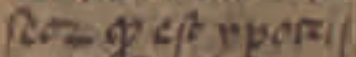
opezfir 20 os buis fombinity no fo. in rencleia Divet * $\mathrm{f}^{2}$ in aure lons nulie foumbintes vobid anurfarcig ablivitin amba her na habefom naf of stiplenicie an =ithabef prive, ches dim lones

Abb. 4 / Katalog Nr. 4: Johannes Franciscus de Pavinis, Oratio in laudem Leopoldi Marchionis Austriae (1485 [?]), Einband mit Pergamentmakulatur. 


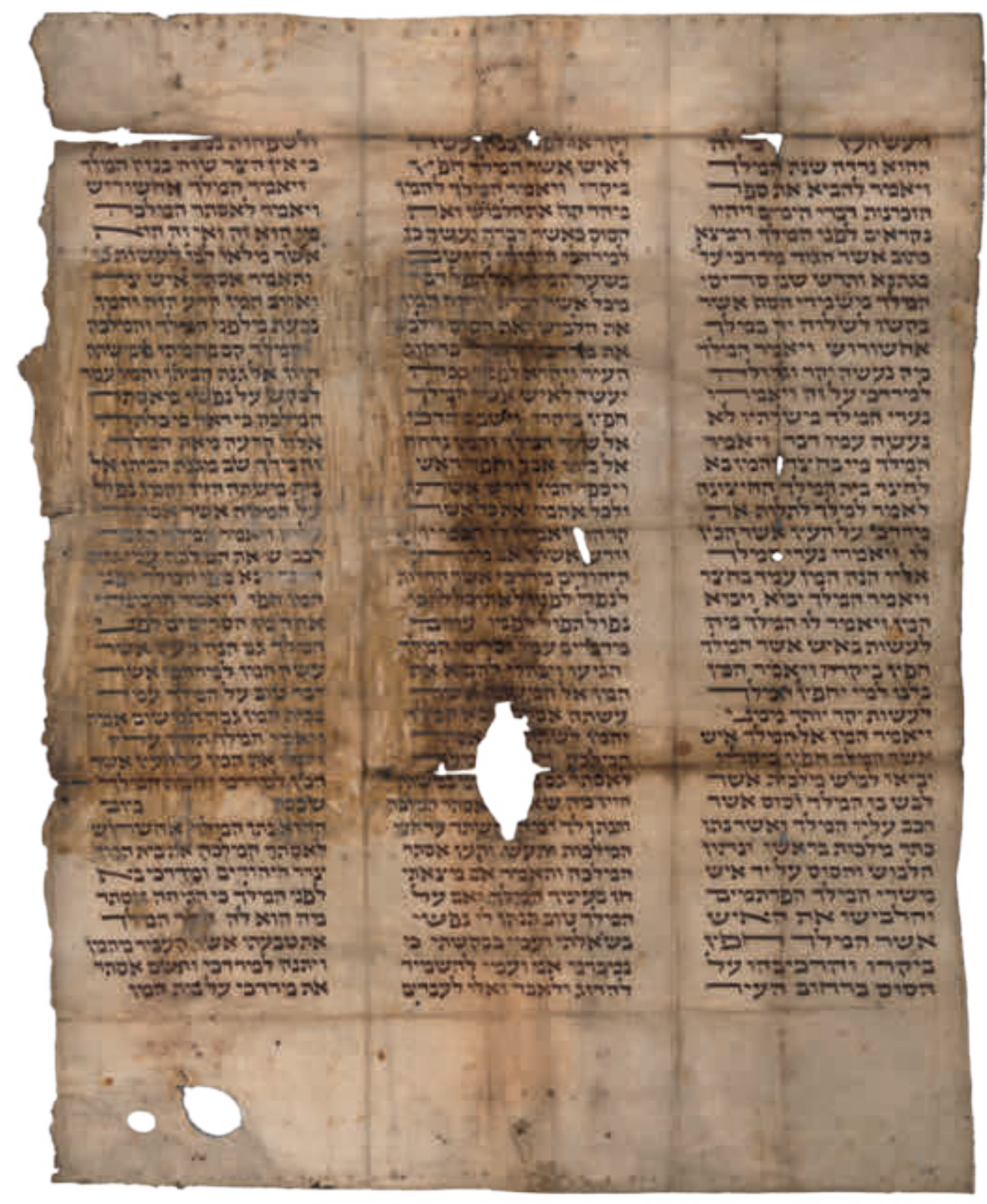

\section{5}

Fragment. NÖ Landesarchiv, Signatur Varia 012

ca. 1400-1420. - 1

Blatt; $49,0 \times 60,5 \mathrm{~cm}$

Pergamentrolle (Megilla)

Bibel. Ester. Hebräisch.

Hebräische Schrift

Abb. 5 


\subsection{Die Herkunft des Wortes Bibel}

Bibel - was ist das eigentlich? Vordergründig betrachtet, liegt die Pluralform $\beta \imath \beta \lambda i ́ \alpha$ biblia des griechischen Wortes $\beta 1 \beta \lambda$ íov biblion (Büchlein, Schrift, Buch; Diminutiv zu $\beta$ í $\beta \lambda$ os biblos Buch) vor. Der Wortstamm findet sich auch in Bibliothek, Bibliothekar, Bibliografie oder Bibliophilie wieder. Von der griechischen Herkunft abgesehen, ergibt sich somit, dass „,die Bibel“ eigentlich die Mehrzahlform „die Bücher“ wiedergibt und lediglich als Einzahlwort reinterpretiert worden ist, man denke dabei an die einzelnen biblischen Bücher.

Weniger bekannt ist, dass biblion oder biblos $^{8}$ sich nicht aus dem Griechischen selbst erklärt; in Wahrheit steckt

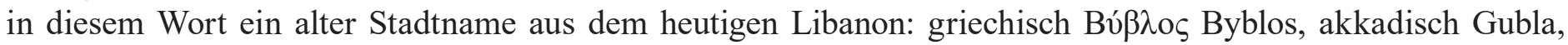
ägyptisch k-b-n oder k-b-n-j, im bis 1289 existierenden Kreuzfahrerstaat Tripolis Gibelet, heute Jbeil (arabisch جبيلjubayl), eine bedeutende phönizische Hafenstadt, deren Geschichte aber deutlich weiter zurückreicht, nämlich an den Anfang des dritten Jahrtausends vor Christus. Byblos war der Hauptumschlagplatz für Papyrus aus Ägypten, wodurch der Stadtname zum Synonym für Bast aus Papyrus und die daraus hergestellte Buchrolle wurde, bis zur Verdrängung durch den Kodex im vierten Jahrhundert nach Christus die hauptsächliche antike Buchform. ${ }^{9}$ Zum Y (Ypsilon) in Byblos sei noch erwähnt, dass dieser Buchstabe im Griechischen eigentlich das Zeichen für U war und nur ionisch-attisch durch Lautwandel zu gesprochenem Ü wurde, was die Schreibung OY (Omikron + Ypsilon) für späteres gesprochenes U nötig machte, ähnlich wie im Französischen. In Diphthongen wie z. B. AY (Alpha + Ypsilon), EY (Epsilon + Ypsilon) und OY (Omikron + Ypsilon) blieb der ursprüngliche Lautwert U/W/F erhalten, siehe Thesaurus (Schatz), Zeus und Muse. Neugriechisch wird Y (Ypsilon) entrundet

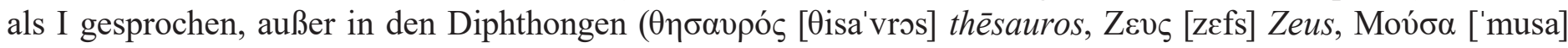

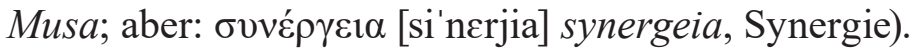

\subsection{Die Struktur der Bibel}

Die christliche Bibel besteht aus zwei Teilen, deren älterer und umfangreicherer sich mit dem Inhalt der hebräischen Bibel deckt: den Heiligen Schriften des Alten Bundes bzw. des Neuen Bundes oder auch des Alten Testaments

8 Vgl. Wilhelm Schubart, Das Buch bei den Griechen und Römern: eine Studie aus der Berliner Papyrussammlung = Handbücher der königlichen Museen zu Berlin (Berlin 1907).

9 Ältere Literatur, die nicht spätestens zu diesem Zeitpunkt kodifiziert, d. h. in die Form des Kodex übertragen wurde, ist größtenteils verloren, soweit davon nicht Papyri (meistens nur fragmentarisch) oder epigraphische Zeugnisse wie Inschriften, allenfalls auch Nebenüberlieferungen wie Zitate die Zeiten überdauert haben. 
bzw. Neuen Testaments; ${ }^{10}$ Bund oder Testament ${ }^{11}$ gibt dabei den hebräischen Begriff schen Begriff $\delta \iota \theta \eta \dot{\kappa} \kappa$ diathēkē wieder. Während der Grundtext des Alten Testaments, abgesehen von einigen aramäischen Passagen, ${ }^{12}$ in hebräischer Sprache und Schrift vorliegt, ist das Neue Testament in griechischer Sprache und Schrift ${ }^{13}$ abgefasst worden. Übersetzungen der Bibel sollten sich also nach Möglichkeit an den Urtexten in diesen beiden Sprachen orientieren und nicht von daraus erstellten Übersetzungen ausgehen, wie z. B. der lateinischen Vulgata.

Das Problem dabei ist die Ermittlung des eigentlichen Urtextes, den man mit Mitteln der Textkritik aus den vorhandenen alten Textzeugen zu gewinnen versucht. Da sich das Bild dieses Urtextes also, abgesehen von auch nicht ausgeschlossenen Fehldeutungen, mit jeder neu gewonnenen Erkenntnis wandelt, ist der jeweilige Zeitpunkt maßgeblich dafür, was als Urtext gilt: Für Luther war beispielsweise der von Erasmus von Rotterdam edierte sogenannte „Textus receptus“ der maßgebliche Urtext des griechischen Neuen Testaments; aktuell liefert die 28. Auflage des „Novum Testamentum Graece“ den maßgeblichen Text, ${ }^{14}$ was aber vor allem seitens mancher evangelikaler Anhänger von Übersetzungen auf Grundlage des „Textus receptus“ wie der „King James Bible“ nicht akzeptiert wird.

Beim Alten Testament zeigen sich zwei wesentliche Probleme: Das erste bilden die deuterokanonischen oder nach evangelischer Auffassung apokryphen Bücher bzw. „Spätschriften des Alten Testaments“, die zwar Bestandteil der Septuaginta, einer bereits um 100 vor Christus vorliegenden griechischen Übersetzung der hebräischen Bibel, nicht aber des erst um 100 nach Christus endgültig festgelegten Konsonantentextes der hebräischen Bibel waren. Heute gelten diese zwar im katholischen und orthodoxen Christentum, nicht aber im evangelischen Christentum als (vollwertiger) Bestandteil der Bibel. ${ }^{15}$ Das zweite Problem liegt im Wesen der hebräischen Schrift begründet, die, abgesehen von der teilweisen Plene-Schreibung von Langvokalen, nur Konsonanten wiedergibt; erst die Ma-

10 Verkürzt auch als Altes Testament bzw. Neues Testament bezeichnet.

11 Von lateinisch testamentum.

12 Neben einigen möglicherweise aramäischen Stellen sind sicher aramäisch: Daniel 2,4b-7,28, Esra 4,8-6,18, Esra 7,12-7,26, Jeremia 10,11 und Genesis 31,47 .

13 Bibelgriechisch oder genauer Neutestamentliches Griechisch ist der seit Beginn des Hellenismus als Verkehrssprache verwendeten Ausgleichs-Sprachform Koine zuzurechnen. Die Koine basiert zwar auf dem attischen Dialekt, ionischen Ursprungs ist aber z. B. -ss- statt des attischen -tt- ( $\tau \dot{\varepsilon} \sigma \sigma \alpha \rho \varepsilon \varsigma$ tessares bzw.

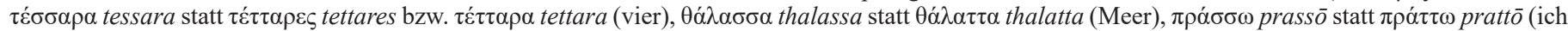
mache), $\gamma \lambda \tilde{\omega} \sigma \sigma \alpha$ glōssa statt $\gamma \lambda \tilde{\omega} \tau \tau \alpha$ glötta (Zunge, Sprache).

14 Siehe auch die 5. Auflage des „Greek New Testament“ und die im Erscheinen begriffene „Editio Critica Maior“. Zu den bekannten Fehlern im „Textus receptus“ gehört die griechische Rückübersetzung biblu zoēs des korrumpierten lateinischen libro vitae (Buch des Lebens) in Offenbarung 22,19 durch Erasmus von Rotterdam. Richtig wäre xylu tēs zoēs (ligno vitae, also Baum des Lebens) gewesen. In der Erasmus vorliegenden griechischen Handschrift fehlte das Blatt mit dieser Stelle, weshalb er auf eine (mangelhafte) Vulgata zurückgriff, wie auch bei anderen Gelegenheiten, was er übrigens auch offen einräumte.

15 Das sind: Judit, Tobit, Baruch, Jesus Sirach, Weisheit Salomos, Makkabäer 1. 2. sowie Zusätze zu Daniel und zu Ester. 
soreten ${ }^{16}$ schufen in der Zeit von 700 bis 1000 nach Christus den „Masoretischen Text“ mit einer nachträglichen Vokalisierung des vorliegenden Konsonantentextes. Die älteste heute noch vollständig erhaltene Handschrift dieses „Masoretischen Textes“ ist der sogenannte „Codex Leningradensis“ von 1008, der die Grundlage heutiger Ausgaben der hebräischen Bibel ${ }^{17}$ bildet, wenngleich frühe Textzeugen im Einzelfall Abweichungen von dem im „Masoretischen Text“" ersichtlichen Konsonantentext bieten.

Eine in diesem Sinne vollständige Bibel mit den Urtexten bildet die „Biblia sacra utriusque testamenti“ von 1994, die den Text der „Biblia Hebraica Stuttgartensia“ (BHS) mit dem Text des „Novum Testamentum Graece“ kombiniert. Beide Teile liegen in Ausgaben der Jahre 1997 (BHS) bzw. 2015 (Novum Testamentum Graece, 28. Auflage) ${ }^{18}$ auch gesondert vor.

6

Bibel. Altes Testament. Hebräisch (Masoretischer Text). Hebräische Schrift und Bibel. Neues Testament. Griechisch. Griechische Schrift

Biblia sacra utriusque testamenti: editio Hebraica et Graeca. - Stuttgart, 1994

NÖ Landesbibliothek, Signatur 118.733 B

7

Bibel. Altes Testament. Hebräisch (Masoretischer Text). Hebräische Schrift

[Torah, nevi'im u-khetuvim] = Biblia Hebraica Stuttgartensia / quae antea cooperantibus A. Alt, O. Eißfeldt, P. Kahle ediderat R. Kittel. - Editio funditus renovata / adjuvantibus H. Bardtke [...] cooperantibus H.P. Rüger et J. Ziegler ediderunt K. Elliger et W. Rudolph; Textum Masoreticum curavit H.P. Rüger; Masoram elaboravit G.E. Weil. Editio quinta emendata / opera A. Schenker. - Stuttgart, 1997 NÖ Landesbibliothek, Signatur 122.969 B

16 Durchgesetzt hat sich das System der zu den westlichen Masoreten zählenden Familie Ben Ascher aus Tiberias; bekannt ist auch die Familie Ben Naftali aus Tiberias. Von Aharon ben Mosheh ben Asher († um 960) stammt die Masora des um 920 im Konsonantentext geschriebenen „Codex von Aleppo“, der infolge des Pogroms von 1947 nicht mehr vollständig erhalten ist. Wann genau der erst nach der Übernahme des Codex in das Israel-Museum in Jerusalem (Anfang 1958) festgestellte Verlust der rund 200 fehlenden Blätter eingetreten ist, ist nicht völlig geklärt.

17 Erstmals die 1937 erschienene 3. Auflage der „Biblia Hebraica“ (BHK³) von Rudolf Kittel (1853-1929), dann die ab 1968 in Teillieferungen und 1977 vollständig erschienene „Biblia Hebraica Stuttgartensia“ (BHS), aktuell die noch nicht abgeschlossene „Biblia Hebraica Quinta“ (BHQ), von der seit 2004 sieben der geplanten zwanzig Lieferungen erschienen sind.

18 Ausgabe mit „Kleinem Wörterbuch zum Neuen Testament (Griechisch-Deutsch)“ von Rudolf Kassühlke. 
Bibel. Neues Testament. Griechisch. Griechische Schrift

Novum Testamentum Graece / Nestle-Aland; begründet von Eberhard und Erwin Nestle; herausgegeben von Barbara und Kurt Aland, Johannes Karavidopoulos, Carlo M. Martini, Bruce M. Metzger; herausgegeben vom Institut für Neutestamentliche Textforschung Münster/Westfalen unter der Leitung von Holger Strutwolf. 28. revidierte Auflage. - Stuttgart, 2015

NÖ Landesbibliothek, Signatur 179.078 B 28. Aufl.

\subsubsection{Apokryphen (Pseudepigraphen)}

Dass die deuterokanonischen Bücher des Alten Testaments aus evangelischer Sicht als Apokryphen betrachtet werden, wurde schon gesagt; Schriften im Umfeld der Bibel, die auch aus katholischer Sicht nicht zum Kanon der Bibel zählen und daher als Apokryphen gelten, werden von evangelischer Seite als Pseudepigraphen bezeichnet. Als Beispiel für solche Apokryphen (Pseudepigraphen) zum Neuen Testament soll die wahrscheinlich aus dem ersten nachchristlichen Jahrhundert stammende „Didache“ (Lehre der zwölf Apostel, Zwölfapostellehre) dienen. Diese älteste Kirchenordnung ${ }^{19}$ wurde bis Eusebius von Caesarea (um 260 - um 340) als kanonisch angesehen. Wie die im gleichen Band der „Schriften des Urchristentums“ enthaltenen Werke „Barnabasbrief“, „Zweiter Klemensbrief“ und „Schrift an Diognet“" gehört die „Didache“ hingegen zum Kanon der Apostolischen Väter.

\section{9}

Schriften des Urchristentums. Griechisch. Griechische Schrift und Deutsch. Lateinische Schrift Schriften des Urchristentums / herausgegeben von Joseph A. Fischer ...

2, Didache (Apostellehre), Barnabasbrief, Zweiter Klemensbrief, Schrift an Diognet / eingeleitet, herausgegeben, übertragen und erläutert von Klaus Wengst. - Sonderausgabe (unveränderter Nachdruck der Ausgabe von 1984). - Darmstadt, 2006

NÖ Landesbibliothek, Signatur 113.221 B 2 


\subsection{Der Ausgangspunkt - die hebräische Bibel}

Die hebräische Bibel, der Tanakh (תנ"ך, Tanach), bezieht diesen letzteren Namen aus den Anfangsbuchstaben ת כ כברי T der תורה Torah (Weisung), נ נביאים N deri'im (Propheten) und כ K der כתובים Ketuvim (Schriften); es handelt sich also um ein Akronym.

Die 24 Schriften sind:

תורה Torah (Pentateuch): שרשית Bereshit (Genesis) שמות Shemot (Exodus) ביקרא Ba-yikra (Leviticus) במדבר Bemidbar (Numeri) דברים Devarim (Deuteronomium)

נביאים Nevi'im (Propheten):

נביאים ראשונים Nevi'im rishonim (vordere Propheten): יהושוע Yehoshua' (Josua) שופטים Shofetim (Richter) שמואל Shemuel (Samuel) מלכים Melakhim (Könige)

נביאים אחרונים Nevi'im aharonim (hintere Propheten): ישעיהו Yesha'yahu (Jesaja) ירמיהו Yirmeyahu (Jeremia)

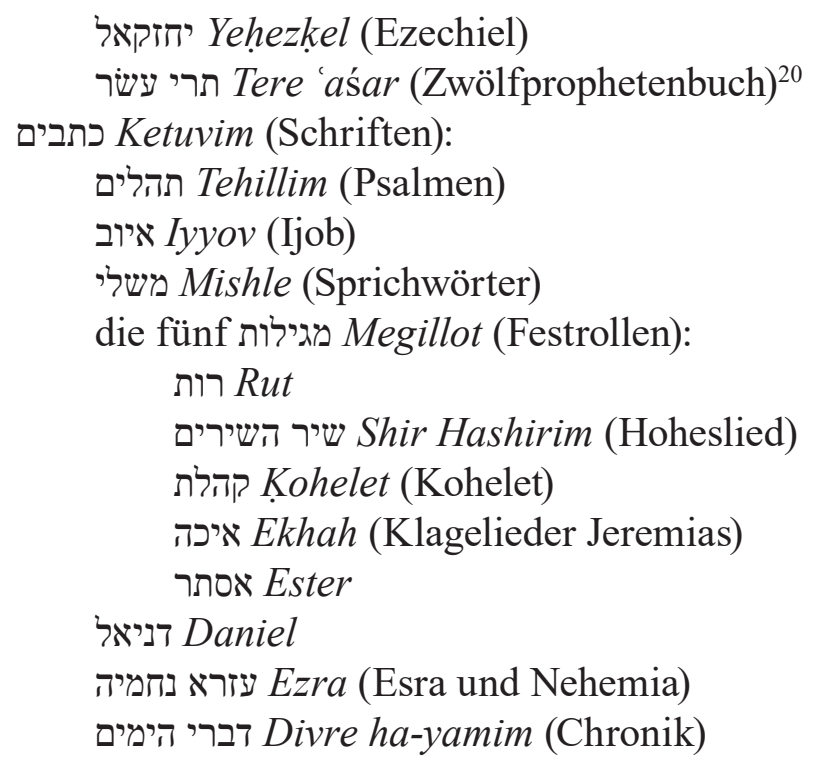

Aufgrund der Teilung der Bücher Samuel, Könige, Chronik und Esra in jeweils zwei Teile und des Zwölfprophetenbuchs in seine zwölf Teile entsprechen diesen 24 Büchern im christlichen Alten Testament 39 Bücher. Diese werden in Pentateuch ${ }^{21}$, Geschichtsbücher ${ }^{22}$, Lehrbücher ${ }^{23}$ und große ${ }^{24}$ bzw. kleine Propheten ${ }^{25}$ eingeteilt. In katholischen Bibeln treten die sieben deuterokanonischen Bücher ${ }^{26}$ (als Teil der genannten Gruppen) hinzu.

20 Die kleinen Propheten Hosea, Joel, Amos, Obadja, Jona, Micha, Nahum, Habakuk, Zefanja, Haggai, Sacharja und Maleachi.

21 Umfang wie Torah.

22 Josua, Richter, Rut, Samuel 1. 2., Könige 1. 2., Chronik 1. 2., Esra und Nehemia, (Tobit), (Judit), Ester, (Makkabäer 1. 2.).

23 Ijob, Psalmen, Sprichwörter, Kohelet, Hoheslied, (Weisheit Salomos), (Jesus Sirach).

24 Jesaja, Jeremia, Klagelieder Jeremias, (Baruch), Ezechiel, Daniel.

25 Das Zwölfprophetenbuch (Dodekapropheton) in seinen zwölf Teilen.

26 Tobit, Judit, Makkabäer 1. 2., Weisheit Salomos, Jesus Sirach, Baruch; Zusätze zu Daniel und Ester. 
Neben der Tora-Rolle kommt den fünf Megillot (Plural zu Megilla, Festrolle) eine besondere Bedeutung zu, weil jede von ihnen einem bestimmten jüdischen Fest zugeordnet ist, an dem sie zur öffentlichen Lesung in der Synagoge gelangt: Rut - Shavuot (Schawuot), Hoheslied - Pesah (Pessach), Kohelet - Sukkot, Klagelieder Jeremias - Tish 'ah be-Av, Ester-Purim. Die Ester-Rolle (Megillat Ester) wird beispielsweise am Abend des Purimfestes und am folgenden Morgen gelesen. Aus diesem Grund wurde die erste Lieferung der hiermit ebenfalls vorgestellten „Biblia Hebraica Quinta“ ausgewählt, die neben der „,general introduction“ (allgemeinen Einführung) eben diese fünf Megillot zum Inhalt hat. Zugleich wird damit der kulturgeschichtliche Hintergrund des schon zuvor genannten Fragments einer mittelalterlichen Ester-Rolle aus dem Niederösterreichischen Landesarchiv (Signatur Varia 012) nachgeliefert.

Erwähnt sei der in der auf der althebräischen Schrift beruhenden samaritanischen Schrift geschriebene „Samaritanische Pentateuch“ der auch im heutigen Israel lebenden Samaritaner. Zu deren Besonderheiten gehört nicht nur der Berg Garizim als zentrale Kultstätte, sondern auch die Beschränkung auf die Tora als einzige heilige Schrift.

Ergänzend zum „Masoretischen Text“ der „Biblia Hebraica Stuttgartensia“ wird deren Masora als gesonderter Apparat vorgestellt. Darunter versteht man die Gesamtheit der über die bloße Vokalisierung und Akzentuierung des Konsonantentextes hinausgehenden textkritischen Anmerkungen. Diese wird in die kleine Masora oder $M a-$ sora parva $^{27}$ und große Masora oder Masora magna ${ }^{28}$ unterteilt.

Häufig und fälschlich wird der Talmud (Belehrung, Studium) ${ }^{29}$ anstelle des Tanakh als jüdische Bibel betrachtet. Der Talmud liegt als „Jerusalemer Talmud“ (Palästinischer Talmud) und - umfangreicher und bekannter - als „Babylonischer Talmud“ (Talmud Bavli) vor. Der Talmud basiert auf der zu Beginn des dritten nachchristlichen Jahrhunderts redigierten Mischna (Mishnah, Wiederholung), der Niederschrift der mündlichen Tora, die als ursprünglich nur mündliche Überlieferung zur schriftlichen Tora hinzutritt. Gemeinsam mit der bis ins siebente Jahrhundert erarbeiteten Gemara, welche sie erläutert und ergänzt, bildet die Mischna den Talmud. Die Sprache des Talmuds ist Aramäisch (Jüdisch-Palästinisch im Falle des Jerusalemer Talmud, Babylonisch-Talmudisch im Falle des Babylonischen Talmud). Über den Bereich von Tanakh und Talmud hinaus reichen die Midraschim (Midrashim); Midrasch ${ }^{30}$ meint dabei eine spezifische Zusammenstellung rabbinischer Schriftauslegungen, die

27 Marginale Anmerkungen neben der Textspalte. Eine der Anwendungen besteht in ketiv (so steht es geschrieben) und kere (zu lesen): Das mit ${ }^{\circ}$ (Circellus) markierte ketiv im Konsonantentext wird mit den zu lesenden Vokalen versehen; am Rand wird als kere die mit kleinem $>$ (k) markierte ersatzweise konsonantische Lesung (die mit der im ketiv eingetragenen Vokalisierung zu verstehen ist) angegeben. Im Falle des bei einigen häufigen Wörtern üblichen Qere perpetuum werden nur die Vokale des zu lesenden Wortes im ketiv eingetragen und auf Markierung sowie kere verzichtet: Beispielsweise wird das tabuisierte Tetragramm YHWH Yahweh regelmäßig als Adonay (mein Herr, meine Herren) oder ersatzweise als Elohim (Gott, eigentlich Plural Götter zu Singular Eloah, siehe auch El und vgl. dazu arabisch Allāh aus dem Artikel al- und 'ilāh) vokalisiert; eine weitere Ersatzlesung ist ha-Shem (der Name). Eine Fehlinterpretation der Vokalisierung Adonay hat übrigens zur falschen Lesung Jehova geführt. Regelmäßig wird auch Yerushalem (Jerusalem) als Yerushalayim vokalisiert.

28 Kommentar oberhalb oder unterhalb des Seitentextes; im Falle der Masora finalis am Anfang oder Ende des Buches. 
je nach Inhalt der Halacha (Halakhah, Gesetz) oder der Aggada (Aggadah, Erzählung, Sage) zuzurechnen sind. Diese Traditionen des rabbinischen Judentums (mündliche Tora bzw. Mischna, Gemara, Talmud, Midraschim) wurden oder werden von jüdischen Randgruppen wie Karäern (Karaim, Karaiten), Samaritanern (Shamerim) und Falaschen (Beta Israel, Falasha) nicht mitgetragen.

Diesen Themenkomplex verkörpert der erste Band der ursprünglich 1929 bis 1936 erschienenen, zwölfbändigen deutschsprachigen Ausgabe des „Babylonischen Talmuds“ von Lazarus Goldschmidt (1871-1950). ${ }^{31}$

\section{0}

\section{Bibel. Altes Testament. Hebräisch (Masoretischer Text). Hebräische Schrift}

[Torah, nevi'im u-khetuvim] = Biblia Hebraica. - Quinta editione, cum apparatu critico novis curis elaborato [Biblia Hebraica quinta BHQ] / participantibus R. Althann, P.B. Dirksen, N. Fernández Marcos, A. Gelston, A. Gianto, C.G. den Hertog, I. Himbaza, J. Lust, D. Marcus, M. Rösel, M. Sæbø, S. Sipilä, P. Schwagmeier, A. Tal, Z. Talshir; consultis A. Dotan pro masora, A. Groves et Soetjianto pro impressione electronica, S. Lind pro redactione et stylo; communiter ediderunt A. Schenker (praeses), Y.A.P. Goldman, A. Van der Kooij, C. McCarthy, G.J. Norton, S. Pisano, R. Schäfer, J. de Waard, R.D. Weis. - Stuttgart, 2004-

\section{Fascicle 18 (von 20), Megillot}

[Megilot] = General introduction and Megilloth. - Stuttgart, 2004

NÖ Landesbibliothek, Signatur 138.945 B 18

\section{1}

\section{Kelley, Page H., 1924-1997. The Masorah of Biblia Hebraica Stuttgartensia}

Die Masora der Biblia Hebraica Stuttgartensia: Einführung und kommentiertes Glossar / Page H. Kelley, Daniel S. Mynatt, Timothy G. Crawford. - Stuttgart, 2003

NÖ Landesbibliothek, Signatur 122.968 B

\section{2}

\section{Babylonischer Talmud}

Der babylonische Talmud / nach der ersten zensurfreien Ausgabe unter Berücksichtigung der neueren Ausgaben und handschriftlichen Materials ins Deutsche übersetzt von Lazarus Goldschmidt. - Frankfurt am Main, 2002 Band 1 (von 12). - 2002

NÖ Landesbibliothek, Signatur 100.183 B 1

31 Katalog Nr. 12. 


\subsection{Textgrundlagen}

Zwar keine Urtexte, aber trotzdem für das Verständnis der Bibel grundlegend sind die Texte der Septuaginta (neben den von Origenes in seiner „Hexapla“ zum textkritischen Vergleich herangezogenen, aber nur fragmentarisch erhaltenen jüdischen Übersetzungen des zweiten nachchristlichen Jahrhunderts von Aquila, Symmachus dem Ebioniten und Theodotion), der Vulgata des heiligen Hieronymus (samt den Varianten Sixto-Clementina von 1592 und Nova Vulgata von 1979 und den als Vetus Latina oder Itala bezeichneten Vorläuferübersetzungen) und bis zu einem gewissen Grad auch der Peshițta (Peschitta) sowie der Targumim (Targume).

Die Septuaginta ${ }^{32}$ ist eine im dritten Jahrhundert vor Christus begonnene und um 100 vor Christus weitgehend vorliegende Übertragung der Schriften des Tanakh in das Griechische ${ }^{33}$ für das hellenistische Judentum in Alexandria. Ursprünglich bezog sich die Bezeichnung nur auf die Übersetzung der Tora, die der Legende nach von 72 jüdischen Gelehrten in 72 Tagen unabhängig voneinander mit identem Ergebnis vorgenommen worden sein soll. Die Septuaginta stand in kanonischem Ansehen und wurde vom frühen Christentum als Altes Testament in die christliche Bibel aufgenommen. Nicht zuletzt deswegen erfolgte im Judentum eine stärkere Hinwendung zurück zum Hebräischen und die endgültige Festlegung des Umfangs des Tanakh um 100 nach Christus, der die deuterokanonischen Schriften der Septuaginta mit fehlender oder verloren gegangener hebräischer Vorlage ausschloss. ${ }^{34}$ Den Versuchen jüdischer Neuübersetzungen des Tanakh in das Griechische im zweiten Jahrhundert nach Christus durch Aquila, Symmachus den Ebioniten und Theodotion war kein dauerhafter Erfolg beschieden; seit Origines werden sie jedoch zur Textkritik an der Septuaginta und im Falle des Theodotion zur teilweisen Textkonstituierung oder sogar Textsubstituierung ${ }^{35}$ herangezogen.

Der Kanon der griechischen Bibel (Septuaginta und Neues Testament) umfasst folgende Bücher:

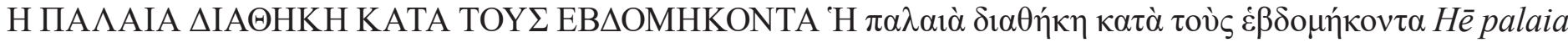
diathēkē kata tus hebdomēkonta (Das Alte Testament nach den Siebzig, Septuaginta):

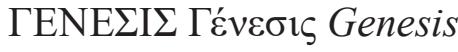

$\mathrm{E} \Xi \mathrm{O} \Delta \mathrm{O} \Sigma$ ”'E $\xi$ odo $\operatorname{Exodos}$ (Exodus)

$\Lambda$ EYITIKON $\Lambda$ Evï̃ıкòv Leuitikon (Leviticum)

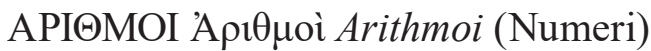

$\triangle$ EYTEPONOMION $\Delta \varepsilon v \tau \varepsilon \rho o v o ́ \mu ı v$ Deuteronomion (Deuteronomium)

34 Dadurch unterscheidet sich der Kanon von Tanakh und Septuaginta.

35 Beim Buch Daniel. 


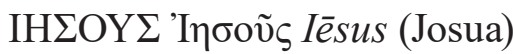

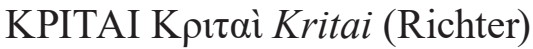

POY $\Theta$ Pov̀ $\theta$ Ruth (Rut)

BA $\Sigma \mathrm{I} \Lambda \mathrm{EI} \Omega \mathrm{N} \mathrm{A}^{\prime} \mathrm{B}^{\prime} \Gamma^{\prime} \Delta^{\prime} \mathrm{B} \alpha \sigma \imath \lambda \varepsilon \imath \tilde{\omega} v \mathrm{~A}^{\prime} \mathrm{B}^{\prime} \Gamma^{\prime} \Delta^{\prime}$ Basileiōn 1. 2. 3. 4. (Samuel 1. 2. und Könige 1. 2.)

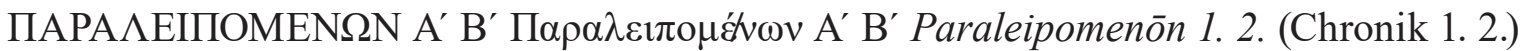

$\mathrm{E} \Sigma \Delta \mathrm{PA} \Sigma \mathrm{A}^{\prime}$ 'Е $\sigma \delta \rho \alpha_{\varsigma} \mathrm{A}^{\prime}$ Esdras 1. (Esra 3.)

$\mathrm{E} \Sigma \Delta \mathrm{PA} \Sigma \mathrm{B}^{\prime}$ 'E $\sigma \delta \rho \alpha \varsigma \mathrm{B}^{\prime}$ Esdras 2. (Esra und Nehemia)

$\mathrm{E} \Sigma \Theta H P$ 'E $\sigma \theta \grave{\rho} \rho$ Esthēr (Ester)

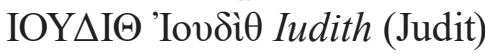

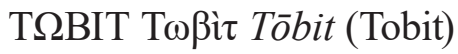

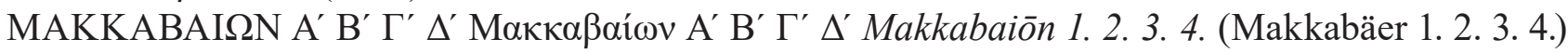

$\Psi A \Lambda$ MOI $\Psi \alpha \lambda \mu$ oì Psalmoi (Psalmen)

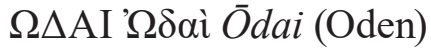

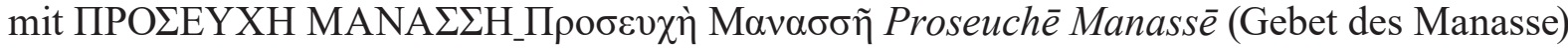

ПАРOIMIAI Пароциíaı Paroimiai (Sprichwörter)

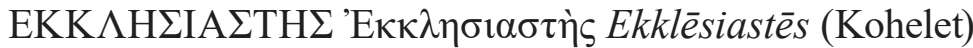

A $\Sigma$ MA 'A $\sigma \mu \alpha$ Asma (Hoheslied)

$\mathrm{I} \Omega \mathrm{B}$ 'I⿳亠口冋 Iōb (Ijob)

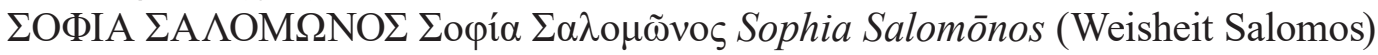

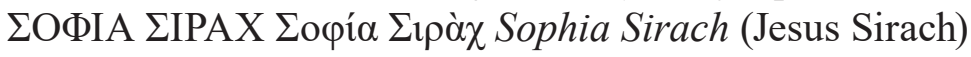

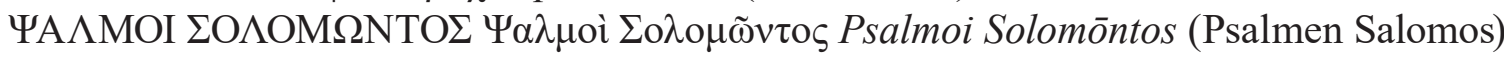

$\Omega \Sigma \mathrm{HE}^{\prime} \Omega \sigma \eta \dot{\varepsilon}$ Osēe (Hosea)

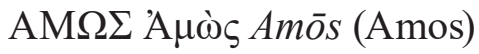

MIXAIA $\Sigma$ Miqaías Michaias (Micha)

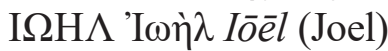

$\mathrm{AB} \triangle \mathrm{IOY}$ 'A $\beta \delta$ เov̀ Abdiu (Obadja)

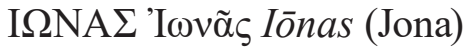

NAOYM Naov̀ $\mu$ Naum (Nahum)

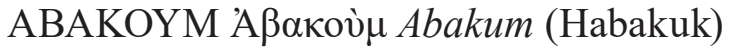

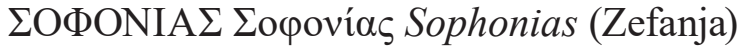

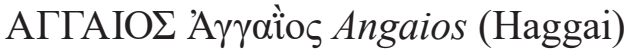

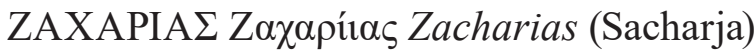

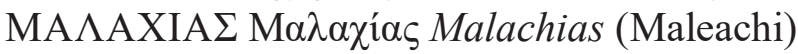

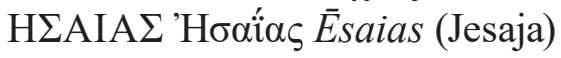




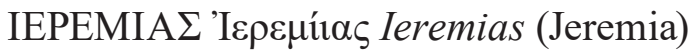

BAPOYX Bapov̀ $\chi$ Baruch

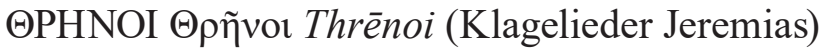

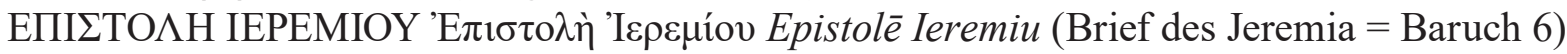

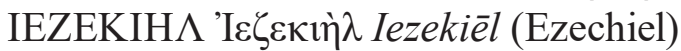

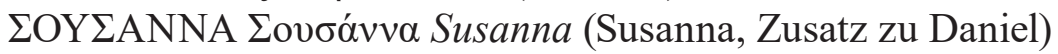

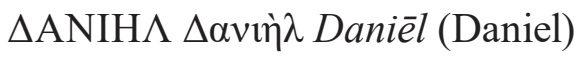

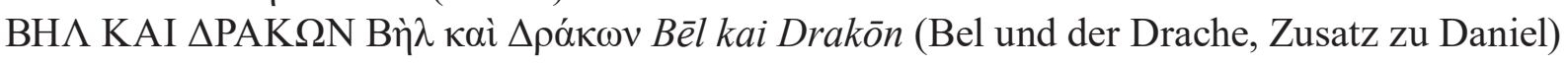

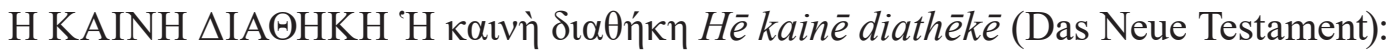

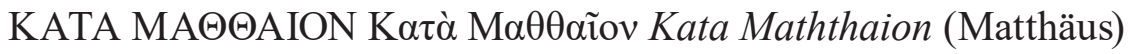

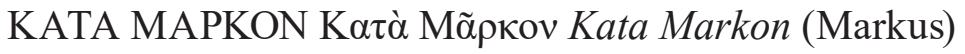

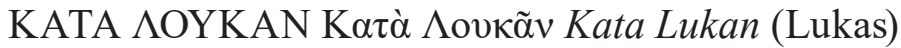

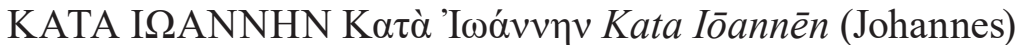

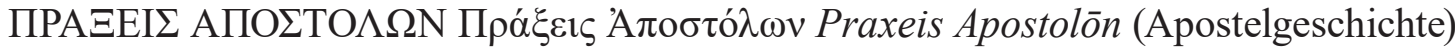

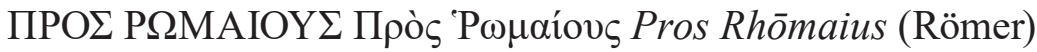

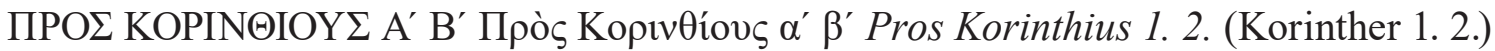

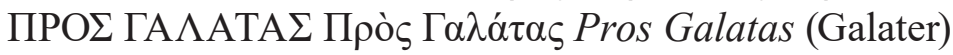

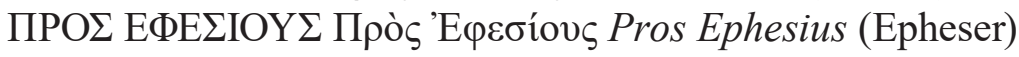

ПРО

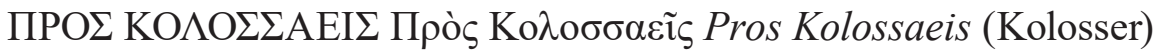

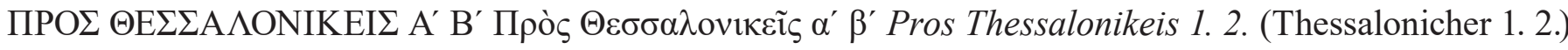

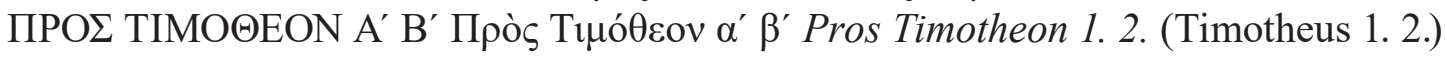

ПPO $\Sigma$ TITON Прòs Títov Pros Titon (Titus)

ПРО

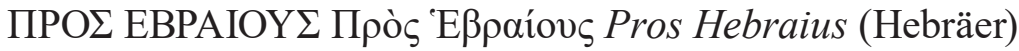

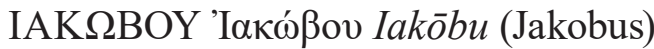

ПЕTPOY A' B' Пе́єроv $\alpha^{\prime} \beta^{\prime}$ Petru 1. 2. (Petrus 1. 2.)

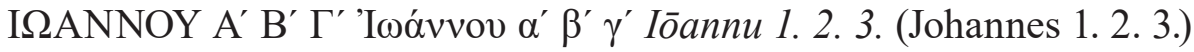

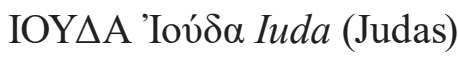

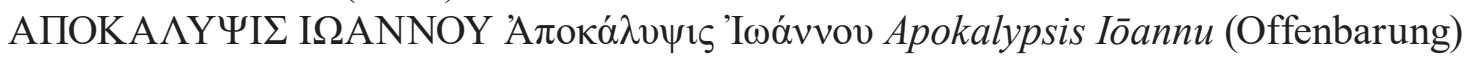


In der katholischen Kirche werden Tobit, Judit, Makkabäer 1. 2., Jesus Sirach, die Weisheit Salomos, Baruch, der Brief des Jeremia (als Baruch 6) und die Zusätze zu Ester und Daniel (inklusive Susanna) anerkannt, nicht aber Makkabäer 3. 4., Esra 3. (4. ist nur lateinisch und slawisch überliefert) und die Oden mit dem Gebet des Manasse; diese Schriften werden aber in unterschiedlichem Umfang von orthodoxen Kirchen anerkannt.

Vorgestellt wird die kritische Ausgabe von Rahlfs-Hanhart, aber auch die „Septuaginta deutsch“, ${ }^{36}$ was dem Umstand Rechnung trägt, dass allein schon wegen des größeren Umfangs im Vergleich mit dem Tanakh nicht einfach eine übliche Übersetzung des Alten Testaments den Zweck erfüllt.

Nachdem schon zuvor biblische Texte in das Lateinische übersetzt worden waren, die zusammen als Vetus Latina oder Itala bezeichnet werden und zum Teil eingeflossen sind, hat der heilige Hieronymus (eigentlich Sophronius Eusebius Hieronymus, 347-420) im Auftrag des Papstes Damasus I. († 384) ab 382 die später als Vulgata ${ }^{37}$ bezeichnete lateinische Bibelübersetzung verfasst. Diese Bibelübersetzung erlangte im Laufe des Mittelalters Allgemeingültigkeit im Bereich der katholischen Kirche, was in Reaktion auf Luthers Rückgriff auf die hebräischen und griechischen Urtexte im Zuge des Konzils von Trient 1546 noch bekräftigt wurde; in der Folge erschien 1590 die Sixtina und bereits 1592 die Sixto-Clementina als päpstlich autorisierte Version der Vulgata. Der Grundsatz des Vorrangs für die Vulgata, die somit zur Grundlage aller katholischen Bibelübersetzungen geworden war, wurde erst im Zuge des Zweiten Vatikanums aufgegeben. Dies führte neben dem Entstehen volkssprachlicher katholischer Bibelübersetzungen aus den Urtexten wie im Falle der „Einheitsübersetzung“ auch zur Neuedition der lateinischen Bibel als Nova Vulgata 1979. Davon zu unterscheiden sind die jeweils neuesten textkritischen Ausgaben der Vulgata, die deren ursprünglichen Wortlaut zu ermitteln suchen.

Die Vulgata umfasst folgende mit Prologen des Hieronymus versehene Bücher:

Vetus Testamentum (Altes Testament):

(Prologus in Pentateucho [Prolog zum Pentateuch])

Liber Beresith id est Genesis

Liber Ellesmoth id est Exodus

Liber Vaiecra id est Leviticus

Liber Vaiedabber id est Numeri

Liber Helleaddabarim id est Deuteronomium

(Praefatio in libro Iosue [Vorwort zum Buch Josua])

36 Katalog Nr. 13 und 14.

$37 \mathrm{Zu}$ lateinisch vulgus (Volk), also etwa: die Volkstümliche. 
Liber Iosue Bennun id est Iesu Nave (Josua)

Liber Sopthim ${ }^{38}$ id est Iudicum (Iudices, Richter)

Liber Ruth (Rut)

(Prologus in libro Regum [Prolog zum Buch der Könige])

Liber Samuhelis id est Regum primus et secundus (Samuhel, Samuel 1. 2.)

Liber Malachim id est Regum tertius et quartus (Reges, Könige 1. 2.)

(Prologus in libro Paralipomenon [Prolog zu Chronik])

Liber Dabreiamin id est Verba Dierum qui Graece dicitur Paralipomenon (Chronik 1. 2.)

(Prologus in libro Ezrae [Prolog zum Buch Esra])

Liber Ezrae (Ezra, Esra-Nehemia)

(Prologus Tobiae [Prolog zu Tobit])

Liber Tobiae (Tobias, Tobit)

(Prologus Iudith [Prolog zu Judit])

Liber Iudith (Judit)

(Prologus Hester [Prolog zu Ester])

Liber Hester (Ester)

(Prologus in libro Iob [Prolog zum Buch Ijob])

Liber Iob (Ijob)

(Praefationes in libro Psalmorum [Vorwörter zum Buch der Psalmen])

Liber Psalmorum iuxta Septuaginta emendatus

Liber Psalmorum iuxta Hebraicum translatus (Psalmi, Psalmen nach der Septuaginta sowie aus dem Hebräischen übersetzt)

(Prologus in libris Salomonis [Prolog zu den Büchern Salomos])

Liber Proverbiorum Salomonis (Proverbia Salomonis, Sprichwörter)

38 Sollte aus Sicht des Hebräischen eher Sophtim (eigentlich Shofețim bzw. Shoftim) als Sopthim heißen. 
Liber Ecclesiastes (Kohelet)

Liber Canticum Canticorum (Cantica canticorum, Hoheslied)

Liber Sapientiae Salomonis (Sapientia Salomonis, Weisheit Salomos)

(Prologus in libro Iesu filii Sirach [Prolog zum Buch Jesus Sirach])

Liber Iesu filii Sirach (Iesus filius Sirach, Jesus Sirach)

(Prologus in Isaia propheta [Prolog zum Propheten Jesaja])

Liber Isaiae prophetae (Isaias propheta, Jesaja)

(Prologus in libro Hieremiae prophetae [Prolog zum Buch Jeremia])

Liber Hieremiae prophetae (Hieremias propheta, Jeremia)

Lamentationes (Klagelieder Jeremias)

Liber Baruch

(Prologus Hiezechielis prophetae [Prolog zum Propheten Ezechiel])

Liber Hiezechielis prophetae (Hiezechiel propheta, Ezechiel)

(Prologus in Danihele propheta [Prolog zum Propheten Daniel])

Liber Danihelis prophetae (Danihel propheta, Daniel)

(Prologus Duodecim Prophetarum [Prolog zu den Zwölf Propheten])

Osee propheta (Hosea)

Iohel propheta (Joel)

Amos propheta (Amos)

Abdias propheta (Obadja)

Iona propheta (Jona)

Micha propheta (Micha)

Naum propheta (Nahum)

Abacuc propheta (Habakuk)

Sofonias propheta (Zefanja)

Aggeus propheta (Haggai)

Zaccharias propheta (Sacharja)

Malachi propheta (Maleachi) 
Liber primus Macchabeorum (Makkabäer 1.)

Liber secundus Macchabeorum (Makkabäer 2.)

Novum Testamentum (Neues Testament):

(Praefatio in Evangelio [Vorwort zum Evangelium])

Canones Evangeliorum (Kanon der Evangelien):

Evangelium secundum Mattheum (Matthäus)

Evangelium secundum Marcum (Markus)

Evangelium secundum Lucam (Lukas)

Evangelium secundum Iohannem (Johannes)

Liber Actuum Apostolorum (Actus Apostolorum, Acta Apostolorum, Apostelgeschichte)

(Prologus in Epistulis Pauli [Prolog zu den Paulusbriefen])

Ad Romanos (Römer)

Ad Corinthos I (1. Korinther)

Ad Corinthos II (2. Korinther)

Ad Galatas (Galater)

Ad Ephesios (Epheser)

Ad Philippenses (Philipper)

Ad Colossenses (Kolosser)

Ad Thessalonicenses I (1. Thessalonicher)

Ad Thessalonicenses II (2. Thessalonicher)

Ad Timotheum I (1. Timotheus)

Ad Timotheum II (2. Timotheus)

Ad Titum (Titus)

Ad Philomonem (Philemon)

Ad Hebraeos (Hebräer)

Epistulae Catholicae (Katholische Briefe):

Epistula Iacobi (Jakobus)

Epistula Petri I (1. Petrus)

Epistula Petri II (2. Petrus)

Epistula Iohannis I (1. Johannes)

Epistula Iohannis II (2. Johannes) 
Epistula Iohannis III (3. Johannes)

Epistula Iudae (Judas)

Apocalypsis (Offenbarung)

Appendix (Anhang):

Oratio Manasse (Gebet des Manasse)

Liber Ezrae III (Esra 3. )

Liber Ezrae IIII (Esra 4. )

Psalmus CLI (Psalm 151)

Epistula ad Laodicenses (Brief an die Laodizener)

Neben einer wissenschaftlichen Ausgabe der Vulgata und dem ersten Band der erst seit kurzem vorliegenden fünfbändigen lateinisch-deutschen Vulgata-Ausgabe in der bekannten Reihe zweisprachiger Textausgaben antiker Autoren „Sammlung Tusculum“ werden die Nova Vulgata und schlussendlich die Sixto-Clementina in einer zweisprachigen Ausgabe des neunzehnten Jahrhunderts zusammen mit der Übersetzung von Joseph Franz von Allioli (1793-1873) vorgestellt. ${ }^{39}$ Beispiele für die Vulgata sind auch die eingangs präsentierte Handschrift 54 der Diözesanbibliothek St. Pölten, die als Einband verwendete Pergamentmakulatur der beiden genannten Inkunabeln zum heiligen Leopold oder die als Faksimile vorgestellte „Gutenberg-Bibel“ .40

Wegen der engen Querbeziehung zwischen Hebräisch und Aramäisch inklusive Syrisch soll auch noch auf die Peshițta (Peschitta, die Einfache) eingegangen werden, eine christliche Bibelübersetzung in das Syrische, deren älteste Handschriften in das fünfte nachchristliche Jahrhundert zurückreichen. Da das Aramäische das Hebräische als Umgangssprache abgelöst hatte, sodass sogar einige Textpassagen des Tanakh in aramäischer Sprache abgefasst sind, entstanden zwischen 200 vor bis 800 nach Christus jüdische Übersetzungen alttestamentlicher Texte in das Aramäische, die sogenannten Targumim (Targume, Übersetzungen, Erklärungen); auch der in zwei Formen vorliegende Talmud ist jeweils in Varianten der aramäischen Sprache abgefasst. Die Peshitta umfasst das Alte und Neue Testament und hat die zuvor verwendete Evangelienharmonie „Diatessaron“ des Syrers Tatian aus dem zweiten Jahrhundert aus dem Feld geschlagen; sie wird sowohl in der ostsyrischen (nestorianischen) Assyrischen Kirche des Ostens wie in der westsyrischen (jakobitischen und monophysitischen) Syrisch-Orthodoxen Kirche von Antiochien verwendet, wobei die letztere die Offenbarung des Johannes nicht anerkennt.

39 Katalog Nr. 15 bis 18.

40 Katalog Nr. 1, 4 und 38. 
Präsentiert wird eine zweisprachige Ausgabe des Neuen Testaments der Peshitta in den Sprachen Neuhebräisch und Aramäisch jeweils in hebräischer Schrift; ${ }^{41}$ diese Schrift beruht, wie später näher ausgeführt, ohnedies ebenso auf der aramäischen Schrift wie die für die Peshitta sonst übliche syrische Schrift mit ihren Varianten Estrangelo, Serto (Westsyrisch) und Nestorianisch (Ostsyrisch). Im Abschnitt zu den semitischen Sprachen werden aber auch Bibelausgaben in westsyrischer sowie ostsyrischer Schrift vorgestellt. ${ }^{42}$

\section{3}

\section{Bibel. Altes Testament. Griechisch (Septuaginta). Griechische Schrift}

Septuaginta: id est Vetus Testamentum graece iuxta LXX interpretes: duo volumina in uno $=\mathrm{H} \Pi$ ПAIA

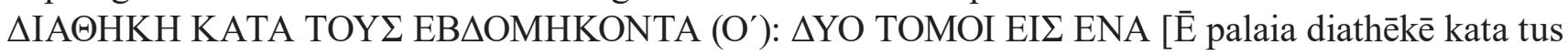
ebdomēkonta (70): dyo tomoi eis ena] / edidit Alfred Rahlfs. - Editio altera quam recognovit et emendavit Robert Hanhart. - Stuttgart, [2006]

NÖ Landesbibliothek, Signatur 118.731 B

\section{4}

\section{Bibel. Altes Testament. Deutsch (Septuaginta deutsch). Lateinische Schrift}

Septuaginta deutsch: das griechische Alte Testament in deutscher Übersetzung / herausgegeben von Wolfgang Kraus ... - Stuttgart, 2009

NÖ Landesbibliothek, Signatur 123.861 B

\section{5}

Bibel. Lateinisch (Vulgata). Lateinische Schrift

Biblia sacra: iuxta Vulgatam versionem / recensuit et brevi apparatu critico instruxit Robert Weber. - Editio quintam emendatam retractatam / praeparavit Roger Gryson. - Stuttgart, 2007

NÖ Landesbibliothek, Signatur 118.730 B 
Bibel. Lateinisch (Vulgata) und Deutsch. Lateinische Schrift

Biblia sacra vulgata: lateinisch-deutsch / Hieronymus; herausgegeben von Andreas Beriger, Widu-Wolfgang Ehlers und Michael Fieger. - Berlin, Boston, Mass. - (Sammlung Tusculum)

Band 1 (von 5), Genesis - Exodus - Leviticus - Numeri - Deuteronomium. - [2018]

NÖ Landesbibliothek, Signatur 201.936 B 1

17

Bibel. Lateinisch (Sixto-Clementina) und Deutsch (Allioli). Lateinische Schrift

Biblia sacra vulgatae editionis / Sixti V. Pontificis Maximi iussu recognita et Clementis VIII. auctoritate edita, nunc novissime ad exemplar Vaticanum expressa cura Dr. Josephi Francisci Allioli = Die Heilige Schrift des Alten und Neuen Testamentes, aus der Vulgata / mit Bezug auf den Grundtext neu übersetzt und mit Anmerkungen erläutert von Dr. Joseph Franz Allioli. - Editio Stereotypa. - Regensburg, New York, NY, und Cincinnati, Ohio Tomus $1=1$. Band (von 3). - Editio quinta $=5$. Auflage. -1874

NÖ Landesbibliothek, Signatur 147.543 B 1 5. Aufl.

Abb. 6

18

Bibel. Lateinisch (Nova Vulgata). Lateinische Schrift

Nova Vulgata bibliorum sacrorum editio / Sacros. Oecum. Concilii Vaticani II ratione habita iussu Pauli PP. VI recognita auctoritate Ioannis Pauli PP. II promulgata. - Vatikanstadt, 1979

NÖ Landesbibliothek, Signatur 134.422 B

19

Bibel. Neues Testament. Syrisch (Peschitta). Hebräische Schrift und Neuhebräisch. Hebräische Schrift

The New Covenant: commonly called The New Testament: Peshițta Aramaic text with a Hebrew translation / קימא חדתא ה' כתבא דדיתקא חדתא: = edited by The Aramaic Scriptures Research Society in Israel

צורת כתב איך אצחתא דמתקריא פשיטתא בלשנא עתיקא עם פושקא עבריא

[Keyama ḥadta h. ketava dadyateḳe ḥadata:

tsurat ketav aykh atsaḥta demitḳarya peshiṭta be-lishana 'atiḳa 'am pushaḳa 'ivraya] =

ספרי הברית החדשה: נסח הפשיטתא בארמית עם תרגום עברי

[Sifre ha-Berit ha-ḥadashah: nesah ha-Peshițta be-Aramit 'im targum 'Ivri]. - Jerusalem, 2005

NÖ Landesbibliothek, Signatur 119.545 B

Abb. 7 


\section{BIBLIA SACRA}

VULGATE EDITIONIS SIXTI V. PONTIFICIS MAXIMII

JUSEU REOOONITA

st

\section{CLEMENTIS VIIL.}

AtomourTAT: EDTA

SUNE NOVISSIIE AD EXEMIPLAR VATICANCM EXPIE:SA

nivi

D* JOSEPAI FRANCISCI ALHOH.

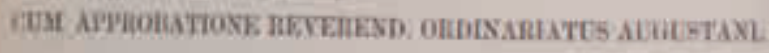
EOMO OUINTA.

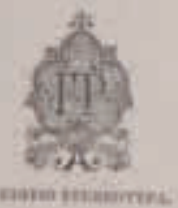

Tomes paDito.

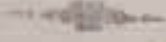

mocoetxxuv.

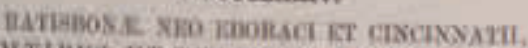
SIMTIUES ET TYUS YHIDERICI PUBTEF.

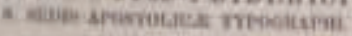

Dit

\section{Sgeilige Sdifrift}

bes

\section{Alten und ucuen êfftnmentes.}

\section{Ins Ber Butgata}

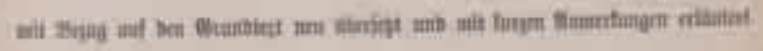
*n

Dr. Soicph frens grilioli.

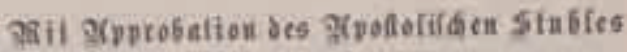

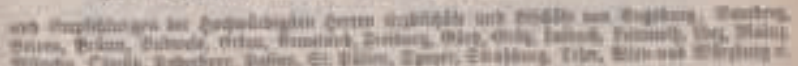

\section{Ier Ausgave}

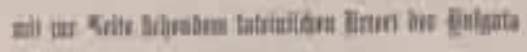

ientit anflens.
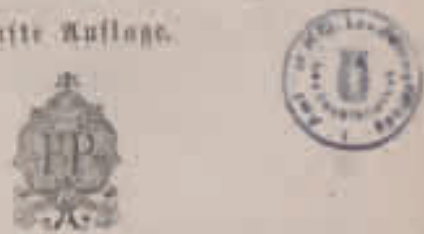

in sicrotsme nitreat.

Grifer Yaub.

$\ln 7$.

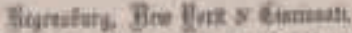

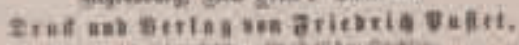

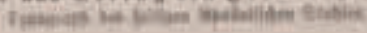

Abb. 6 / Katalog Nr. 17: Sixto-Clementina mit deutscher Übersetzung von Joseph Franz Allioli (1874). 
Abb. 7 / Katalog Nr. 19:

The New Covenant commonly called The New Testament:

Peshitta Aramaic text with a Hebrew translation (2005).

THE

NEW COVENANT ARAMAIC PESHITTA TEXT

\section{WITH HEBREW TRANSLATION}




\subsubsection{Nach der historisch-kritischen Methode erschlossene Textquellen}

Neben den weiter oben ausführlich vorgestellten Grundtexten sei nun kurz auf im Wege der Textkritik gewonnene hypothetische Schriftquellen eingegangen. Diese gelten als in die erhaltenen Texte eingewoben und werden daraus isoliert.

Für das Neue Testament ist hier die Logienquelle oder Spruchquelle $\mathrm{Q}^{43} \mathrm{zu}$ nennen: Die Evangelien nach Matthäus und Lukas seien jeweils unter Rückgriff auf das deutlich kürzere (und theoriegemäß ältere) Evangelium nach Markus und eine sonst nicht erhaltene Spruchsammlung mit Aussprüchen von Jesus entstanden; diese Logienquelle Q zeige sich anhand paralleler Verse im Matthäusevangelium und Lukasevangelium ohne Parallele im Markusevangelium, dem dritten synoptischen Evangelium.

Auch im alttestamentlichen Bereich, besonders für den Pentateuch, gibt es textkritische Versuche, hypothetische enthaltene Quellentexte zu extrahieren. Ohne Stellungnahme zur Stichhaltigkeit der vertretenen Argumentationen sei hier der Jahwist (J) genannt, der nach der Neueren Urkundenhypothese gemeinsam mit dem Elohisten (E), der Priesterschrift (P) und dem Deuteronomium (D) den Pentateuch hervorgebracht haben soll. Kennzeichen des Jahwisten sei die bevorzugte Verwendung des Tetragramms YHWH als Gottesname; konkret werden dem von Christoph Levin als israelitisches Nationalepos bezeichneten Jahwisten folgende Textkomplexe zugeordnet: Urgeschichte (Genesis 2-11), Vätergeschichte (Genesis 12-35), Josefs-Geschichte (Genesis 37-50), die Erzählungen von Mose (Exodus 2-4), Exodus und Wüstenzug (Exodus 12 - Numeri 20) und die Erzählung von Bileam (Numeri 22-24); zur Kritik am Jahwisten gehört der fehlende klare Abschluss dieser Zusammenstellung. Was diese Textkritik aber jedenfalls gezeigt hat: Moses ist nicht der Verfasser des Pentateuchs, der sogenannten „,ünf Bücher Mose“.

\section{0}

\section{Logienquelle}

Die Spruchquelle Q: griechisch und deutsch: griechischer Text nach der „Critical Edition of Q“ des International

Q Project ... / herausgegeben und eingeleitet von Paul Hoffmann .... - Darmstadt, 2007

NÖ Landesbibliothek, Signatur 114.072 B 


\section{Große Texte alter Kulturen}

Große Texte alter Kulturen: literarische Reise von Gizeh nach Rom / herausgegeben von Martin Hose. -

Darmstadt, [2004]

darin Seite 63-85 (aufgeschlagen Seite 65):

Levin, Christoph, 1950-. Das israelitische Nationalepos: Der Jahwist

NÖ Landesbibliothek, Signatur 121.734 B

\subsection{Schriftfunde zur Bibel}

Neben Handschriftenfunden wie dem des berühmten „Codex Sinaiticus “444 aus dem vierten Jahrhundert im Jahr 1844 durch Konstantin von Tischendorf(1815-1874) im Katharinenkloster am Berg Sinai gibt es auch Funde von Textzeugen zur Bibel und ihrem Umfeld außerhalb der Hauptlinie der Überlieferung.

Zu diesen Schriftquellen gehören die „Schriftrollen vom Toten Meer“ oder „Qumranschriften“. Diese wurden zwischen 1947 und 1956 in Felshöhlen bei Qumran entdeckt, den Ruinen einer 68 nach Christus zerstörten Ansiedlung im Westjordanland unweit der Nordwestküste des Toten Meeres. Es wurden rund 15.000 Fragmente von knapp 1.000 Buchrollen aus der Zeit zwischen 250 vor und 40 nach Christus zutage gefördert; die rund 200 Texte aus dem Tanakh stellen die ältesten erhaltenen Bibelhandschriften dar. Zu den Bibeltexten gehört unter anderem die „Große Jesajarolle“ aus der Zeit um 200 vor Christus mit trotz aller Übereinstimmung zahlreichen Abweichungen vom „Masoretischen Text“. Auch die Samuel-Fragmente zeigen Abweichungen vom „Masoretischen Text" und stimmen diesbezüglich zum Teil mit der Septuaginta überein, was den Rückschluss auf das höhere Alter dieser Lesarten erlaubt. Zu den eigentlichen biblischen Texten treten kommentierende Schriften, aber auch Apokryphen (Pseudepigraphen) wie das „Gigantenbuch“, die Fragmente des „Henochbuches“ und das „Jubiläenbuch“, deren beide letztere zum Bibelkanon des äthiopischen Christentums und der Beta Israel zählen, sowie weitere Texte.

In der Nähe von Nag Hammadi ca. 130 km nördlich von Luxor in Oberägypten entdeckten einheimische Bauern Ende 1945 einen Tonkrug mit dreizehn Papyrus-Codices aus dem vierten Jahrhundert nach Christus und rund fünfzig Texten im sahidischen Dialekt des Koptischen, vorwiegend frühchristlich-gnostischen Inhalts. Viele dieser Texte waren vorher nicht bekannt; die Gleichsetzung mit bei Kirchenlehrern erwähnten Titeln erweist sich im Einzelfall als schwierig. Sie dürften zum Bestand eines nahegelegenen Klosters gehört haben und wurden

44 Mit dem vollständigen griechischen Neuen Testament und weiten Teilen der Septuaginta. 
vielleicht als häretisch ausgeschieden. Der bekannteste Text ist das „Thomasevangelium“ (NHC II,2), von dem eine Ausgabe im Bereich Ägyptisch-Koptisch Berücksichtigung findet. ${ }^{45}$

22

\section{Qumrantexte}

Die Schriftrollen von Qumran: Übersetzung und Kommentar: mit bisher unveröffentlichten Texten [The Dead Sea scrolls] / Michael Wise, Martin Abegg, Edward Cook. - Augsburg, 1997

NÖ Landesbibliothek, Signatur 69.862 B

23

\section{Nag-Hammadi-Schriften}

Nag Hammadi deutsch: NHC I-XIII, Codex Berolinensis 1 und 4, Codex Tchacos 3 und 4 / hrsg. von HansMartin Schenke ... - Berlin, 2013

NÖ Landesbibliothek, Signatur 164.879 B

Abb. 8

\subsection{Textgattungen von Übersetzungen in Auswahl}

Bibelübersetzungen stehen im Spannungsfeld der Treue zum Ausgangstext und den sprachlichen Bedürfnissen des Zielpublikums; je nach stärkerer Hinwendung zu einem der beiden Aspekte ergeben sich unterschiedliche Arten von Bibelübersetzungen. Ohne Anspruch auf Vollständigkeit seien genannt: die Interlinearübersetzung, die sowohl für das Alte Testament als auch für das Neue Testament demonstriert werden kann; zeilenweise und Wort für Wort wird der originalsprachliche Text in Originalschrift, dann in Lateinschrift und schließlich in deutscher Übersetzung dargeboten. Stark am Ausgangstext orientiert ist auch die sogenannte konkordante Bibelübersetzung, die eine eindeutige Wiedergabe von Begriffen anstrebt; neben dem hier nicht weiter beschriebenen „Konkordanten Neuen Testament“ und der „Elberfelder Bibel“ gilt diese Vorgangsweise für die an anderer Stelle behandelte „Schrift" von Martin Buber und Franz Rosenzweig ${ }^{46}$ und für das hier vorgestellte „Münchener Neue Testament“. 


\section{Ursula Ulrike Kaiser,} Hans-Gebhard Bethge (Hrsg.) NAG HAMMADI DEUTSCH STUDIENAUSGABE

3. AUFLAGE

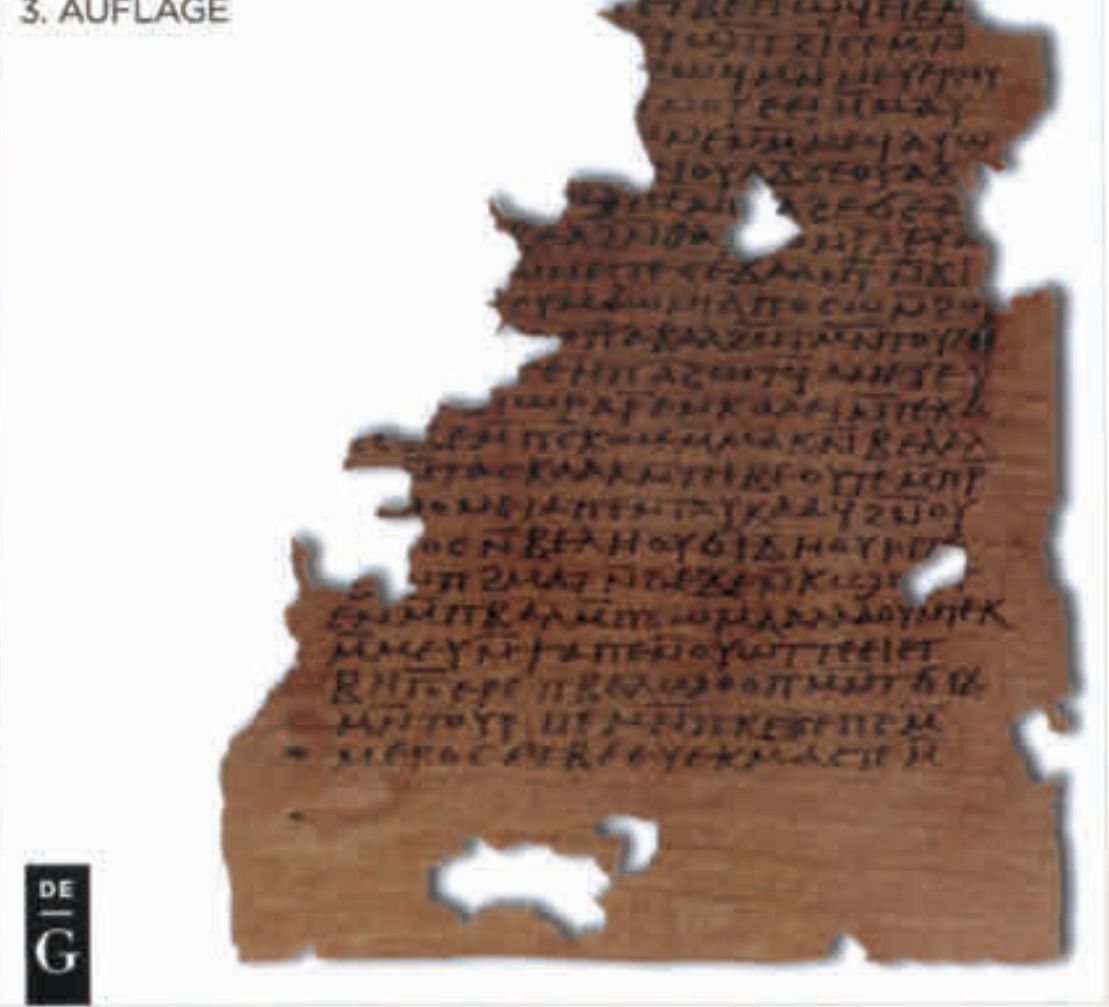


Am anderen Ende des Spektrums stehen kommunikative Bibelübersetzungen wie die „Gute Nachricht Bibel“47 oder die „Neue Genfer Übersetzung“"48; eine gemäßigte Mittelposition nimmt die „Einheitsübersetzung“449 ein.

Eine spezielle Form der Textedition ist die Synopse oder Synopsis (Zusammenschau); neben der Anwendung als Psalter-Synopse (der hebräischen Bibel und der Septuaginta) ist hier vor allem die Evangelien-Synopse zu nennen; eine Synopse war natürlich auch die „Hexapla“ des Origines. Zwecks Textvergleichs werden hierbei parallele Textstellen in Spalten für den jeweiligen Textträger nebeneinander angeordnet. Die drei Evangelien nach Matthäus, Markus und Lukas gelten wegen ihrer Ähnlichkeiten als synoptisch und ihre Evangelisten als Synoptiker; die hier vorgestellte Ausgabe enthält sogar alle vier Evangelien und dies sowohl in der Sprache des Urtextes, also Griechisch, als auch in Deutsch, in einer Anordnung in acht Spalten je Doppelseite.

Wesentlich weiter geht die Evangelienharmonie, eine Zusammenführung der vier kanonischen Evangelien $\mathrm{zu}$ einem einzigen Text. Neben dem an anderer Stelle behandelten „Diatessaron“ des Syrers Tatian aus dem zweiten Jahrhundert nach Christus und seiner als „Althochdeutscher Tatian“ bezeichneten althochdeutschen Übersetzung (die der lateinischen Übersetzung des Victor von Capua gegenübergestellt ist), ${ }^{50}$ dem ebenfalls erörterten altsächsischen (altniederdeutschen) „Heliand“ ${ }^{“ 51}$ und dem mittelhochdeutschen „Klosterneuburger Evangelienwerk“ des Österreichischen Bibelübersetzers ${ }^{52}$ ist das hier präsentierte althochdeutsche „Evangelienbuch“ des Otfrid von Weißenburg (mit einer neuhochdeutschen Übersetzung versehen) zu nennen, ein bereits endreimendes Bibelepos.

\section{4}

\section{Bibel. Altes Testament. Hebräisch (Masoretischer Text). Hebräische Schrift und lateinische Schrift und} Deutsch. Lateinische Schrift

Das Alte Testament / Interlinearübersetzung Hebräisch-Deutsch und Transkription des hebräischen Grundtextes nach der Biblia Hebraica Stuttgartensia 1990 / Rita Maria Steurer. - Witten

Band 1 (von 5), Genesis-Deuteronomium. - 2010

NÖ Landesbibliothek, Signatur 144.056 B 1

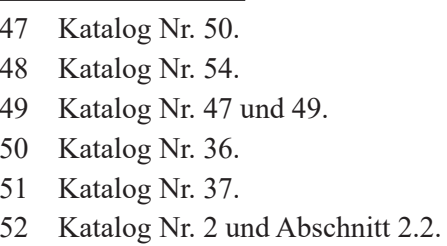


Bibel. Neues Testament. Griechisch. Griechische Schrift und Deutsch. Lateinische Schrift

Das Neue Testament / Interlinearübersetzung Griechisch-Deutsch: griechischer Text: Nestle-Aland-Ausgabe / übersetzt von Ernst Dietzfelbinger. - Witten, 2012

NÖ Landesbibliothek, Signatur 144.224 B

26

Bibel. Neues Testament. Deutsch (Münchener Neues Testament). Lateinische Schrift

Münchener Neues Testament: Studienübersetzung / [erarbeitet vom Collegium Biblicum München e.V.];

[herausgegeben von Josef Hainz ...]. - Düsseldorf, 2007

NÖ Landesbibliothek, Signatur 121.094 B 8. Aufl.

27

Synopsis quattuor Evangeliorum. Griechisch. Griechische Schrift und Deutsch. Lateinische Schrift

Synopse der vier Evangelien: griechisch-deutsche Ausgabe der Synopsis quattuor Evangeliorum: auf der Grundlage des Novum Testamentum Graece von Nestle-Aland, 26. Auflage, und des Greek New Testament, 3rd edition, sowie der Lutherbibel, revidierter Text 1984, und der Einheitsübersetzung 1979 / herausgegeben von Kurt Aland. - Stuttgart, 1989

NÖ Landesbibliothek, Signatur 122.974 C

28

Otfrid (von Weißenburg), 790-870. Evangelienbuch. Althochdeutsch und Deutsch

Evangelienbuch: Auswahl: Althochdeutsch/Neuhochdeutsch / Otfrid von Weissenburg; herausgegeben, übersetzt und kommentiert von Gisela Vollmann-Profe. - Stuttgart, 2001. - (Reclams Universal-Bibliothek; 8384: Althochdeutsche Literatur; 3)

NÖ Landesbibliothek, Signatur 19.660 B 8384

\subsection{Liturgische Bücher in Auswahl}

In aller Kürze sei auch auf liturgische Bücher eingegangen, die mit dem Text der verwendeten Bibelübersetzung einhergehen. Für die Schriftlesung werden Perikopen (Leseabschnitte) gebildet, die nach einer festgelegten Ordnung im Laufe des Kirchenjahres gelesen werden. Die so angeordneten Texte ergeben ein Lektionar; wenn die Texte nur aus den Evangelien stammen, spricht man von einem Evangelistar im Unterschied zu einem Evangeliar 
mit dem Normaltext der vier Evangelien; in der katholischen Kirche wird das Evangelistar allerdings heute ebenfalls als Evangeliar bezeichnet. In den orthodoxen Kirchen entspricht dem Evangelistar das Aprakos-Evangelium und dem Evangeliar (im ursprünglichen Sinn) das Tetraevangelium.

Für die Sonn- und Festtage ist in der katholischen Kirche ein dreijähriger Lesezyklus (Lesejahr A, Lesejahr B, Lesejahr C) üblich; die neue „Einheitsübersetzung 2016“ machte die Neuveröffentlichung der Lektionare in den Jahren 2018 bis 2020 notwendig, der eigentliche Anlass für die aktuellen ,Jahre der Bibel“. Präsentiert werden die 2019 erschienene liturgische Ausgabe für das Lesejahr A und die entsprechende Ausgabe des Volksmessbuches „Schott ${ }^{\text {‘53 }}$, die das Lektionar mit dem Messbuch (Missale) kombiniert; zum Vergleich wird auch die Vorgängerausgabe des „Schott“ (nach der „Einheitsübersetzung 1980“) angeboten. ${ }^{54}$

Als katholisches Gebet- und Gesangbuch des deutschen Sprachraums dient das „Gotteslob“55, dessen aktuelle Ausgabe von 2013 allerdings wie ihr Vorgänger noch auf der „Einheitsübersetzung 1980“ beruht; neu ist nur, dass bisher Ausgaben mit Österreichteil und Diözesananhängen üblich waren, ${ }^{56}$ während nunmehr eine Gemeinschaftsausgabe für die österreichischen Diözesen mit Österreichteil ${ }^{57}$ vorliegt. Als Vorläufer des „Gotteslob“ in der Erzdiözese Wien gilt die „Betende Gemeinde“ von Jakob Zeggl (1890-1967). ${ }^{58}$

\section{9}

\section{Die Feier der Heiligen Messe}

Die Feier der Heiligen Messe: Lektionar für die Bistümer des deutschen Sprachgebiets: authentische Ausgabe für den liturgischen Gebrauch. Band 1, Die Sonntage und Festtage im Lesejahr A. - Freiburg im Breisgau, 2019 NÖ Landesbibliothek, Signatur 196.785 C 1

Abb. 9

53 Nach Anselm Schott OSB (1843-1896), dem Herausgeber eines Laienmessbuches mit inoffiziellen deutschen Übersetzungen des lateinischen „Missale Romanum“.

54 Katalog Nr. 29 bis 31.

55 Katalog Nr. 33 und 34.

56 Vorgestellt wird die Ausgabe der Diözese St. Pölten mit Österreichteil: Gebete/Lieder 800-857 und Diözesanhang: Gebete/Lieder 901-950.

57 Österreichteil: Gebete/Lieder 700-999.

58 Katalog Nr. 32 
Abb. 9 / Katalog Nr. 29: Die Feier der Heiligen Messe. Die Sonn- und Festtage im Lesejahr A (2019).

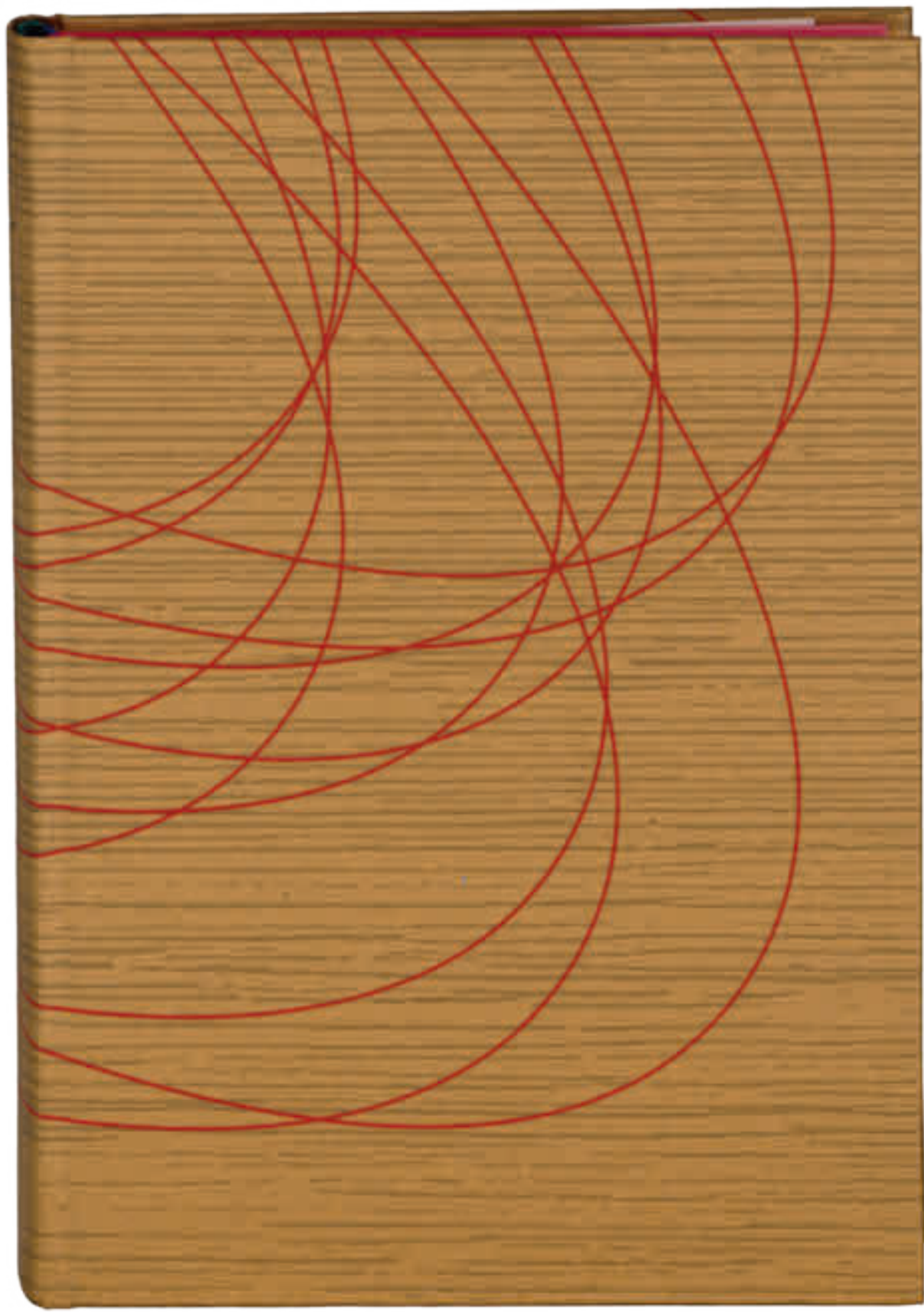




\section{Katholische Kirche. Missale Romanum. Deutsch}

Schott Messbuch für die Sonn- und Festtage des Lesejahres ...: Originaltexte der authentischen deutschen Ausgabe des Messbuches und des Messlektionars / mit Einführungen herausgegeben von den Benediktinern der Erzabtei Beuron

A. - Freiburg im Breisgau, 2019

NÖ Landesbibliothek, Signatur 120.263 B A 2019

\section{1}

\section{Katholische Kirche. Missale Romanum. Deutsch}

Schott Messbuch für die Sonn- und Festtage des Lesejahres ...: Originaltexte der authentischen deutschen Ausgabe des Messbuches und des Messlektionars / mit Einführungen herausgegeben von den Benediktinern der Erzabtei Beuron.

A. - Freiburg im Breisgau, 2004

NÖ Landesbibliothek, Signatur 120.263 B A

\section{2}

\section{Zeggl, Jakob. Die betende Gemeinde}

Die betende Gemeinde: Gebet- und Gesangbuch der Erzdiözese Wien / herausgegeben vom Erzbischöflichen Ordinariat; [Verfasser: Jakob Zeggl]. - 21. Auflage (Ausgabe mit Noten). - Wien, 1962

NÖ Landesbibliothek, Signatur 131.365 B

\section{3}

\section{Gotteslob}

Gotteslob: katholisches Gebet- und Gesangbuch Diözese Sankt Pölten / herausgegeben von den Bischöfen Deutschlands und Österreichs und der Bistümer Bozen-Brixen, Lüttich und Luxemburg. - [Neuauflage]. Klagenfurt, [2004]

NÖ Landesbibliothek, Signatur 122.821 B

34

\section{Gotteslob}

Gotteslob: katholisches Gebet- und Gesangbuch / herausgegeben von den (Erz-)Bischöfen Deutschlands und Österreichs und dem Bischof von Bozen-Brixen. - Ausgabe für die (Erz-)Diözesen Österreichs. - Stuttgart, 2013 


\section{DIE BIBEL AUS DEUTSCHSPRACHIGER UND AUS NIEDERÖSTER REICHISCHER SICHT}

\subsection{Die Bibel aus deutschsprachiger Sicht}

\subsubsection{Gotisch}

Die eingangs vorgestellte gotische Bibel kann man zwar nicht dem Deutschen zurechnen, doch stellt das Gotische - abgesehen vom Nordwestgermanischen (oder: Älteren Urnordischen) mit seinen Runeninschriften - die älteste hinreichend schriftlich überlieferte germanische Sprache dar. Die Nähe der Verwandtschaft wird am besten durch den heute noch verständlichen Anfang des Vaterunsers (Mt 6,9-13) demonstriert: Atta unsar pu in himinam weihnai namo pein ...

Vorgestellt wird eine Druckausgabe ${ }^{59}$ mit den aus den verschiedenen, hauptsächlich in Italien niedergeschriebenen handschriftlichen Quellen des sechsten bis achten Jahrhunderts ${ }^{60}$ zusammengetragenen Bruchstücken der gotischen Bibelübersetzung. Diese geht auf den arianischen (homöischen) Bischof der Westgoten bzw. Terwingen Wulfila ${ }^{61}$ zurück und ist Mitte des vierten Jahrhunderts (noch vor der lateinischen Vulgata) in Nicopolis ad Istrum ${ }^{62}$ entstanden. Wulfila hatte für diese Übersetzung ein eigenes gotisches Alphabet auf Grundlage der griechischen

59 Katalog Nr. 35.

60 Vor allem: „Codex Argenteus“ (Universitätsbibliothek Uppsala Sign. DG. 1, 187 von ursprünglich 336 Blättern): Bruchstücke der Evangelien nach Matthäus, Johannes, Lukas und Markus; bedeutende Codices rescripti: „Codex Carolinus“ (Herzog August Bibliothek Wolfenbüttel Sign. 4148): Bruchstücke Römerbrief 11-15, „Codex Ambrosianus A“ (Biblioteca Ambrosiana in Mailand, ursprünglich aus dem Kloster Bobbio, Sign. S. 36 parte superiore) mit „Codex Taurinensis“: Bruchstücke der paulinischen Briefe; „Codex Ambrosianus B“ (Sign. S. 45 parte superiore): ebenfalls paulinische Briefe; „Codex Ambrosianus C“ (Sign. J. 61 parte superiore): Bruchstücke Evangelium nach Matthäus; „Codex Ambrosianus D“ (Sign. G. 82 parte superiore): Bruchstücke Nehemia 5-7; „Codex Ambrosianus E“ (Sign. E. 147 parte superiore) mit „Codex Vaticanus Latinus 5750“: „Skeireins“, Erläuterungen zum Johannesevangelium. Der nach der silbernen Tinte auf purpurnem Pergament benannte „Codex Argenteus“ stammt vom Beginn des sechsten Jahrhunderts wahrscheinlich aus Ravenna und aus dem Umfeld des Ostgotenkönigs Theoderich des Großen. Nach seiner Entdeckung im Kloster Werden im sechzehnten Jahrhundert gelangte er in den Besitz des Kaisers; 1648 nahmen ihn die Schweden als Kriegsbeute aus der kaiserlichen Burg in Prag mit sich; lediglich das „Speyerer Fragment“ befindet sich heute nicht in Uppsala.

61 Lateinisch: Ulfilas (* um 311, †383 Konstantinopel), 336 oder spätestens 341 zum Bischof geweiht, bis 348 auf Mission unter den Terwingen, nach seiner Vertreibung in Nicopolis ad Istrum.

62 In Niedermösien südlich der unteren Donau, heute Nordbulgarien. 


\section{WIL.HELM STREITBERG †}

\section{Die Gotische Bibel}

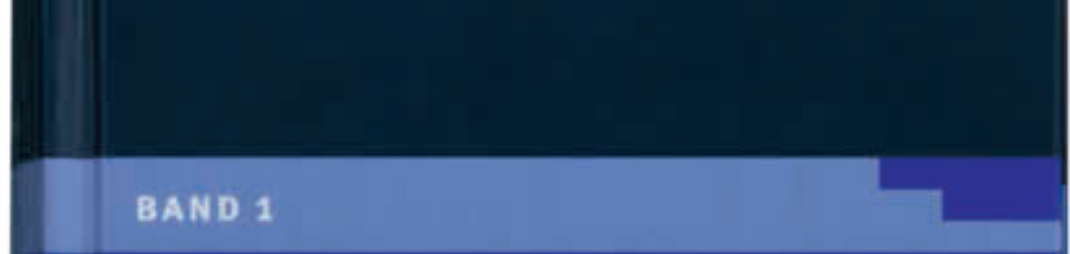

Der gotische Text

und seine griechische Vorlage

7. Auflage
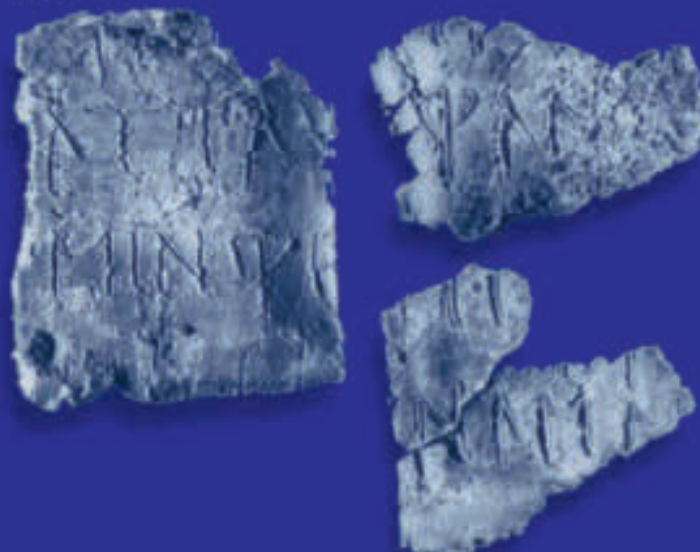

Universifatsverlag

C. WINTER

Heidelberg

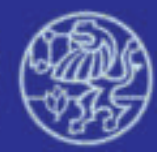

Abb. 10 / Katalog Nr. 35: Wilhelm Streitberg (Hrsg.), Die gotische Bibel. Band 1, Der gotische Text und seine griechische Vorlage (2000).
Schrift entwickelt, trotz vorauszusetzender Kenntnis der Runenschrift. ${ }^{63}$ Die vorliegende Druckausgabe bringt den gotischen Text in lateinischer Schrift und stellt diesen der griechischen Vorlage gegenüber.

\section{5}

Bibel. Griechisch. Griechische Schrift und

Gotisch. Lateinische Schrift (statt gotischer Schrift)

Die gotische Bibel / herausgegeben von Wilhelm Streitberg: mit einem Nachtrag von Piergiuseppe Scardigli

Band 1 (von 2), Der gotische Text und seine griechische Vorlage: mit Einleitung, Lesarten und Quellennachweisen sowie den kleineren Denkmälern als Anhang. - 7. Auflage. - Heidelberg, 2000. -

(Germanistische Bibliothek; Band 3) NÖ Landesbibliothek, Signatur 109.817 B 3 7. Aufl.

Abb. 10
63 Nach den zwei gotischen Alphabeten der „Wiener AlkuinHandschrift" (Codex Vindobonensis 795 in der Österreichischen Nationalbibliothek) mit Wiedergabe der Reihenfolge, Namen und Aussprache der Buchstaben zu schließen. 


\subsubsection{Althochdeutsch und Altsächsisch}

Für die Sprachstufe des zwischen 750 und 1050 gesprochenen Althochdeutschen sind zunächst die kurz nach 800 im Kloster Mondsee entstandenen „Mondseer (Monseer) Fragmente ${ }^{\text {“64 }}$ zu nennen, zu denen der „Mondseer Matthäus" gehört; dessen Sprachform ist als Altbairisch einzustufen.

Im Kloster St. Gallen befindet sich der ,althochdeutsche Tatian“, eine unter Abt Hrabanus Maurus um 830 im Kloster Fulda angefertigte Übersetzung des „Diatessaron“, einer Evangelienharmonie des Syrers Tatian aus dem zweiten Jahrhundert nach Christus. Diese war zuvor von Viktor von Capua ins Lateinische übersetzt worden und vertritt die Stelle der Evangelien im „Codex Fuldensis“ (Victor-Codex, Codex Bonifatianus I), einer 547 fertiggestellten Vulgata-Handschrift des Neuen Testaments. Der „Codex Fuldensis“ soll vom heiligen Bonifatius (Wynfreth, Winfried) nach Fulda mitgebracht worden sein; eine Abschrift des lateinischen „Diatessaron“-Textes ist der althochdeutschen Übersetzung gegenübergestellt, die also als Bilingue anzusehen ist.

Eine weitere althochdeutsche Evangelienharmonie und zugleich ein endreimendes Bibelepos bildet das zwischen 863 und 871 entstandene südrheinfränkische „Evangelienbuch“ oder „Liber evangeliorum“ des Otfrid von Weißenburg ${ }^{65}$, das in Kapitel 1.6 (Textgattungen von Übersetzungen) die Evangelienharmonien vertritt; ${ }^{66}$ die Sprache des „althochdeutschen Tatian“ und von Otfrids „Evangelienbuch“ gilt dabei als Normalalthochdeutsch.

Mit dem „Evangelienbuch“vergleichbar ist der noch stabreimende „Heliand“ in altsächsischer (altniederdeutscher) Sprache aus der Zeit um 830.

Für das Mittelhochdeutsche aus der Zeit von 1050-1350 ist schließlich das an anderer Stelle näher besprochene Werk des Österreichischen Bibelübersetzers ${ }^{67}$ zu nennen, für das bis ca. 1600 gesprochene Mittelniederdeutsche die Lübecker Bibeln von 1494 bzw. 1533/34.

\section{6}

\section{Tatianus (Syrus), $\uparrow$ 172. Diatessaron. Lateinisch und Althochdeutsch}

Tatian: lateinisch und altdeutsch: mit ausführlichem Glossar / herausgegeben von Eduard Sievers. - Paderborn, 1872. - (Bibliothek der ältesten deutschen Litteratur-Denkmäler; 5. Band)

NÖ Landesbibliothek, Signatur 202.844 B 5

64 Im Verlag de Gruyter erscheint 2021: Stephan MüllER u. Elke Krotz (Hrsg.), Die Monseer Fragmente. Bd. 1: Edition und Übersetzung, Bd. 2: Wörterbuch und Kommentar.

65 Gemeint ist Wissembourg oder Weißenburg im Elsass.

66 Katalog Nr. 28.

67 Katalog Nr. 2 und Kapitel 2.2. 


\section{Heliand. Altsächsisch}

Heliand / herausgegeben von Heinrich Rückert. - Leipzig, 1876. - (Deutsche Dichtungen des Mittelalters; 4. Band)

NÖ Landesbibliothek, Signatur 202.985 B 4

\subsubsection{Gutenberg-Bibel und deutschsprachige Bibeldrucke in Auswahl}

Wenn man die in den Jahren 1452 bis 1454 entstandene „Gutenberg-Bibel“ (B42) an den Anfang der Betrachtung der Bibel in Deutsch stellt, geschieht dies natürlich nicht in Verkennung der Tatsache, dass sie den Text der lateinischen Vulgata wiedergibt; mit der „Gutenberg-Bibel“ als erstem gedruckten Buch ${ }^{68}$ beginnt die Geschichte der Bibel im deutschen Sprachraum in gewissem Sinne aber neu. ${ }^{69}$ Dabei unterscheidet sie sich gar nicht so sehr von zeitgenössischen Bibelhandschriften: Als Schriftart dient eine Textura oder Textualis formata; die Verwendung von verschiedenen Typen inklusive Ligaturen und Abbreviaturen führt nicht nur entsprechende handschriftliche Traditionen fort, sondern ermöglicht auch ein geschlossenes Schriftbild des in zwei Kolumnen angeordneten zweiundvierzigzeiligen Textes. ${ }^{70}$ Von den 180 seinerzeit gedruckten Exemplaren sind heute noch 49 zumindest teilweise erhalten; eine der ersten Nachrichten über deren Fertigstellung ist dem bekannten Brief vom 12. März 1455 von Enea Silvio Piccolomini, dem späteren Papst Pius II., über einen Besuch in Frankfurt am Main zu entnehmen. Zumindest anhand einer Faksimile-Ausgabe kann dieses Glanzlicht der Buchkunst veranschaulicht werden.

Als „Korrekturbibeln“ oder „Gegenbibeln“ werden katholische Bibelübersetzungen bezeichnet, die zeitnah zu Martin Luthers Neuem Testament von 1522 oder zur „Luther-Bibel“ von 1534 gedruckt wurden; bereits 1527 er-

68 Genauer: in der von Johannes Gensfleisch genannt Gutenberg (ca. 1400-1468) aus Mainz erfundenen Buchdrucktechnik mit Verwendung eines Satzes aus beweglichen Lettern. Im Hochdruckverfahren hergestellte Bücher hat es schon vor und auch einige Zeit nach Erfindung des Buchdrucks gegeben, sogenannte Blockbücher, bei denen die ganze Seite mit Text und Bild seitenverkehrt als Holzschnitt ausgeführt ist (Blockdruck oder Holztafeldruck); beim Buchdruck ist dagegen der Holzschnitt auf die Wiedergabe von Bildinhalten beschränkt und wird gegebenenfalls mit dem gesetzten Text zu einer Druckvorlage kombiniert. Ungefähr gleichzeitig und vielleicht teilweise auch schon etwas früher als die B42 entstanden Drucke mit der Donat-Kalender-Type: „Donate“ („Ars minor“ von Aelius Donatus, ca. 310-380, eine lateinische Schulgrammatik im Umfang von knapp 30 Seiten), Ablassbriefe, Kalender usw. Ausgeklammert bleibt hierbei Ostasien, wo der Blockdruck schon im sechsten Jahrhundert und ein Druck mit beweglichen Lettern bereits im elften Jahrhundert erfunden worden sein soll; auf 1377 datiert ist ein mit Lettern gedrucktes Buch aus Korea.

69 Die erste gedruckte Bibel in deutscher Sprache ist die „Mentelin-Bibel“ von 1466, benannt nach Johannes Mentelin aus Straßburg (* um 1410 Schlettstadt, $\dagger 1478$ Straßburg); eine berühmte jüngere Bibel mit demselben Text ist die 1483 erschienene „Koberger-Bibel“ des Nürnberger Druckers Anton Koberger

(* um 1440 Nürnberg, $\dagger 1513$ Nürnberg), der auch für den Druck der „Schedelschen Weltchronik“ 1493 bekannt ist.

70 Daher der Name B42 oder B 42. 
schien auf Veranlassung Herzog Georgs des Bärtigen (1471-1539) ${ }^{71}$ das Neue Testament von Hieronymus Emser (* 1478 Weidenstetten, Baden-Württemberg, $\uparrow 1527$ Dresden). Die Korrektur bestand neben der teilweise oberdeutschen Prägung der Übersetzungen im Rückgriff auf die lateinische Vulgata als Grundlage. Luther hingegen stützte nach dem Grundsatz der Übersetzung aus den Urtexten sein Neues Testament auf den später sogenannten „Textus receptus“ der Ausgabe des griechischen Neuen Testaments durch Erasmus von Rotterdam ${ }^{72}$ und seine Übersetzung des Alten Testaments auf die hebräische Bibel. Von Hieronymus Emsers Neuem Testament kann eine spätere Ausgabe aus dem Jahr 1626 im Original vorgestellt werden. ${ }^{73}$ Johann Dietenberger (* um 1475 Frankfurt am Main, $\uparrow 1537$ Mainz) hatte bereits 1529 eine revidierte Fassung von Hieronymus Emsers Neuem Testament herausgebracht, der er 1534, im gleichen Jahr wie Luther, die vollständige Bibel folgen ließ. ${ }^{74}$ Diese erschien bis 1776 in rund hundert Auflagen und erwies sich somit als langlebiger als die 1537 von Johannes Eck (eigentlich Johannes Mayer oder auch Johann Maier, * 1486 Egg an der Günz, † 1543 Ingolstadt) herausgegebene Bibel, deren siebente und letzte Auflage 1630 gedruckt wurde.

Zur Charakterisierung der Bibelübersetzung des Reformators Martin Luther (* 1483 Eisleben, $\dagger 1546$ Eisleben), der „Lutherbibel“, kann auf das zu den „Korrekturbibeln“ Gesagte verwiesen werden; nach dem Neuen Testament von 1522 erschien in Etappen das Alte Testament, dem die vollständige Bibel 1534 folgte, an der unter anderen auch der Humanist Philipp Melanchthon (eigentlich Philipp Schwartzerdt, * 1497 Bretten, $† 1560$ Wittenberg) erheblichen Anteil hatte. Infolge späterer Korrekturen erhielt die 1545 wieder bei Hans Lufft in Wittenberg erschienene „Ausgabe letzter Hand“ quasi-kanonischen Status. Sowohl die Erstausgabe von 1534 als auch die „Ausgabe letzter Hand“" werden anhand von Faksimile-Ausgaben demonstriert. ${ }^{75}$

Infolge kirchenamtlicher Revisionen von 1892, dann 1912 und zuletzt 1984 (1999 in neuer Rechtschreibung) sowie 2017 entstand die heutige „Lutherbibel“, die also wie die Bibel insgesamt ihre eigene Textgeschichte hat: „Lutherbibel“ ist eben nicht gleich „Lutherbibel“; je nach Ausgabe fehlen zudem die Apokryphen oder Spätschriften des Alten Testaments (aus katholischer Sicht: deuterokanonischen Schriften), die aus evangelischer Sicht nicht als kanonisch gelten. Diese vier Revisionen sind alle vertreten. ${ }^{76}$

Katholisches Gegenstück ist die „Einheitsübersetzung“, so genannt wegen ihrer Bestimmung zum einheitlichen liturgischen Gebrauch in allen katholischen Diözesen des deutschen Sprachraums. Nachdem infolge des Zweiten

71 Aus der albertinischen Linie des Hauses Wettin und somit Cousin des Förderers von Martin Luther, Kurfürst Friedrichs des Weisen (1463-1525) aus der ernestinischen Linie desselben Hauses.

72 Erstausgabe: „Novum Instrumentum omne“ 1516. Luther benutzte die 1519 unter dem Titel „Novum Testamentum omne“ erschienene zweite Ausgabe.

73 Katalog Nr. 40

74 Katalog Nr. 39.

75 Katalog Nr. 41 und 42

76 Katalog Nr. 43 bis 46. 
Vatikanischen Konzils 1962-1965 der Grundsatz des Vorrangs für die lateinische Vulgata, genauer für die SixtoClementina von 1592, ${ }^{77}$ zugunsten neuer volkssprachlicher Übersetzungen aus den Urtexten aufgegeben und 1979 die Nova Vulgata ${ }^{78}$ als revidierte lateinische Bibelübersetzung herausgegeben worden war, erschien die „Einheitsübersetzung 1980“79 in Lizenz der Katholischen Bibelanstalt GmbH im Verlag Katholisches Bibelwerk GmbH (beide Stuttgart). Durch die Mitwirkung der Evangelischen Kirche in Deutschland (EKD) gelten das Neue Testament und die Psalmen als ökumenischer Text; die Schreibweise biblischer Namen folgt dem „Ökumenischen Verzeichnis der biblischen Eigennamen nach den Loccumer Richtlinien“ konsequenter als die „Lutherbibel“.

Infolge des Rückzugs der Evangelischen Kirche in Deutschland (EKD) im Jahr 2005 gilt die zuvor päpstlich approbierte revidierte „Einheitsübersetzung $2016^{\text {“80 }}$ nicht mehr als teilweise ökumenische Übersetzung. Die Lektionare nach der neuen „Einheitsübersetzung 2016“81 liegen seit 2020 vor, was den Anlass für die „10 Tage der Bibel" darstellt.

Eine für den nicht-liturgischen Gebrauch ökumenische kommunikative Bibelübersetzung ins Deutsche ist die „Gute Nachricht Bibel“82, eine erstmals 1997 erschienene Revision der „Bibel in heutigem Deutsch“ von 1982, die auf den Titel des 1968 erschienenen Neuen Testaments „Gute Nachricht für Sie - NT 68“ zurückgreift. Die Namensähnlichkeit mit der „Good News Bible“ („Good News Translation“, „Today’s English Version“) von 1976 und dem Neuen Testament „Good News for Modern Man: The New Testament in Today’s English Version“ von 1966 ist kein Zufall.

Unter dem Namen „Jerusalemer Bibel“"83 erschien 1968 eine Revision der später von der „Einheitsübersetzung“ verdrängten katholischen „Herder-Bibel“ des Verlages Herder in Freiburg im Breisgau. Für die „Jerusalemer Bibel“ wurde die Übersetzung der „Herder-Bibel“ mit den Anmerkungen der französischen „Bible de Jérusalem“ von 1955 kombiniert. Unter dem Namen „Neue Jerusalemer Bibel“"84 erschien 1985 die Kombination von „Einheitsübersetzung“ und den Anmerkungen der „Jerusalemer Bibel“; eine Neuausgabe mit dem Text der revidierten „Einheitsübersetzung 2016“ steht aus.

Katalog Nr. 17

78 Katalog Nr. 18. Bereits 1969 war die heute maßgebliche kritische Ausgabe der Vulgata von Robert Weber und Roger Gryson erschienen (Katalog Nr. 15).

79 Katalog Nr. 47.

80 Katalog Nr. 49. Die Erstausgabe enthielt einen groben Fehler in Matthäus 21,28-32, wonach im „Gleichnis vom willigen und unwilligen Sohn“ fälschlich der zweite, der seine Zusage nicht einhielt und somit den Worten keine Taten folgen ließ, statt des ersten, der trotz anfänglicher Ablehnung den Wunsch des Vaters erfüllte, als richtige Antwort auf Jesu Frage genannt wurde; der Fehler wurde im Herbst 2017 korrigiert.

81 Katalog Nr. 29 und 30.

82 Katalog Nr. 50.

83 Katalog Nr. 55

84 Katalog Nr. 48 
In der Tradition der reformierten Kirchen bzw. des Helvetischen Bekenntnisses ist zunächst die von der Evangelisch-reformierten Landeskirche des Kantons Zürich herausgegebene „Zürcher Bibel“685 zu nennen: Sie geht auf den Zürcher Reformator Ulrich ${ }^{86}$ Zwingli (* 1484 Wildhaus im Kanton St. Gallen, $† 1531$ Kappel am Albis) und seinen Freund Leo Jud (1482-1542) zurück und ist als „Froschauer-Bibel“67 erstmals bereits 1531 bei Christoph Froschauer (um 1490-1564) in Zürich erschienen, nachdem dieser bereits ein Jahr zuvor eine Vorläuferbibel gedruckt hatte. Nach verschiedenen Revisionen wie zuletzt 1931 erschien die 1984 begonnene „Zürcher Bibel 2007“88. Als Neuübersetzung in der Tradition der ebenfalls von ihr herausgegebenen, Schlachter-Bibel“"89 gilt die „Neue Genfer Übersetzung“ (NGÜ) ${ }^{90}$ der Genfer Bibelgesellschaft; das 1988 begonnene Projekt fand seinen vorläufigen Abschluss mit der vollständigen Ausgabe des Neuen Testaments 2009; 2011 fand eine Erweiterung um die Übersetzung der Psalmen und 2015 um die der Sprichwörter statt; das gesamte Alte Testament ist in Arbeit. Auch von der von der Deutschen Bibelgesellschaft herausgegebenen, an neuen Medien orientierten „BasisBibel“ liegen bisher (seit 2012) das Neue Testament und die Psalmen vor; die Fertigstellung soll 2021 erfolgen.

Eine jüdische Übersetzung des Tanakhs (der hebräischen Bibel) ${ }^{91}$ bildet „Die Schrift“ von Martin Buber (* 1878 Wien, $\uparrow 1965$ Jerusalem) und Franz Rosenzweig (* 1886 Kassel, $\uparrow 1929$ Frankfurt am Main); sie ist in den Jahren 1926 bis 1938 erschienen und wurde von Buber 1954-1962 revidiert. ${ }^{92}$

Als Beispiel einer Bilderbibel soll die „Allgemeine, wohlfeile Bilderbibel für die Katholiken ${ }^{693}$ von 1842 dienen, die auf älteren katholischen Übersetzungen wie der von Joseph Franz von Allioli (1793-1873) aus den Jahren 1830-1834 beruht und mit über 500 Illustrationen ausgestattet ist.

Im ersten Bereich wird auf Interlinearübersetzungen des Alten und Neuen Testaments und das konkordante „Münchener Neue Testament“ eingegangen, ${ }^{94}$ weiter unten auf die Bibelübersetzung von Nivard Schlögl und die von Pius Parsch herausgegebene „Klosterneuburger Bibel“"95.

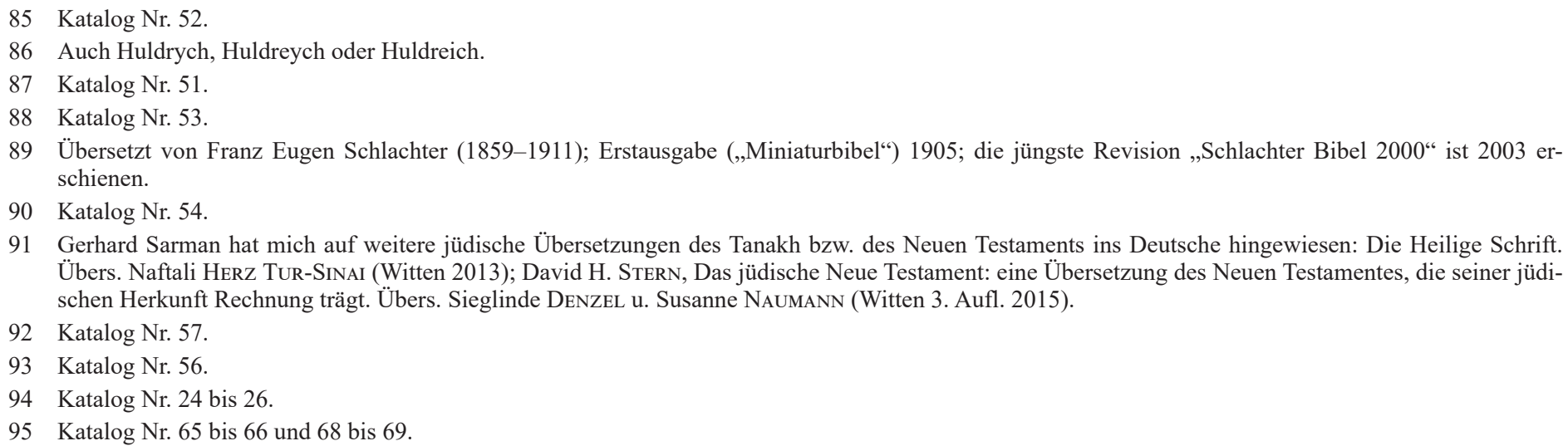

91 Gerhard Sarman hat mich auf weitere jüdische Übersetzungen des Tanakh bzw. des Neuen Testaments ins Deutsche hingewiesen: Die Heilige Schrift. Übers. Naftali Herz Tur-SinaI (Witten 2013); David H. Stern, Das jüdische Neue Testament: eine Übersetzung des Neuen Testamentes, die seiner jüdischen Herkunft Rechnung trägt. Übers. Sieglinde DenZel u. Susanne Naumann (Witten 3. Aufl. 2015).

92 Katalog Nr. 57.

93 Katalog Nr. 56.

94 Katalog Nr. 24 bis 26.

95 Katalog Nr. 65 bis 66 und 68 bis 69. 


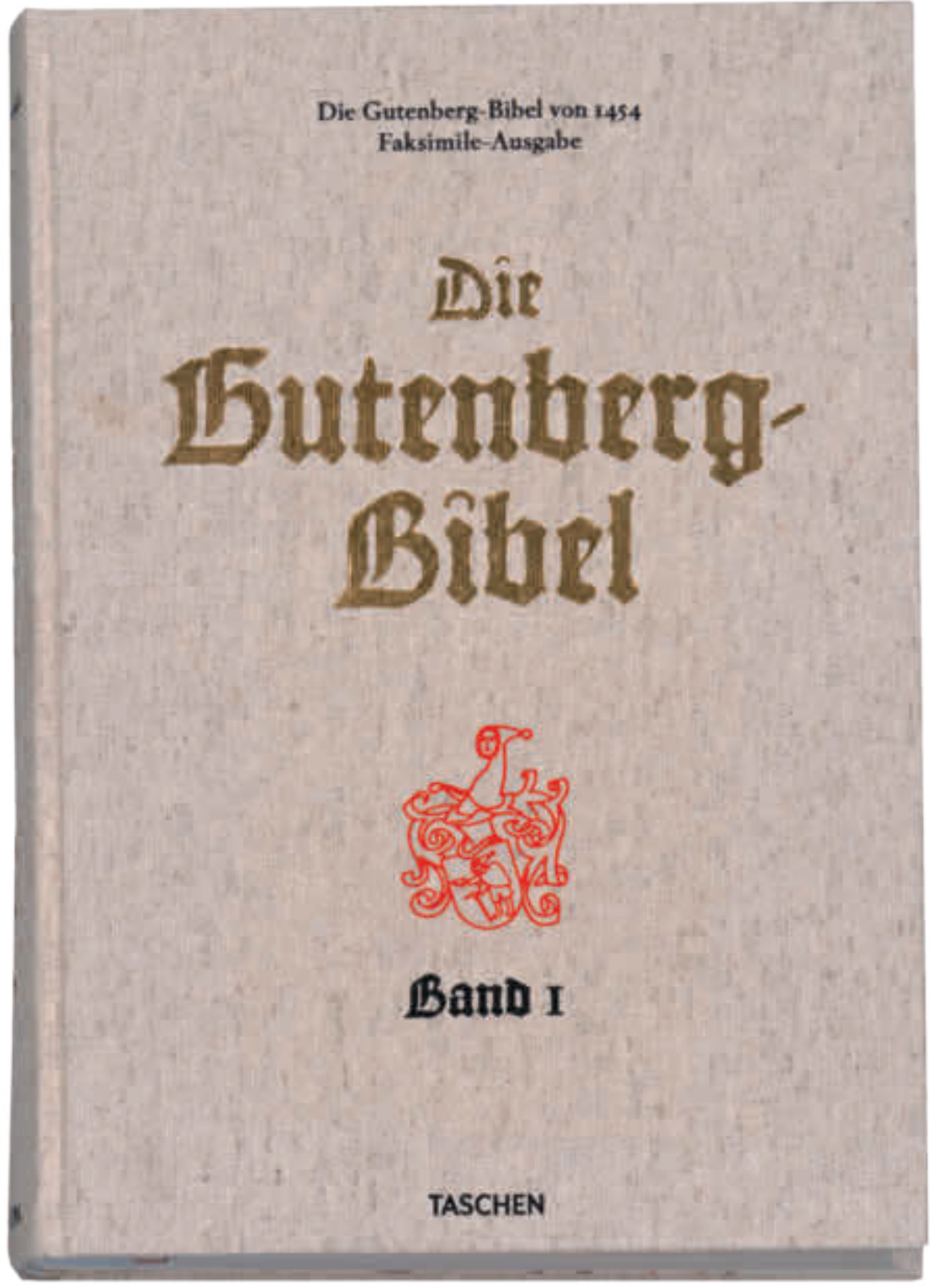

38

Bibel. Lateinisch (Vulgata). Lateinische Schrift

Die Gutenberg-Bibel von 1454. - FaksimileAusgabe

Band 1 (von 3). - Köln, 2018

NÖ Landesbibliothek, Signatur 198.463 C 1

Abb. 11

39

Bibel. Deutsch (Dietenberger). Lateinische Schrift

Biblia, beider Allt vnnd Newen Testamenten

/ Durch D. Johan Dietenberger new

verdeutscht. - Mainz, 1534

Leihgabe Gerhard Sarman

Abb. 12

40

Bibel. Neues Testament. Deutsch (Emser). Lateinische Schrift

Das New Testament / durch den hochgelehrten Herrn Hieronymum Emser. Köln, 1626

NÖ Landesbibliothek, Signatur 22.785 B Abb. 13 und 14

Abb. 11 / Katalog Nr. 38: Die Gutenberg-Bibel von 1454. FaksimileAusgabe. Band 1 (2018). 
41

Bibel. Deutsch (Luther 1534). Lateinische Schrift

Die Luther-Bibel von $1534=$ The Luther Bible of 1534. - Nachdruck

1 (von 3), Das Alte Testament. - Köln, 2002 NÖ Landesbibliothek, Signatur 101.291 C 1 Abb. 15

\section{2}

Bibel. Deutsch (Luther 1545). Lateinische Schrift

Biblia: das ist: die gantze Heilige Schrifft: deudsch [Biblia Germanica 1545] / auffs new zugericht. Luth. - Faksimilierte Ausgabe der Lutherbibel von 1545, auf Handformat verkleinert. - Stuttgart, 1983

NÖ Landesbibliothek, Signatur 122.973 C

\section{3}

Bibel. Deutsch (Luther 1892). Lateinische Schrift

Die Bibel oder die ganze heilige Schrift des Alten und Neuen Testaments / nach der deutschen Übersetzung D. Martin Luthers. Berlin und Köln, 1894

NÖ Landesbibliothek, Signatur 197.210 B Abb. 16

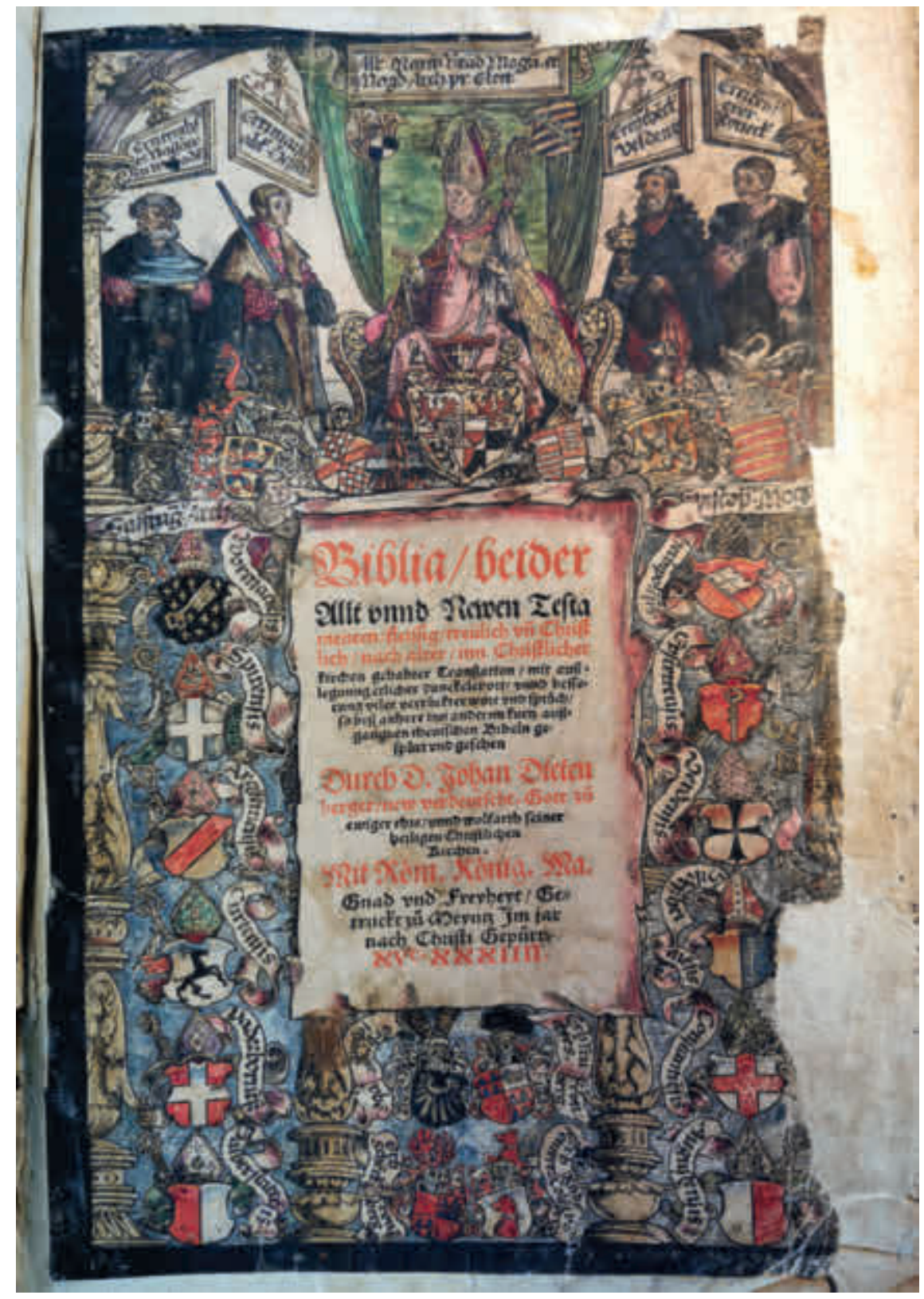

Abb. 12 / Katalog Nr. 39: Johan Dietenberger, Biblia, beider Allt vnnd Newen Testamenten [...] (1534). 


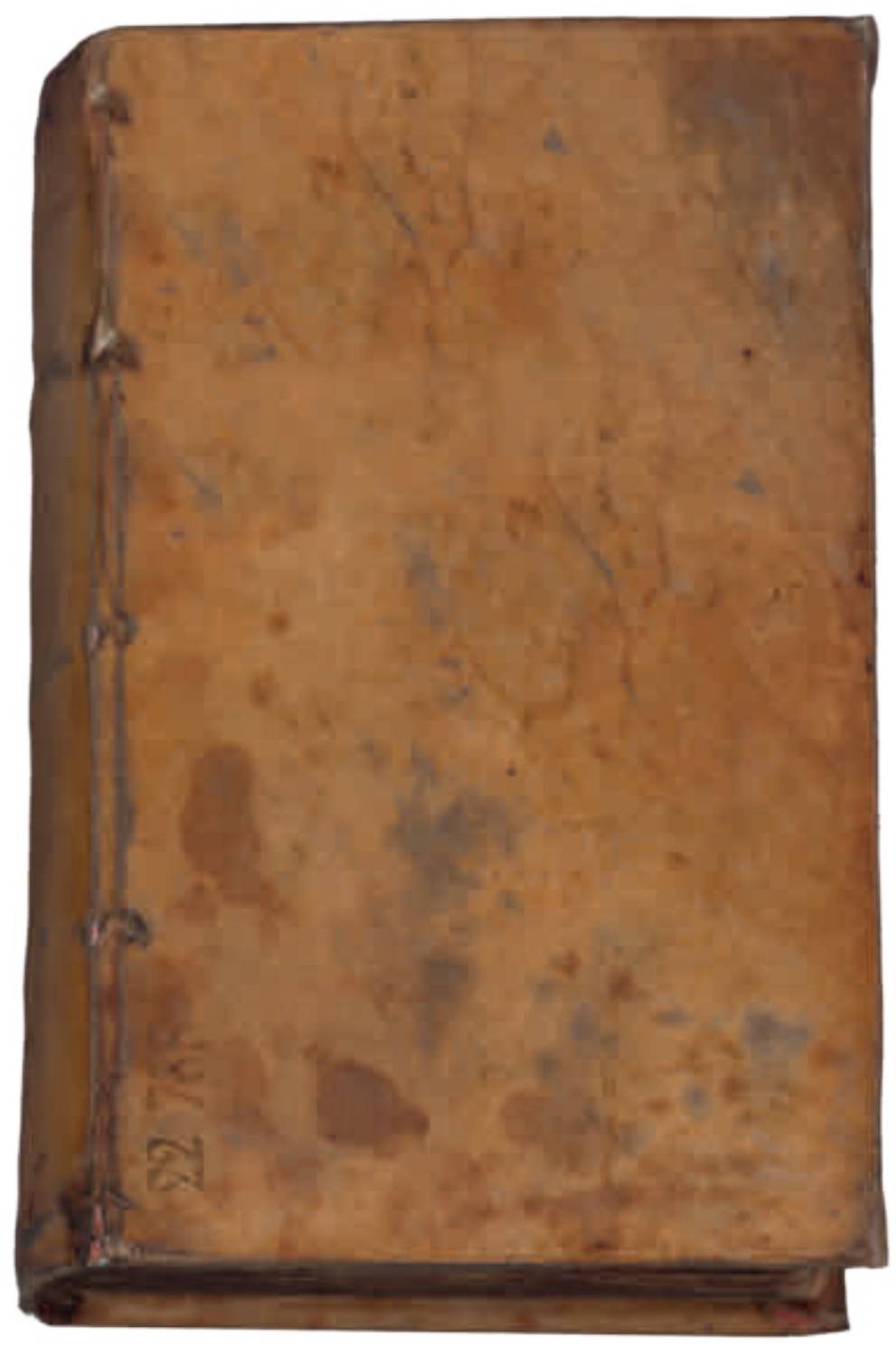

Abb. 13 / Katalog Nr. 40: Hieronymus Emser, Das New Testament [...] (1626), Einband.

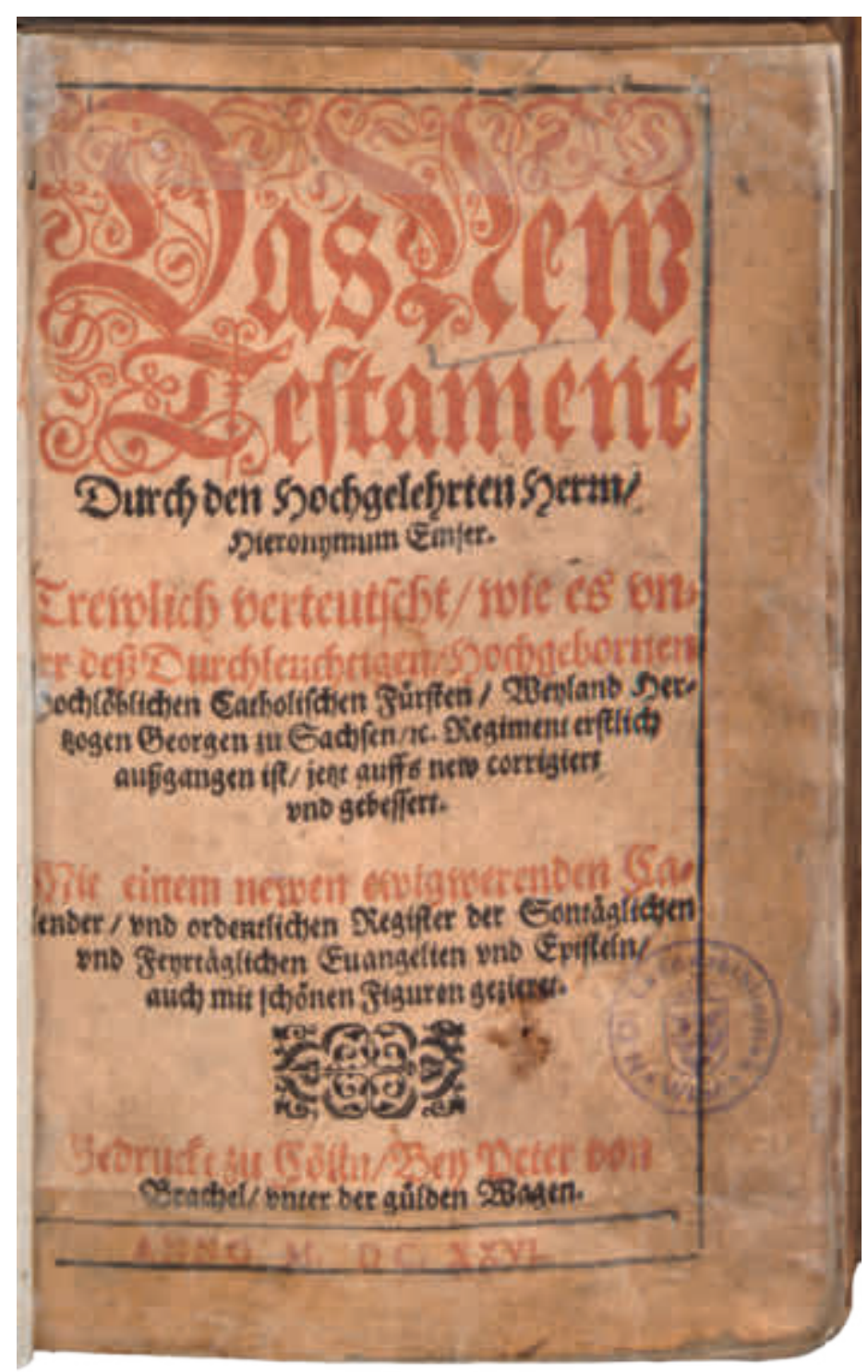

Abb. 14 / Katalog Nr. 40: Hieronymus Emser, Das New Testament [...] (1626), Titelblatt. 


\section{4}

Bibel. Deutsch (Luther 1912). Lateinische

\section{Schrift}

Die Bibel oder die ganze Heilige Schrift des Alten und Neuen Testaments / nach der deutschen Übersetzung D. Martin Luthers [Antiqua-Taschenbibel 1912]. - Stuttgart, 1982

NÖ Landesbibliothek, Signatur 127.071 B

\section{5}

Bibel. Deutsch (Luther 1984). Lateinische Schrift

Die Bibel: mit Apokryphen / nach der

Übersetzung Martin Luthers; [herausgegeben von der Evangelischen Kirche in

Deutschland]. - Bibeltext in der revidierten

Fassung von 1984, Standardausgabe,

durchgesehene Ausgabe in neuer

Rechtschreibung. - Stuttgart, 1999

NÖ Landesbibliothek, Signatur 119.478 B

46

Bibel. Deutsch (Luther 2017). Lateinische

Schrift

Die Bibel: mit Apokryphen / nach Martin

Luthers Übersetzung; herausgegeben von der Evangelischen Kirche in Deutschland. Lutherbibel revidiert 2017, Standardausgabe mit Apokryphen. - Stuttgart, 10.2016

NÖ Landesbibliothek, Signatur 178.880 B

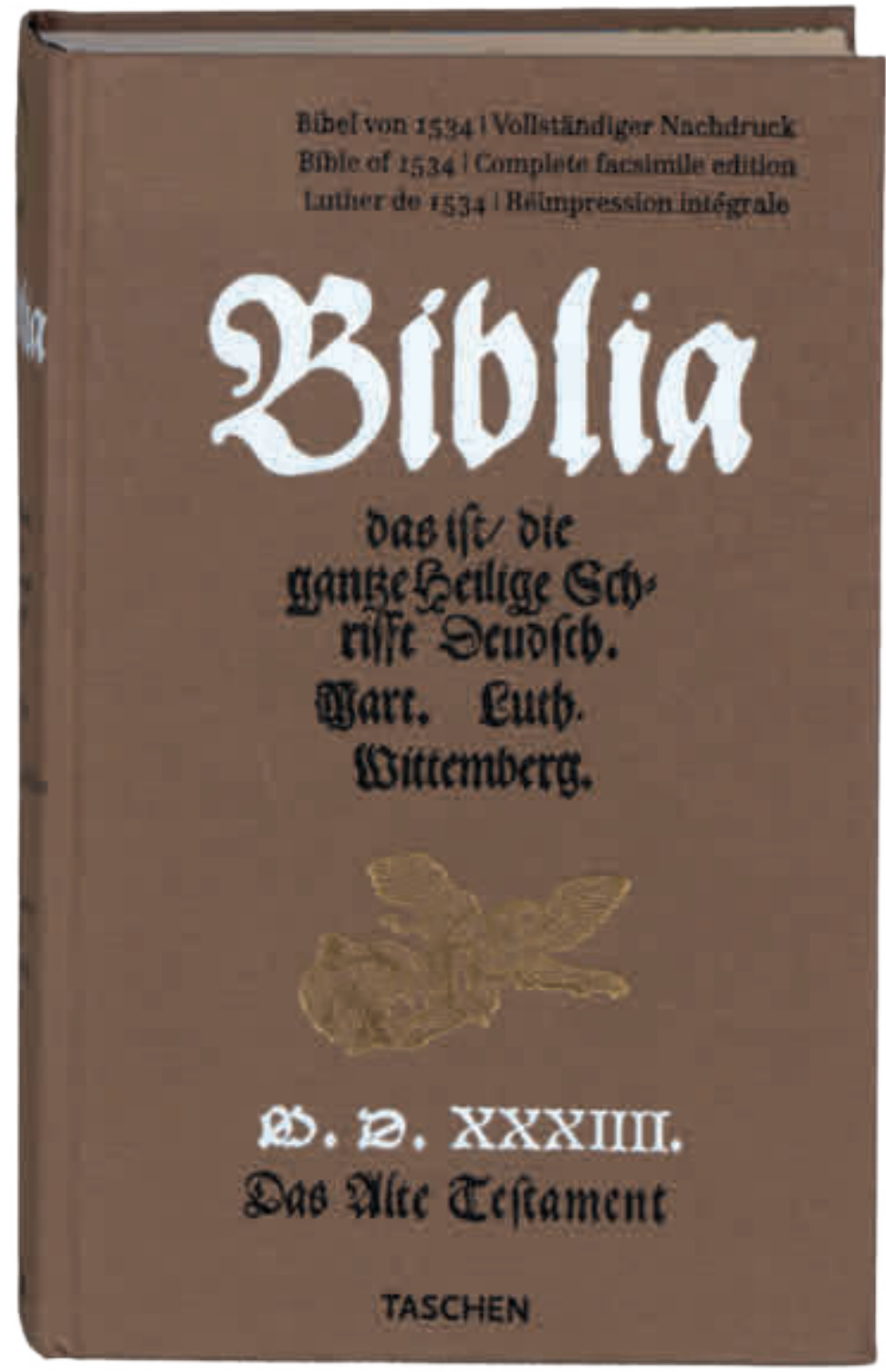

Abb. 15 / Katalog Nr. 41: Bibel von 1534 (Luther): vollständiger Nachdruck. Band 1, Das Alte Testament (2002). 


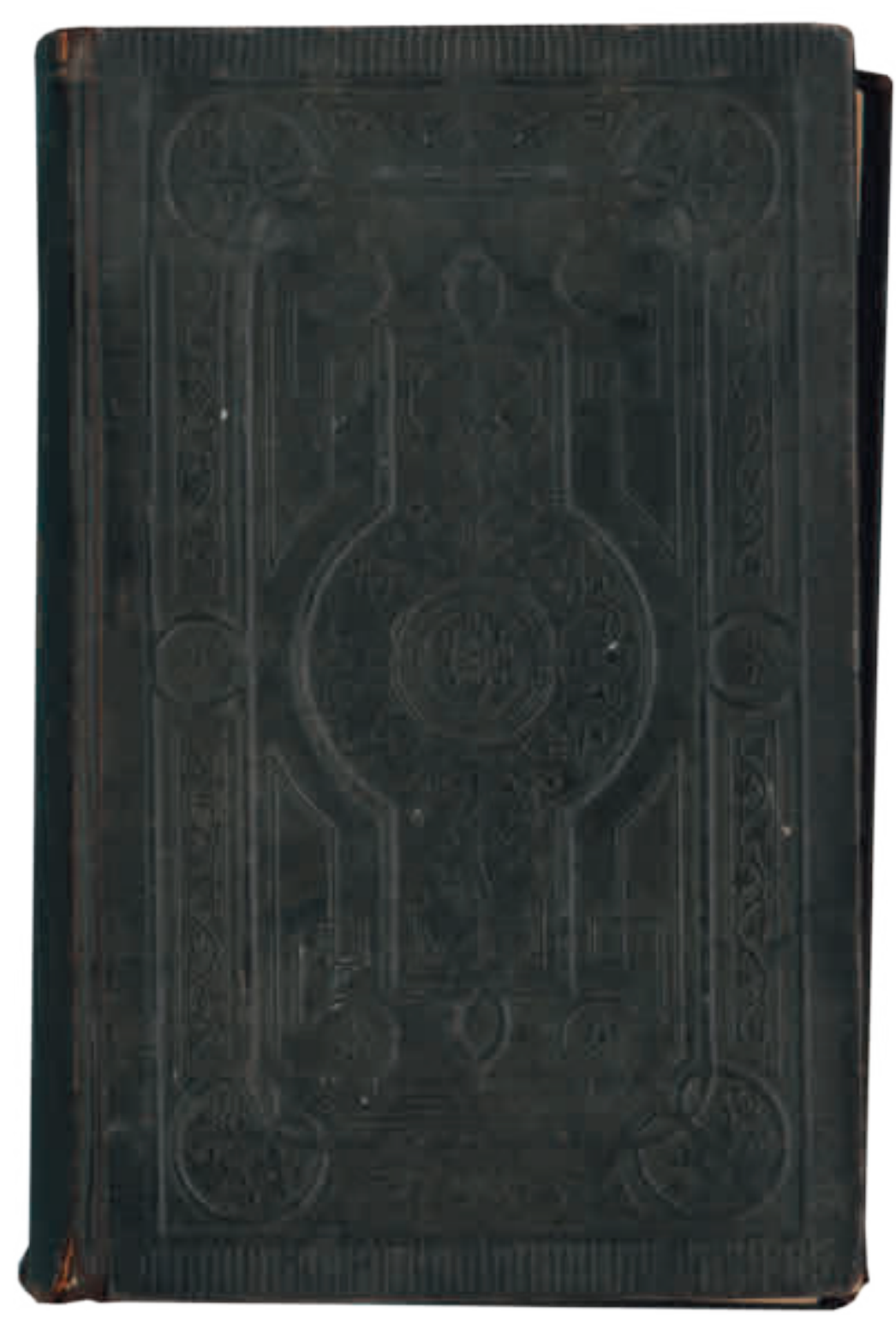

Abb. 16 / Katalog Nr. 43: Die Bibel oder die ganze heilige Schrift des Alten und Neuen Testaments nach der deutschen Übersetzung D. Martin Luthers (1894).

\section{7}

Bibel. Deutsch (Einheitsübersetzung 1980). Lateinische Schrift

Die Bibel: Einheitsübersetzung der Heiligen

Schrift: Gesamtausgabe: Psalmen und

Neues Testament ökumenischer Text /

[herausgegeben im Auftrage der Bischöfe

Deutschlands, Österreichs, der Schweiz, des

Bischofs von Luxemburg, des Bischofs von

Lüttich, des Bischofs von Bozen-Brixen. Für die Psalmen und das Neue Testament auch im Auftrag des Rates der Evangelischen Kirche in Deutschland und der Deutschen Bibelgesellschaft (Evangelisches Bibelwerk)]. - Stuttgart, 1980

NÖ Landesbibliothek, Signatur 53.242 B

\section{8}

Bibel. Deutsch (Neue Jerusalemer Bibel). Lateinische Schrift

Neue Jerusalemer Bibel: Einheitsübersetzung mit dem Kommentar der Jerusalemer Bibel.

- Neu bearbeitete und erweiterte Ausgabe, 4. Auflage / deutsch herausgegeben von Alfons Deissler ... - Freiburg im Breisgau, 1990 NÖ Landesbibliothek, Signatur 96.664 B

\section{9}

Bibel. Deutsch (Einheitsübersetzung 2016). Lateinische Schrift

Die Bibel: Einheitsübersetzung der Heiligen

Schrift: Gesamtausgabe. - Stuttgart, 2016

NÖ Landesbibliothek, Signatur 179.187 B 
Bibel. Deutsch (Gute Nachricht Bibel). Lateinische Schrift

Gute Nachricht Bibel: Altes und Neues Testament: mit den Spätschriften des Alten Testaments

(Deuterokanonische Schriften/Apokryphen): [revidierte Fassung 1997 der „Bibel in heutigem Deutsch“]. Standardausgabe mit Spätschriften, durchgesehene Ausgabe in neuer Rechtschreibung. - Stuttgart, 2008

NÖ Landesbibliothek, Signatur 120.159 B

\section{1}

Bibel. Deutsch (Froschauer 1538). Lateinische Schrift

Bibel Teütsch: Der vrsprünglichen Hebreischen vnd Griechischen warheyt nach, auffs treüwlichest verdolmetschet. - Zürich, 1538

Leihgabe Gerhard Sarman

\section{2}

\section{Bibel. Deutsch (Zürcher Bibel). Lateinische Schrift}

Das Alte Testament. Die apokryphischen Bücher. Das Neue Testament unsers Herrn und Heilandes Jesu Christi: nach der in Zürich kirchlich eingeführten Übersetzung. - Zürich, [1904]

NÖ Landesbibliothek, Signatur 146.625 B

\section{3}

\section{Bibel. Deutsch (Zürcher Bibel 2007). Lateinische Schrift}

Zürcher Bibel: 2007 / [Herausgeber: Kirchenrat der Evangelisch-Reformierten Landeskirche des Kantons Zürich]. -2. Auflage. - Zürich, 2008

NÖ Landesbibliothek, Signatur 122.964 B

\section{4}

Bibel. Neues Testament. Deutsch (Neue Genfer Übersetzung). Lateinische Schrift

Neues Testament: Neue Genfer Übersetzung / Genfer Bibelgesellschaft. - Romanel-sur-Lausanne, 2009

NÖ Landesbibliothek, Signatur 127.889 B 


\section{Bibel. Deutsch (Jerusalemer Bibel). Lateinische Schrift}

Die Bibel: die Heilige Schrift des Alten und Neuen Bundes: mit den Erläuterungen der Jerusalemer Bibel / herausgegeben von Diego Arenhoevel ...; [die Übersetzung der Erläuterungen aus dem Französischen, die Bearbeitung der Bibeltexte und die Einrichtung der Ausgabe besorgte Ulrich Schütz .... - - Deutsche Ausgabe. Freiburg im Breisgau, 1968

NÖ Landesbibliothek, Signatur 28.036 B

\section{6}

\section{Bibel. Deutsch. Lateinische Schrift}

Allgemeine, wohlfeile Bilderbibel für die Katholiken, oder die ganze heilige Schrift des alten und neuen Testaments: nach der Vulgata, unter Zuziehung und Benutzung solcher Uebersetzungen, welche mit Genehmigung hochwürdigster Ordinariate erschienen, als von Cartier, Tirin, Erhard, Weitenauer, Rosalino, Braun, Allioli u. Anderer, durch einen alten katholischen Geistlichen in Bayern rezensirt, mit mehr als 500 schönen in dem Texte eingedruckten Abbildungen und erläuternden Bemerkungen über die dunkelsten Stellen der H. Schrift am Schlusse des Ganzen. - Stereotyp-Pracht-Ausgabe. - Leipzig, 1842

NÖ Landesbibliothek, Signatur 202.988 B

\section{7}

\section{Bibel. Altes Testament. Deutsch (Buber-Rosenzweig). Lateinische Schrift}

Die Schrift: in 4 Bänden / aus dem Hebräischen verdeutscht von Martin Buber gemeinsam mit Franz Rosenzweig

Band 1 (von 4), Die fünf Bücher der Weisung. - 10., verbesserte Auflage der neubearbeiteten Ausgabe von 1954, Lizenzausgabe. - Stuttgart, 1992

NÖ Landesbibliothek, Signatur 122.970 B 1 


\subsubsection{Im Dunstkreis des Deutschen}

Eine Übersicht über deutschsprachige Bibelübersetzungen wäre unvollständig ohne die Berücksichtigung des Niederdeutschen und der Tochtersprachen des Hochdeutschen und Niederdeutschen.

Von Johannes Jessen (*1880 Garding, Kreis Nordfriesland, $\uparrow 1945$ Schleswig), der ab 1914 als Pastor in Kosel in Schwansen, ab 1921 in Schleswig und ab 1930 in Kiel wirkte, stammt eine niederdeutsche Übersetzung des Neuen und Alten Testaments aus den Jahren 1933 bzw. 1937. ${ }^{96}$

Eine Tochtersprache des Niederdeutschen bildet das Plautdietsche, die ursprünglich niederpreußische Mundart der Russlandmennoniten, die aus dem westpreußischen Weichseldelta in das Russische Reich und später zu einem erheblichen Teil von dort in die gesamte Neue Welt ausgewandert sind. Ein Neues Testament in der Übersetzung des Kanadiers John J. Neufeld (*1913 Rosenheim School District, Manitoba, † 2008 Winnipeg) ${ }^{97}$ dokumentiert diese Sprache.

Eine Tochtersprache des Hochdeutschen ist das auf dem Pfälzischen basierende Pennsylvania Dutch, das in Pennsylvania, Ohio, Indiana, Illinois, im kanadischen Ontario und in Belize hauptsächlich von Amischen ${ }^{98}$ alter Ordnung sowie Mennoniten alter Ordnung gesprochen wird; diese Sprache kann anhand einer zweisprachigen Bibelausgabe, in der die englische „King James Bible“ einem pennsylvaniadeutschen Bibeltext gegenübergestellt ist, demonstriert werden. ${ }^{99}$

Noch nicht so weit ausgebaut ist das durch in Siebenbürgen integrierte Landler stark kärntnerisch geprägte Hutterische der nach Jakob Hutter (ca. 1500-1536) benannten Hutterer.

Das in hebräischer Schrift geschriebene Jiddische (Jüdisch-Deutsche) der Aschkenasim, genauer das heute bei weitem vorherrschende Ostjiddische ${ }^{100}$, vervollständigt diesen Abschnitt. Der Tanakh bzw. die hebräische Bibel vertritt zusammen mit einer jiddischen Übersetzung von Yehoash ${ }^{101}$ das Alte Testament. ${ }^{102}$ Von Henry Einspruch ${ }^{103}$ liegt aber auch eine jiddische Übersetzung des Neuen Testaments vor. ${ }^{104} \mathrm{Zu}$ den Kennzeichen des Jiddischen auf

96 Katalog Nr. 58.

97 Katalog Nr. 59.

98 Eine von dem aus der Schweiz stammenden und später im Elsass wirkenden Jakob Ammann (1644-1730) 1693 gegründete Abspaltung von den Mennoniten, die sich ihrerseits auf den Niederländer Menno Simons (1496-1561) zurückführen.

99 Katalog Nr. 60.

100 Mit den Untergruppen litauisches, polnisches und ukrainisches Jiddisch.

101 Eigentlich Solomon Blumgarten oder Blumgarden (1872-1927), 1890 nach New York emigriert, bedeutender jiddischer Schriftsteller.

102 Katalog Nr. 61.

103 Ursprünglich Khaym Aynshprukh (1892-1977), ein Konvertit zum Lutheranismus.

104 Katalog Nr. 62 


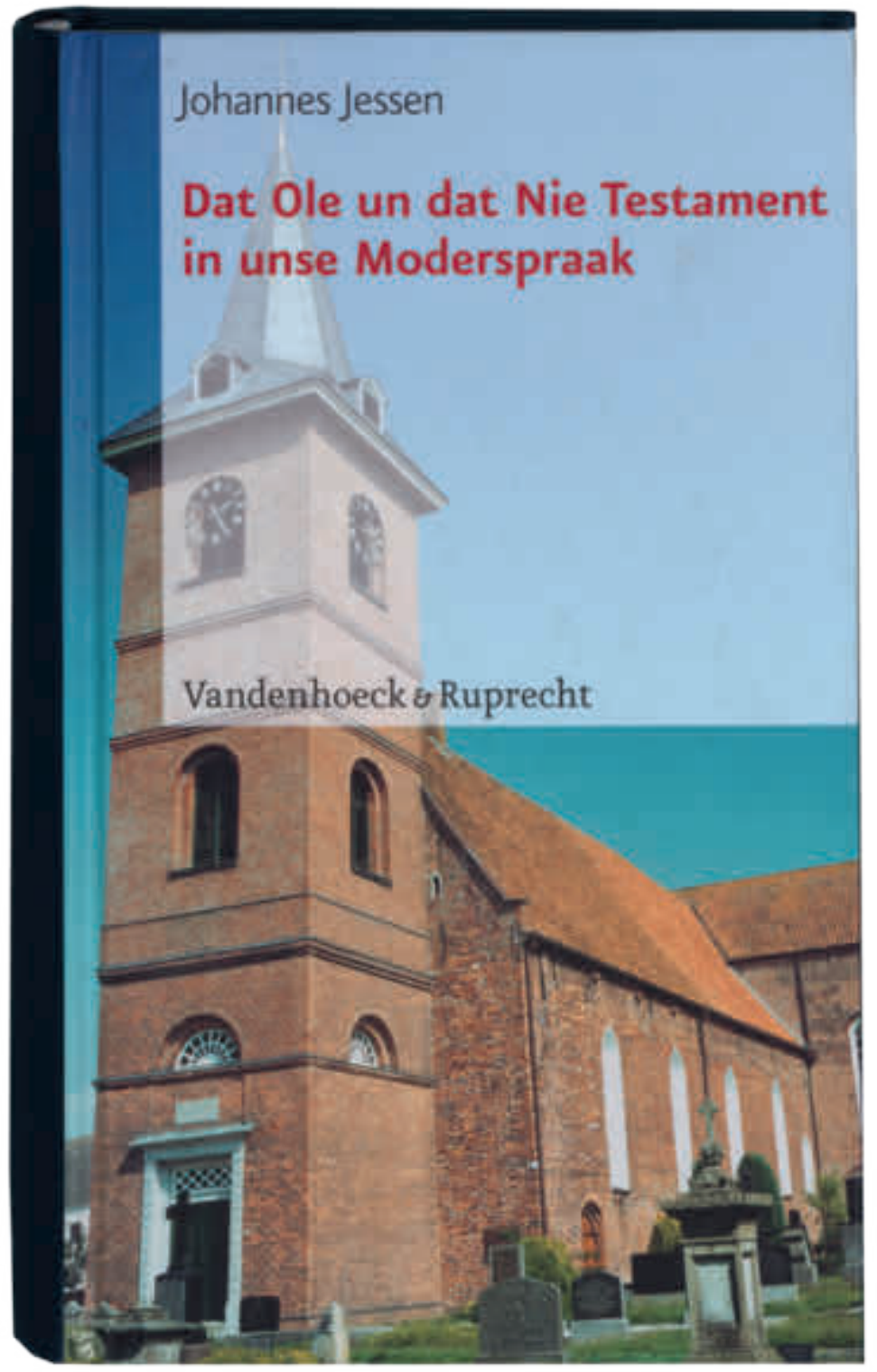

Abb. 17 / Katalog Nr. 58: Johannes Jessen, Dat Ole un dat Nie Testament in unse Moderspraak (Niederdeutsch) (2006). lautlichem Gebiet gehört neben der Entrundung von ö und ü zu e und i die Vertretung von anlautendem pf- durch $\mathrm{f}$ - und von inlautendem oder auslautendem -pf(-) durch unverschobenes -p(-); ansonsten ist unter anderem das Fehlen der schwachen Adjektivdeklination (,,der alter man“ statt „der alte Mann“) auffällig.

58

Bibel. Niederdeutsch (Jessen). Lateinische Schrift

Dat Ole un dat Nie Testament in unse Moderspraak / Johannes Jessen: herausgegeben von Heinrich Kröger ... Ole Testament: 9. Auflage, Nie Testament: 11. Auflage. - Göttingen, 2006

NÖ Landesbibliothek, Signatur 134.169 B Abb. 17

\section{9}

Bibel. Neues Testament.

Mennonitendeutsch (Neufeld). Lateinische Schrift

Daut Niehe Tastament: Plautdietsch /

fonn J.J. Neufeld äwasat. - Winnipeg, 1987

NÖ Landesbibliothek, Signatur 134.427 B

Abb. 18 


\section{DAET}

NIEHE TMSTAMENT

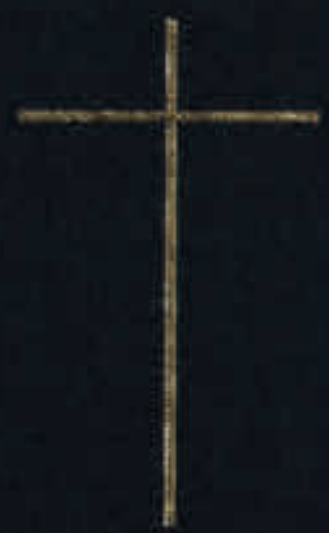

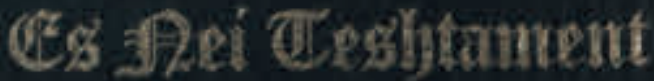

\section{马entispluania Zeits?}

un Qrantion
Abb. 18 / Katalog Nr. 59: J.J. Neufeld, Daut Niehe Tastament (Plautdietsch) (1987). 
Bibel. Neues Testament. Pennsylvaniadeutsch und Englisch (King James Version). Lateinische Schrift Es Nei Teshtament: [Pennsylvania Deitsh un English]: special Pennsylvania Dutch- English edition: German text: textus receptus Greek text and Dr. Martin Luther's German translation: English text: the authorized King James version. - South Holland, Ill., 1993

NÖ Landesbibliothek, Signatur 134.424 B

Abb. 19

\section{1}

Bibel. Altes Testament. Hebräisch und Jiddisch (Yehoash). Hebräische Schrift

[Torah, nevi'im u-khetuvim / 'im targum Yidish fun Yeho'ash; aroysgegebn fun Alṿeḷtlekhn Yidishn Kulțur-Ḳongres] = The Hebrew Bible with a Yiddish translation / by Yehoash-S. Blumgarden. -

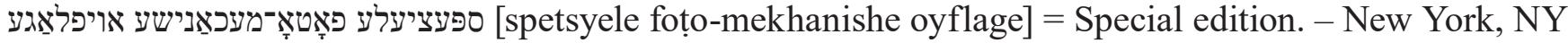
Helek 1 (von 2). - 1982

NÖ Landesbibliothek, Signatur 132.806 C A

62

Bibel. Neues Testament. Jiddisch (Einspruch). Hebräische Schrift

The New Testament / translated by Henry Einspruch, D.D. = דער בּּרית חדשה / איבּערזעצט פוּן דר חיים_איינשפרוּן [Der bris̀ ḥadosheh / iberzetsṭ fun Dr. Ḥaym Aynshprukh]. Fifth edition. - Baltimore, Md., 1977

NÖ Landesbibliothek, Signatur 134.317 B 


\subsection{Der Österreichische Bibelübersetzer}

Der anonyme sogenannte Österreichische Bibelübersetzer ist ein offenbar aus dem Herzogtum Österreich stammender gebildeter Laie aus der Zeit um 1330, dem die Übertragung biblischer Texte aus der lateinischen Vulgata in die damalige, heute unter Mittelhochdeutsch geläufige Volkssprache ein Anliegen gewesen ist, wie er in den Vorreden zu seinen Schriften als Rechtfertigung ausführt.

Von hervorragender Bedeutung ist zunächst das „Evangelienwerk“ oder „Klosterneuburger Evangelienwerk“ aus der Zeit um 1330, eine Evangelienharmonie mit Rückgriffen unter anderem auf den Beginn der Apostelgeschichte, das apokryphe „Nikodemus-Evangelium“ und die „Legenda aurea“. Die älteste erhaltene Handschrift ${ }^{105}$ von 1340 aus der Stadtbibliothek Schaffhausen ${ }^{106}$ gilt nicht als Erstfassung, sondern als „Bearbeitung S“. Niederösterreichische Textzeugen sind: in der Stiftsbibliothek Göttweig der Codex 222 rot (Erstfassung Gö) ${ }^{107}$, in der Stiftsbibliothek Melk der Codex $804^{108}$ (Erstfassung / Auszüge Mk) und in der Stiftsbibliothek Klosterneuburg der Codex 4 (Bearbeitung K1) ${ }^{109}$ sowie der Codex 51 (Bearbeitung K2) ${ }^{110}$.

Das zweite große Werk ist das „Alttestamentliche Werk“ oder „Schlierbacher Alte Testament“ im namensgebenden Codex 16 der Stiftsbibliothek Schlierbach. ${ }^{111}$ Dieses eigentliche „Schlierbacher Alte Testament“ umfasst „Zwei Vorreden zur Verteidigung der deutschen Bibel“" und die Bücher Genesis, Exodus, Tobit, Daniel (letzteres unvollständig); der vollständigere Codex 329 der Stiftsbibliothek Melk ${ }^{112}$ (Version Mel) enthält die beiden Vorreden, die Bücher Daniel, Genesis, Exodus, Tobit und zusätzlich Ijob; nur die beiden Vorreden befinden sich auch im Codex 982 der Stiftsbibliothek Melk ${ }^{113}$ (Version Me2), während der Codex 224 der Stiftsbibliothek Seitenstetten ${ }^{114}$ lediglich das Buch Ijob beinhaltet; der Codex Ross. 694 der Biblioteca Apostolica Vaticana ${ }^{115}$ tradiert schließlich zusätzlich die separat überlieferten Bücher Sprichwörter und Kohelet.

105 Vgl. http://www.handschriftencensus.de/werke/1984, http://www.handschriftencensus.de/werke/746 und http://www.handschriftencensus.de/werke/694 (27.4.2020).

106 Cod. Gen. 8, mit rund 425 marginalen lavierten Federzeichnungen.

107 Weitere Signatur 198 schwarz, früher C 2; 1450-1460, Papier, noch 365 Blätter, Schmuckinitialen, mit Rankenwerk und Drolerien in Federzeichnung.

108 Altsignaturen 805 bzw. O 4; um 1450, Pergament und Papier, noch 201 Blätter.

109 Entstehung um 1410 (textintern auf 1385 datiert), Pergament, 365 Blätter, mit 96 historisierten Deckfarbeninitialen und zwei szenischen Darstellungen in Rankenmedaillons von Heinrich Aurhaym, 1776 als Geschenk von Johann Georg Ferdinand Freiherr von Managetta und Lerchenau erhalten.

110 Datierung 1410-1420, Papier, II, 376 Blätter.

111 Auf Blatt 83ra-178vb; datiert 1433, Version S, Papier, noch 178 Blätter, Vorbesitzer Job Hartmann Enenkel (1576-1627).

112 Altsignaturen 411 bzw. H 24; Teil 3 = Blatt 199ra-282vb von 282 Blättern, datiert Wolkersdorf im Weinviertel 1421, Papier.

113 Altsignaturen 348 bzw. G 8; auf Seite 1-21.

114 Datierung 1395 und 1454 [?], Papier; auf Blatt 120r-128v.

115 Datierung 1380-1390, Papier, 203 Blätter, Fondo Rossiano, früher Jesuitenkolleg Wien-Lainz, Codex X 74. 
Der „Psalmenkommentar“ ist unter anderem in den Codices AB 15 B 1 und AB 15 B 8 der Stiftsbibliothek Altenburg, in der Handschrift 9 der Stiftsbibliothek Geras, in den Codices 11 und 593 der Stiftsbibliothek Klosterneuburg, im Codex $112^{116}$ der Stiftsbibliothek Melk und im Codex 30 der Diözesanbibliothek St. Pölten überliefert.

Nachdem in den Jahren 2005-2012 an der Universität Augsburg ein entsprechendes Projekt zum „Schlierbacher Alten Testament" unter Leitung von Freimut Löser durchgeführt worden war, das mit Stand 2016 im Manuskript abgeschlossen war, startete 2016 ein von der Gemeinsamen Wissenschaftskonferenz mit 4,5 Mio. Euro gefördertes interakademisches Projekt der Bayerischen Akademie der Wissenschaften (Arbeitsgruppe an der Universität Augsburg) und der Berlin-Brandenburgischen Akademie der Wissenschaften unter Federführung von Freimut Löser, Jens Haustein und Martin Schubert zur Erforschung und Edierung des „Evangelienwerks“ und daran anschließend (bis 2027) des „Psalmenkommentars“; Texten des Mittelalters“ erfolgen. Zumindest in den deutschen Medien des Jahres 2016 war von einer deutschen Bibelübersetzung „200 Jahre vor Luther“ die Rede; ${ }^{118}$ dies wird am Vorabend des Lutherjahres 2017 dem Projekt in der öffentlichen Wahrnehmung wohl nicht geschadet haben. Umso erstaunlicher ist die bisherige weitgehende Ignorierung dieses Themas in der Öffentlichkeit in Österreich und insbesondere auch in Niederösterreich.

Hier kann nun der Klosterneuburger Codex 4 mit der prachtvoll ausgestatteten vollständigen Ausgabe des „Klosterneuburger Evangelienwerks" präsentiert werden, ${ }^{119}$ und zwar passend gleich als Einstieg, mit dem aufgeschlagenen, dem Johannesevangelium entnommenen Beginn: In principio erat verbum, zu Deutsch „Im Anfang war das Wort““ ${ }^{20}$ Die Prunkinitiale „I“ zeigt den Evangelisten Johannes beim Schreiben des Evangeliums. Vielleicht kann dies der nötige Anstoß für eine erhöhte Aufmerksamkeit gegenüber dem Österreichischen Bibelübersetzer und seinem „Klosterneuburger Evangelienwerk“ sein, einem der zentralen niederösterreichischen Aspekte zum Thema Bibel.

\subsection{Ein niederösterreichischer Bibelübersetzer auf dem Index librorum prohibitorum}

Einen weiteren niederösterreichischen Anknüpfungspunkt zum Thema Bibel bietet Pater Nivard (Johannes) Schlögl OCist $\left(* 4\right.$. August 1864 Gaaden, $†$ 24. Juni 1939 Wien) ${ }^{121}$ aus dem Stift Heiligenkreuz. Einige seiner

116 Altsignaturen 589 bzw. L 8 .

117 Vgl. dazu https://bibeluebersetzer.badw.de/das-projekt.html (9.6.2020).

118 Siehe z. B. Tagesspiegel (18. März 2016), online unter: https://www.tagesspiegel.de/wissen/200-jahre-vor-luther-bibeluebersetzung-ein-oesterreicher-warder-erste/13336228.html (9.6.2020).

119 Katalog Nr. 2.

120 Auf Blatt 10r.

121 Nach anderen Quellen 4. Juni 1864 und 25. Juni 1939. 
Lebensstationen: 1884 Novize, 1889 Priesterweihe, 1890 Novizenmeister, 1894 Promotion, 1896-1908 Professor für alttestamentliche Exegese in Heiligenkreuz, 1908-1936 Ordentlicher Professor für biblisch-orientalische Sprachen und alttestamentliche Exegese an der Universität Wien. Schlögls wissenschaftliche Leitlinien waren die biblische Metrik, die sich seiner Meinung nach auch in Übersetzungen widerspiegeln müsste, und die damit verbundene Konjekturalkritik.

Schlögls Bibelübersetzungswerk umfasst folgende Schriften:

Die Bücher Samuelis oder Erstes und zweites Buch der Könige. - Wien: Verlag von Mayer \& Co., 1904. (Kurzgefasster wissenschaftlicher Commentar zu den Heiligen Schriften des Alten Testamentes; Abtheilung 1, Band 3, 1. Hälfte)

Die Bücher der Könige (drittes und viertes, hebräisch erstes und zweites). Die Bücher der Chronik. - Wien: Verlag von Mayer \& Co., 1911. - (Kurzgefasster wissenschaftlicher Commentar zu den Heiligen Schriften des Alten Testamentes; Abtheilung 1, Band 3, 2. Hälfte)

Die Psalmen hebräisch und deutsch: mit einem kurzen wissenschaftlichen Kommentar. - Graz und Wien: Verlagsbuchhandlung Styria, 1911

Die Heiligen Schriften des Alten Bundes. Band 4, Die prophetischen Bücher Teil 1, Das Buch des Propheten Ješa ja: aus dem kritisch hergestellten hebräischen Urtext ins Deutsche metrisch übersetzt und erläutert. - Wien und Leipzig: Orion-Verlag, 1915

Die Heiligen Schriften des Alten Bundes. Band 3, Die poetisch-didaktischen Bücher Teil 1, Die Psalmen: aus dem kritisch hergestellten hebräischen Urtext ins Deutsche metrisch übersetzt und erläutert. - Wien und Leipzig: Orion-Verlag, 1915

Die Heiligen Schriften des Alten Bundes. Band 3, Die poetisch-didaktischen Bücher Teil 2, Das Buch Ijob: aus dem kritisch hergestellten hebräischen Urtext ins Deutsche metrisch übersetzt und erläutert. - Wien und Leipzig: Orion-Verlag, 1916

Die Heiligen Schriften des Neuen Bundes: aus dem Urtext übersetzt, mit Erläuterungen und einer Einführung. - Wien: Burgverlag Richter und Zöllner, 1920 (Imprimatur Klosterneuburg 1920 und Wien 1920) 
Die Heiligen Schriften des Alten Bundes: aus dem kritisch wiederhergestellten hebräischen Urtexte übersetzt und kurz erläutert von Dr. Nivard Schlögl

Band 1, Das Buch Mosche, Jehoschua und Schophetim (Pentateuch, Joschua, Richter, 1 Schem. 1-7). - Wien: Burgverlag Richter und Zöllner, 1922 (Imprimatur Wien 1921)

Die Heiligen Schriften des Alten Bundes: aus dem kritisch wiederhergestellten hebräischen Urtexte übersetzt und kurz erläutert von Dr. Nivard Schlögl

Band 2, Das Buch von beiden Reichen (1 Schemuel 8-31, 2 Schemuel, 1 und 2 Könige), das Buch der Chronik (1 und 2 Chr., Esra 1-6, Nehemia 1-13, Esra 7-19), Tobija, Jehudit, Ester, erstes und zweites Buch der Maqqabäer. - Wien: Burgverlag Richter und Zöllner, 1922 (Imprimatur nicht erteilt)

Die 1920 erschienenen „Heiligen Schriften des Neuen Bundes“ wurden am 16. November 1921, der erste Band der „Heiligen Schriften des Alten Bundes“ am 17. Mai 1922 auf den „Index librorum prohibitorum“ (Index Romanus) gesetzt. Dieses erstmals 1559 veröffentlichte Verzeichnis der verbotenen Bücher erschien letztmals 1948, mit Nachträgen bis 1966; in diesem Jahr wurde der „Index“ mit Wirkung vom 29. März 1967 außer Kraft gesetzt. Die letzte in der Niederösterreichischen Landesbibliothek vorhandene Druckausgabe des „Index“ stammt aus dem Jahr 1956 und enthält auch die Nivard Schlögl betreffende Stelle.

Auf dem Umschlag des ersten Bandes der „Heiligen Schriften des Alten Bundes“ ist ein wohl von einem Bibliothekar geschriebener Warnhinweis „Index“ aufgeklebt. Dieses ehemals verbotene Buch darf ebenso wenig fehlen wie die vom kirchlichen Verbot gleichfalls betroffenen „Heiligen Schriften des Neuen Bundes“. Der zweite Band der „Heiligen Schriften des Alten Bundes“ wurde noch 1922 ohne kirchliche Druckerlaubnis veröffentlicht und scheint nicht im „Index“ auf, wie auch die bereits früher erschienenen Veröffentlichungen Schlögls. Dies erklärt auch, dass Schlögl im zweiten Band „Weisheitsbücher und Propheten“ der 1934 erschienenen und von Pius Parsch herausgegebenen Ausgabe der „Heiligen Schrift des Alten Bundes“ (der sogenannten „Klosterneuburger Bibel“) als Übersetzer des Buches Isaias aufscheint. Dieses bildet nämlich keinen Bestandteil des auf dem „Index“ befindlichen ersten Bandes der „Heiligen Schriften des Alten Bundes“, sondern den bereits 1915 erschienenen Teil 1 des vierten Bandes. Obwohl Schlögl weiter als Ordinarius tätig war, bedeutete die Indizierung einen entscheidenden Karriereeinbruch; die ursprünglich geplanten Teile 3,3-4, 4,2-4 und 5 seiner Bibelübersetzung sind deswegen nicht mehr erschienen. 


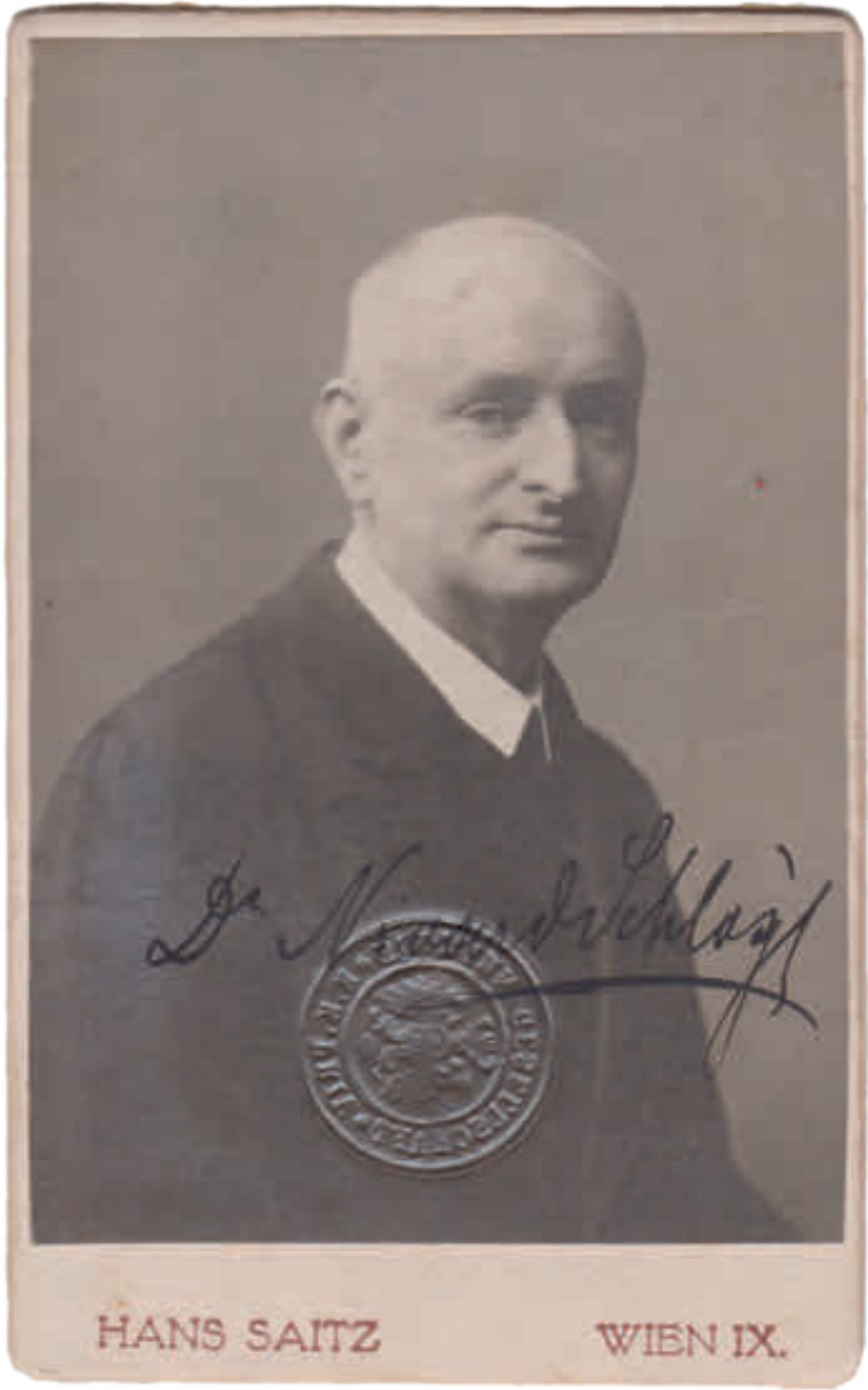

Abb. 20 / Katalog Nr. 63: Signiertes Porträtfoto Nivard Schlögl von Hans Saitz (1867-1944).

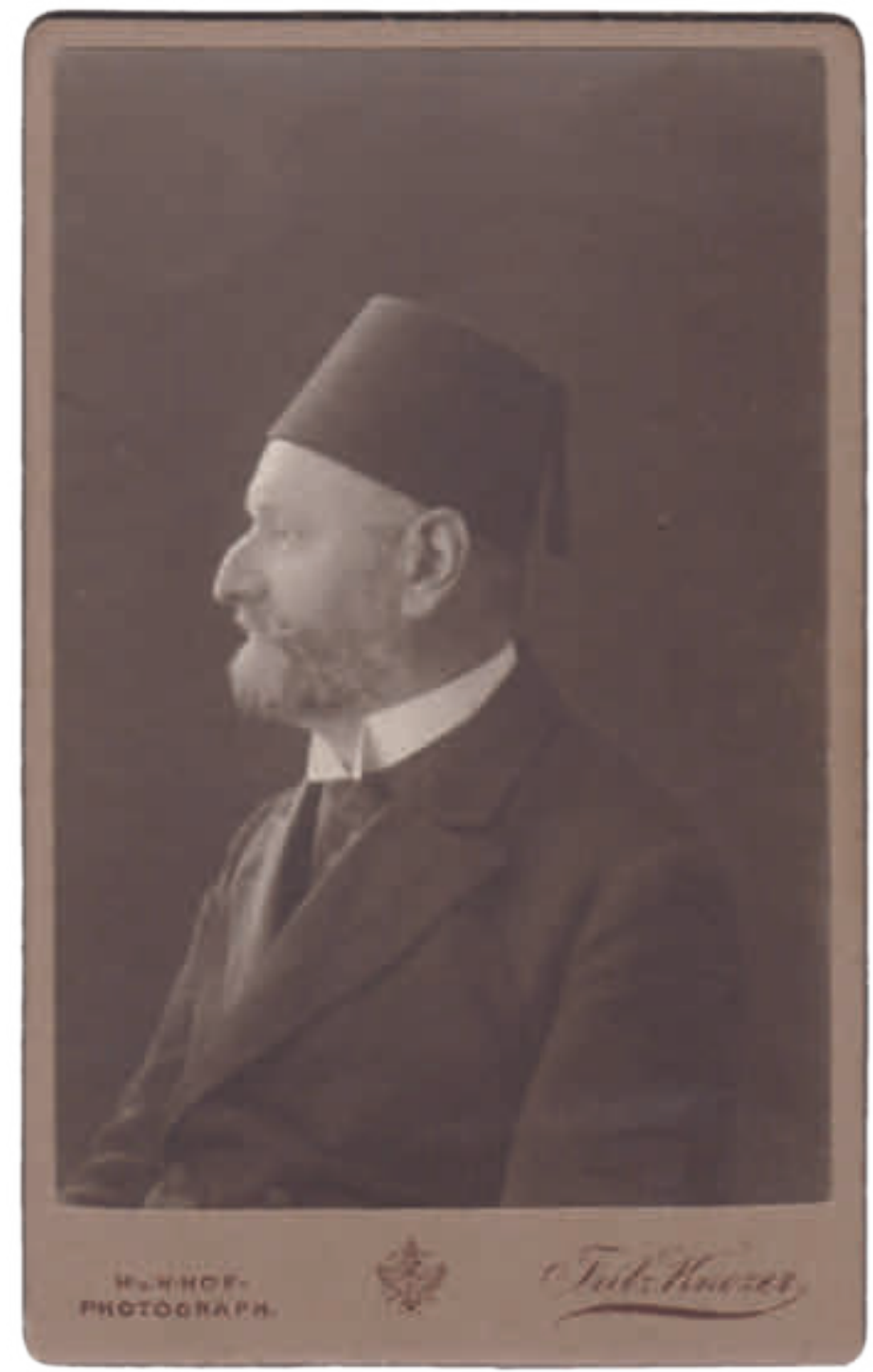

Abb. 21 / Katalog Nr. 63: Porträtfoto Nivard Schlögl von Fritz Knozer (1853-1923). 


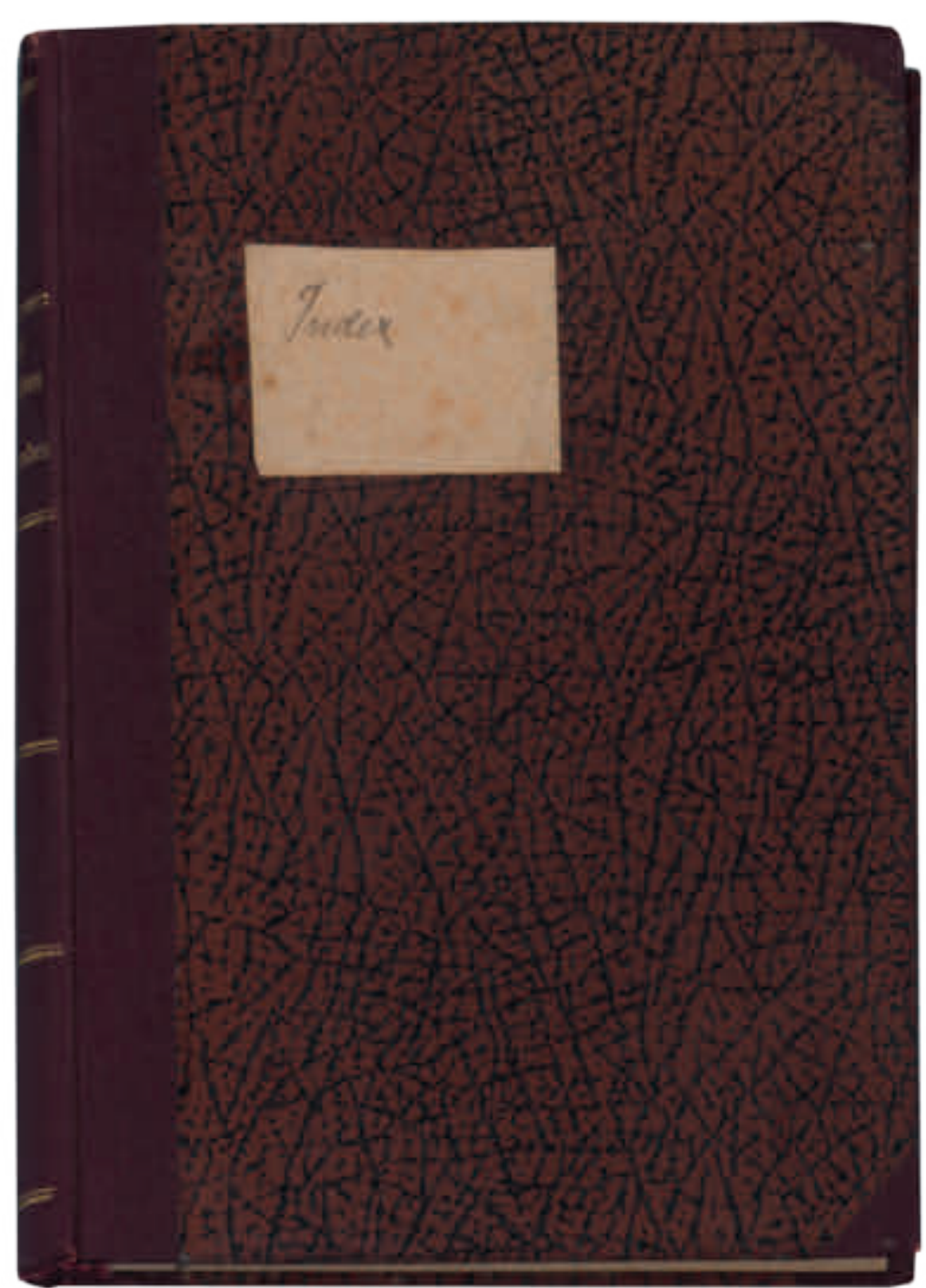

Abb. 22 / Katalog Nr. 66: Nivard Schlögl (Hrsg.), Die heiligen Schriften des Alten Bundes. Aus dem kritisch wiederhergestellten hebräischen Urtexte übersetzt und kurz erläutert. Band 1, Das Buch Mosche, Jehoschua und Schophetim (1922); mit Index-Hinweis.
63

Zwei Porträtfotos zu P. Nivard Schlögl (von Hans Saitz, Wien IX, signiert Dr. Nivard Schlögl, und dem k.u.k. Hof-Fotograf Fritz Knozer)

Stiftsbibliothek Heiligenkreuz

Faksimile

Abb. 20 und 21

64

Grill, Severin, 1893-1975.

Universitätsprofessor Dr. P. Nivard

Johannes Schlögl O. Cist.

Universitätsprofessor Dr. P. Nivard

Johannes Schlögl O. Cist.: 1864-1939: eine

kurze Würdigung / Severin Grill. - 2.,

vermehrte Auflage. - Heiligenkreuz, 1949. -

(Heiligenkreuzer Studien; Nr. 8)

NÖ Landesbibliothek, Signatur 24.097 B 8

\section{5}

Bibel. Neues Testament. Deutsch (Schlögl). Lateinische Schrift (Fraktur)

Die heiligen Schriften des Neuen Bundes: aus dem Urtext übersetzt, mit Erläuterungen und einer Einführung / von Nivard Schlögl. Wien, 1920

NÖ Landesbibliothek, Signatur 18.050 B 


\section{Bibel. Altes Testament. Deutsch (Schlögl). Lateinische Schrift (Fraktur)}

Die heiligen Schriften des Alten Bundes: aus dem kritisch wiederhergestellten hebräischen Urtexte übersetzt und kurz erläutert / von Nivard Schlögl. - Wien, 1922

Band 1, Das Buch Mosche, Jehoschua und Schophetim (Pentateuch, Joschua, Richter, 1 Schem. 1-7). - 1922 NÖ Landesbibliothek, Signatur 32.255 B 1

Abb. 22

\section{7}

\section{Index Romanus. Deutsch}

Index Romanus: Verzeichnis sämtlicher auf dem römischen Index stehenden deutschen Bücher desgleichen aller wichtigen fremdsprachlichen Bücher seit dem Jahre 1750 / zusammengestellt auf Grund der neuesten vatikanischen Ausgabe sowie mit ausführlicher Einleitung versehen von Professor Dr. theol. et phil. Albert Sleumer, Studiendirektor i.R. - Elfte vermehrte Auflage. - Osnabrück, 1956

NÖ Landesbibliothek, Signatur 176.799 B 11.Aufl.

\subsection{Volksliturgie und Schriftenapostolat}

Eine weitere niederösterreichische Persönlichkeit ist Pius (Johann) Parsch CanReg (* 18. Mai 1884 in Neustift/ Nové Sady bei Olmütz/Olomouc, $\uparrow 11$. März 1954 in Klosterneuburg). Stationen seines Lebens sind: Eintritt in das Stift Klosterneuburg (1904), Priesterweihe (1909), Promotion (1912), Aushilfsseelsorger in der Piaristenpfarre Maria Treu in Wien (bis 1913), Militärseelsorger (1915-1918).

$\mathrm{Ab} 1922$ begründet er mit Betsingmessen in St. Gertrud (Klosterneuburg) die Liturgische Bewegung in Österreich und gibt ab 1926 die Zeitschrift „Bibel und Liturgie“ bzw. ab 1928 die Zeitschrift „Lebe mit der Kirche“ heraus; 1927 folgt die Gründung des Volksliturgischen Apostolats samt Verlag und Druckerei. Den Durchbruch erzielt er 1933 mit der Betsingmesse im Schlosspark Schönbrunn im Rahmen des Allgemeinen Deutschen Katholikentags in Wien mit 250.000 Mitfeiernden. Nach Aufhebung des Stiftes Klosterneuburg durch die Nationalsozialisten ist er 1941-1946 als Seelsorger in der Pfarre Wien-Floridsdorf tätig. 
Bleibende Verdienste erwirbt er sich schließlich auch noch 1950 mit der Gründung des Klosterneuburger Bibelapostolats, auf das sich das 1966 gegründete Österreichische Katholische Bibelwerk ${ }^{122}$ zurückführt, welches sich seit 2015 in Wien befindet. ${ }^{123}$

Zum Nachleben von Pius Parsch gehört auch das 1972 durch Norbert Hösinger CanReg (1930-2011) gegründete Pius-Parsch-Institut in Klosterneuburg. Dieses war bis 2006 ein eigenständiger Verein, seit 2012 befindet es sich in Trägerschaft der 2004 gegründeten Liturgiewissenschaftlichen Gesellschaft Klosterneuburg.

Aktuell werden vom Pius-Parsch-Institut folgende Schriftenreihen herausgegeben: die „Schriften des PiusParsch-Instituts“ (seit 1976), die „Pius-Parsch-Studien“ (seit 2004) und die „Protokolle zur Liturgie (seit 2007); zudem wird seit 2009 alle zwei Jahre der Pius-Parsch-Preis vergeben.

Die von Pius Parsch 1926 begründete Zeitschrift „Bibel und Liturgie“ wurde 2017 eingestellt, wie auch die 1974 begonnenen „Perikopen“"124.

Die von Pius Parsch herausgegebene „Klosterneuburger Bibel“ bestand aus der Kombination einer vorliegenden Übersetzung des Neuen Testaments durch Jakob Schäfer (1864-1933) und einer neu zusammengestellten Übertragung des Alten Testaments durch verschiedene Übersetzer, zu denen, wie bereits ausgeführt, auch Nivard Schlögl zählte. Die Übersetzung des Neuen Testaments durch Jakob Schäfer war für „Gottes Wort“ (die „Steyler Bibel“) gedacht; den alttestamentlichen Teil sollte Edmund Kalt (1879-1943) beisteuern. Das Neue Testament erschien nach sechs Teillieferungen ${ }^{125}$ in zwei Bänden $1925^{126}$ und $1928^{127}$; vom alten Testament sind nur fünf Teillieferungen erschienen. ${ }^{128}$ In einer Bearbeitung durch Nikolaus Adler (1902-1970), verlegt von der Steyler Verlagsbuchhandlung in Kaldenkirchen ${ }^{129}$, kehrte das Neue Testament von Jakob Schäfer als „Mainzer Neues Testament“ 1957 an seinen Ursprungsort Steyl zurück.

122 Evangelisches Gegenstück ist die 1970 gegründete Österreichische Bibelgesellschaft; in Deutschland entsprechen diesen Organisationen das 1933 gegründete Katholische Bibelwerk (Stuttgart) und die 1981 gebildete Deutsche Bibelgesellschaft (Zusammenlegung des 1965 gegründeten Evangelischen Bibelwerks und der 1975 durch Fusion der Württembergischen Bibelanstalt und Cansteinschen Bibelanstalt entstandenen Deutschen Bibelstiftung). Bereits 1948 ist der Verband der Evangelischen Bibelgesellschaften in Deutschland gegründet worden.

$123 \mathrm{Vgl}$. http://www.pius-parsch-institut.at/profil/pius-parsch (9.6.2020).

124 Diese erschienen zuvor seit 1968 als „Einführung in die Perikopen“, die ihrerseits die 1959-1967 als Beilage zu „Bibel und Liturgie“ publizierte Zeitschrift „Lebe mit der Kirche“ und damit indirekt die 1928 von Pius Parsch begründete gleichnamige Vorgängerzeitschrift fortsetzten.

1251922 Matthäus, 1922 Markus, 1923 Lukas, 1924 Johannes, 1924 Apostelgeschichte, 1925 Apokalypse.

126 Evangelien und Apostelgeschichte.

127 Briefe und Offenbarung.

128 [1924] Tobias, Judith, Esther, [1924] Job, 1925 Weisheit, Prediger, 1925 Jesus Sirach, 1927 Isaias.

129 Seit 1970 Teil von Nettetal. 
Die „Klosterneuburger Bibel“" gliedert sich in:

Die Heilige Schrift des Alten Bundes (1934)

1. Geschichtliche Bücher

2. Weisheitsbücher und Propheten

Übersetzer:

Josef Franz von Allioli (1793-1873), bearbeitet durch Leo Schabes (1881-1935): Leviticus, Numeri, Josue,

Richter, Samuel 2, Könige 1-2, Chronik 1-2, Nehemia, Esther

Johann Edmayr (1885-?): Tobias, Judith, Makkabäer 1-2

Johann Gabriel (1896-1964): Genesis, Exodus, Deuteronomium, Ruth, Samuel 1, Esra

Severin Grill (1893-1975): Ezechiel

Edmund Kalt (1879-1943): Jeremias, Klagelieder

Athanasius Max Miller (1881-1963): Psalmen

Otto Sauermann (1906-1968): die fünf Weisheitsbücher; Baruch und die kleinen Propheten

Leo Schabes (1881-1935): Job, Daniel

Nivard Schlögl (1864-1939): Isaias

Die Heilige Schrift des Neuen Bundes (1934)

Übersetzer: Jakob Schäfer (1864-1933)

Die Heilige Schrift des Alten Bundes (1951)

1. Geschichtliche Bücher

2. Weisheitsbücher und Propheten

Übersetzer:

Josef Casper (1906-1951): Samuel 2, Esther

Johann Gabriel (1896-1964): zusätzlich Leviticus, Numeri

Severin Grill (1893-1975): zusätzlich Josue, Richter

Otto Sauermann (1906-1968): zusätzlich Könige 1-2, Chronik 1-2

Benediktiner der Erzabtei Beuron: Psalmen

Johannes Bauer (1927-2008): Isaias, Job, Daniel (Überarbeitung der Übersetzungen von Nivard Schlögl bzw.

Leo Schabes)

Sonst wie in der Ausgabe 1934; ersetzt oder überarbeitet wurden also die Übersetzungen von Josef Franz von Allioli, Athanasius Max Miller, Leo Schabes und Nivard Schlögl. 


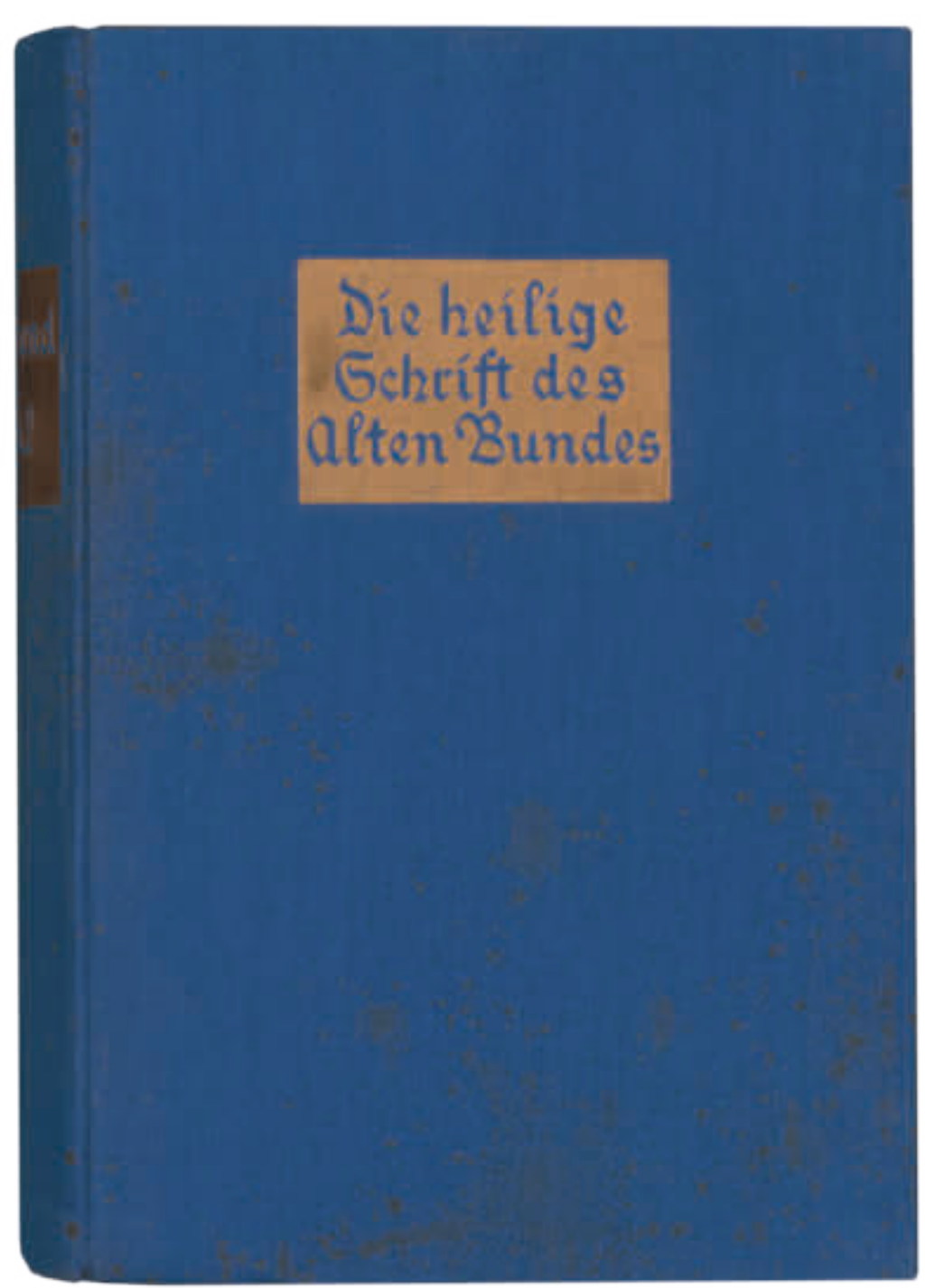

Abb. 23 / Katalog Nr. 68: Pius Parsch (Hrsg.), Die Heilige Schrift des Alten Bundes (1934).
Die Heilige Schrift des Neuen Bundes (1951)

Übersetzer: Jakob Schäfer (1864-1933)

Vorgestellt wird die komplette „Klosterneuburger Bibel“" von 1934 (in zwei Bänden); dazu kommt die 2016 als Band 13 der „Pius-ParschStudien" erschienene Faksimileausgabe der 2. Auflage (1939) ${ }^{130}$ des „Laien-Rituale - das Buch des Lebens" von Pius Parsch mit einem Porträt von Pius Parsch auf dem Buchcover. Nicht fehlen darf eine Originalausgabe dieser 2. Auflage mit der handschriftlichen Widmung für den späteren Vizekanzler und Außenminister Alois Mock (1934-2017) Ein froher Weihnachtsgruß meinem lieben Alois. Onkel Franz und dem Firmenstempel August Mock Autounternehmung $u$. Lagerhaus, Euratsfeld 142, N.-Ö.

\section{8}

Bibel. Altes Testament. Deutsch (Klosterneuburger Bibel). Lateinische Schrift

Die Heilige Schrift des Alten Bundes / herausgegeben von Pius Parsch. Klosterneuburg, 1934

Enthält: 1. Band, Geschichtliche Bücher Enthält: 2. Band, Weisheitsbücher und Propheten

NÖ Landesbibliothek, Signatur 127.508 B Abb. 23

130 Erstauflage 1932 
Bibel. Neues Testament. Deutsch (Klosterneuburger Bibel). Lateinische Schrift Die Heilige Schrift des Neuen Bundes / herausgegeben von Pius Parsch; [von Jakob Schäfer übersetzt und erklärt]. Klosterneuburg, 1934

NÖ Landesbibliothek, Signatur 147.557 B Abb. 24

\section{0}

Parsch, Pius, 1884-1954. Laien-Rituale Laien-Rituale - das Buch des Lebens / Pius Parsch; neu eingeleitet von Manfred Probst. Freiburg im Breisgau, Basel und Wien, [2016]. (Pius-Parsch-Studien: Quellen und Forschungen zur Liturgischen Bewegung; Band 13) Porträt von Pius Parsch auf dem Cover NÖ Landesbibliothek, Signatur 202.989 B Abb. 25 und 26

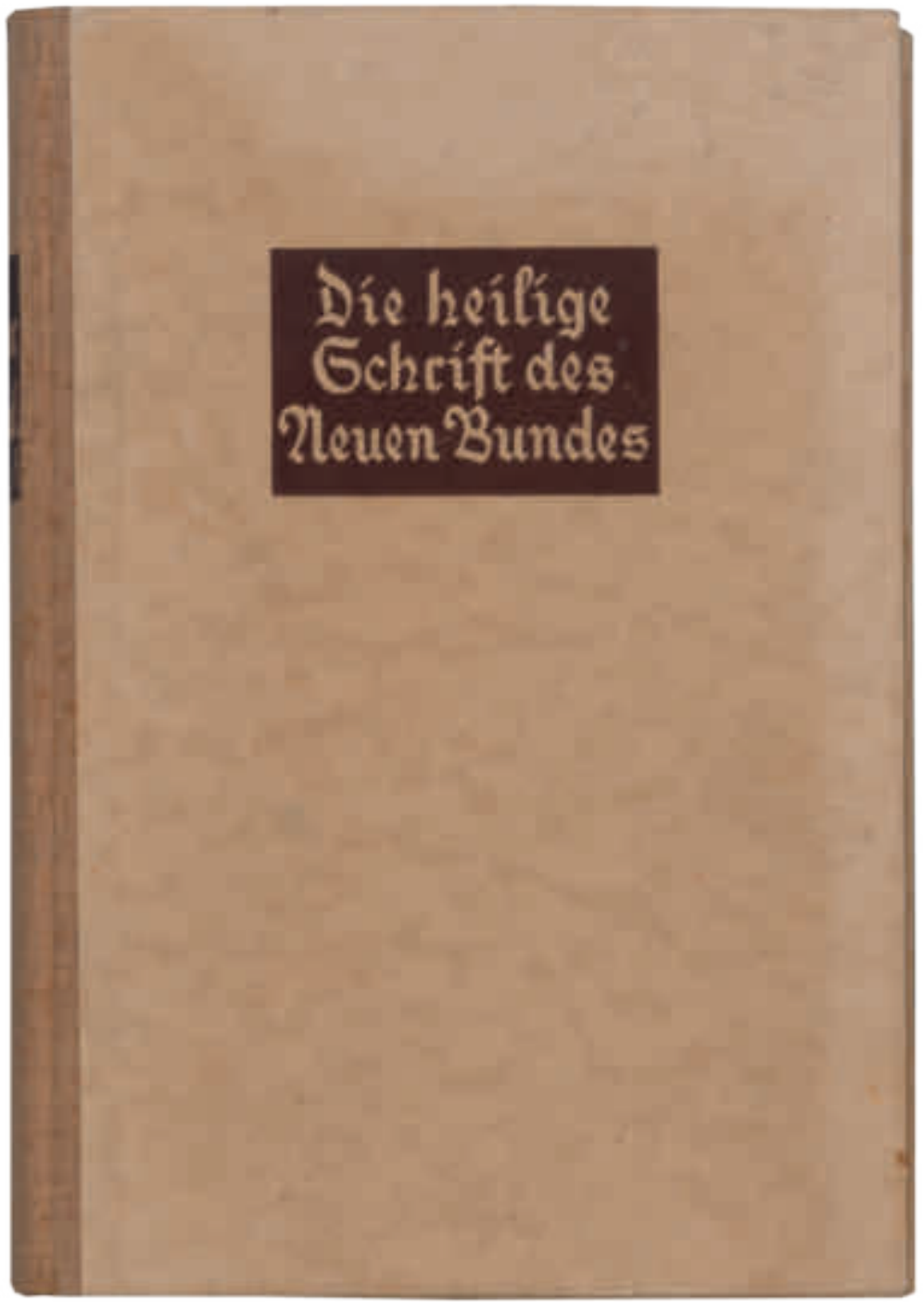

Abb. 24 / Katalog Nr. 69: Pius Parsch (Hrsg.), Die Heilige Schrift des Neuen Bundes (1934). 


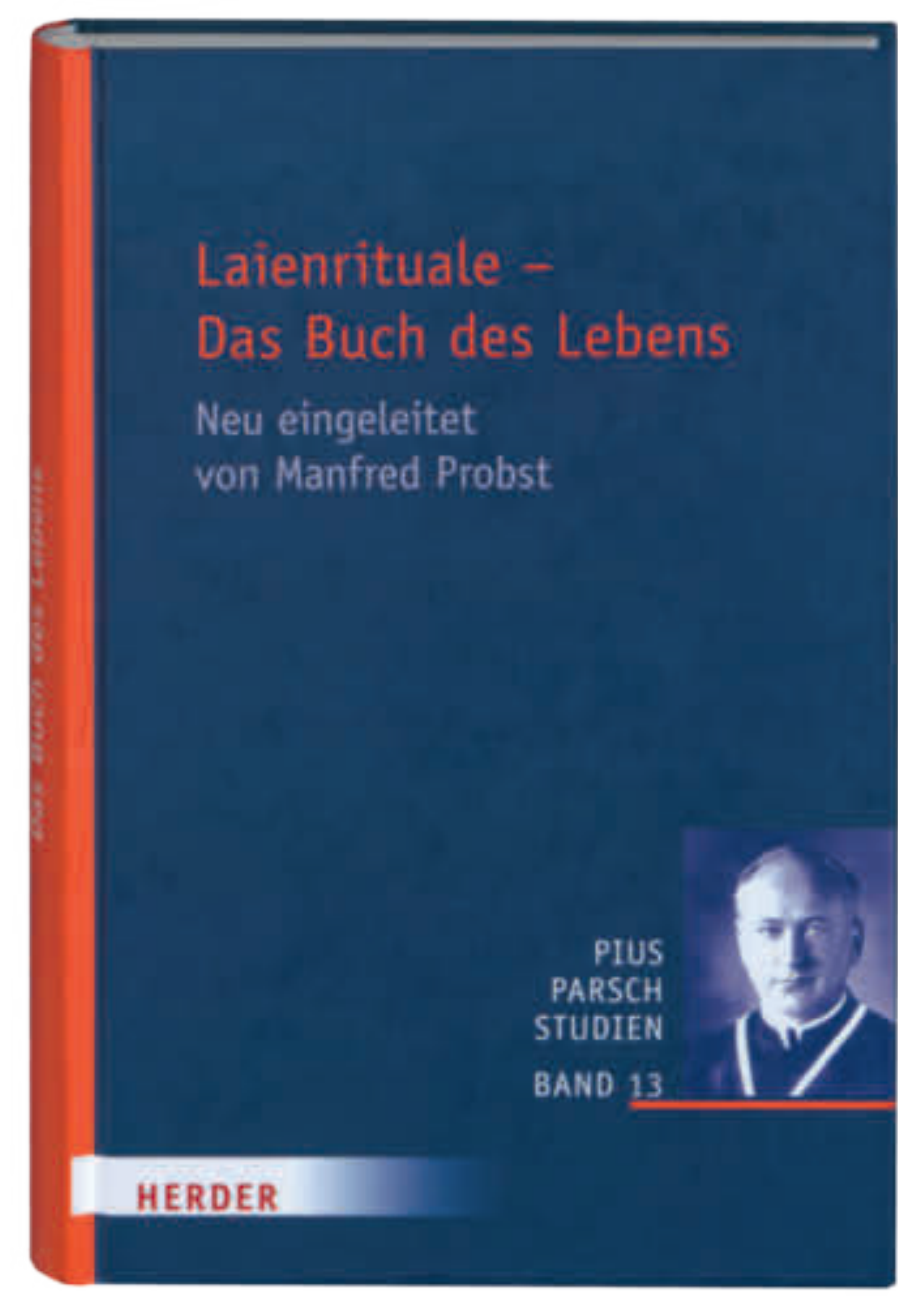

Abb. 25 / Katalog Nr. 70: Pius Parsch, Laien-Rituale - das Buch des Lebens (2016).

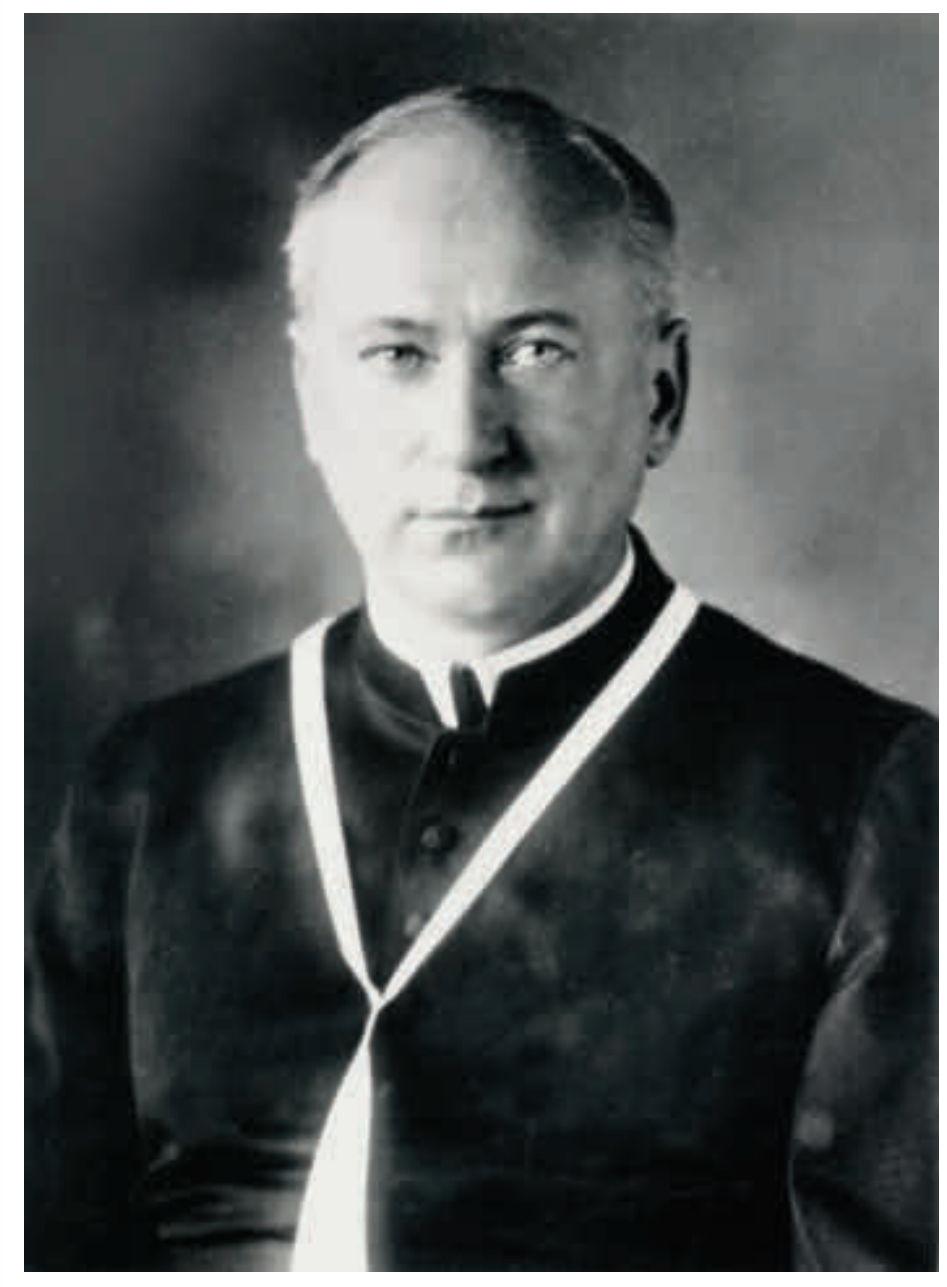

Abb. 26 / Katalog Nr. 70: Porträtfoto Pius Parsch. 


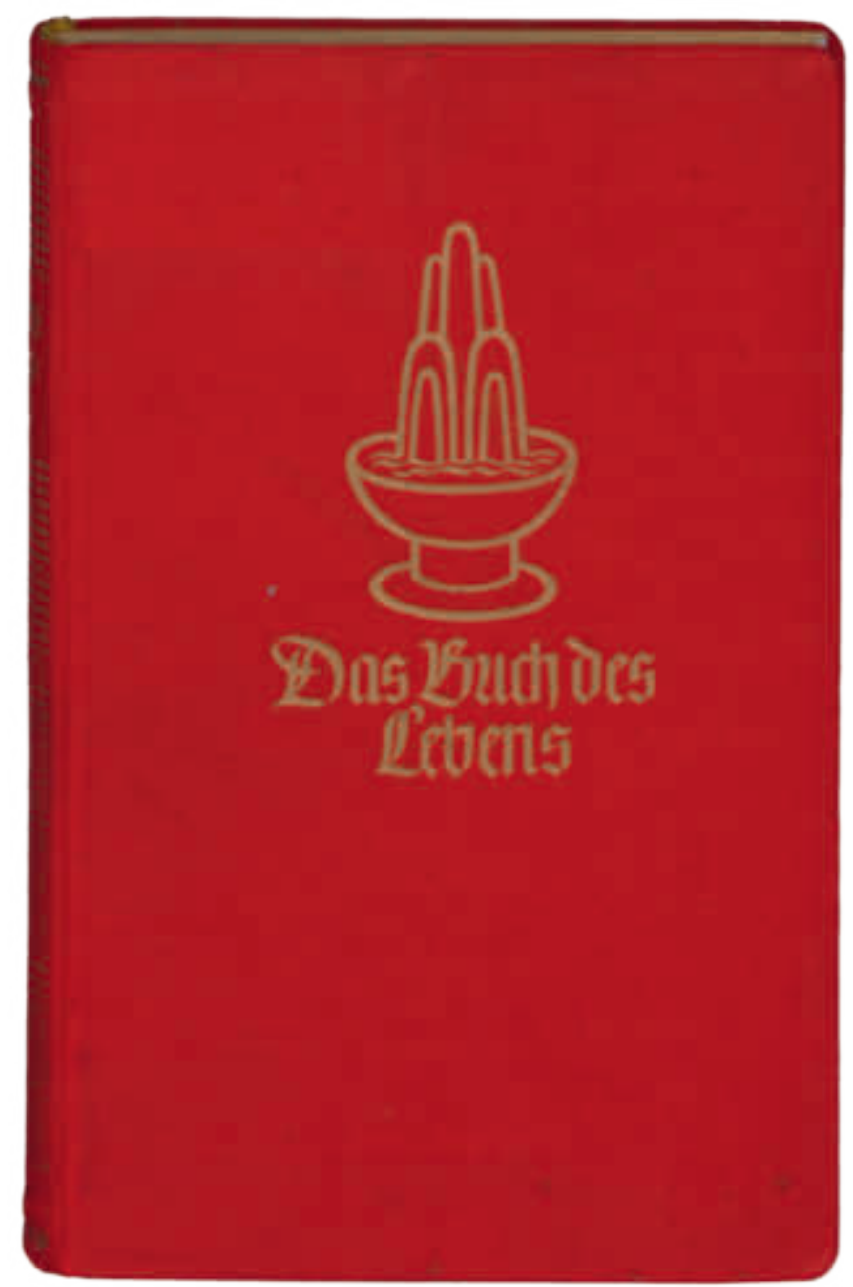

Abb. 27 / Katalog Nr. 71: Pius Parsch, Laien-Rituale - das Buch des Lebens (1939).

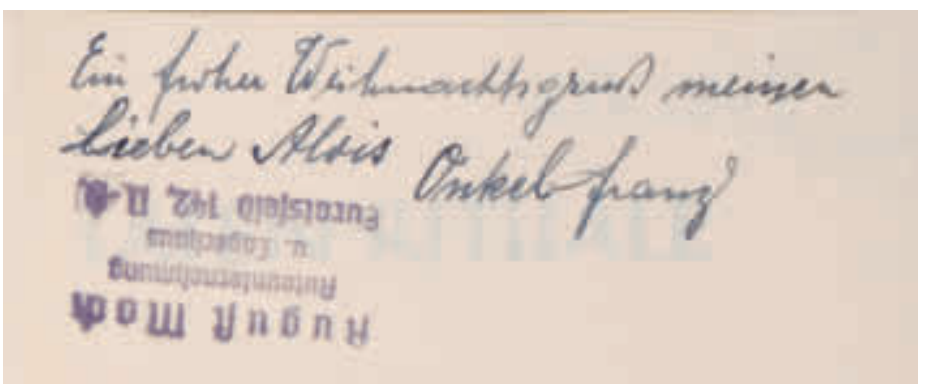

Abb. 28 / Katalog Nr. 71: Pius Parsch, Laien-Rituale - das Buch des Lebens (1939), Widmung für Alois Mock und Firmenstempel.

71

Parsch, Pius, 1884-1954. Laien-Rituale

Laien-Rituale: das Buch des Lebens / von Pius. 2. Auflage. - Wien 26 Klosterneuburg, 1939 NÖ Landesbibliothek, Signatur 184.250 B 2. Aufl. (Verbuchungsnummer 548254)

Exemplar mit handschriftlicher Widmung für Alois Mock Ein froher Weihnachtsgruß meinem lieben Alois. Onkel Franz sowie Firmenstempel August Mock Autounternehmung u. Lagerhaus, Euratsfeld 142, N.- $\ddot{O}$.

Abb. 27 und 28 


\subsection{Das Missionshaus St. Gabriel der Steyler Missionare (SVD) in Maria Enzersdorf}

Die Übersetzung der Bibel in andere Sprachen hat ursächlich immer mit der Idee der Mission zu tun, auch wenn dies unter Umkehrung dieser Zielrichtung statt des Zugangs zur Bibel in einer bestimmten Sprache den Zugang zu dieser Sprache anhand der Bibel ermöglicht. Unter diesem Blickwinkel darf auch das von Steyler Missionaren betriebene wichtigste Missionshaus in Niederösterreich bei einer Beschäftigung mit dem Thema Bibel aus niederösterreichischer Sicht nicht fehlen.

Arnold Janssen (* 5. November 1837 Goch, $\uparrow$ 15. Jänner 1909 Steyl) hat 1875 in Steyl ${ }^{131}$ in der niederländischen Provinz Limburg das Missionshaus St. Michael als Mutterhaus der Steyler Missionare ${ }^{132}$ gegründet; zur Ordensfamilie gehören auch die Steyler Missionsschwestern ${ }^{133}$ und die Steyler Anbetungsschwestern ${ }^{134}$. Nach Erhalt des Heimatrechtes der Gemeinde Goggendorf ${ }^{135}$ gründete Arnold Janssen 1889 das Missionshaus St. Gabriel in Maria Enzersdorf als zweite Ordensniederlassung. Das deutsche Pendant, das Missionshaus St. Augustin in der danach benannten, nördlich an Bonn angrenzenden Stadt Sankt Augustin, wurde 1913 gegründet und beherbergt neben der Kölner Hochschule für Katholische Theologie (KHKT) - St. Augustin unter anderem das Museum Haus Völker und Kulturen und das 1931 von P. Wilhelm Schmidt (1868-1954) im Missionshaus St. Gabriel gegründete und 1962 nach Sankt Augustin übersiedelte Anthropos-Institut ${ }^{136} .2010$ wurde auch die Bibliothek des Missionshauses St. Gabriel nach der 2002 erfolgten Schließung der Hochschule mit über 100.000 Bänden nach Sankt Augustin übersiedelt, wodurch die dortige Hochschulbibliothek auf 250.000 Bände angewachsen ist.

Das Missionshaus St. Gabriel ist nach wie vor Sitz der Mitteleuropäischen Provinz des Ordens und gibt die beiden Zeitschriften „Stadt Gottes“ und „Michaelskalender“ heraus; in den Räumlichkeiten der Pfarre Herz Jesu Mödling betreibt es seit 1926 die mittlerweile größte Hostienbäckerei Österreichs. ${ }^{137}$ Die 1900 eingeweihte neoromanische Heilig-Geist-Kirche, die in einer zweiten Bauphase 1912-1914 unter Architekt Sepp Hubatsch (1873-1935) aus-

131 Heute Stadtteil von Venlo, in unmittelbarer Nachbarschaft der Stadt Nettetal mit dem Ortsteil Kaldenkirchen (Nordrhein-Westfalen, Regierungsbezirk Düsseldorf, Kreis Viersen).

132 Auch: Gesellschaft des Göttlichen Wortes, Societas Verbi Divini oder SVD. Eines der bekanntesten Ordensmitglieder war der als Missionar in China tätige heilige Josef Freinademetz (1852-1908).

133 Auch: Dienerinnen des Heiligen Geistes, Congregatio Servarum Spiritus Sancti, SSpS oder Blaue Schwestern; gegründet 1889.

134 Auch: Dienerinnen des Heiligen Geistes von der Ewigen Anbetung, Congregatio Servarum Spiritus Sancti de Adoratione Perpetua, SSpSAP oder Rosa Schwestern; gegründet 1896.

135 Heute Katastralgemeinde von Sitzendorf an der Schmida.

136 Herausgeber der bereits 1906 begründeten, ethnologisch-linguistisch orientierten Zeitschrift „Anthropos“

137 Zur Geschichte der 1921 gegründeten und 2009 aufgelösten Sängerknaben vom Wienerwald vgl. das Österreichische Musiklexikon online, https://www. musiklexikon.ac.at/ml/musik_S/Saengerknaben_vom_Wienerwald.xml (9.6.2020). 
gebaut ${ }^{138}$ wurde, ist auf einer 1930 gelaufenen Farbpostkarte (Verlag Missionshaus St. Gabriel) aus den Beständen der Topographischen Sammlung der Niederösterreichischen Landesbibliothek zu sehen.

Aus den Reihen der Steyler Missionare von St. Gabriel kamen die wichtigsten Vertreter der an der Kulturkreislehre orientierten Wiener völkerkundlichen Schule:

P. Wilhelm Schmidt $\left(* 16\right.$. Februar 1868 Hörde [Dortmund], $\uparrow$ 10. Februar 1954 Freiburg im Üechtland) ${ }^{139}$

P. Paul Schebesta (* 20. März 1887 Groß Peterwitz/Pietrowice Wielkie, $†$ 17. September 1967 Mödling) $)^{140}$

P. Martin Gusinde $(* 22 \text {. Oktober } 1886 \text { Breslau/Wrocław, } \uparrow \text { 18. Oktober } 1969 \text { St. Gabriel })^{141}$

P. Wilhelm Koppers (* 8. Februar 1886 Menzelen in Nordrhein-Westfalen), $†$ 23. Jänner 1961 Wien) $)^{142}$

Aus ihrem Schaffen werden zwei Werke vorgestellt: Paul Schebestas reich illustriertes „Baba wa Bambuti“ von 1957 über seine vier Reisen zu den Bambuti-Pygmäen des Ituri-Regenwalds und der Atlasband von Wilhelm Schmidts „Die Sprachfamilien und Sprachenkreise der Erde“ aus dem Jahr 1926 (Nachdruck von 1977). Mit dem letzteren Werk ist ein passender Übergang zum dritten Abschnitt gegeben, der der Bibel in Sprachen und Schriften aus der ganzen Welt gewidmet ist.

138 Errichtung von drei Jochen des Langhauses und der Türme; die farbigen Glasfenster wurden 1914 hergestellt

1391892 Priesterweihe in Steyl; ab 1895 in St. Gabriel tätig; 1902 österreichische Staatsbürgerschaft; 1906 Gründung der Zeitschrift „,Anthropos“; Feldkaplan von Kaiser Karl I.; 1921 Dozent am Lehrstuhl für Anthropologie und Ethnographie an der Universität Wien; $1927-1939$ Direktor des von ihm aufgebauten Pontificio Museo Missionario-Etnologico Lateranense; seit 1931 auch Direktor des neu gegründeten Anthropos-Instituts in Mödling; 1938 Emigration über Rom in die Schweiz und Verlegung des Anthropos-Instituts nach Hauterive (Kanton Freiburg, Schweiz), 1942 ordentlicher Professor an der Universität Freiburg. Die Begriffe austronesische Sprachen, austroasiatische Sprachen und deren Zusammenfassung als austrische Sprachen gehen auf Wilhelm Schmidt zurück.

140 Ab 1905 Studium in St. Gabriel; 1911 Priesterweihe, anschließend in Mosambik; 1921 Dozent in St. Gabriel; Forschungsreisen nach Malaysia 1924/25 und auf die Philippinen 1938/39 sowie zu den Bambuti (Pygmäen) im Ituri-Regenwald (im Nordosten der Demokratischen Republik Kongo) 1929, 1934/35, 1949/50, 1954; ab 1947 Dozent an der Hochschule für Welthandel in Wien.

1411900 Ordenseintritt; ab 1905 Studium in St. Gabriel; 1911 Priesterweihe; 1912-1924 in Chile, 1912-1922 Lehrer am Liceo Alemán Santiago in Santiago de Chile und ab 1913 Tätigkeit am Museo de Etnología y Antropología de Chile in Santiago de Chile (seit 1918 als Abteilungsleiter); 1918/19, 1919/20, 1920 und 1923/24 Forschungsreisen nach Feuerland zu den Feuerland-Indianern mit Aufnahme von Tondokumenten; 1924-1926 Unterstützung von Wilhelm Schmidt beim Aufbau des Pontificio Museo Missionario-Etnologico Lateranense; 1926 Promotion in Ethnologie an der Universität Wien; 1928-1929 Aufenthalt in den USA (Studium der Sioux, Cheyenne und Zuñi), 1934-1935 mit Paul Schebesta bei den Bambuti im Ituri-Regenwald; 1949-1957 Professor an der Catholic University of America in Washington D.C., 1950 und 1953 Expeditionen in die Kalahari, 1956 nach Neuguinea, $1959-1960$ und 1964-1965 Lehrer an der Nanzan-Universität in Nagoya, zuletzt wieder in St. Gabriel tätig. 1974 wurde das Museo Antropológico Martin Gusinde in Puerto Williams (Chile) eröffnet.

142 Ab 1913 Mitarbeiter von Wilhelm Schmidt, 1921-1922 mit Martin Gusinde bei den Feuerland-Indianern, 1928 Professor für Völkerkunde an der Universität Wien, 1938 abberufen, 1940-1944 in der Schweiz; arbeitete unter anderem über die Bhil in Indien. 

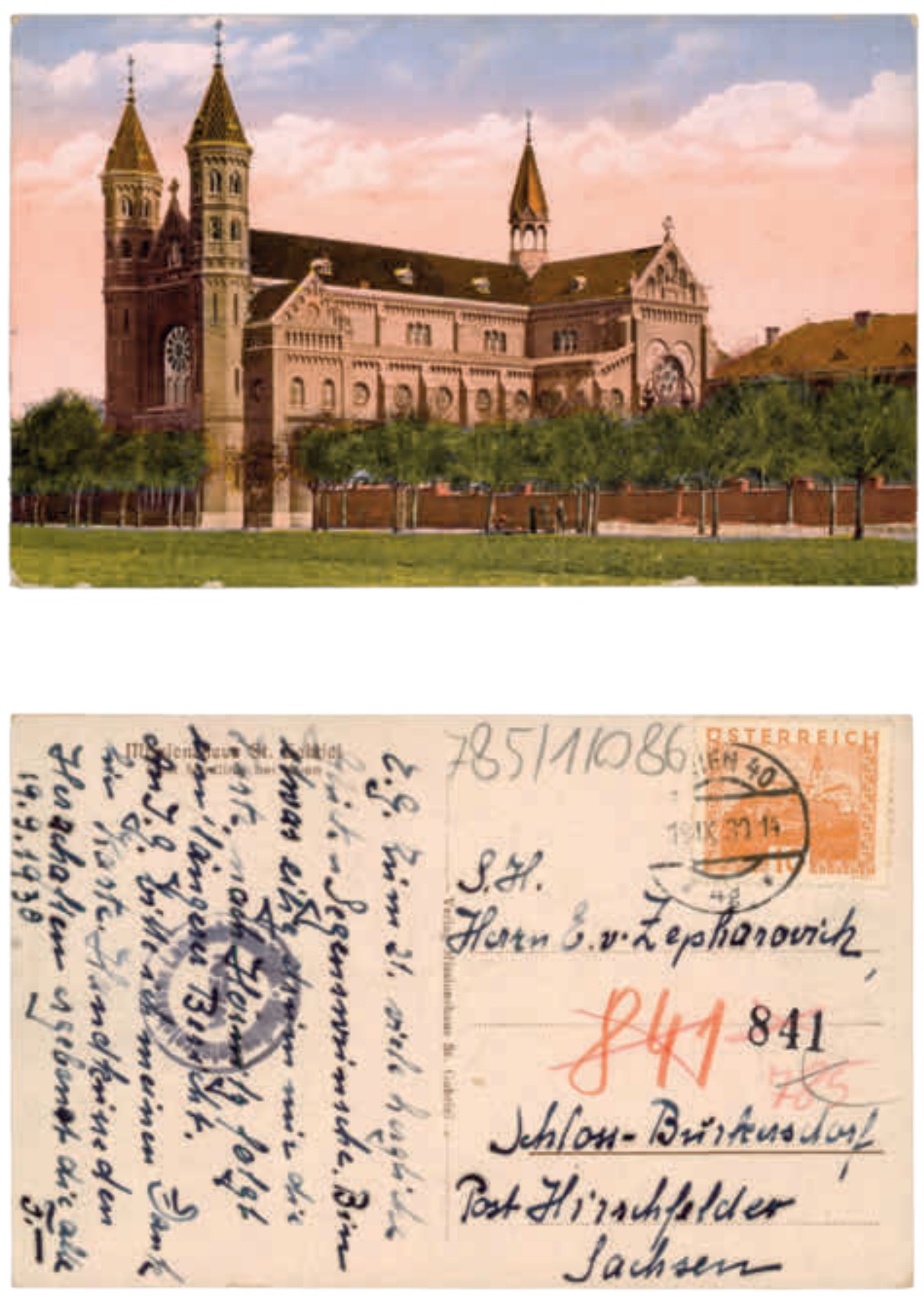

Abb. 29 / Katalog Nr. 72: Missionshaus St. Gabriel (Verlag Missionshaus St. Gabriel), Druck nach koloriertem Schwarzweiß-Lichtbild, 1930, Vorderseite.
Abb. 30 / Katalog Nr. 72: Missionshaus St. Gabriel (Verlag Missionshaus St. Gabriel), Druck nach koloriertem Schwarzweiß-Lichtbild, 1930, Rückseite. 
72

Missionshaus St. Gabriel

[rev.] Missionshaus St. Gabriel [...] / [rev.]

Verlag Missionshaus St. Gabriel

Druck nach koloriertem SW-Lichtbild, gelaufen 1930

NÖ Landesbibliothek, Signatur PK 785/1:

Ansichtskarten Maria Enzersdorf; 86

Abb. 29 und 30

\section{3}

Schebesta, Paul, 1887-1967. Baba wa

\section{Bambuti}

Baba wa Bambuti: vier Fahrten zu den Ituri-

Pygmäen / Paul Schebesta. - Mödling, [1957].

- (Fahrt-Reihe; 1)

NÖ Landesbibliothek, Signatur 21.923 B 1

Abb. 31

\section{4}

Schmidt, Wilhelm, 1868-1954. Die Sprachfamilien und Sprachenkreise der Erde

Die Sprachfamilien und Sprachenkreise der

Erde / von P. W. Schmidt S.V.D.

Atlas. - Nachdruck der Ausgabe von 1926 mit freundlicher Genehmigung des Carl Winter

Universitätsverlages, Heidelberg. - Hamburg, 1977

NÖ Landesbibliothek, Signatur 44.660 D

Abb. 32

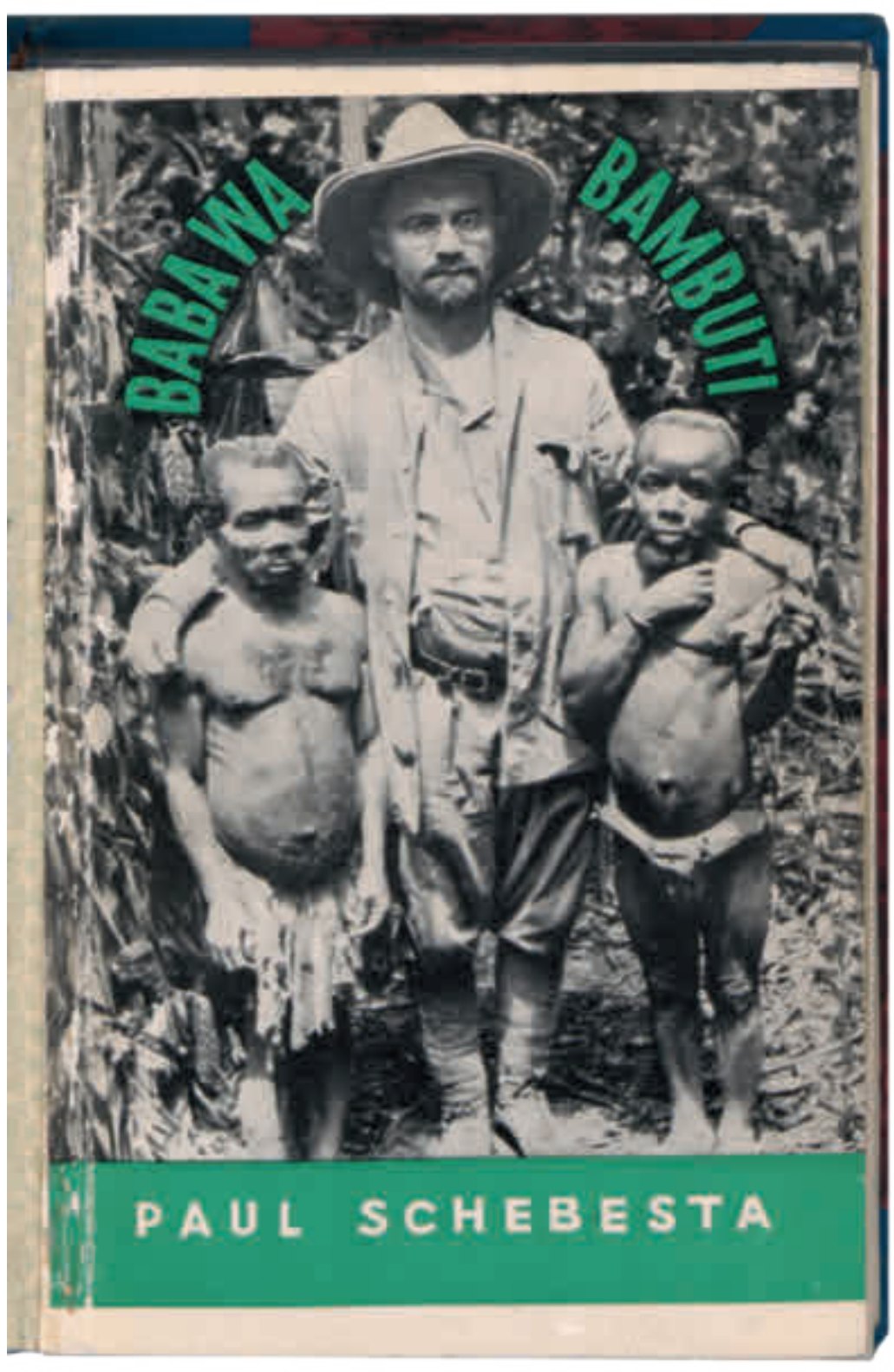

Abb. 31 / Katalog Nr. 73: Paul Schebesta, Baba wa Bambuti: vier Fahrten zu den Ituri-Pygmäen (1957). 


\section{Die Sprachfamilien und Sprachenkreise der Erde}

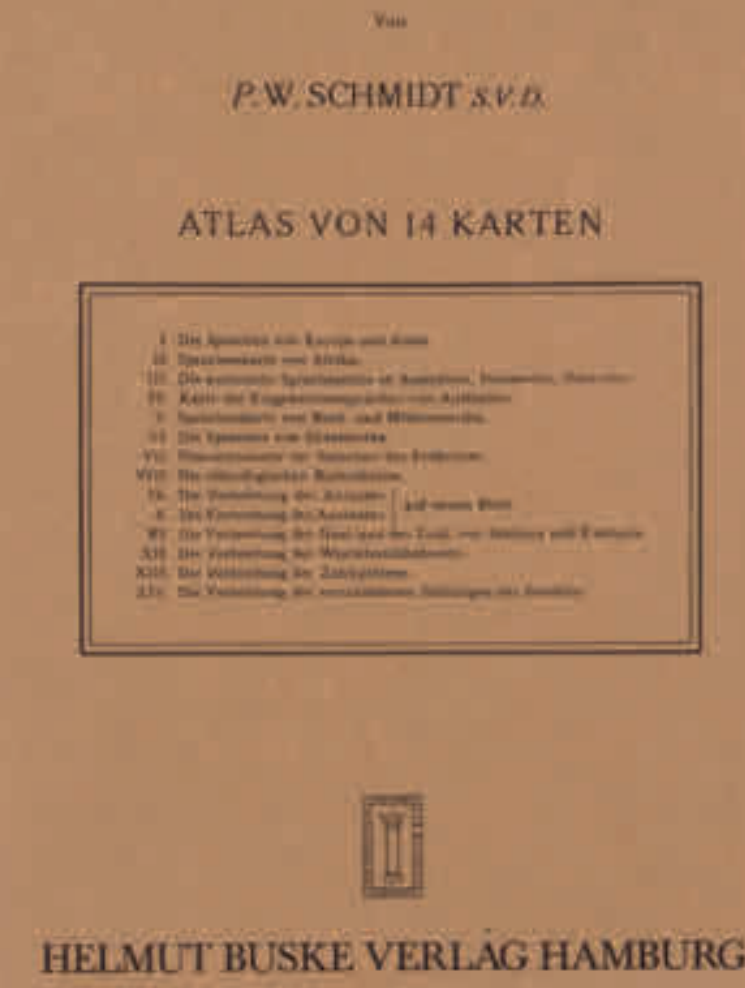




\section{SPRACHFAMILIEN UND SCHRIFTSYSTEME}

Im dritten und zugleich umfassendsten Teilbereich wird die Bibel oder Teile der Bibel in Sprachen und Schriften aus aller Welt präsentiert, natürlich nur soweit sie in der Niederösterreichischen Landesbibliothek vorhanden sind - das Angebot ist aber wohl reichhaltiger, ${ }^{143}$ als man glauben würde. Anknüpfend an den „Atlas der „Sprachfamilien und Sprachenkreise der Erde" von P. Wilhelm Schmidt seien eingangs einige Überblickswerke und Literaturempfehlungen genannt.

SIL International, das frühere Summer Institute of Linguistics, betreibt die kostenpflichtige Datenbank „Ethnologue: languages of the world“; die Druckausgabe der 15. Auflage 2005 mit fast 7.000 beschriebenen Sprachen, farbigen Karten und zugleich Grundlage für den ISO 639-3-Sprachencode wird zu Beginn vorgestellt. Nicht unerwähnt bleiben soll dabei die enge Zusammenarbeit mit der evangelikalen Organisation Wycliff (benannt nach John Wyclif), die sich die Schaffung und Verbreitung von Bibelübersetzungen gerade für exotischere und auch bisher nicht verschriftlichte Sprachen zum Ziel gesetzt hat. ${ }^{144}$

Fast ein Vorreiter unserer Zusammenstellung ist der „Mithridates“ von Johann Christoph Adelung (1734-1806), der ab dem zweiten Band von Johann Severin Vater (1771-1826) weitergeführt wurde: Rund 500 Sprachen aus aller Welt werden anhand des Vaterunsers als Sprachprobe vorgestellt. Natürlich darf man sich von diesem vierteiligen Werk (in fünf Bänden) der Jahre 1806-1817 nicht die linguistischen Erkenntnisse der seither vergangenen zwei Jahrhunderte erwarten; umgekehrt entbehrt natürlich auch die Einsicht in damalige Annahmen und Vorstellungen nicht eines gewissen Reizes. Gerade bei schlecht dokumentierten und vor allem zwischenzeitlich ausgestorbenen Sprachen kommt dem Werk auch heute noch ein gewisser Quellenwert zu. Der Veranschaulichung dient ein Reprint von 1970.

Sehr gutes Kartenmaterial bietet der Band 1 „Sprache, Sprachentstehung, Sprachen“ des „Handbuches der Linguistik und Kommunikationswissenschaft" von Georg Friedrich Meier (1919-1992). In Nürnberg geboren, wuchs Meier in Bayern auf und übersiedelte nach dem Zweiten Weltkrieg in die DDR, wo er zunächst 1959 in Leipzig und dann 1961 an der Humboldt-Universität Professor für Sprachwissenschaft wurde. Nach Veröffentlichung des

143 Rund 450 Bibeln oder Teile der Bibel, davon etwa 250 in einer Fremdsprache.

144 Siehe z. B. Maasina-Fulfulde, Katalog Nr. 190. 
genannten Bandes 1979 verhinderte eine Intervention der bulgarischen Staatsführung, die sich an der Einstufung des Mazedonischen als eigenständiger Sprache stieß, das Erscheinen weiterer Bände; 1986 kehrte Meier nach Bayern an die Universität München zurück.

Literaturtipps:

Bußmann, Hadumod. Lexikon der Sprachwissenschaft. - 2. Auflage. - Stuttgart, 1990. - (Kröners Taschenausgabe; 452)

Kausen, Ernst. Die Sprachfamilien der Welt. - Hamburg

Teil 1, Europa und Asien. - 2013.

Teil 2, Afrika - Indopazifik - Australien - Amerika. - 2014

Klose, Albrecht. Sprachen der Welt: ein weltweiter Index der Sprachfamilien, Einzelsprachen und Dialekte, mit Angabe der Synonyma und fremdsprachigen Äquivalente. - 2. Auflage. - München, 2001

\section{5}

\section{Ethnologue}

Ethnologue: languages of the world. - 15. edition / Raymond G. Gordon, Jr., ed. - Dallas, Tex., 2005

NÖ Landesbibliothek, Signatur 120.545 B

\section{6}

Adelung, Johann Christoph, 1734-1806. Mithridates, oder allgemeine Sprachenkunde

Mithridates oder allgemeine Sprachenkunde / Johann Christoph Adelung; fortgesetzt und bearbeitet von Johann Severin Vater. - Hildesheim und New York, NY, 1970

NÖ Landesbibliothek, Signatur 203.201 B (4 Teile in 5 Bänden)

\section{7}

\section{Meier, Georg Friedrich, 1919-1992. Handbuch der Linguistik und Kommunikationswissenschaft}

Band 1, Sprache, Sprachentstehung, Sprachen. - Berlin, 1979

NÖ Landesbibliothek, Signatur 203.199 B 1

Kartenbeilagen 


\subsection{Esperanto}

Das 1887 vom polnischen Augenarzt Ludwik Lejzer Zamenhof (1859-1917) entwickelte Esperanto dient als einziges Beispiel einer Plansprache; es stellt auch mit bis zu zwei Millionen Sprechern weltweit deren erfolgreichsten Vertreter dar.

\section{8}

\section{Bibel. Esperanto. Lateinische Schrift}

La Sankta Biblio: malnova kaj nova testamentoj kun la duakanonaj libroj tradukitaj el la originalaj lingvoj = The Holy Bible in Esperanto. - Hongkong, 2003

NÖ Landesbibliothek, Signatur 120.545 B

\subsection{Baskisch}

Als einzige isolierte Sprache Europas gilt das Baskische im westlichen Pyrenäengebiet beiderseits der spanischfranzösischen Grenze; als antiker Vorläufer wird Aquitanisch (nicht aber Iberisch) angesehen. Zu den Eigenheiten des Baskischen zählen der ergativsprachliche ${ }^{145}$ Charakter und das Zwanziger-Zahlensystem, wobei letzteres auch in keltischen Sprachen und in Resten auch im Französischen vorkommt.

\section{9}

\section{Bibel. Baskisch. Lateinische Schrift}

Elizen arteko biblia. - Lazkao, 2007

NÖ Landesbibliothek, Signatur 121.850 B

\subsection{Indogermanische Sprachen}

Die indogermanischen oder indoeuropäischen Sprachen stellen - gemessen an der Zahl ihrer Sprecherinnen und Sprecher - die größte und wohl auch am besten erforschte Sprachfamilie der Welt dar; rund drei Milliarden Menschen sprechen eine indogermanische Sprache. $\mathrm{Zu}$ den heute noch lebenden Gruppen zählen die keltischen

145 In einer Ergativsprache steht das Agens im transitiven Satz im Kasus Ergativ, das Agens im intransitiven Satz ebenso wie das Patiens (im transitiven Satz) im Kasus Absolutiv. In einer Akkusativsprache steht hingegen das Agens sowohl im transitiven wie im intransitiven Satz im Kasus Nominativ und das Patiens (im transitiven Satz) im Kasus Akkusativ. 
Sprachen, die germanischen Sprachen, die romanischen Sprachen, die baltischen Sprachen, die slawischen Sprachen, Griechisch, Albanisch, Armenisch und die indoiranischen Sprachen; letztere bestehen ihrerseits aus den iranischen, den indoarischen und den hier nicht vertretenen Nuristani-Sprachen. Wichtige ausgestorbene Zweige bilden die anatolischen Sprachen ${ }^{146}$ (mit dem Hethitischen und Luwischen) und das Tocharische ${ }^{147}$; sicher indogermanisch waren auch das Phrygische, das Thrakische, das teilweise mit dem Griechischen in Verbindung gebrachte Makedonische, das Illyrische, das Messapische, das teilweise zum Italischen gerechnete Venetische und Sikulische sowie das dem Keltischen nahestehende Lusitanische.

Ein Beispiel für die Verwandtschaft der indogermanischen Sprachen: Altindisch (Sanskrit) abharam / abharas / abharat / abharāma / abharata / abharan entspricht griechisch épheron / épheres / éphere / ephéromen / ephérete / épheron und setzt indogermanisch *ébherom / *éb eres / *éb $b^{h}$ eret / *éb ${ }^{h}$ erome / *éb erete / *éb $b^{h}$ eront fort. ${ }^{148} \mathrm{Im}$ Wesentlichen sind im Altindischen e und o mit a zusammengefallen, im Griechischen $b^{\text {h }}, \mathrm{d}^{\text {h }}, \mathrm{g}^{\mathrm{h}}$ durch $\mathrm{ph}$, th, kh vertreten, womit bis auf den teilweisen Wegfall von auslautendem -t praktisch alles geklärt ist.

Literaturtipp:

Meier-Brügger, Michael. Indogermanische Sprachwissenschaft. - 9. Auflage. - Berlin, 2010

\subsubsection{Keltische Sprachen}

Die lebenden keltischen (inselkeltischen) Sprachen umfassen die goidelischen Sprachen Irisch, Gälisch-Schottisch und Manx ${ }^{149}$ sowie die britannischen Sprachen Kymrisch (Walisisch), Bretonisch und Kornisch ${ }^{150}$. Die goidelischen Sprachen zählen wie das ausgestorbene Keltiberische zu den q-keltischen Sprachen ${ }^{151}$, während die britannischen Sprachen mit den ausgestorbenen restlichen festlandkeltischen Sprachen Lepontisch, Gallisch, Galatisch, Norisch etc. als p-keltische Sprachen ${ }^{152}$ zusammengefasst werden. Um den Unterschied zwischen QKeltisch und P-Keltisch zu demonstrieren: Gälisch-schottisch ceithir entspricht walisisch pedwar ${ }^{153}$, verglichen werden auch irisch cruithin (Pikten) und walisisch Prydain (Britannien). Ein weiterer Unterschied zwischen den goidelischen und den britannischen Sprachen besteht in der unterschiedlichen Vertretung der indogermanischen

\footnotetext{
146 Hethitisch, Keilschrift-Luwisch, Hieroglyphen-Luwisch, Palaisch, Lydisch, Lykisch A, Lykisch B (Milyisch), Karisch, Pisidisch, Sidetisch.

147 Tocharisch A oder Osttocharisch (Oase Turfan), Tocharisch B oder Westtocharisch (Region Kuqa).

148 Jeweils 1. bis 3. Person Singular und Plural Indikativ Imperfekt Aktiv zur Verbalwurzel * $b^{h}$ er- (tragen, bringen).

149 Letzteres $\dagger$ bzw. wiederbelebt.

150 Letzteres $\uparrow$ bzw. wiederbelebt.

151 Mit Erhalt von indogermanischem $\mathrm{k}^{\mathrm{w}}$ als Tektal.

152 Mit dem Lautwandel indogermanisch $\mathrm{k}^{\mathrm{w}} \mathrm{zu} \mathrm{p}$.

$153 \mathrm{Zu}$ indogermanisch *kwetwóres bzw. *kwetwōres (vier)
} 
sonantischen Nasale als goidelisch -em-/-en- gegenüber britannisch -am-/-an-, vergleiche gälisch-schottisch ceud und walisisch cant $^{154}$. Wie die Bezeichnung Bretonisch nahelegt, stammt die Sprache von den britischen Inseln; eine veraltete Bezeichnung für die Bretagne lautet übrigens Kleinbritannien. Einem der Dialekte des Bretonischen, dem Vannetais (Gwenedeg), wird allerdings eine Beeinflussung durch das in der Folge ausgestorbene Gallische zugeschrieben; wie Asterix mit dem widerspenstigen gallischen Dorf in Aremorica (Bretagne) zeigt, ist die Frage, ob die Bretonen überlebende Gallier und somit Ur-Franzosen oder vor den Angelsachsen geflohene und zugewanderte Briten sind, in Frankreich nicht ganz ohne Relevanz. Mit den keltischen Briten fest verbunden sind auch die Sagenkreise um Artus und Merlin.

Die Germanen bezeichneten die Kelten übrigens nach dem Stamm der Volker (Volcae) als Walhaz (Welsche), was später wohl infolge der Romanisierung ehemals keltischer Gruppen auch auf die Romanen übertragen wurde. ${ }^{155}$

Alle heutigen goidelischen Sprachen basieren auf dem Altirischen; die Erklärung findet sich darin, dass der ursprünglich in der nordirischen Provinz Ulster ansässige irische Stamm der Skoten das Gebiet seines Königreiches Dalriada auf das westliche Schottland ausdehnte und zugleich Sprache und Namen mitbrachte. 843 wurde unter Kenneth I. MacAlpin das Gebiet der im östlichen Schottland beheimateten Pikten, deren ausgestorbene Sprache vielleicht zum britannischen Zweig der keltischen Sprachen gehörte, mit Dalriada zum Königreich Alba (Schottland) vereinigt. Nicht verwechselt werden darf die gälisch-schottische Sprache der Hebriden und westlichen Highlands mit dem zum Englischen gehörenden Scots der Lowlands. Vom Irischen ist das Gälisch-Schottische nicht zuletzt durch die Nichtteilnahme an der irischen Orthographiereform von 1948 getrennt, bei der nicht mehr gesprochene Konsonanten aus dem Schriftbild entfernt wurden.

Mit dem Namen der Skoten verbunden ist die frühmittelalterliche iroschottische Mission Europas durch Wandermönche der auf St. Patrick zurückgehenden iroschottischen Kirche; auf eine zweite hochmittelalterliche Welle der iroschottischen Mission gehen die benediktinischen Schottenklöster wie jenes in Wien ${ }^{156}$ zurück. Erwähnenswert sind auch die auf der Halbunziale basierenden insularen (Minuskel-)Schriften, nämlich die irische und die davon abgeleitete angelsächsische Schrift; auf der ersteren basiert auch die irische Druckschrift.

Beide heutigen Hauptzweige der keltischen Sprachen sind durch Kymrisch (Walisisch) sowie Gälisch-Schottisch vertreten.

\section{Literaturtipp:}

Pilch, Herbert. Die keltischen Sprachen und Literaturen. - Heidelberg, [2007]

$154 \mathrm{Zu}$ indogermanisch *dk̂kmtóm (hundert).

155 Vgl. Wales, Walisisch, Wallonen, Welschtirol, Welschriesling, Walachei, Rotwelsch, Kauderwelsch usw.

156 Entgegen dem Namen waren an der 1155 erfolgten Gründung lediglich Iren, aber keine Schotten im heutigen Sinn beteiligt. 
Bibel. Kymrisch (Walisisch). Lateinische Schrift

Y Beibl cymraeg newydd. - Swindon, 2004

NÖ Landesbibliothek, Signatur 121.851 B

81

Bibel. Neues Testament und Bibel. Psalmen. Gälisch-Schottisch und Englisch (King James Version). Lateinische Schrift

Tiomnadh Nuadh: ar Tighearna agus ar Slanaighir Iosa Criosd: air a Tharraing on Ghrèigis a-chum Gàidhlig na h-Alba: Maille ri Eadar-theangachadh gu Beurla a rèir Teacsta Ur Breatannach an Rìgh Seumas (New King James British text $)=$ The New Testament and Metrical Psalms: the Scottish Gaelic and English text in adjoining columns. - Edinburgh, 2002

NÖ Landesbibliothek, Signatur 134.872 B

\subsubsection{Germanische Sprachen}

Als konstituierendes Merkmal der germanischen Sprachen wird meist die germanische oder erste Lautverschiebung angesehen, als deren regelmäßige Folge die indogermanischen Tenues p, t, k, $\mathrm{k}^{\mathrm{w}} \mathrm{zu}$ den stimmlosen Reibelauten $\mathrm{f}, \mathrm{P}, \chi(\mathrm{h})$ und $\chi^{\mathrm{w}}\left(\mathrm{h}^{\mathrm{w}}\right)$, die Mediae $\mathrm{b}, \mathrm{d}, \mathrm{g}, \mathrm{g}^{\mathrm{w}} \mathrm{zu}$ den Tenues $\mathrm{p}, \mathrm{t}, \mathrm{k}, \mathrm{k}^{\mathrm{w}}$ und die Mediae aspiratae $\mathrm{b}^{\mathrm{h}}$, $\mathrm{d}^{\mathrm{h}}, \mathrm{g}^{\mathrm{h}}, \mathrm{g}^{\text {wh }} \mathrm{zu}$ den stimmhaften Reibelauten b, đ, $\mathrm{g}$ bzw. w verschoben wurden. Außer im Anlaut und in der Stellung nach dem ursprünglichen indogermanischen Akzent wurden die stimmlosen Reibelaute einschließlich $\mathrm{s}$ allerdings stimmhaft, erscheinen also als b, đ, g, $\mathrm{g}^{\mathrm{w}}$ und z; dies erinnert an den Ausspracheunterschied Hannóver (mit stimmlosem f) versus Hannoveráner (mit stimmhaftem v) und erklärt den Unterschied ziehen zu gezogen (*déuk-/ *duk-, der sogenannte grammatische Wechsel).

Man unterscheidet die historischen Untergruppen Nordseegermanisch (Ingwäonisch) ${ }^{157}$, Weser-Rhein-Germanisch (Istwäonisch) ${ }^{158}$, Elbgermanisch (Erminonisch) ${ }^{159}$, Nordgermanisch ${ }^{160}$ sowie Ostgermanisch $^{161}$. Die ersten

157 Mit dem (Alt-)Friesischen, (Alt-)Englischen oder Angelsächsischen und (Alt-)Niederdeutschen oder Altsächsischen.

158 Mit dem (Alt-)Niederländischen oder (Alt-)Niederfränkischen, dem Mittelfränkischen (Ripuarisch und Moselfränkisch), dem Rheinfränkischen (Pfälzisch und Hessisch), dem Südfränkischen und Ostfränkischen.

159 Mit dem Alemannischen, Bairischen und Langobardischen $\dagger$.

160 Mit den Sprachen Isländisch, Färöisch, Norn †, Nynorsk und Bokmål (beides Norwegisch, ersteres auf Grundlage norwegischer Dialekte, früher Landsmål, letzteres auf dänischer Grundlage, früher Riksmål), Dänisch, Schwedisch und Altgutnisch $\dagger$.

161 Mit Gotisch †. 
drei Untergruppen werden auch als Westgermanisch, die ersten vier heute auch als Nordwestgermanisch zusammengefasst.

Man erkennt, dass das Deutsche aus verschiedenen nordseegermanischen, weser-rhein-germanischen und elbgermanischen Sprachen entstanden ist, wobei jeweils das politische Zentrum tonangebend war: Althochdeutsch (ca. 750-1050) war durch die Vorherrschaft der fränkischen Karolinger, Mittelhochdeutsch (ca. 1050-1350) durch die Vorherrschaft der alemannischen Staufer geprägt. Das Hochdeutsche ist durch die hochdeutsche oder zweite

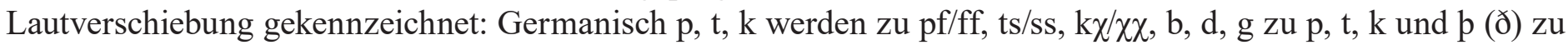
d verschoben. Im Süden ist dieser Wandel nahezu vollständig durchgeführt; man spricht vom Oberdeutschen ${ }^{162}$, weiter nördlich nur teilweise, dann spricht man vom Mitteldeutschen; beide zusammen werden als Hochdeutsch bezeichnet. Die Bezeichnung Hochdeutsch für die neuhochdeutsche Standardsprache oder Schriftsprache besagt eigentlich nur, dass auch diese Varietät hierhergehört. Keinen Anteil an der zweiten Lautverschiebung ${ }^{163}$ haben das Niederländische bzw. Niederfränkische ${ }^{164}$, das in Westfalen, Engern und Ostfalen ${ }^{165}$ gesprochene Altsächsische samt dem heutigen Niederdeutschen oder Plattdeutschen und das Friesische.

Während das niederfränkische Niederländisch ${ }^{166}$ trotz des Umstandes, dass in den heutigen Niederlanden niederdeutsche Dialekte mit Niederländisch als Dachsprache und in Deutschland niederfränkische Dialekte mit Deutsch

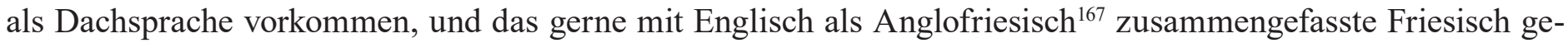
meinhin als eigenständige Sprachen angesehen werden, gilt dasselbe für das seit dem Aussterben des Mittelniederdeutschen um 1600 von der hochdeutschen Standardsprache überdachte Niederdeutsche nur eingeschränkt.

Kompliziert ist die Situation beim Friesischen: Eine Standardsprache existiert nur für das Westfriesische in der niederländischen Provinz Friesland mit rund 440.000 Sprechern; den letzten Rest des Ostfriesischen bildet das Saterfriesische in der Gemeinde Saterland; zum Nordfriesischen zählen die Dialekte Sölring (Sylt), Fering und Öömrang (Föhr und Amrum), Halunder (Helgoland), Wiedingharder, Bökingharder ${ }^{168}$, Karrharder, Norder-, Mittel- und Südergoesharder Friesisch sowie Halligfriesisch.

162 Alemannisch, Bairisch, Südfränkisch, Ostfränkisch; Langobardisch †.

163 Ausgenommen den Wandel p zu d.

164 Samt dem ausgestorbenen Westfränkischen.

165 Und somit nicht im heutigen Bundesland Sachsen.

166 Samt seiner Tochtersprache Afrikaans.

167 Mit Palatalisierungen wie bei cheese/Käse und chicken/Küken und Nasalschwund vor Reibelaut wie bei five/fünf, us/uns.

168 Mit den Varianten Wester- und Ostermooring. 
Tochtersprachen des Deutschen sind Jiddisch, Pennsylvaniadeutsch (Pennsylvania Dutch) und Lëtzebuergesch ${ }^{169}$; eine Tochtersprache des Niederdeutschen bildet das Plautdietsche (Mennonitendeutsche).

Gotisch $\dagger$, Althochdeutsch $\dagger$ und Altsächsisch $\dagger$, Deutsch mit den Tochtersprachen Pennsylvaniadeutsch und Jiddisch sowie Niederdeutsch mit der Tochtersprache Plautdietsch (Mennonitendeutsch) sind in Kapitel $2.1^{170}$ und Mittelhochdeutsch in Kapitel 2.2 ${ }^{171}$ vertreten und dort weiter beschrieben. Darüber hinaus werden Niederländisch samt seiner Tochtersprache Afrikaans, Westfriesisch, Saterfriesisch und Sölring (Sylter Friesisch), Englisch mit mehreren Bibelausgaben, Isländisch, Färöisch, Nynorsk, Bokmål, Schwedisch und Dänisch vorgestellt.

Näher muss auf Englisch eingegangen werden. Als Beginn englischer Bibelübersetzungen gilt meist die „WyclifBibel“ oder „Lollarden-Bibel“, eine Überarbeitung bereits bestehender Bibelübersetzungen aus der Vulgata in das Mittelenglische in den Jahren 1380 bis 1388. Sie ist nach dem 1415 posthum zum Ketzer erklärten John Wyclif (Wycliffe, $†$ 1384) und seinen Anhängern, den Lollarden, benannt. Ab 1525 brachte der 1535 verhaftete und 1536 hingerichtete William Tyndale (ca. 1484-1536) eine Bibelübersetzung heraus, die von Myles Coverdale (um 1488-1569) vervollständigt und 1535 als erste vollständige englische Bibelübersetzung gedruckt wurde. Die 1537 erschienene „Matthew-Bibel“ basiert auf dem Werk von Tyndale und Coverdale und bildet die Grundlage späterer englischer Bibelübersetzungen: die „Great Bible“ von 1539 als erste autorisierte englische Bibelübersetzung, die calvinistisch geprägte „Geneva Bible“ von 1557-1560, die anglikanische „Bishops’ Bible“ von 1568 bzw. 1572 und schließlich die „King James Bible“172 von 1611. Letztere wird in einer modernen Druckausgabe vorgestellt. Als Sprachprobe der frühneuenglischen Sprache dieser Übersetzung möge der Anfang der Zehn Gebote ${ }^{173}$ dienen: „And God spake all these words, saying, I am the Lord thy God, which have brought thee out of the land of Egypt, out of the house of bondage. Thou shalt have no other gods before me“. Eine bekannte Kuriosität bildet die „Wicked Bible“ von 1631 mit dem verhängnisvollen Druckfehler „Thou shalt commit adultery“ statt „Thou shalt NOT commit adultery“.

Als Beispiel einer modernen englischen Bibelübersetzung dient die „Revised English Bible“ (REB) von 1989. ${ }^{174}$ Ein ebenfalls vorgestelltes Exemplar der „New American Standard Bible“ enthält eine Widmung für Alois Mock. Diese modernen Bibelübersetzungen basieren auf den heutigen wissenschaftlichen Ausgaben der hebräischen Bibel und des griechischen Neuen Testaments, also nicht mehr auf dem „Textus receptus“ des sechzehnten und

169 In diesem Zusammenhang seien auch Sprachinselmundarten wie Zimbrisch oder Fersentalerisch (Mochenisch) und Soziolekte wie Jenisch (Rotwelsch) erwähnt.

170 Katalog Nr. 35 bis 62.

$171 \mathrm{Zu}$ Katalog Nr. 2.

172 „King James Version“, „Authorized Version“.

173 Exodus 20,1-17.

174 Eine Überarbeitung der „New English Bible“ (NEB) von 1970, (C Oxford University Press und Cambridge University Press. 
siebzehnten Jahrhunderts, der letztlich auf der ersten Druckausgabe des griechischen Neuen Testaments durch Erasmus von Rotterdam 1516 beruht. Evangelikale Christen bevorzugen zum Teil auch heute noch Übersetzungen auf Grundlage des „Textus receptus“ und sind diesbezüglich den früheren Anhängern der katholischen SixtoClementina vergleichbar. Ein kleines passendes Bonmot sei noch zum Schluss erwähnt: ,,remember [...] that your native language is the language of Shakespeare and Milton and The Bible [...]“, so Professor Henry Higgins zu Eliza Doolittle in George Bernard Shaw's „Pygmalion“.

\section{2}

\section{Bibel. Niederländisch. Lateinische Schrift}

Groot Nieuws Bijbel: met deuterocanonieke boeken = Bible in today's Dutch. - Heerenveen, 2003

NÖ Landesbibliothek, Signatur 119.710 B

83

Bibel. Afrikaans. Lateinische Schrift

Die Bybel vir almal. - Kapstadt, 2009

NÖ Landesbibliothek, Signatur 134.006 B

84

Bibel. Westfriesisch. Lateinische Schrift

Bibel: út de oarspronklike talen op 'e nij yn it Frysk oerset = Bible in Frisian $=$ Handbijbel in Friese vertaling. Haarlem, 1995

NÖ Landesbibliothek, Signatur 121.934 B

\section{5}

\section{Bibel. Neues Testament und Bibel. Psalmen. Saterfriesisch. Lateinische Schrift}

Dät Näie Tästamänt un do Psoolme in ju aasterlauwersfräiske Uurtoal fon dät Seelterlound, Fräislound, Butjoarlound, Aastfräislound un do Groninger Umelounde / uursät fon Marron Fort = Das Neue Testament und die Psalmen in der osterlauwersfriesischen Ursprache des Saterlandes, Frieslands, Butjadingens, Ostfrieslands und der Groninger Ommelanden. - Oldenburg (Oldenburg), [2000]

NÖ Landesbibliothek, Signatur 134.428 B 
Bibel. Evangelien. Sylter Friesisch. Lateinische Schrift

Üt dit Nii Testament: di fjuur Evangelien: Matthäus, Markus, Lukas, Johannes / [Johann Frank]. - 2006

NÖ Landesbibliothek, Signatur 134.337 B

87

Bibel. Englisch (King James Version). Lateinische Schrift

The Holy Bible: containing the Old and New Testaments: translated out of the original tongues and with the former translations diligently compared and revised by His Majesty's special command: appointed to be read in churches: [King James version]. - Cambridge, [1995?]

NÖ Landesbibliothek, Signatur 123.090 B

88

Bibel. Englisch (Revised English Bible). Lateinische Schrift

The Revised English Bible. - Oxford, [2000]

NÖ Landesbibliothek, Signatur 119.480 B

89

Bibel. Englisch (New American Standard Bible). Lateinische Schrift

New American Standard Bible. - Chicago, Ill., [1975]

NÖ Landesbibliothek, Signatur 202.990 B

Exemplar mit Widmung für Alois Mock

Abb. 33

90

Bibel. Isländisch. Lateinische Schrift

Biblían: heilög ritning: Gamla Testamentið og Nýja Testamentið. - Reykjavik, 1995

NÖ Landesbibliothek, Signatur 121.146 B

91

Bibel. Färöisch. Lateinische Schrift

Biblia: Halgabók: Gamla Testamenti og Nýggja: týdd úr frummálunum: [Gamla Testamenti sett í gildi hevur hansara hátign Fríðrikur kongur IX 27. februar 1961]: [Nýggja Testamenti sett í gildi hevur hansara hátign

Christian kongur X 29. desember 1937]. - Kopenhagen, 2000

NÖ Landesbibliothek, Signatur 132.334 B 


\section{2}

Bibel. Nynorsk. Lateinische Schrift Bibelen: den Heilage Skrifta: det gamle og det nye testamentet: [nynorsk]. - Oslo, 2006

NÖ Landesbibliothek, Signatur $121.632 \mathrm{~B}$

\section{3}

Bibel. Bokmål. Lateinische Schrift Bibelen: den Hellige Skrift: det gamle og det nye testamentet: [bokmål]: [det gamle testamentet 1978/85]: [det nye testamentet 2005]. - Oslo, 2009 NÖ Landesbibliothek, Signatur 132.335 B

\section{4}

\section{Bibel. Schwedisch. Lateinische} Schrift

Bibeln: Bibelkommissionens översättning. - Örebro, 2004 NÖ Landesbibliothek, Signatur $121.633 \mathrm{~B}$

\section{5}

Bibel. Dänisch. Lateinische Schrift Bibelen: den Hellige Skrifts kanoniske bøger: autoriseret af Hendes Majestæt Dronning Margrethe II. - Kopenhagen, 2006 NÖ Landesbibliothek, Signatur 120.541 B

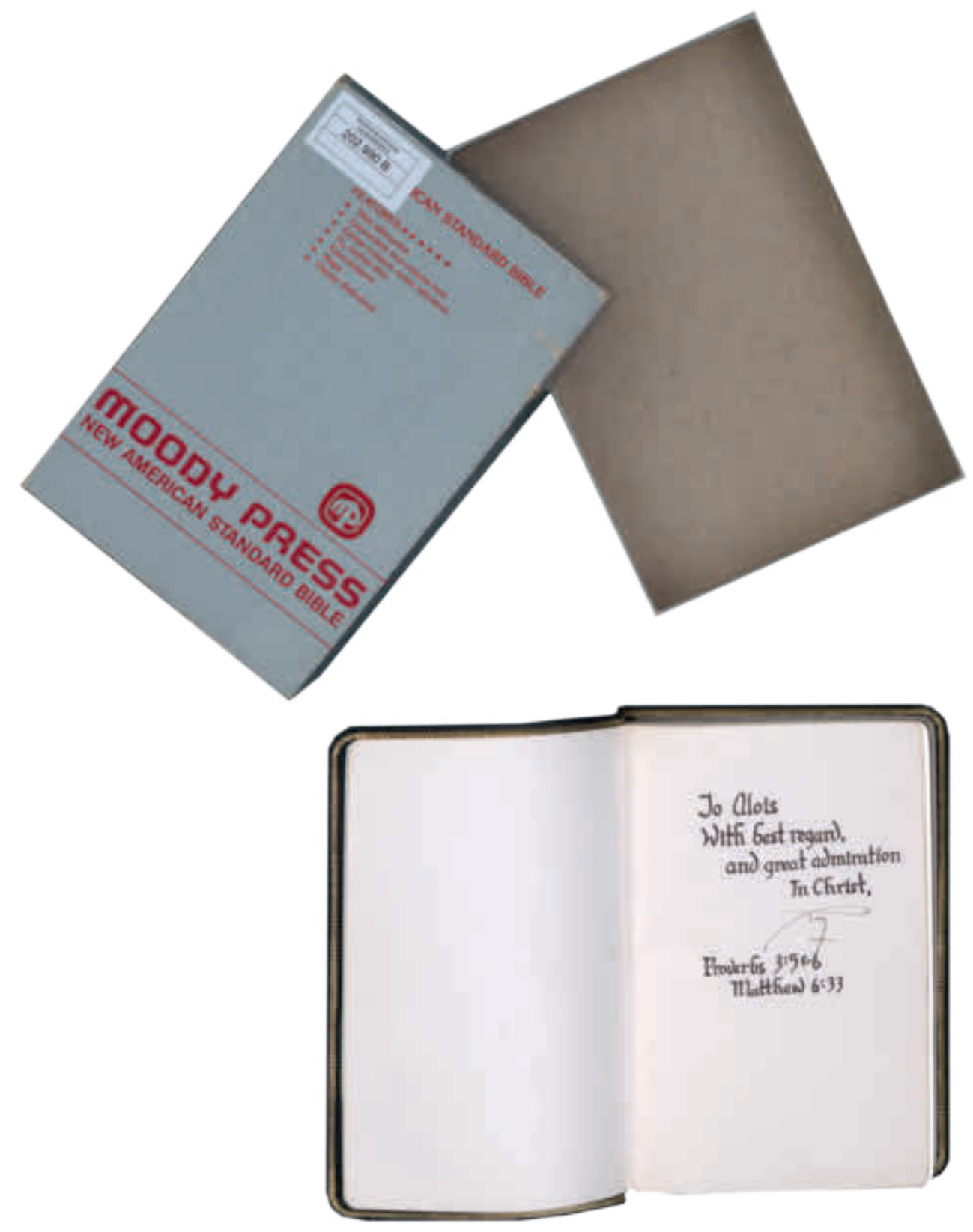

Abb. 33 / Katalog Nr. 89: New American Standard Bible (1975). Mit Widmung für Alois Mock und Originalschachtel. 


\subsubsection{Romanische Sprachen}

Vom antiken Italischen, einem eigenständigen Zweig der indogermanischen Sprachen, der aus einer latino-faliskischen Untergruppe mit Latein und Faliskisch ${ }^{175}$ und einer oskisch-umbrischen Untergruppe mit Oskisch, Umbrisch und Süd-Pikenisch und weiteren Sprachen ${ }^{176}$ bestand und dem vielleicht auch Venetisch ${ }^{177}$, Sikulisch und Elymisch ${ }^{178}$ angehörten, lebt nur das Lateinische durch seine Tochtersprachen, die romanischen Sprachen, fort. Analog zur Dichotomie der keltischen Sprachen können Latino-Faliskisch und Venetisch als q-Italisch und Oskisch-Umbrisch als p-Italisch beschrieben werden. $\mathrm{Zu}$ erwähnen ist das altitalische Alphabet, das auf einem westgriechischen Alphabet ${ }^{179}$ beruht; ${ }^{180}$ auf der altitalischen Schrift beruht die Lateinschrift und über Zwischenstufen wohl auch die germanische Runenschrift.

Die heutigen romanischen Sprachen, die auf das gesprochene Vulgärlatein zurückgeführt werden können, gliedern sich in die westromanischen Sprachen, bestehend aus dem Iberoromanischen ${ }^{181}$, dem Galloromanischen ${ }^{182}$ und dem Alpenromanischen bzw. Rätoromanischen ${ }^{183}$ und die ostromanischen Sprachen, bestehend aus dem Italoromanischen ${ }^{184}$ und dem Balkanromanischen ${ }^{185}$; eine Sonderstellung kommt dem Sardischen mit seinen Varianten Logudoresisch, Nuoresisch und Campidanesisch zu. ${ }^{186}$

Das Katalanische nimmt eine Übergangsstellung zum Galloromanischen bzw. Okzitanischen ein; die norditalienischen Dialekte ${ }^{187}$ zählen noch zum Westromanischen, das Galloitalienische bildet dabei den Übergang zum

175 In Latium.

176 Im östlichen Mittelitalien (Umbrien, Marken) und in Süditalien (Kampanien).

177 In Venetien und Friaul-Julisch Venetien; nicht zu verwechseln mit der heutigen romanischen Sprache in diesem Raum.

178 Sikulisch im Osten, Elymisch im Westen Siziliens; das im Zentrum Siziliens gesprochene Sikanische ist nicht klassifiziert.

179 Mit dem Lautwert ks für $\chi$ statt $\mathrm{k}^{\mathrm{h}}$ wie in den ostgriechischen Alphabeten.

180 Mit Varianten für das Etruskische und die italischen Sprachen Oskisch, Umbrisch und Venetisch.

181 Portugiesisch und Galicisch, Asturleonisch inklusive Mirandés, Kastilisch bzw. Spanisch, Aragonesisch, Katalanisch.

182 Okzitanisch inklusive dem Gaskognischen und dessen Variante Aranesisch, Franko-Provenzalisch sowie Französisch inklusive der Varietäten Gallo, Normannisch, Pikardisch, Wallonisch usw.

183 Bündnerromanisch mit den Dialekten Surselvisch (Sursilvan), Sutselvisch (Sutsilvan), Surmeirisch (Surmiran), Oberengadinisch (Puter), Unterengadinisch (Vallader), Münstertalerisch (Jauer) und der Schriftsprache Rumantsch Grischun; (Dolomiten-)Ladinisch mit den Dialekten Grödnertalisch (Gherdëina), Gadertalisch/Abteitalisch (Badiot), Ennebergisch (Maréo), Fassatalisch (Fascian), Ampezzanisch (Anpezan), Buchensteinisch (Fodom) und der Schriftsprache Ladin Dolomitan; Friaulisch/Friulanisch (Furlan).

184 Italienisch und Istriotisch, letzteres als Relikt des Dalmatoromanischen.

185 Rumänisch inklusive Moldauisch, Aromunisch, Meglenitisch und Istrorumänisch.

$186 \mathrm{Zu}$ dessen Besonderheiten zählt die fehlende Palatalisierung bzw. der Erhalt der velaren Aussprache von c vor e und i (im Logudoresischen und Nuoresischen).

187 Venezianisch und die galloitalienischen Varietäten Ligurisch, Piemontesisch, Lombardisch und Emilianisch. 
Galloromanischen. Der Unterschied zwischen Westromanisch und Ostromanisch besteht in der Pluralbildung ${ }^{188}$ sowie in der Erweichung intervokalischer Konsonanten ${ }^{189}$.

Latein ist im Abschnitt $1.4^{190}$ vertreten; als Vertreter romanischer Sprachen werden Portugiesisch, Spanisch, Katalanisch, Französisch, Italienisch, Rumänisch und Ladinisch vorgestellt. Letztere Übersetzung in zwei Bänden (Neues Testament 2005, Altes Testament 2015) ist besonders hervorzuheben und stammt von Christian (Cristl) Moroder (1924-2016) aus St. Ulrich in Gröden (auch Urtijëi oder Ortisei); er war zuletzt 1993-1999 Pfarrer von Stern (auch La Ila oder La Villa, Fraktion der Gemeinde Abtei oder Badia).

\section{6}

\section{Bibel. Portugiesisch. Lateinische Schrift}

Bíblia Sagrada: tradução interconfessional do hebraico, do aramaico e do grego em português corrente: a boa nova em português corrente. - Lissabon, 2004

NÖ Landesbibliothek, Signatur 119.714 B

\section{7}

\section{Bibel. Spanisch. Lateinische Schrift}

La Biblia de estudio: Dios habla hoy: edición interconfesional: la Biblia en versión popular: traducción interconfesional directa de los textos originales: hebreo, arameo y griego. - Madrid, 2002

NÖ Landesbibliothek, Signatur 119.713 B

\section{8}

\section{Bibel. Katalanisch. Lateinische Schrift}

La Biblia: edició d'estudi: traducció interconfessional en català. - Barcelona, 1993

NÖ Landesbibliothek, Signatur 133.663 B

188 -s statt Vokaländerung a zu e bzw. o, e zu i.

189 Vgl. spanisch amiga - amigas bzw. amigo - amigos gegenüber Italienisch amica - amiche bzw. amico - amici zu lateinisch amica - amicae (Akkusativ Plural: amicas) bzw. amicus - amici (Akkusativ Plural: amicos).

190 Katalog Nr. 15 bis 18. 


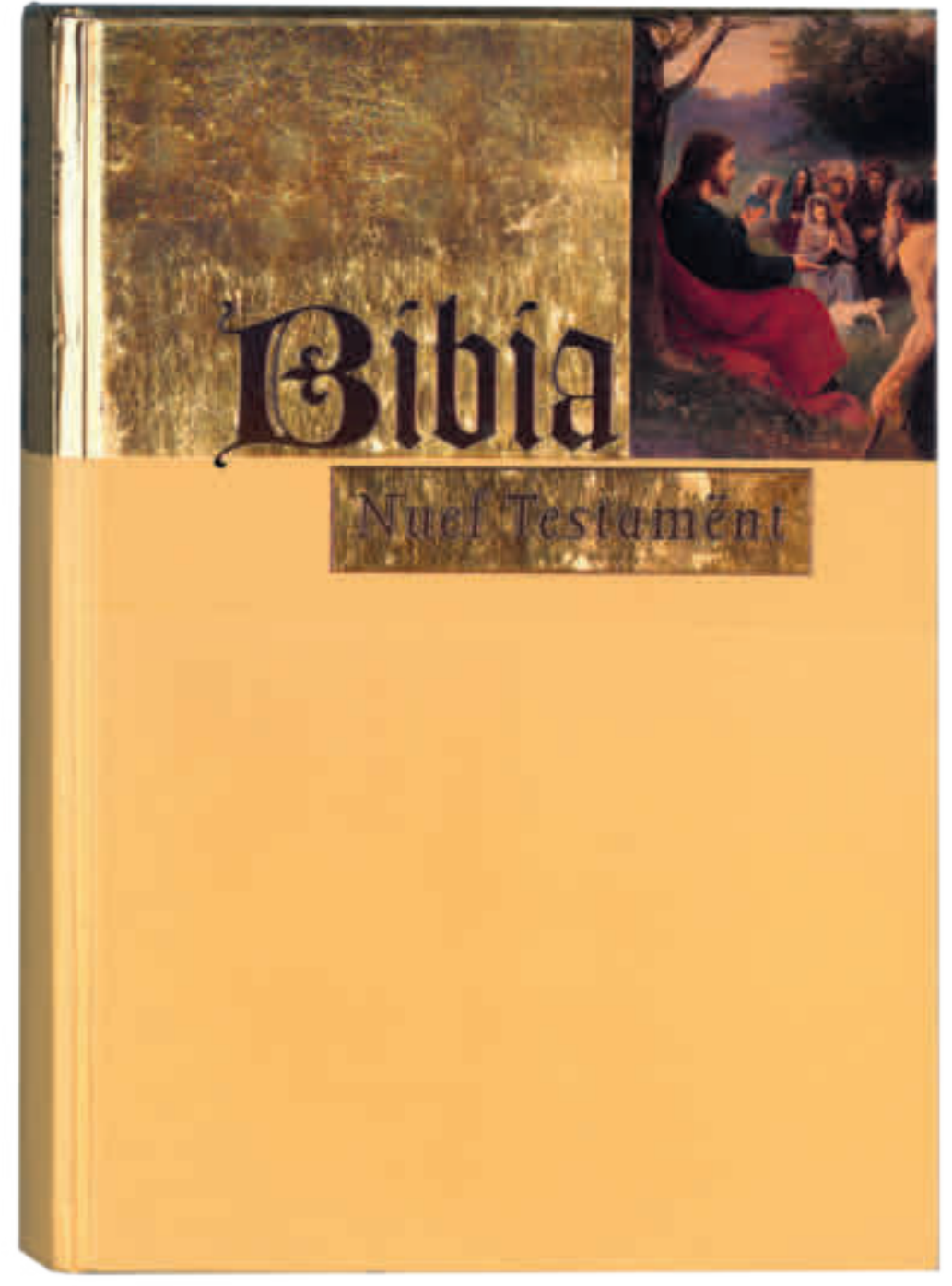

Abb. 34 / Katalog Nr. 102: Bibia. Nuef Testamënt (Ladinisch) (2005).
99

Bibel. Französisch. Lateinische Schrift Traduction œcuménique de la Bible: comprenant l'Ancien et le Nouveau Testament: traduits sur les textes originaux hébreu et grec avec introductions, notes essentielles, glossaire. - Paris, 2004

NÖ Landesbibliothek, Signatur 119.712 B

\section{0}

Bibel. Italienisch. Lateinische Schrift La Bibbia: parola del signore; traduzione interconfessionale in lingua corrente per la lettura: nuova versione NT. - Turin, 2001 NÖ Landesbibliothek, Signatur 119.711 B

101

Bibel. Rumänisch. Lateinische Schrift Biblia sau Sfânta Scriptură: a Vechiului şi Noului Testament cu trimiteri / [Cornilescu, Dumitru (trad.)]. - Bukarest, 2005

NÖ Landesbibliothek, Signatur 120.186 B

102

Bibel. Neues Testament. Ladinisch (Mundart Grödner Tal). Lateinische Schrift

Nuef Testamënt. - St. Martin in Thurn, 2005. - (Bibia / redazion, traduzion y sistemazion: Cristl Moroder)

NÖ Landesbibliothek, Signatur 134.007 B

Abb. 34 


\subsubsection{Baltische Sprachen}

Die in vielerlei Hinsicht archaischen baltischen Sprachen stehen den slawischen Sprachen nahe, sind untereinander aber weniger nahe verwandt als diese. Querbeziehungen bestehen auch zu den germanischen Sprachen: Nur diese drei Sprachfamilien zeigen im Dativ, Ablativ und Instrumental Plural m-haltige Endungen, vergleiche litauisch vilkams und gotisch wulfam. ${ }^{191}$ Heute leben nur mehr zwei baltische Sprachen: Litauisch mit den Dialekten Aukschtaitisch ${ }^{192}$ und Schemaitisch oder Samogitisch ${ }^{193}$ und Lettisch mit den Dialekten Tahmisch ${ }^{194}$, Mittellettisch ${ }^{195}$ und Hochlettisch ${ }^{196}$. Ansätze zu einer eigenständigen Schriftsprachlichkeit sind beim Lettgallischen festzustellen; Lettisch und zum Teil auch Litauisch erstrecken sich über die historischen Sprachgebiete des Lettgallischen, Selischen, Semgallischen, Kurischen und Livischen, letzteres eine kürzlich ausgestorbene finno-ugrische Sprache.

Eine besonders archaische ausgestorbene baltische Sprache war das zuerst im vierzehnten Jahrhundert belegte und im Laufe des siebzehnten Jahrhunderts ${ }^{197}$ ausgestorbene Altpreußische, dessen Sprecher, die Prußen oder Pruzzen, namensgebend für Preußen, genauer Ostpreußen, also das Gebiet zwischen Weichsel und Memel, wurden. Zu den Stammesgebieten zählen Pomesanien ${ }^{198}$, Pogesanien, Ermland, Natangen, Samland, Nadrauen, Schalauen, das Kulmerland, Lubawa, Sassen, Galinden, Barten, Sudauen und das Gebiet der Jatwinger. Inwiefern dem Dialekt- oder gar Sprachunterschiede entsprechen, ist unklar, weil nur der pomesanische und samländische Dialekt hinreichend belegt sind; ein Vokabular wird als jatwingisch eingestuft.

Die wichtigsten altpreußischen Sprachdenkmäler sind zwei Katechismen aus dem Jahr 1545 und ein dritter aus dem Jahr 1561 („Enchiridion“); als Sprachprobe werden die Zehn Gebote anhand eines Reprints des Büchleins von Ferdinand Nesselmann zu den altpreußischen Sprachüberresten vorgestellt; ${ }^{199}$ diverse Vaterunser-Versionen kann man auch dem zweiten Band von Johann Christoph Adelungs „Mithridates“ entnehmen. Altpreußisch ist ein Beispiel für Sprachen, deren nahezu gesamtes schriftliches Erbe aus kirchlichen Texten besteht; die ältesten

$191 \mathrm{Zu}$ litauisch vilkas und gotisch wulfs (Wolf).

192 Hochlitauisch.

193 Niederlitauisch.

194 Kurländisches und livländisches Tahmisch.

195 Mittellivländisches, semgallisches, kurisches und semgallisch-kurisches Mittellettisch.

196 Hochlettische Mundarten Lettgallens und Nordostlivlands sowie die selischen Mundarten.

197 Spätestens 1711.

198 Für *Po-medzanie (hinter dem Wald).

199 Kleiner Auszug: „Stas Kettwirts Pallaips. Tou turri twaian Tâwan bhe Mûtien smûnint, kai tebbe labban êit bhe ilgi giwassi no semien.“ „Das vierte Gebot: Ehre deinen Vater und deine Mutter, damit du lange lebst in dem Land, das der HERR, dein Gott, dir gibt!“ (Wiedergabe nach der „Einheitsübersetzung $\left.2016^{6}\right)$. 
litauischen bzw. lettischen Bücher sind ebenfalls Katechismen ${ }^{200}$, womit der Beginn ihrer Schriftlichkeit dem Altpreußischen gleicht.

Litauen ist wegen seiner Vergangenheit als Teil der polnisch-litauischen Union überwiegend katholisch, Lettland hingegen protestantisch geprägt. Diese beiden Sprachen sind durch Bibeln vertreten.

Literaturtipp:

Eckert, Rainer. Die baltischen Sprachen: eine Einführung / Rainer Eckert, Elvira-Julia Bukevičiūtè, Friedhelm Hinze. - Leipzig, Berlin, München, Wien, Zürich und New York, 1994

103

Bibel. Litauisch. Lateinische Schrift

Biblija, arba Šventasis Raštas: trečias pataisytas ir papildytas ekumeninis leidimas = Lithuanian bible / senasis testamentas iš hebrajų, aramèjų ir graikų kalbų vertė Antanas Rubšys, naujasis testamentas iš graikų kalbos verte Česlovas Kavaliauskas. - Vilnius, 2005

NÖ Landesbibliothek, Signatur 120.188 B

\section{4}

\section{Bibel. Lettisch. Lateinische Schrift}

Bībele: 1965. gada izdevuma revidētais teksts ar pielikumiem = Latvian Bible. - Riga, 2005

NÖ Landesbibliothek, Signatur 121.147 B

105

Nesselmann, Ferdinand, 1811-1881. Die Sprache der alten Preussen an ihren Überresten erläutert. Reprint der Ausgabe Berlin, Reimer, 1845. - Ardagger, 2006

aufgeschlagen: Zehn Gebote

NÖ Landesbibliothek, Signatur 122.211 B 


\subsubsection{Slawische Sprachen}

Die slawischen Sprachen gliedern sich in die ostslawischen Sprachen ${ }^{201}$, die westslawischen Sprachen ${ }^{202}$ sowie die südslawischen Sprachen ${ }^{203}$. Ein Einteilungsmerkmal ist die Vertretung der ursprünglichen Lautgruppen Konsonant-e/o-Liquida-Konsonant: Urslawisch gordb ergibt kaschubisch ${ }^{204}$ gard, polnisch ${ }^{205}$ gród, altkirchenslawisch ${ }^{206}$ gradb, russisch $^{207}$ gorod; die Fachbezeichnung hierfür ist Liquidametathese ${ }^{208}$ bzw. Polnoglasie (Volllaut) ${ }^{209}$. Ein Stadtname wie Leningrad ist daher südslawischen (kirchenslawischen) und nicht ostslawischen (russischen) Ursprungs wie Nowgorod.

Das Serbokroatische wird einerseits in Štokavisch, Čakavisch und Kajkavisch ${ }^{210}$ sowie das Torlakische ${ }^{211}$ eingeteilt, andererseits in Ekavisch (Serbisch), Ikavisch und Ijekavisch/Jekavisch (Kroatisch, Bosnisch und Montenegrinisch), vergleiche serbisch reka gegenüber kroatisch rijeka (Fluss) ${ }^{212}$. Čakavisch sind lediglich die Küstendialekte des Kroatischen sowie größtenteils das Burgenlandkroatische, kajkavisch die nördlichen Dialekte des Kroatischen (inklusive des Raums Zagreb) im Übergang zum Slowenischen und im Unterschied zur štokavischen kroatischen Standardsprache. Daraus folgt, dass die kroatische und die serbische Standardsprache beide štokavisch und somit miteinander näher verwandt sind als die kroatische Standardsprache und das Burgenlandkroatische, welches als eine eigenständige serbokroatische Schriftsprache anzusehen ist. Der prinzipielle Unterschied zwischen Serbisch und Kroatisch ist außersprachlicher Natur: Eigenstaatlichkeit, lateinische versus kyrillische Schrift und katholisches versus orthodoxes Christentum (im Falle des Bosnischen versus Islam). Schrift und Religion bedingen hier einander: Die ostslawischen Sprachen Russisch, Ukrainisch, Weißrussisch und die südslawischen Sprachen Bulgarisch, Mazedonisch und Serbisch bzw. Montenegrinisch sind orthodox-kyrillisch, die westslawischen Sprachen Polnisch, Tschechisch, Slowakisch und die südslawischen Sprachen Slowenisch und Kroatisch katholisch-latein-

201 Namentlich Russisch, Ukrainisch, Weißrussisch, Karpato-Russinisch, Jugoslawo-Russinisch und Westpolessisch.

202 Mit den lechischen Sprachen Polnisch und Kaschubisch (nach dem Aussterben von Polabisch, Pomoranisch und Slowinzisch der letzte Rest des Elb- und Ostseeslawischen), dem Obersorbischen und Niedersorbischen, dem Tschechischen und Slowakischen.

203 Slowenisch samt Resianisch, Serbokroatisch mit den Varietäten Kroatisch nebst dem Burgenlandkroatischen und Moliseslawischen, Serbisch, Bosnisch und Montenegrinisch sowie das Bulgarische, das Banater Bulgarische, das Mazedonische und das (Alt-)Kirchenslawische.

204 Elb- und ostseeslawisch, prinzipiell mit Erhalt der Lautgruppe.

205 Westslawisch, mit Umstellung.

206 Südslawisch, parallele Entwicklung im Tschechischen und Slowakischen, mit zusätzlicher Vokaldehnung.

207 Ostslawisch, mit Vokaleinschub.

208 Umstellung Vokal-Liquida $\rightarrow$ Liquida-Vokal, vgl. deutsch Born und Brunnen.

209 Aufsprengung der Doppelkonsonanz Vokal-Liquida-Konsonant $\rightarrow$ Vokal-Liquida-Vokal-Konsonant.

210 Nach dem jeweiligen Fragepronomen für ,,was“.

211 Übergangsdialekt zum Bulgarischen und Mazedonischen.

212 Nach der Entwicklung von ursprünglichem *ě (Jat). 
schriftlich und spiegeln die quer durch die slawischen Völker und Sprachen verlaufende europäische Kulturgrenze zwischen Westrom und Ostrom wider.

Das Sorbische besteht aus den beiden Standardvarietäten Obersorbisch in der Oberlausitz mit dem Zentrum Bautzen (in Sachsen) und ca. 20.000-25.000 Sprechern sowie Niedersorbisch in der Niederlausitz mit dem Zentrum Cottbus (in Brandenburg) und ca. 7.000 Sprechern. Das Obersorbische steht dem Tschechischen, das bereits vom Sprachtod bedrohte Niedersorbische dem Polnischen näher. Bemerkenswert ist auch der Konfessionsunterschied zwischen den katholischen Obersorben und den lutherischen Niedersorben. Vor allem letztere werden auch als Wenden bezeichnet; Wenden, Wendisch und Windisch sind veraltete Bezeichnungen für die Slawen und lautlich zu Veneter zu stellen, womit in der Antike verschiedene Völker bezeichnet wurden.

Im sechsten Jahrhundert nach Christus war nördlich des Schwarzen Meeres das turksprachige Großbulgarische Reich entstanden; unter den Söhnen des 668 verstorbenen Khans Kubrat erfolgte eine Abwanderung in verschiedene Richtungen: Khan Kotrag gründete im Norden das Reich der Wolgabulgaren mit der Hauptstadt Bolgar, als deren Nachfahren die Tschuwaschen gelten; ihre Sprache gilt zugleich als letzter Rest der oghurischen Turksprachen, zu denen neben Bolgarisch auch Chasarisch zählte; die Zugehörigkeit der Sprachen der antiken Hunnen und frühmittelalterlichen Awaren ist zumindest spekulativ. Eine weitere Gruppe stellen die den Tscherkessen benachbarten Balkaren dar, deren Sprache allerdings zu den nordwestlichen (kiptschakischen) Turksprachen zählt. Khan Asparuch gründete 678 das Erste Bulgarische Reich, auch Donaubulgarisches Reich oder Reich der Blauen Bulgaren, dessen Bevölkerung 864 christianisiert wurde, wobei die Protobulgaren sukzessive von den schon zuvor dort siedelnden Slawen assimiliert wurden, zugleich aber ihren Namen auf diese übertrugen: Das heutige Bulgarisch ist eine südslawische Sprache. Bereits 863 waren auf Bitte des mährischen Fürsten Rastislav an den byzantinischen Kaiser Michael III. die Brüder Kyrill (ursprünglich Konstantin) und Method aus Thessaloniki als Missionare nach Mähren entsandt worden, die mit der slawischen Sprache ihrer Nachbarschaft vertraut waren. Gemeinhin wird ihnen die Erfindung und Verwendung der glagolitischen Schrift zugeschrieben, die unter anderem auf griechischen Minuskeln basiert und in der Folge in einer runden Variante in Bulgarien und einer eckigen Variante in Kroatien verwendet wurde; sie wurde allmählich von der etwas später und auf Grundlage griechischer Majuskeln (Unziale) entstandenen sogenannten kyrillischen Schrift verdrängt. Die ursprüngliche altkyrillische Schrift wurde 1710 infolge einer Reform von Zar Peter dem Großen durch die moderne kyrillische Schrift ersetzt und hat sich nur im Bereich des Kirchenslawischen gehalten. ${ }^{213}$

Dessen ursprüngliche Form, das Altkirchenslawische (auch Altslawische oder Altbulgarische), die Sprache von Kyrill und Method und der von ihnen übersetzten Texte, unterscheidet sich von den späteren lokalen Redaktio- 
nen des Kirchenslawischen: dem Tschechisch-Kirchenslawischen ${ }^{214}$, dem Kroatisch-Kirchenslawischen ${ }^{215}$, dem Serbisch-Kirchenslawischen, dem Bulgarisch-Kirchenslawischen ${ }^{216}$ und dem Russisch-Kirchenslawischen ${ }^{217}$; kennzeichnendes Merkmal des Altkirchenslawischen ist dabei der Erhalt bzw. die fehlerfreie Vertretung der urslawischen Nasalvokale *ę und *a.. ${ }^{218}$

Zunächst werden zwei altkirchenslawische Sprachdenkmäler vorgestellt: der „Codex Zographensis“, ein Tetraevangelium in glagolitischer Schrift ${ }^{219}$ und die „Savvina kniga“, ein Aprakos-Evangelium (Evangelistar) in kyrillischer Schrift. Das Neukirchenslawische wird anhand einer modernen Bibelausgabe präsentiert und ist gleichzeitig ein Beispiel für die altkyrillische Schrift. Das Russische ist in Form der synodalen Übersetzung vertreten; der Heiligste Regierende Synod war das von Peter dem Großen 1721 gegründete Lenkungsorgan der Russischen Orthodoxen Kirche; die Übersetzung, die sich im Unterschied zu der auf der Septuaginta beruhenden kirchenslawischen Bibel wie alle modernen Bibelausgaben auf den „Masoretischen Text“ der hebräischen Bibel stützt, wurde 1813 unter Zar Alexander I. in Angriff genommen und nach einer längeren Unterbrechung unter Zar Nikolaus I. erst 1876 unter Zar Alexander II. fertiggestellt und ist mit dem Namen des Metropoliten Philaret von Moskau (Philaret Drosdow 1783-1867) verbunden.

Auch Ukrainisch, Polnisch, Tschechisch, Slowakisch, Slowenisch, Kroatisch, Serbisch, Mazedonisch und Bulgarisch werden vorgestellt; hervorgehoben seien ein niedersorbisches Altes Testament von 1824 neben einer obersorbischen Bibel von 2006 und als besondere Rarität die 2014 vollendete Bibelübersetzung in das Burgenlandkroatische in fünf Bänden, deren erster den Pentateuch beinhaltet und das Werk hier repräsentiert. Diese Übersetzung ist vor allem das Werk des katholischen Pfarrers von Klimpuh (Klingenbach) Stefan Geosits (* 1927), einzelne biblische Bücher wurden allerdings von Augustin Blazović (1921-2004) bzw. Branko Kornfeind (* 1952) übersetzt.

\section{Literaturtipp:}

Einführung in die slawischen Sprachen: (mit einer Einführung in die Balkanphilologie) / herausgegeben von Peter Rehder. - 5. Auflage. - Darmstadt, 2006

\footnotetext{
$214+1097$

215 Mit eckiger glagolitischer Schrift, als Liturgiesprache vom Papst verboten.

216 Auch Mittelbulgarisch.

217 Seit den Reformen durch Patriarch Nikon (1605-1681) im Jahr 1652, die zur Abspaltung der Altgläubigen oder Raskolniki unter Awwakum (um 1620 1682) führten, Etablierung als Neukirchenslawisch oder Synodalkirchenslawisch für alle orthodoxen Slawen, also auch die Serben und Bulgaren.

218 Aus *m, *n sowie *em, *en bzw. *am, *an sowie *om und *on zwischen Konsonanten.

219 Die vorliegende Ausgabe ist allerdings in kyrillischer Schrift gedruckt.
} 


\section{6}

Bibel. Evangelien. Altkirchenslawisch. Kyrillische (statt glagolitischer) Schrift

Quattuor evangeliorum Codex Glagoliticus, olim Zographensis nunc Petropolitanus: characteribus Cyrillicis transcriptum notis criticis prolegomenis appendicibus auctum / ed. V. Jagić. - Graz, 1954. - (Editiones monumentorum Slavicorum veteris dialecti)

NÖ Landesbibliothek, Signatur 122.495 B

107

Sawabuch (Aprakosevangelium). Altkirchenslawisch. Kyrillische Schrift

Savvina Kniga / V. Ščepkin. - Graz, 1959. - (Editiones monumentorum Slavicorum veteris dialecti)

NÖ Landesbibliothek, Signatur 122.494 B

\section{8}

\section{Bibel. Russisch-Kirchenslawisch. Kyrillische (kirchenslawische) Schrift}

Библия: книги священного писания ветхого и нового завета на церковнославянском языке с параллельными местами / по благослобению Святейшего Патриарха Московского и всея Руси Алексия II [Biblija: knigi svjaščennogo pisanija vetchogo i novogo zaveta na cerkovnoslavjanskom jazyke s parallel'nymi mestami / po blagosloveniju Svjatejšego Patriarcha Moskovskogo i vseja Rusi Aleksija II]. - Moskau, 2001 Nachdruck von: Бі́блї^ си́рьчь кнйги Св^щеннагш Писа́нї^ Ве́тұагш и Но́вагw Завб́́та. Санктпетербурга: Сӥнодальна^ тйпографї^, ғац

NÖ Landesbibliothek, Signatur 133.692 B

\section{9}

\section{Bibel. Russisch (Synodale Übersetzung). Kyrillische Schrift}

Библия: книги священного писания ветхого и нового завета: канонические: в русском переводе с параллельными местами и словарем [Biblija: knigi svjaščennogo pisanija Vetchogo i Novogo Zaveta: kanoničeskie: v russkom perevode s parallel'nymi mestami i slovarem]. - Moskau, 2001

NÖ Landesbibliothek, Signatur 136.044 B

\section{0}

\section{Bibel. Altes Testament. Niedersorbisch. Lateinische Schrift (Fraktur)}

To Bóże Pißmo Starego Testamenta sa Lutherußom: do Niederlausiskeje ßerskeje Rėzi pschėstajone wot Johann Friedrich Friza a wotnowotki pschègledane wot Johann Sigismund Friedrich Schindler. - Berlin, 1824 
111

Bibel. Obersorbisch. Lateinische Schrift Swjate pismo: stareho a noweho zakonja. Bautzen, 2006

NÖ Landesbibliothek, Signatur 134.443 B

\section{2}

Bibel. Pentateuch.

Burgenländischkroatisch. Lateinische Schrift

Petoknjižje. - Klimpuh (Klingenbach), 2014.

- (Biblija na gradišćanskohrvatskom jeziku /

Dr. Stefan Geosits. Stari teštamenat; 1)

NÖ Landesbibliothek, Signatur 202.662 C 1

Abb. 35

\section{3}

Bibel. Polnisch. Lateinische Schrift

Biblia: to jest Pismo Święte Starego i Nowego

Testamentu: nowy przekład z języków hebrajskiego i greckiego opracowany przez

Komisję Przekładu Pisma Świętego. -

Warschau, 1975

NÖ Landesbibliothek, Signatur 120.183 B

\section{4}

Bibel. Tschechisch. Lateinische Schrift

Bible: písmo svaté starého a nového zákona:

český ekumenický překlad = Bible in Czech ecumenical translation / Česká Biblická

Společnost. - Prag, 2005

NÖ Landesbibliothek, Signatur 119.706 B

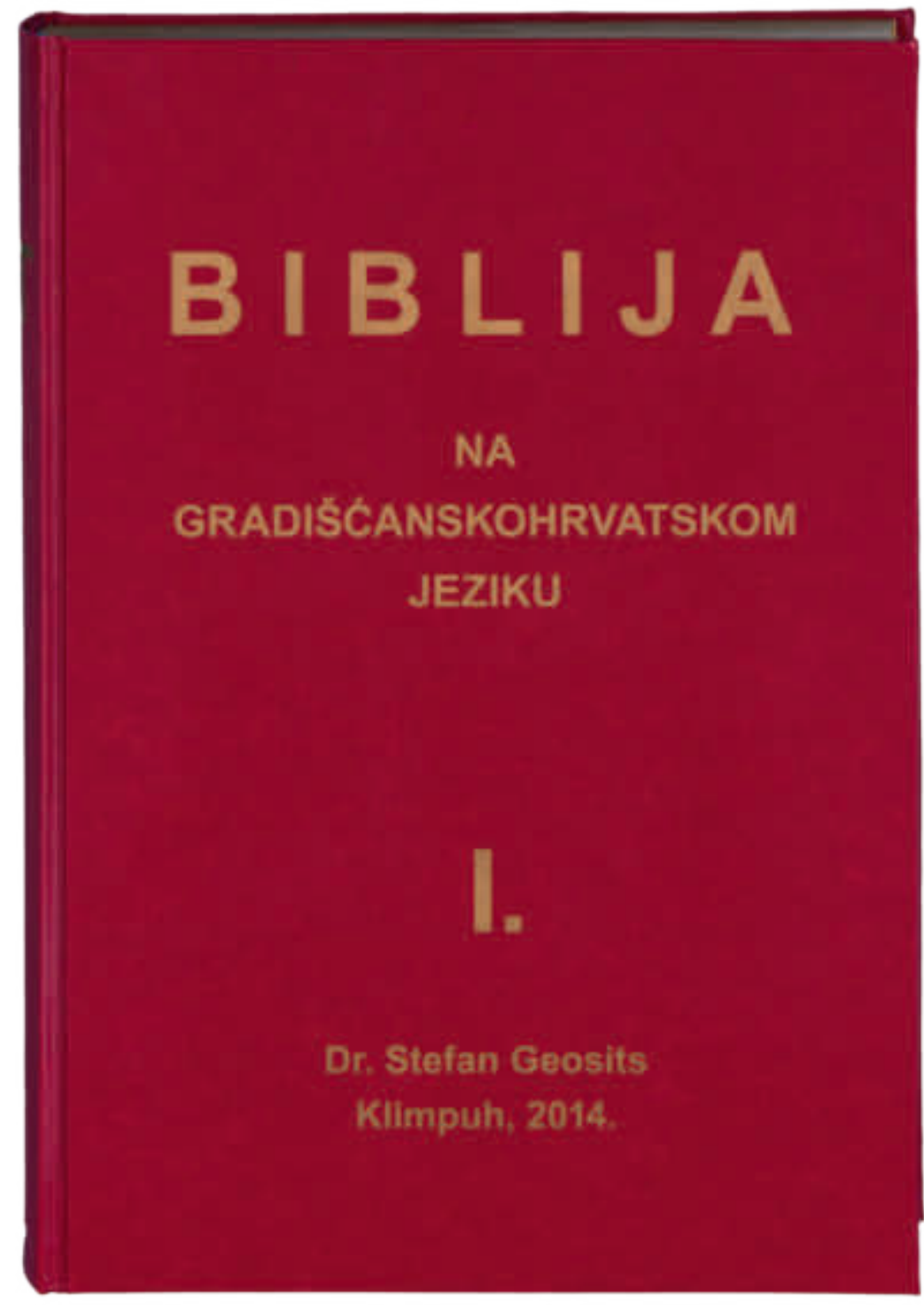

Abb. 35 / Katalog Nr. 112: Stefan Geosits (Übers.), Biblija na gradišćanskohrvatskom jeziku. Band 1 (2014). 


\section{5}

\section{Bibel. Slowakisch. Lateinische Schrift}

Biblia: písmo sväté starej a novej zmluvy / Tranoscius Liptovský Mikuláš a Slovenská Biblická Spoločnost’; [Text z poverenia Bohoslužobného výboru ECAV na Slovensku overili Juraj Bándy ...]. - Banská Bystrica, 1999 NÖ Landesbibliothek, Signatur 119.707 B

\section{6}

\section{Bibel. Slowenisch. Lateinische Schrift}

Sveto Pismo: Stare in Nove Zaveze [z devterokanoničnimi/apokrifnimi knjigami]: Slovenski standardni prevod: jubilejna izdaja ob petstoletnici rojstva Primoža Trubarja = Slovenian Bible. - Ljubljana, 2008

NÖ Landesbibliothek, Signatur 122.844 B

\section{7}

\section{Bibel. Kroatisch. Lateinische Schrift}

Biblija: Sveto Pismo Staroga i Novoga Zavjeta / preveo Ivan Ev. Šarić. - Zagreb, 2007

NÖ Landesbibliothek, Signatur 120.184 B

\section{8}

\section{Bibel. Serbisch. Kyrillische Schrift}

Библија или Свето Писмо Старога и Новога Завјета / издавачи: Библијско Друштво Србије и Црне Горе; за издаваче: Звонимир Смиљанић; уредник: Звонимир Смиљанић; превод Стари Завјет: Ћура Даничић, Нови Завјет: Вук Стефановић Караџић [Biblija ili Sveto Pismo Staroga i Novoga Zavjeta / izdavači: Biblijsko Društvo Srbije i Crne Gore; za izdavače: Zvonimir Smiljanić; urednik: Zvonimir Smiljanić; prevod Stari Zavjet: Đuro Daničić, Novi Zavjet: Vuk Stefanović Karadžić] = Serbian Bible. - Belgrad, [2004]

NÖ Landesbibliothek, Signatur 120.187 B

\section{9}

\section{Bibel. Mazedonisch. Kyrillische Schrift}

Свето Писмо на Стариот и на Новиот Завет / со благослов на Светиот Архиерејски Синод на Македонската Православна Црква [Sveto Pismo na Stariot i na Noviot Zavet / so blagoslov na Svetiot Archierejski Sinod na Makedonskata Pravoslavna Crkva] = Macedonian Bible. - Skopje, 2007 NÖ Landesbibliothek, Signatur 122.275 B 


\section{0}

\section{Bibel. Bulgarisch. Kyrillische Schrift}

Библия или Свещеного Писание на Стария и Новия Завет: вярно и точно преведена от оригинала [Biblija ili Sveštenoto Pisanie na Starija i Novija Zavet: vjarno i točno prevedena ot originala]. - Sofia, 2000

NÖ Landesbibliothek, Signatur 120.546 B

\section{1}

\section{Bibel. Ukrainisch. Kyrillische Schrift}

Біблія або книги Святого Письма Старого й Нового Заповіту: із мови давньоєврейської та грецької на Українську наново перекладена [Biblija abo knyhy svjatoho pys'ma Staroho j Novoho Zapovitu: iz movy davn'ojevrejs'koï ta hrec'koï na ukraïns'ku nanovo perekladena] = Ukrainian Bible. - Kiew, 2001

NÖ Landesbibliothek, Signatur 120.185 B

\subsubsection{Griechisch}

Eine der wichtigsten und am längsten zu belegenden indogermanischen Sprachen ist das Griechische; in seiner ältesten überlieferten Sprachform, dem Mykenischen, reicht es bis 1650 vor Christus zurück ${ }^{220}$ und wurde zunächst auf Tontafeln in Linear-B-Schrift, einer Silbenschrift, festgehalten. Verwandte dieses Schriftsystems sind die kretischen Hieroglyphen und die davon abgeleitete Linear-A-Schrift des minoischen Kreta als Vorläufer sowie die kypro-minoische Linear-C-Schrift samt der kyprischen Schrift, die für Eteokyprisch wie auch für den kyprischen Dialekt des Griechischen verwendet wurde. Nach den dunklen Jahrhunderten zwischen dem zwöften und achten vorchristlichen Jahrhundert etablierte sich ungefähr zeitgleich mit dem Beginn der griechischen Literatur, den homerischen Epen, das griechische Alphabet, eine von den Phöniziern übernommene Schrift, wie man sowohl an den übernommenen Buchstabennamen ${ }^{221}$ als auch an deren Reihenfolge ${ }^{222}$ erkennt. Nicht benötigte Konsonantenzeichen wurden als Vokalzeichen verwendet, ${ }^{223}$ womit eine Alphabetschrift vorliegt, während die phönizische Schrift eine reine Konsonantenschrift (Abdschad) bildete. Deren linksläufige Schreibrichtung wurde über die Zwischenstufe Bustrophedon ${ }^{224}$ letztlich zu einer rechtsläufigen Schreibrichtung gewandelt. Während

220 Darin wird es nur vom Hethitischen übertroffen.

221 Die im Phönizischen nach dem akrophonen Prinzip Wörter mit dem entsprechenden Anfangskonsonanten darstellen, zum Beispiel ?alf (Rind).

222 Alpha-Beta-Gamma ...

223 Z. B. Alpha für a statt für ?

224 Abwechselnde Schreibrichtung. 
zunächst verschiedene lokale Alphabete in Gebrauch waren, ${ }^{225}$ bewirkte die 403 vor Christus erfolgte Übernahme des Alphabets von Milet durch Athen eine Standardisierung des griechischen Alphabets, das in der Folge eine ähnliche Entwicklung wie die lateinische Schrift über Unzialschrift zur Minuskelschrift nahm. Als erweiterte Sonderformen des griechischen Alphabets sind das koptische Alphabet ${ }^{226}$ und das gotische Alphabet ${ }^{227}$ anzusehen, Tochterschriften sind die lateinische Schrift ${ }^{228}$, die glagolitische und kyrillische Schrift; auch die armenische und georgische Schrift folgen zumindest dem Vorbild des griechischen Alphabets.

Das nachmykenische Altgriechisch war keine einheitliche Sprache; mehrere seiner Dialekte sind sogar als Literatursprachen anzusehen. Man unterscheidet die enger zusammengehörigen Dialekte Nordwestgriechisch, Achaiisch, Elisch und Dorisch ${ }^{22}$, weiters Äolisch ${ }^{230}$, das Arkadische und Kyprische, das Pamphylische, das Ionische und Attische; Literatursprachen sind Attisch, Ionisch, Lesbisch und zum Teil Boiotisch sowie mehrere dorische Dialekte; das antike Makedonisch war vielleicht auch ein griechischer Dialekt. In hellenistischer Zeit entstand die sogenannte Koine als Ausgleichssprache auf attischer Grundlage. In dieser Sprache sind die Septuaginta und das Neue Testament abgefasst, ebenso wie weitere Schriften des Urchristentums; diese Grundtexte werden in den Abschnitten 1.2 und 1.4 behandelt. ${ }^{231}$

Mit Ausnahme des Tsakonischen, einer Fortsetzung des kaiserzeitlichen Junglakonischen, geht das heutige Neugriechisch über die Zwischenstufe des Mittelgriechischen oder Byzantinischen auf diese Koine zurück; der Streit über den Vorrang für die antikisierende Sprachform Katharevousa wurde 1976 de facto zugunsten der Dimotiki entschieden, wenngleich das heutige Neugriechisch letztendlich eine Synthese dieser beiden Sprachebenen darstellt.

Neugriechisch wird durch eine 2006 in Athen erschienene Bibel in heutiger Standardsprache verkörpert; als liturgische Sprache des Ökumenischen Patriarchats von Konstantinopel sowie der Kirchen von Griechenland bzw. Zypern gilt jedoch weiterhin das Altgriechische (Koine).

Literaturtipp:

Schmitt, Rüdiger. Einführung in die griechischen Dialekte. - 2. Auflage. - Darmstadt, 1991

225 Südgriechisch auf Kreta, Melos, Thera: ohne Phi, Chi, Xi, Psi; ostgriechisch (a) in Kleinasien samt vorgelagerten Inseln außer Rhodos sowie auf der nördlichen Peloponnes samt den Kolonien: mit Phi, Chi; Xi, Psi; ostgriechisch (b) auf den nördlichen Kykladen und Attika: mit Phi und Chi, ohne Xi und Psi; westgriechisch auf dem restlichen griechischen Festland und Euboia samt den unteritalienischen Kolonien sowie auf Rhodos: mit Phi, Chi mit Lautwert ks und Psi mit Lautwert kh.

226 Mit einigen demotischen Zusatzzeichen.

227 Mit Zusatzzeichen und akrophonen Buchstabennamen aus dem Runenalphabet.

228 Über die Zwischenstufe der altitalischen Schriften, die wohl auch die Vorstufe der Runen bilden, aus einem westgriechischen Alphabet.

229 Saronisch, Westargolisch, Inseldorisch, Kretisch und Lakono-Messenisch.

230 Boiotisch, Thessalisch, Lesbisch. 


\section{Bibel. Neugriechisch. Griechische Schrift}

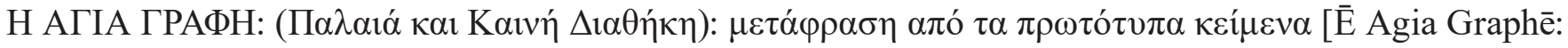
(Palaia kai Kainē Diathēkē): metaphrasē apo ta prōtotypa keimena] = The Holy Bible in today's Greek version. - Athen, 2008

NÖ Landesbibliothek, Signatur 134.014 B

\subsubsection{Albanisch}

Das Albanische wird zusammen mit dem Griechischen, dem Armenischen, den antiken Sprachen Makedonisch und Phrygisch, vielleicht auch Thrakisch und Illyrisch, zum Balkanindogermanischen gerechnet; seine oft behauptete Abstammung vom antiken Illyrischen ist nicht erwiesen. Mit dem Griechischen, Bulgarischen, Mazedonischen, dem torlakischen Dialekt des Serbokroatischen und dem Rumänischen bildet das Albanische den Balkansprachbund. In Nordalbanien und Mittelalbanien sowie im Kosovo und in angrenzenden Gebieten in Montenegro, Serbien und Nordmazedonien wird Gegisch, in Südalbanien hingegen Toskisch gesprochen; zum Toskischen gehören auch das Arvanitische in Griechenland und das Arbëresh in Mittel- und Süditalien einschließlich Sizilien. Die 1972 vereinheitlichte heutige Standardsprache beruht auf dem toskischen Dialekt. Die Mehrheit der auch Skipetaren oder Arnauten genannten Albaner gehört heute dem sunnitischen Islam an; trotzdem ist gerade der Nationalheld Skanderbeg, eigentlich Georg Kastrioti (1405-1468), seit 1423 als Geisel am Hof des türkischen Sultans zum Janitscharen erzogen und 1438 als Bey ${ }^{232}$ nach Albanien entsandt, in Verbindung mit seiner Machtergreifung in Albanien 1443 zum Katholizismus konvertiert und hat den Osmanen in der Folge erfolgreich getrotzt. Erst 1478, zehn Jahre nach Skanderbegs Tod, gelang ihnen die Eroberung Albaniens.

Auch die in Skopje geborene Mutter Teresa (1910-1997), war albanischer Abstammung, ebenso der in Venedig geborene Carl Ritter von Ghega (1802-1860), der Erbauer der Semmeringbahn.

\section{3}

\section{Bibel. Albanisch. Lateinische Schrift}

Bibla: dhiata e vjetër dhe dhiata e re = Albanian Bible. - Tirana, 2003

NÖ Landesbibliothek, Signatur 120.537 B 


\subsubsection{Armenisch}

Das Armenische, das in die Nähe des Griechischen und letztlich zum Balkanindogermanischen gestellt wird, soll nach Herodot vom Phrygischen abstammen, was diese Einordnung unterstützen würde. Nicht zu vernachlässigen ist dabei allerdings der Einfluss iranischer Sprachen auf das Armenische. Wie das Indoiranische, Baltische, Slawische und Albanische - nicht aber das Griechische - gehört Armenisch zu den Satem-Sprachen ${ }^{233}$, womit allerdings nicht unbedingt eine nähere Verwandtschaft, sondern lediglich eine vergleichbare Entwicklung bestimmter indogermanischer Laute angezeigt ist. ${ }^{234}$ Ähnlich wie die germanischen Sprachen ist das Armenische durch eine Lautverschiebung gekennzeichnet. Als klassische Sprachform gilt das seit dem siebzehnten Jahrhundert nach Christus überlieferte Altarmenische oder Grabar; diesem folgt das (kilikische) Mittelarmenisch und die heutigen Varietäten Ostarmenisch (in der Republik Armenien) und Westarmenisch (ursprünglich in Anatolien beheimatet, heute in der Diaspora). Westarmenisch weist gegenüber Ostarmenisch eine zweite westarmenische Lautverschiebung auf, wodurch die armenischen Mediae zu Tenues aspiratae (also z. B. $\mathrm{d} \mathrm{zu} \mathrm{t}^{\mathrm{h}}$ ) und die armenischen Tenues zu Mediae (also z. B. t zu d) verschoben wurden, was im Schriftbild allerdings nicht zum Ausdruck kommt.

Als Schrifterfinder der armenischen Schrift nach dem Vorbild der griechischen Schrift gilt Mesrop Maštoc' († 440 in Etschmiadsin); er war auch an der ersten armenischen Bibelübersetzung, die 435 fertiggestellt wurde, beteiligt.

Die Armenische Apostolische Kirche wurde der Legende nach bereits im Jahre 301 nach Christus durch den heiligen Gregor den Erleuchter († um 331) gegründet und als Staatsreligion etabliert. Diese Kirche zählt zu den vorchalzedonischen oder altorientalischen Kirchen und verfügt über Katholikate in Etschmiadsin sowie Sis (für Kilikien, heute in Antelias im Libanon) sowie Patriarchate in Jerusalem und Konstantinopel.

Durch den armenischen Ritus mit dieser Kirche verbunden ist die armenisch-katholische Kirche als unierter Zweig des Katholikats von Kilikien (Kleinarmenien). Mechitar von Sebaste (1676-1749) gründete 1701 in Konstantinopel eine Kongregation, die nach päpstlicher Bestätigung und Annahme der Regel des heiligen Benedikt den Ordensgründer Mechitar 1713 zum ersten Abt dieses nunmehr armenisch-katholischen Ordens wählte. Nach der Zerstörung ihres Klosters Methoni ${ }^{235} 1717$ im Zuge des Venezianisch-Österreichischen Türkenkrieges fand die Kongregation noch im gleichen Jahr eine neue Heimat auf San Lazzaro bei Venedig. 1772 entstand ein weiterer Ordenszweig in Triest, der sich infolge der Napoleonischen Kriege 1805 nach Wien begab und dort 1810 ein ehe-

233 Nach dem awestischen Wort für hundert satəm (aus indogermanisch *d kmtóm).

234 Die indogermanischen Labiovelare $\mathrm{k}^{\mathrm{w}}, \mathrm{g}^{\mathrm{w}}, \mathrm{g}^{\mathrm{wh}}$ verlieren ihr labiales Element und fallen daher mit den Velaren $\mathrm{k}$, $g$, $\mathrm{g}^{\mathrm{h}} \mathrm{zusammen}$; die indogermanischen Palatale k, g, g ${ }^{\mathrm{h}}$ entwickeln sich dagegen je nach Sprache zu postalveolaren oder alveolaren Affrikaten oder Frikativen; in den Kentum-Sprachen (Keltisch, Romanisch, Germanisch, Griechisch, aber auch Hethitisch oder Tocharisch) fallen hingegen die Palatale mit den Velaren zusammen. 235 Auf der Peloponnes, bis 1715 venezianisch. 
maliges Kapuzinerkloster erhielt. 2000 kam es zur Wiedervereinigung der beiden Ordenszweige; der Sitz des Generalabts befindet sich seitdem in Venedig.

Sowohl eine ostarmenische wie auch eine westarmenische Bibel können hier präsentiert werden.

\section{4}

Bibel. Ostarmenisch. Armenische Schrift

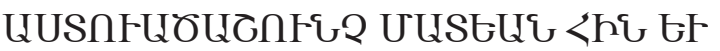

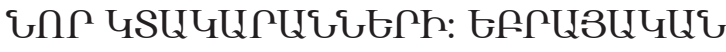

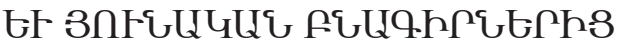
मLAQULGกFLO [Astuatsashunch' matean hin ew nor ktakaranneri: ebrayakan ew yunakan bnagirnerits' t'argmanuats] $=$ Bible in Armenian Modern Eastern (Ararat). Jerewan, 2003

NÖ Landesbibliothek, Signatur 119.717 B

125

Bibel. Westarmenisch. Armenische Schrift

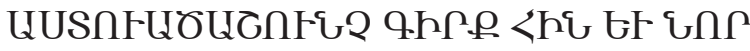
YSLYLPLGUERกF: GPRLBLYLU

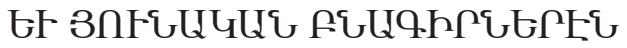
ALPQUUGกFUC [Astuatsashunch' girk' hin ew nor ktakaranneru: ebrayakan ew yunakan bnagirnerēn t'argmanuats] = Western Armenian Bible. - Beirut, 1981 NÖ Landesbibliothek, Signatur 119.716 B Abb. 36

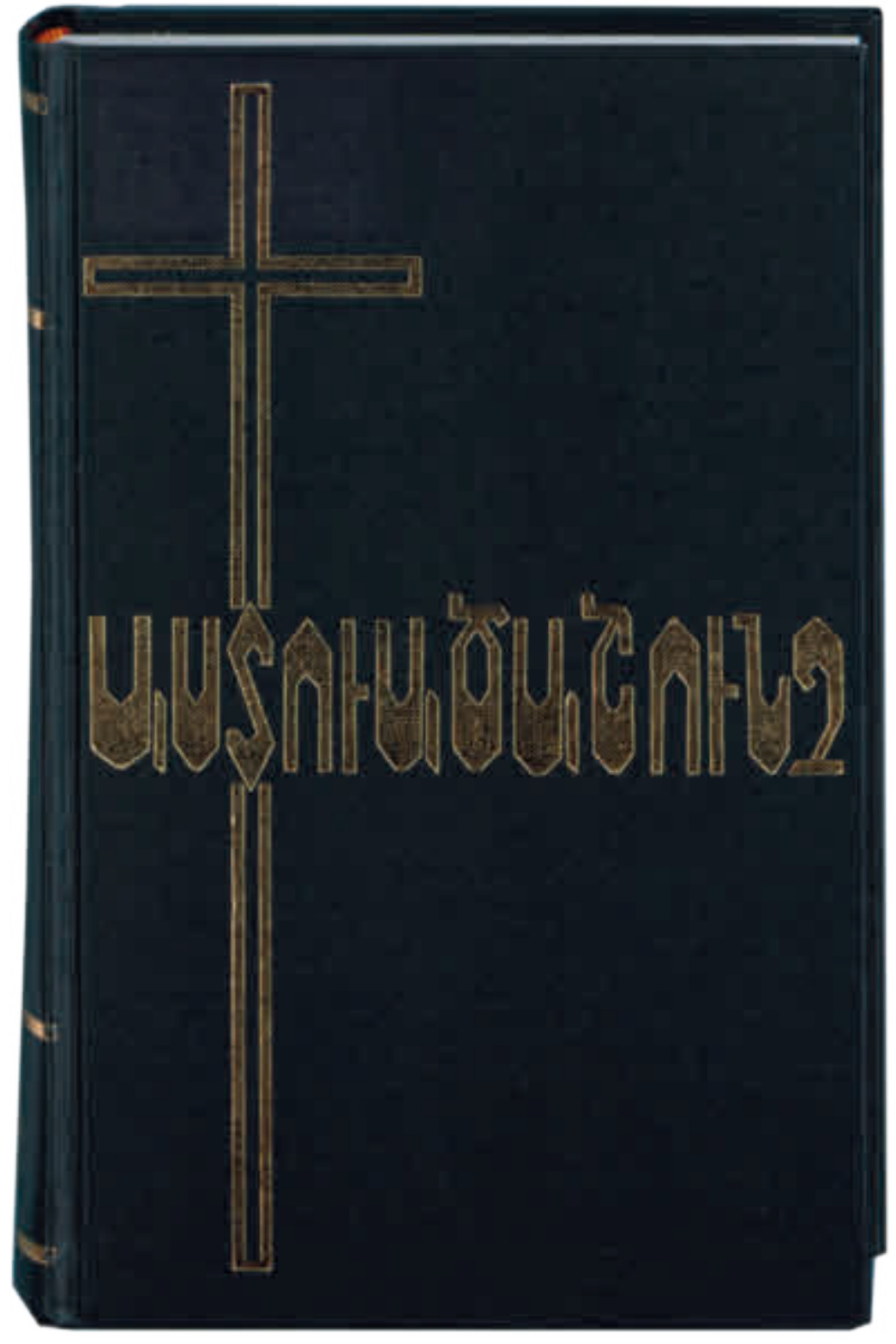

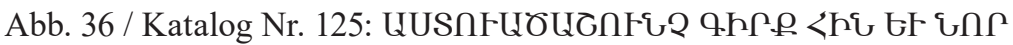

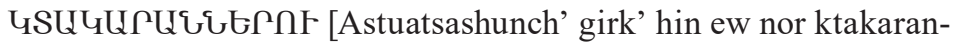
neru $]=$ Western Armenian Bible (1981). 


\subsubsection{Indoiranische Sprachen}

Dieser Zweig des Indogermanischen umfasst die iranischen Sprachen, die hier nicht vertretenen NuristaniSprachen und die indoarischen Sprachen. Das Indoiranische (oder, nach der Eigenbezeichnung seiner Sprecher, Arische) gehört zu den sogenannten Satem-Sprachen: Die indogermanischen Labiovelare fallen nach dem Verlust ihres labialen Elements mit den indogermanischen Velaren zusammen; die Palatale werden (zunächst) zu Affrikaten weiterentwickelt. Die Velare samt den damit zusammengefallenen Labiovelaren werden vor ursprünglichem e ebenso wie vor i sekundär palatalisiert. Erst danach kann der indoiranische Zusammenfall der Vokale a, e, o und der sonantischen Nasale zu a ${ }^{236}$ sowie $\bar{a}, \bar{e}, \bar{o}$ zu ā erfolgt sein; Laryngale in interkonsonantischer Stellung werden allerdings als i vokalisiert, zum Teil verschwinden sie sogar völlig. ${ }^{237}$ Die Liquiden sind instabil; in den meisten Sprachen fallen sie zusammen, meist sind sie als $\mathrm{r}$ vertreten. ${ }^{238} \mathrm{Sehr}$ alt ist vermutlich die sogenannte Ruki-Regel, wonach s nach $\mathrm{r}$, $\mathrm{u}, \mathrm{k}$ oder i zu š ${ }^{239}$ verschoben wird, weil diese Regel auch für das Baltische und Slawische (letzteres mit dem Ergebnis $\chi$ ) zutrifft.

\subsubsection{Iranische Sprachen}

Die iranischen Sprachen ${ }^{240}$ unterscheiden sich von den indoarischen Sprachen unter anderem durch den $\mathrm{Zu}$ sammenfall der ursprünglichen Mediae aspiratae mit den Mediae (bh, dh, gh usw. zu b, d, g); auffällig ist auch die Entwicklung von Tenuis ( $\mathrm{p}, \mathrm{t}, \mathrm{k}$ ) zum stimmlosen Reibelaut ( $\mathrm{f}, \mathrm{P}, \chi$ ) vor Konsonant ${ }^{241}$ und die weitgehende Entwicklung von s zu h; ${ }^{242}$ die Vertretung der indogermanischen Palatale $* \hat{\mathrm{k}},{ }^{*} \mathrm{~g}$, ${ }^{*} \mathrm{~g}{ }^{\mathrm{h}}$ wird gegenüber indoarisch

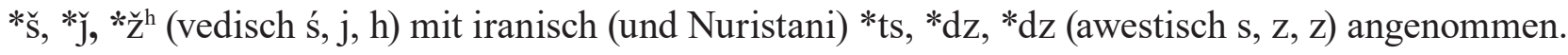

Die iranischen Sprachen werden einerseits in altiranische, mitteliranische und neuiranische Sprachen, andererseits in west- und ostiranische oder noch präziser in nordwest-, südwest-, nordost- und südostiranische Sprachen gegliedert. An bedeutenderen Sprachen sind für das Altiranische Medisch † (nordwestiranisch), Altpersisch ${ }^{243}$

236 Vgl. Mahārāja magnus rex. Mit der Einschränkung: o in ursprünglich offener Silbe zu ā.

237 Vgl. altawestisch $(p) t \bar{a}=$ jungawestisch $p(i) t a$, altpersisch pitāa, vedisch pitá zu lateinisch pater, griechisch patếr, germanisch fađer, indogermanisch *ph $h^{2} t \bar{e} r$.

238 Ein lehrreiches Beispiel ist Sanskrit cákra-, vgl. dazu griechisch kýklos und englisch wheel (Rad) zu indogermanisch * $k^{w} e k^{w} l o s$, womit die Wandel indoiranisch $\mathrm{k}^{\mathrm{w}} \mathrm{zu} \mathrm{k}$ und weiter zu č (vor e), später e zu a sowie 1 zu r gezeigt sind; englisch wheel geht auf das zu erwartende germanische *hwehwlaz zurück.

239 Altindisch: ș.

240 Iran aus altpersisch Aryānam, (Land der) Arier.

241 Z. B. awestisch friia- gegenüber vedisch priyá- (lieb).

242 Z. B. jungawestisch hapta gegenüber vedisch saptá (sieben), vgl. griechisch heptá

243 Die Sprache der Achaimeniden, in der im Auftrag von Dareios I. entwickelten und 1802 von Georg Friedrich Grotefend entzifferten altpersischen Keilschrift geschrieben, allerdings nicht die Verwaltungssprache des Perserreiches (dies war Reichsaramäisch). 
$\dagger$ (südwestiranisch), Awestisch ${ }^{244} \dagger$ und Skythisch $\dagger$ (beide ostiranisch) zu nennen, für das Mitteliranische Parthisch $^{245} \dagger$ (nordwestiranisch), Mittelpersisch oder Pahlavi ${ }^{246} \dagger$ (südwestiranisch), Baktrisch $\dagger$, Choresmisch $\dagger$, Sogdisch $\uparrow$, Sarmatisch $\uparrow$ inklusive Alanisch $\uparrow$ sowie Sakisch $\uparrow$ (alle ostiranisch) und für das Neuiranische Kur$\operatorname{disch}^{247}$ nebst Zazaki ${ }^{248}$ und Gorani sowie Belutschisch (jeweils nordwestiranisch), Persisch ${ }^{249}$ (südwestiranisch), Ossetisch $^{250}$ und Jaghnobisch ${ }^{251}$ (jeweils nordostiranisch) sowie Paschto (südostiranisch) zu nennen.

Das Persische ist mit einer Bibel vertreten, Nordkurdisch (Kurmandschi) und Zentralkurdisch (Sorani) werden jeweils durch ein Neues Testament vorgestellt.

Besondere Beachtung verdient ein Büchlein über den Ablauf der katholischen Messe in persischer Sprache samt lateinischer Umschrift und deutschem Paralleltext, das 2018 in Heiligenkreuz erschienen ist. Die Übersetzerin Anna Maria (Nahid) Jalalifar, ${ }^{252}$ als Flüchtling nach Österreich gekommen, ist zum Katholizismus konvertiert und hat in der Folge ein Theologiestudium abgeschlossen.

\section{6}

\section{Bibel. Persisch (Fārsī). Arabische Schrift}

[Kitāb-i Muqaddas] = The Holy Bible, Today’s Persian Version. - 2007

NÖ Landesbibliothek, Signatur 123.490 B

Abb. 37

244 Die Sprache Zarathustras, benannt nach dem „Avesta“, den heiligen Texten der Zoroastrier. Man unterscheidet Altawestisch oder Gāthā-Awestisch, die eigentliche Sprache Zarathustras, in der drei heilige Gebete, 17 zu insgesamt 5 Gāthās zusammengefasste Gedichte und der Prosatext ,Yasna Haptanhāiti“ (Buch „Yasna“ 27,13-54,1, mit Ausnahmen, vor allem Yasna 42 und Yasna 52) vorliegen, und Jungawestisch, das nicht nur jünger ist, sondern auch auf einem anderen Dialekt beruht und in dem alle anderen Partien des „Avesta“ abgefasst sind. Die Handschriften sind lange nach der Entstehung der enthaltenen Texte in der von der Pahlavi-Schrift, einer Variante der aramäischen Schrift, abgeleiteten awestischen Schrift aufgezeichnet worden.

245 Im Partherreich der Arsakiden.

246 Im Sassanidenreich.

247 Nordkurdisch oder Kurmandschi, vor allem in der Türkei gesprochen und überwiegend in lateinischer Schrift geschrieben, Zentralkurdisch oder Sorani im Irak und Iran und überwiegend in arabischer Schrift geschrieben, Südkurdisch.

248 Möglicherweise ein Nachfahre des Parthischen.

249 Zum Persischen (Fārsi) gehört auch das Dari in Afghanistan und das in kyrillischer Schrift geschriebene Tadschikisch.

250 Im Kaukasus, mit den Dialekten Iron und Digor, kyrillische Schrift, Nachfahre des Alanischen.

251 Letzter Rest des Sogdischen.

252 In der NÖ Landesbibliothek sind bereits fünf Publikationen von Anna Maria Jalalifar vorhanden. 


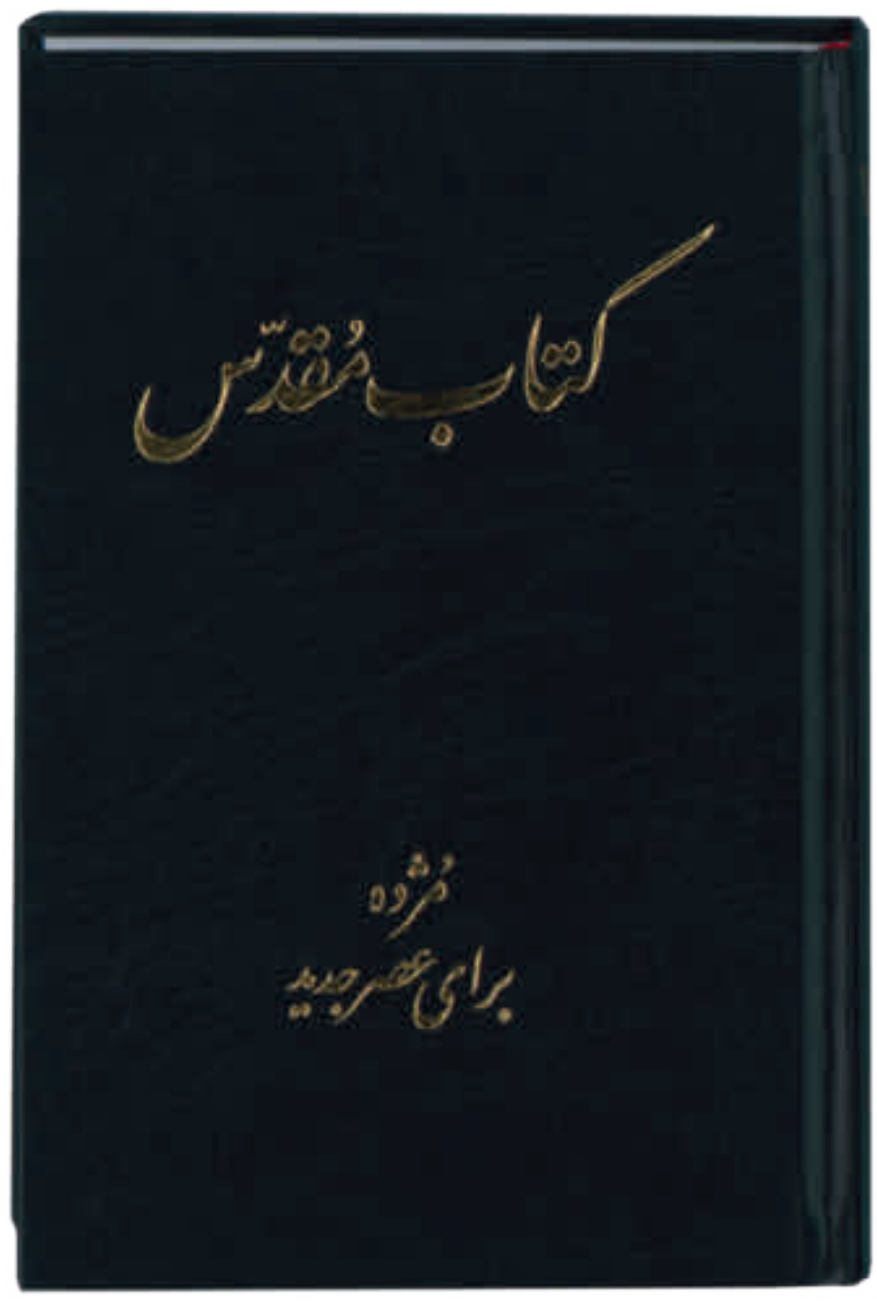

Abb. 37 / Katalog Nr. 126: كتاب مُقدّس [Kitāb-i Muqaddas] $=$ The Holy Bible. Today's Persian Version (2007).

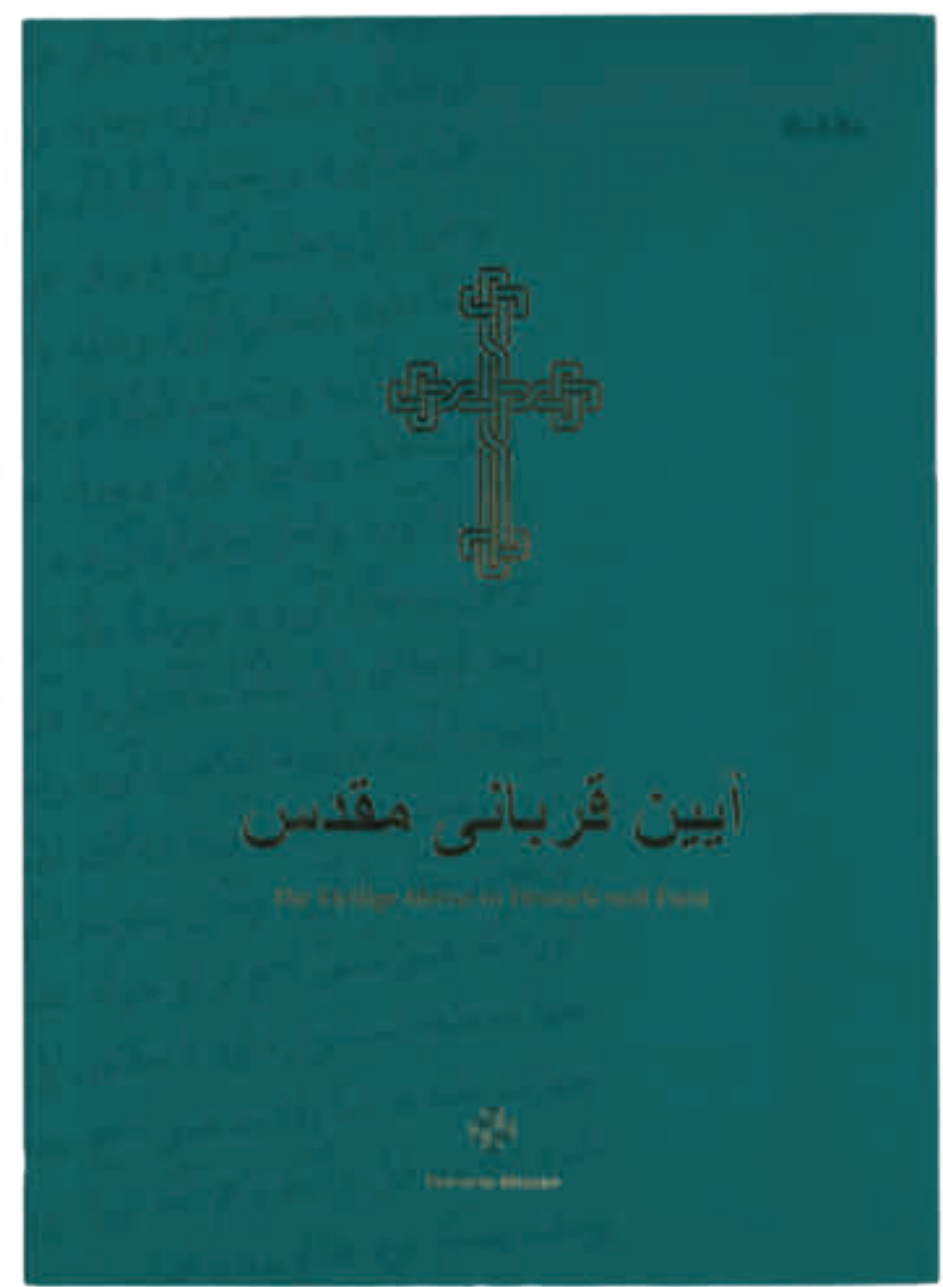

Abb. 38 / Katalog Nr. 127: Jalalifar N. Anna Maria (Übers.), آيين قربانى مقدس [Āyīn-i qurbānī muqaddas] = Die Heilige Messe in persischer Sprache mit deutscher Umschrift (2018). 
آيين قربانى مقدس [Āyīn-i qurbānī muqaddas] = Die Heilige Messe in persischer Sprache mit deutscher

Umschrift: der Messritus der katholischen Kirche / übersetzt von Mag. theol. Jalalifar N. Anna Maria. -

Heiligenkreuz, 2018. - (Edition Missio)

NÖ Landesbibliothek, Signatur 192.729 B

Abb. 38

\section{8}

Bibel. Neues Testament. Kurmandschi. Lateinische Schrift

Încîl: (Mizgînî). - Istanbul, 2005

NÖ Landesbibliothek, Signatur 133.666 B

129

Bibel. Neues Testament. Soranī. Arabische Schrift

[Injil-i piroz Mizgini: Payman-i Noy-i Hazrat-i Isa ba-shywa-y Kurdi Sorani] = Kurdish New Testament (Sorani). - Colorado Springs, Colo., 2004

NÖ Landesbibliothek, Signatur 134.009 B

\subsubsection{Indoarische Sprachen}

Zu den indoarischen Sprachen ${ }^{253}$ zählt in diachroner Betrachtung zunächst das Altindoarische (Altindische), zuerst in der Form Vedisch ${ }^{254}$ überliefert. Eine frühe Nebenüberlieferung stammt aus dem hurritischen Mittani-Reich ${ }^{255}$. Das Vedische näherte sich allmählich der Sprachform des klassischen Sanskrit, das durch den Grammatiker Pāṇini um 400 vor Christus kodifiziert wurde, zu einer Zeit, als bereits mittelindische Sprachen (Prakrits) gesprochen

253 Unpräziser: indischen.

254 Nach den heiligen Schriften Indiens, den „Veden“ oder dem „Veda“ (Wissen). Zur Wortsippe vgl. lateinisch vidēre (sehen) und dessen 1. Person Singular Perfekt $v \bar{\imath} d \bar{l}$, griechisch oida, Sanskrit veda, deutsch ich weiß (ich habe gesehen). Man unterscheidet den Rigveda, den Samaveda, den Yajurveda und den Atharvaveda. Der Rigveda ist der älteste und besteht im Kern (der Rigveda-Samhita) aus 1.028 Hymnen an Götter, eingeteilt in zehn Mandalas (Liederkreise), die sprachlich bis 1200 vor Christus zurückreichen. Neben den Samhitas ( Synthesis) bilden Brahmanas, Aranyakas und Upanishaden weitere (Prosa-)Textschichten der Teile des „Veda“. Kennzeichen des Vedischen gegenüber dem Sanskrit sind vor allem das Betonungssystem sowie ein größerer morphologischer Reichtum (Konjunktiv, Injunktiv, zahlreiche Infinitivbildungen usw.).

255 Auch Mitanni, Mittanni oder Hanigalbat, im syrischen Großraum des fünfzehnten bis dreizehnten vorchristlichen Jahrhunderts, Hauptstädte Waššukanni und Taite. Es finden sich altindoarische Sprachspuren: Königsnamen wie Artatama, die Götternamen Indra, Mitra, Varuna und die beiden Nasatyas, hippologische Fachtermini (unter anderem im Werk des Kikkuli). Wegen des hohen Alters des Mitanni-Indoarischen muss mit einer Einwanderung noch vor oder gleichzeitig mit dem Eindringen der Indoarier nach Indien gerechnet werden. 
wurden. Bedeutende Werke der Sanskritliteratur sind die beiden Epen „Mahabharata“ (mit der „Bhagavadgita“) und „Ramayana“; auch der Dramatiker Kalidasa ${ }^{256}$ hat mit „Shakuntala“ einen festen Platz in der Weltliteratur.

$\mathrm{Zu}$ den soeben erwähnten mittelindischen Sprachen ${ }^{257}$, die natürlich keine Nachfolger der literarischen Sprachformen Vedisch und Sanskrit, sondern nicht schriftlich überlieferter verwandter Volkssprachen sind, gehört vor allem Pạ̣̄i, die Sprache der frühen Schriften des Buddhismus. ${ }^{258}$ Ein frühes Zeugnis verschiedener Prakrits und zugleich der Beginn der Schriftlichkeit in Indien sind die in vielen Teilen Indiens auf Felsen oder Säulen angebrachten Edikte des buddhistischen Kaisers Aśoka (304-232 vor Christus) aus der von Candragupta Maurya begründeten Dynastie, die ihr Machtzentrum in Magadha mit der Hauptstadt Pataliputra hatte. Außer Pāli sind die Sprachen Gāndhārī, Śaurasen̄̄, Ardhamāgadh̄̄, Māgadh̄̄, Mahārāșțri und Eḷu zu nennen. Die Sprachstufe der verschiedenen Prakrits am Übergang zu den neuindischen Sprachen wird als Apabhramsa bezeichnet.

An Schriften ist zunächst die auf die aramäische Schrift zurückführbare Kharoșțhī-Schrift zu nennen, die im Wesentlichen lediglich für die Sprache Gāndhārī im Nordwesten des indoarischen Sprachraums verwendet wurde. Die zeitgleich verwendete Brāhmī-Schrift stellt den Anfangspunkt des indischen Schriftenkreises dar; auch für sie wird zumindest eine Vorbildwirkung der aramäischen Schrift angenommen. Bei den indischen Schriften handelt es sich um sogenannte Abugidas, die neben reinen Vokalzeichen Zeichen für die Gruppe Konsonant + a aufweisen; andere Vokale oder Vokallosigkeit werden mit entsprechenden diakritischen Zeichen angezeigt, wobei für Konsonantengruppen auch Ligaturen gebräuchlich sind. Zu nennen ist zunächst die Devanāgarī-Schrift, die heute außer für Hindi für weitere Sprachen wie Nepali, Kashmiri, Marathi und Konkani und insbesondere für Sanskrit verwendet wird, das früher auch in anderen indischen Schriften aufgezeichnet wurde. Für weitere indoarische Sprachen werden die bengalische Schrift, die Oriya-Schrift, die Gujarati-Schrift, die Gurmukhi-Schrift ${ }^{259}$ und die singhalesische Schrift verwendet; darüber hinaus gehören unter anderem die tibetische Schrift, die Khmer-Schrift, die thailändische Schrift, die laotische Schrift, die birmanische Schrift, die Tamil-Schrift, die Malayalam-Schrift, die Kannada-Schrift und die Telugu-Schrift zum indischen Schriftenkreis.

$\mathrm{Zu}$ den wichtigsten neuindischen Sprachen zählen Hindi und $\mathrm{Urdu}^{260}$ (a) zentralindisch), Kashmiri (b) dardisch), Nepali (c) nordindisch oder Pahari), Sindhi, Lahnda (besonders Hindko und Saraiki) und Panjabi (d) nordwestindisch), Rajasthani (besonders Marwari) und Gujarati (e) westindisch), Bengali, Assami, Oriya und Bihari, also

256 Ende des vierten bis Beginn des fünften nachchristlichen Jahrhunderts.

$257 \mathrm{Zu}$ den Kennzeichen gehört neben dem Zusammenfall der verschiedenen Sibilanten ś, ș, s die Entwicklung von Konsonantengruppen zu Doppelkonsonanten, z. B. Pāḷi ațtha gegenüber Sanskrit aștá (acht).

258 Der Pali-Kanon wird auch Tipițaka (Pali) bzw. Tripitaka (Sanskrit) „Dreikorb“ genannt.

259 Für die Sprache Panjabi.

260 In arabischer Schrift geschrieben, Sprache muslimischer Inder und Amtssprache Pakistans. 
Bhojpuri, Maithili und Magahi (f) ostindisch), Marathi und Konkani (g) südindisch), Singhalesisch und Divehi ${ }^{261}$, Romani, Domari ${ }^{262}$ und Lomavren ${ }^{263}$.

Dem heute in weiten Teilen Europas verbreiteten Romani wird eine zentralindische Herkunft und eine spätere Beeinflussung durch nordwestindische Sprachen zugeschrieben. Sicher ist auch ein mittelgriechischer (byzantinischer) Einfluss, wie man beispielsweise an den übernommenen Zahlwörtern efta (sieben), ochto (acht) und enja (neun) ersehen kann; das Vlach-Romani ist zusätzlich durch die Kontaktsprache Rumänisch geprägt. Man unterscheidet die nordwestlichen (Sinti-Manuš ${ }^{264}$ sowie Kaale ${ }^{265}$ ) und nordöstlichen Dialekte ${ }^{266}$, die nördlichen zentralen $^{267}$ und südlichen zentralen Dialekte (mit dem Burgenland-Romani [Roman], dem Vend-Romani ${ }^{268}$, dem Prekmurje-Romani ${ }^{269}$ und den Romungro-Dialekten ${ }^{270}$ ), die Balkan-Dialekte und Zis-Dialekte, die Nordvlach-271 und die Südvlach-Dialekte.

Als Kuriosität wird zunächst ein Neues Testament in Sanskrit präsentiert, das schließlich ähnlich wie Latein eine tote Sprache darstellt, sodass das Motiv der Übersetzung nur im hohen Prestige dieser Sprache in Indien gesehen werden kann: Sanskrit ist eine der 22 offiziellen und zugleich eine der 6 klassischen Sprachen Indiens. Wie auch die ebenfalls vorgestellte Bibel in Hindi, der nach Englisch und Chinesisch drittgrößten Sprache der Welt, stellt das Neue Testament in Sanskrit zugleich ein Beispiel für die Devanāgarī-Schrift dar. Das Gegenstück zu Hindi bildet das in arabischer Schrift geschriebene Urdu in Pakistan. Die wichtigste indoarische Sprache nach Hindi und Urdu ist das Bengali mit der ihm eigenen bengalischen Schrift; es wird in Bangladesch und im indischen Bundesstaat Westbengalen gesprochen. Ein bemerkenswertes Exponat ist die in Ungarn approbierte katholische Bibel in Lovara-Romani (Lovari), übersetzt von Zoltán Vesho-Farkas (* 1974); dies ist die erste vollständige Bibel in einer Varietät des Romani, womit zugleich der Sprung zur Schriftsprachlichkeit geschafft ist. Abgerundet wird der Bereich der indoarischen Sprachen durch die 2004 erschienene deutschsprachige Kinderbibel „Gott spricht zu seinen Kindern“ von Eleonore Beck (1926-2014), der eine 2008 erschienene Übersetzung in das Burgenland-Romani (Roman) gegenübergestellt ist; ${ }^{272}$ dies verkörpert nicht nur dieses Idiom, sondern auch die

261 Auf den Malediven, mit der vom arabischen Alphabet abgeleiteten Schrift Thaana.

262 Im Nahen Osten.

263 Im Raum Armenien.

264 In Frankreich, den Niederlanden, Belgien, Deutschland, Österreich und Italien.

265 In Schweden und Finnland.

266 In Russland, Ukraine, Weißrussland, Polen, Estland, Lettland, Litauen.

267 In Polen, Tschechien, der Slowakei und der Ukraine.

268 In Ungarn.

269 In Slowenien.

270 In Ungarn und der Slowakei.

271 Mit den Dialekten Kalderaš (Kupferschmied) und Lovari (Pferdehändler).

272 Katalog Nr. 135 und 136. 


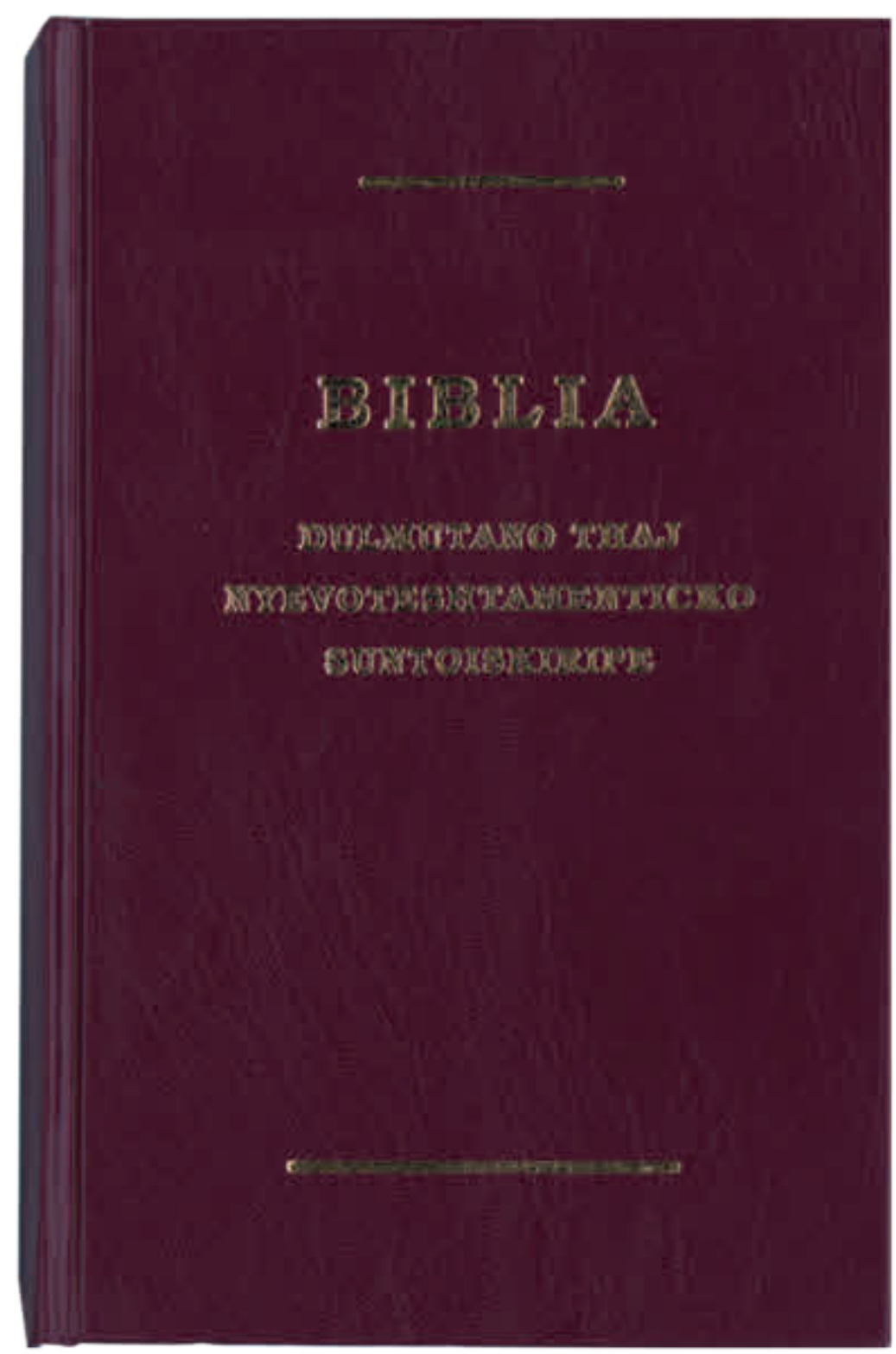

Literaturgattung der Kinderbibeln und stellt zugleich eine Rückkehr aus dem fernen Indien in heimatliche Gefilde dar.

\section{0}

Bibel. Neues Testament. Sanskrit.

Devanagari-Schrift

धर्म्मपुस्तकस्य शेषांशः । अर्थतः । प्रभुणा यीशुख्रीष्टेन निरूप पितस्य नूतनधम्मीन नियस्य ग्रन्थसड्ग्रहः । [Dharmmapustakasya śeșāmśah arthatah Prabhuṇā Yīśukhrīṣtena nirūpitasya nūtanadharmmaniyamasya granthasangrahah] $=$ The New Testament Sanskrit. - Bangalore, [2000?]

NÖ Landesbibliothek, Signatur 122.723 B

131

Bibel. Hindi. Devanagari-Schrift पवित्र बाइबल अर्थात् पुराना और नया धर्म नियम [Pavitra bāibala arthāt purānā aura nayā dharma niyama] $=$ The Holy Bible Hindi O.V. - Bangalore, [2007?]

NÖ Landesbibliothek, Signatur 133.299 B

132

Bibel. Urdu. Arabische Schrift

[Kitāb-i muqaddas] = The Holy Bible Urdu (Persian) O.V. - Bangalore, 2008 NÖ Landesbibliothek, Signatur 134.008 B

Abb. 39 / Katalog Nr. 134: Vesho-Farkas Zoltán (Übers.), Biblia: Dulmutano thaj Nyevoteshtamenticko Suntoiskiripe (2008). 
133

Bibel. Bengali. Bengalische Schrift পবিত্র বাইবেল: পুরাতন ও নূতন নিয়ম। [Pabitra bāibela: purātana o nūtana niỷama] $=$ The Holy Bible Bengali O.V - - Bangalore, [2002?]

NÖ Landesbibliothek, Signatur 123.489 B

\section{4}

Bibel. Lovari. Lateinische Schrift

Biblia: Dulmutano thaj Nyevoteshtamenticko Suntoiskiripe / boldasles: Vesho-Farkas Zoltán = Ó- és Újszövetségi Szentírás. Budapest, 2008

NÖ Landesbibliothek, Signatur 137.085 B Abb. 39

\section{5}

Beck, Eleonore, 1926-2014. Gott spricht zu seinen Kindern

O Del use pre fatschuvtscha vakerel: pisintschago andar i Biblina

/ khangeri andi briga Kirche in Not/ Ostpriesterhilfe; [Teksti: Eleonore Beck]; [Kipi: Miren Sorne]; [Prik bescharipe: Emmerich Gärtner-Horvath]. - Ed. en Burgenland-roman (Bbur/1). - Königstein im Taunus, 2008

NÖ Landesbibliothek, Signatur 131.072 B Abb. 40

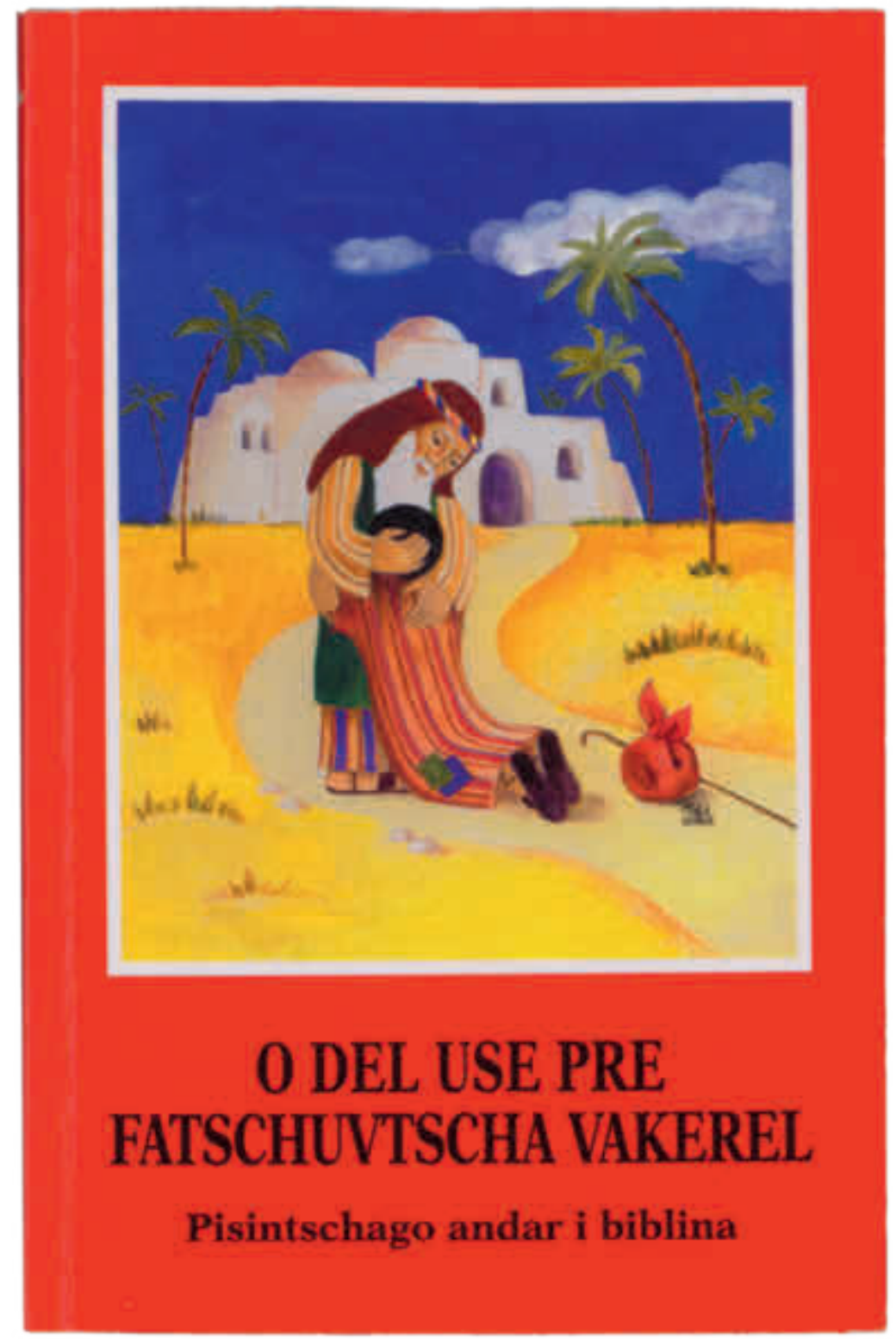

Abb. 40 / Katalog Nr. 135: Eleonore Beck, O Del use pre fatschuvtscha vakerel: pisintschago andar i Biblina (2008). 


\section{Beck, Eleonore, 1926-2014. Gott spricht zu seinen Kindern}

Gott spricht zu seinen Kindern: Texte aus der Bibel / herausgegeben vom Internationalen Katholischen Hilfswerk Kirche in Not/Ostpriesterhilfe; [Text: Eleonore Beck]; [Bilder: Miren Sorne]. - Königstein im Taunus, 2004

NÖ Landesbibliothek, Signatur 131.308 B

\subsection{Drawidische Sprachen}

Wohl schon vor der Einwanderung indoarisch sprechender Gruppen im zweiten vorchristlichen Jahrtausend siedelten die auf den indischen Subkontinent beschränkten Sprecher drawidischer Sprachen in diesem Raum; sie sind offenbar von den aus dem Nordwesten vorstoßenden Einwanderergruppen nach Süden abgedrängt worden. Neben den indoarischen und den drawidischen Sprachen existieren weitere Sprachen in Indien: Sie gehören teils zur sinotibetischen (tibetobirmanischen) Sprachfamilie, teils zur Gruppe der Munda-Sprachen ${ }^{273}$ innerhalb des Austroasiatischen; isoliert oder nicht klassifiziert sind das Nahali (Nihali, Kalto) in Indien, das Kusunda in Nepal und das Burushaski im Karakorumgebirge im nördlichen Pakistan. Nicht bewiesen ist die Annahme einer Verwandtschaft des altorientalischen Elamischen im südwestlichen Iran ${ }^{274}$ mit den drawidischen Sprachen, ebenso die mangels Entzifferung der Indus-Schrift nicht überprüfbare Annahme einer Beziehung zur Indus-Kultur. Typologisch lassen sich die drawidischen Sprachen als suffigierend und agglutinierend ${ }^{275}$ beschreiben. Vom weit entfernten Brahui in Pakistan (Belutschistan) abgesehen, werden die meisten heutigen Drawida-Sprachen in Südindien gesprochen; bedeutend sind Telugu ${ }^{276}$, Kannada (Kanaresisch) ${ }^{277}$, Tamil (Tamilisch) ${ }^{278}$ und das damit nahverwandte Malayalam ${ }^{279}$, die alle zu den klassischen Sprachen Indiens zählen und jeweils über eine eigene Schrift aus dem indischen Schriftenkreis verfügen.

Neben dem als Drawida-Sprache par excellence anzusehenden Tamil sind die drawidischen Sprachen durch Malayalam vertreten, letzteres mit Rücksicht auf den Umstand, dass die sogenannten Thomaschristen in Indien

273 Die bedeutendste dieser Sprachen ist Santali.

274 Zentrum: Susa.

275 Als agglutinierend werden Sprachen bezeichnet, die grammatische Funktionen durch Affixe (angefügte unselbständige Bestandteile zur Erweiterung eines Wortes) ausdrücken; der Unterschied zu flektierenden Sprachen besteht darin, dass die Affixe nicht mehrere grammatische Kategorien gleichzeitig kennzeichnen (wie z. B. das -s im deutschen Vater-s Genetiv, Singular und maskulin repräsentiert) und der Wortstamm in der Regel nicht verändert wird (wie z. B. bei deutsch sing-en/sang/ge-sung-en). Sofern diese Affixe an das Wortende treten, spricht man von Suffixen (im Gegensatz zu Präfixen am Wortanfang).

276 In Andhra Pradesh und Telangana.

277 In Karnataka.

278 In Tamil Nadu und auf Sri Lanka (neben dem indoarischen Singhalesisch), mit einer über zweitausendjährigen Literaturtradition, an deren Beginn der grammatische Text „Tolkāppiyam” steht. 
untrennbar mit dem Bundesstaat Kerala und der Sprache Malayalam verbunden sind. Es handelt sich um eine zunächst dem ostsyrischen Ritus ${ }^{280}$ zugehörige Kirche mit einer später entstandenen westsyrischen Abspaltung; die teilweise Union mit der römisch-katholischen Kirche bzw. der anglikanischen Kirche sowie erlangte Autokephalie ergibt heute mehrere Kirchen: die Syro-malabarische Katholische Kirche ${ }^{281}$, die Metropolie von Malabar und Ganz Indien ${ }^{282}$, die Malankara Syrisch-Orthodoxe Kirche ${ }^{283}$, die Indisch-Orthodoxe Kirche ${ }^{284}$, die SyroMalankara Katholische Kirche ${ }^{285}$ und die Mar-Thoma-Kirche ${ }^{286}$.

\section{7}

\section{Bibel. Malayalam (New India Bible version). Malayalam-Schrift}

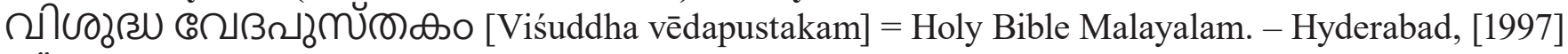

NÖ Landesbibliothek, Signatur 123.491 B

\section{8}

\section{Bibel. Tamil. Tamil-Schrift}

பழைய ஏற்பாடிம் புதிய ஏற்பாடிம் அடங்கிய பரிசுத்த வேதாகமம்: இது எபிரேயு கிரேக்கு என்னும் மூல பாஷைகளிலிருந்து தமிழில் மொழிபெயர்க்கப்பட்டது [Palaiya ērpāṭum putiya êrpāțum ațankiya paricutta vētākamam: itu epirēyu kirēkku ennñum mūla pāṣaikaliiliruntu tamilil molipeyarkkappattatu] $=$ The Holy Bible Tamil. - Bangalore, [2008?]

NÖ Landesbibliothek, Signatur 134.160 B

\subsection{Uralische Sprachen}

Neben dem Baskischen und den indogermanischen Sprachen stellen die uralischen Sprachen die dritte bodenständige Gruppe europäischer Sprachen dar. Typologisch sind sie als agglutinierende Sprachen einzustufen, in

\footnotetext{
280 Siehe dazu die Erläuterungen zu Syrisch.

281 Ostsyrischer Ritus, Großerzbistum Ernakulam-Angamaly, mit ca. vier Mio. Gläubigen.

282 Ostsyrischer Ritus, Metropolie der Assyrischen Kirche des Ostens, mit ca. 0,5 Mio. Gläubigen.

283 Westsyrischer Ritus, Katholikat von Indien der Syrisch-Orthodoxen Kirche von Antiochien, mit ca. 3,5 Mio. Gläubigen.

284 Auch Indische Orthodoxe Kirche oder Malankara Orthodox-Syrische Kirche, Westsyrischer Ritus, unabhängige Kirche, mit ca. 2,5 Mio. Gläubigen.

285 Westsyrischer Ritus, Großerzbistum Trivandrum, mit ca. 500.000 Gläubigen

286 Auch Malankara Mar Thoma Syrian Church, Westsyrischer Ritus, Kommunionsgemeinschaft mit der anglikanischen und altkatholischen Kirche, mit ca. 1 Mio. Gläubigen, 1952 Abspaltung der St. Thomas Evangelical Church of India (ca. 50.000 Gläubige).
} 
mehreren Sprachen herrscht Vokalharmonie ${ }^{287}$ oder Stufenwechsel, ein grammatisches Genus fehlt ebenso wie eine Kongruenz zwischen Substantiven und Adjektiven. Meist wird eine Zweiteilung in finno-ugrische Sprachen einerseits und samojedische Sprachen andererseits angenommen, häufig auch eine verwandtschaftliche Beziehung zu dem außerhalb stehenden Jukagirischen; zum Indogermanischen und besonders zum Indoiranischen bestehen Lehnbeziehungen. Zum Samojedischen zählen vor allem Nenzisch und Selkupisch, die finno-ugrischen Sprachen gliedern sich in die Gruppen Ugrisch (Ungarisch und Ob-Ugrisch ${ }^{288}$ ) und Finno-Permisch (Samisch ${ }^{289}$, Ostseefinnisch ${ }^{290}$, Mordwinisch ${ }^{291}$, Mari $^{292}$ und Permisch ${ }^{293}$ ).

Einige Wortgleichungen: finnisch kota (Haus, Hütte), kala (Fisch), kolme (drei) entspricht ungarisch ház, hal, három.

Die Sprecher des Ungarischen, der größten der uralischen Sprachen, sind wahrscheinlich aus einem früheren Wohnsitz im heutigen Baschkirien nach Westen vorgestoßen und haben Ende des neunten Jahrhunderts nach Christus unter Fürst Árpád (* um 845, † um 907) die Landnahme im heutigen Ungarn durchgeführt. Die zunächst verwendete linksläufige altungarische Schrift (ungarische Runen) ist vielleicht mit den Orchon-Runen verwandt; nach der Gründungsurkunde des Klosters Tihany, einem lateinischen Text mit einzelnen Magyarismen, stellt die Leichenrede „halotti beszéd“ vom Ende des zwölften Jahrhunderts das älteste ungarische Schriftdenkmal dar.

Neben den drei Nationalsprachen Ungarisch, Finnisch und Estnisch ist auch das Nordsamische vertreten.

\section{9}

\section{Bibel. Finnisch. Lateinische Schrift}

Pyhä Raamattu: Vanha Testamentti Uusi Testamentti: Suomen Evankelis-Luterilaisen Kirkon kirkolliskokouksen vuonna 1992 käyttöön ottama suomennos. - Helsinki, 2006

NÖ Landesbibliothek, Signatur 120.538 B

287 Vgl. z. B. ungarisch vízben gegenüber házban zu víz (Wasser) und ház (Haus).

288 Chantisch oder Ostjakisch und Mansisch oder Wogulisch, in Westsibirien.

289 Nordsamisch (Nordsaamisch) mit 15.000 bis 25.000 Sprechern in Norwegen, Schweden und Finnland und die kleineren Sprachen Lulesamisch, Pitesamisch, Umesamisch, Südsamisch, Inarisamisch, Skoltsamisch, Kildinsamisch, Tersamisch; ausgestorben sind Akkalasamisch und Kemisamisch. Wie das Finnische sind auch die samischen Sprachen durch die Erscheinung des Stufenwechsels gekennzeichnet (vgl. finnisch Nominativ kukka - Genetiv kukan (Blume), Nominativ katu - Genetiv kadun [Straße]).

290 Finnisch nebst Ingrisch und Karelisch (inklusive Olonetzisch und Lüdisch), Wepsisch, Wotisch, Estnisch und Livisch †.

291 Ersa-Mordwinisch und Mokscha-Mordwinisch.

292 Auch Tscheremissisch, bestehend aus Wiesen-Mari und Berg-Mari.

293 Komi-Syrjänisch und Komi-Permjakisch sowie Udmurtisch (Wotjakisch). 
Bibel. Estnisch. Lateinische Schrift

Piibel: Vana ja Uus Testament $=$ The Bible in Estonian. - Tallinn, 1991

NÖ Landesbibliothek, Signatur 120.547 B

141

Bibel. Nordsaamisch. Lateinische Schrift

Bibal daihe Basse cala: mi sistes doalla Boares ja Ođđa Testamenta kanonalas̉ girjid. - Oslo, 1988

NÖ Landesbibliothek, Signatur 126.592 B

142

\section{Bibel. Ungarisch. Lateinische Schrift}

Biblia: istennek az ószövetségben és újszövetségben adott kijelentése: magyar nyelvre fordította a Magyar bibliatanács ószövetségi és újszövetségi bibliafordító szakbizottsága / [A Magyarorzsági Református Egyház

Kálvin János Kiadója]: [felelős kiadó: Tarr Kálmán]. - Budapest, 2006

NÖ Landesbibliothek, Signatur 119.708 B

\subsection{Turksprachen}

Die untereinander relativ eng verwandten Turksprachen gliedern sich in Oghurisch (Bolgar-Türkisch) ${ }^{294}$, Kiptschakisch (nordwesttürkische Sprachen) ${ }^{295}$, Oghusisch (südwesttürkische Sprachen) ${ }^{296}$, Karlukisch (südosttürkische

294 Tschuwaschisch, Bolgarisch $\uparrow$, Chasarisch $\uparrow$, Awarisch $\uparrow(?)$ und Hunnisch $\uparrow(?)$, vgl. den entsprechenden Abschnitt zur Genese des Bulgarischen (Katalog Nr. 120) bei den slawischen Sprachen. Zu den augenfälligen Kennzeichen zählt die Entsprechung von oghurisch auslautendem -r gegenüber auslautendem -z in den übrigen Turksprachen.

295 Als Vorläufersprache gilt die Sprache der Kiptschak(en), auch Kumanen oder Polowzer. Zum Kiptschakischen zählen vor allem das Kasachische, Kirgisische, Karakalpakische und Nogaische, das Tatarische und Baschkirische, das Krim-Tatarische, Kumykische und Karatschai-Balkarische; fast ausgestorben sind das Karaimische der jüdischen Karäer (vor allem in Litauen) und das ebenfalls jüdische Krimtschakische.

296 Zum Oghusischen zählen außer dem Türkischen unter anderem das Aserbaidschanische (im nordwestlichen Iran und in Aserbaidschan, Sprache der schiitischen Aserbaidschaner oder Aseri), das Gagausische (in Gagausien in der Republik Moldau, Sprache der mehrheitlich dem orthodoxen Christentum angehörenden Gagausen) und das Turkmenische (in Turkmenistan und im nordöstlichen Iran). Vor der Einführung der lateinischen Schrift 1928 war das in arabischer Schrift geschriebene Osmanisch die Amtssprache der Türkei bzw. ihres Vorgängerstaates, des Osmanischen Reiches (benannt nach der von Osman I. [1258-1326] begründeten Dynastie der Osmanen). Bereits 1071 war das byzantinische Reich unter Romanos IV. Diogenes in der Schlacht von Manzikert dem Sultan der Großseldschuken Alp Arslan unterlegen, was den Beginn der türkischen Besiedlung Anatoliens markierte. In dem 1077 abgefallenen Sultanat der Rum-Seldschuken erlangte besagter Osman die Würde eines lokalen Fürsten (Bey), womit die Keimzelle des Osmanischen Reiches gelegt war. 
Sprachen) ${ }^{297}$, Sibirisch (nordosttürkische Sprachen) ${ }^{298}$ und Arghu ${ }^{299}$. Typologisch besteht eine Ähnlichkeit zu den nicht verwandten uralischen Sprachen; auch die Turksprachen sind agglutinierend, besitzen kein grammatisches Genus und keine Nomen-Adjektiv-Kongruenz; als Beispiel für die ausgeprägte Vokalharmonie soll türkisch denizler (Meere) gegenüber dağlar (Berge) dienen. Nicht allgemein anerkannt ist der Sprachfamiliencharakter der altaischen Sprachen, bei enger Fassung die gemeinsame Klammer für die Turksprachen, mongolischen Sprachen und tungusischen Sprachen.

Als Beispiele dienen Bibeln in Türkisch und Aserbaidschanisch (in kyrillischer Schrift), das Lukasevangelium in Uigurisch (in kyrillischer Schrift), und das Neue Testament in Jakutisch sowie in Tschuwaschisch (in kyrillischer Schrift). Im Titelzusatz der türkischen Bibel „Kutsal kitap: Eski ve Yeni Antlaşma“ („Heilige Schrift: Altes und Neues Testament“) heißt es „Tevrat, Zebur, İncil“ (Tora bzw. Altes Testament, Psalter, Evangelien bzw. Neues Testament). Dies bezieht sich auf die heiligen Bücher des Islam: Taurāh (Tora, Offenbarung an Mūsā [Moses]), Zabūr (Psalter, Offenbarung an Dāwūd [David]), Inğīl/Injīi/Indschīl (Evangelium, Offenbarung an 'Īsā [Jesus], genannt al-Masīḥ [Messias]) und Qur'ān (Koran, Offenbarung an Muhammad [Mohammed]). Dabei werden die vier kanonischen Evangelien als korrumpiert angesehen und mit „Inğîl“ meist auf ein nicht erhaltenes Urevangelium abgestellt, ${ }^{300}$ zum Teil auch auf das apokryphe „Barnabasevangelium“. Arabische Christen betrachten hingegen die vier kanonischen Evangelien als „Inğîl“; fälschlich wird auch oft das ganze Neue Testament damit bezeichnet. Der Begriff findet sich in zahlreichen Sprachen der islamischen Welt.

\section{3}

\section{Bibel. Türkisch. Lateinische Schrift}

Kutsal Kitap: Eski ve Yeni Antlaşma (Tevrat, Zebur, İncil). - Istanbul, 2001

NÖ Landesbibliothek, Signatur 121.631 B

297 Dazu zählen das Usbekische (in Usbekistan) und das Uigurische (in Xinjiang) samt deren Vorläufersprachen Tschagataisch, Choresm-Türkisch und Karachanidisch; kein Vorläufer ist das auch als Altuigurisch bezeichnete Alttürkisch der Kök-Türken, das zunächst vom siebenten bis zehnten Jahrhundert durch Inschriften in alttürkischer Schrift, den nach dem mongolischen Fluss Orchon benannten linksläufigen Orchon-Runen, überliefert ist, vgl. die ebenfalls linksläufige altungarische Schrift (ungarische Runen).

298 Am bedeutendsten ist das in der russischen Republik Sacha (in Ostsibirien, im Einzugsgebiet der Flüsse Lena, Jana, Indigirka und Kolyma) gesprochene Jakutische mit ca. 500.000 Sprechern, die im neunzehnten Jahrhundert zum orthodoxen Christentum bekehrt wurden, aber Reste des alten Schamanismus zeigen; eine Islamisierung hat nicht stattgefunden.

299 Chaladsch im Iran in persischer Umgebung, was sowohl den iranischen Einfluss als auch die Beibehaltung von Archaismen infolge langer Isolation von den anderen Turksprachen erklärt. 
Bibel. Aserbaidschanisch. Kyrillische Schrift

Мүгәддәс китаб: әһди-әтиг вә әһди-чәдид [Mügäddäs kitab: ähdi-ätig vä ähdi-gaädid] = The Holy Bible (Azerbaijani Cyrillic). - Baku, 2009

NÖ Landesbibliothek, Signatur 133.664 B

\section{5}

Bibel. Lukasevangelium. Uigurisch. Kyrillische Schrift

Хуш Хәвәр: инжилниң бир қисми / Лука Хатирилигән [Нuš hävär: inğilniņ bir ķismi / Luķa Hatiriligän] = Евангелие от Луки на уйгурском языке [Evangelie ot Luki na ujgurskom jazyke] = Gospel of Luke in the Uighur language. - Stockholm, 1994

NÖ Landesbibliothek, Signatur 138.067 B

\section{6}

\section{Bibel. Neues Testament. Jakutisch. Kyrillische Schrift}

Сана кэс тыл: көннөрүллүбүт иккис таһаарыы. Көннөрүү Д.К. Сивцев - Суорун Омоллоон бађатын аахсан туран онорулунна [Saņa kès tyl: könnörüllübüt ikkis tahaaryy. Könnörüü D.K. Sivcev - Suorun Omolloon bagatyn aahsan turan oṇorulunna] = Новый Завет на якутском языке [Novyj Zavet na jakutskom jazyke] $=$ New Testament in Yakut. - Moskau, 2008

NÖ Landesbibliothek, Signatur 138.066 B

\section{7}

\section{Bibel. Neues Testament. Tschuwaschisch. Kyrillische Schrift}

Иисус Христос Хус̧амӑр панӑ С̧ӗне Халал: Рас̧сейри Наукӑсен академийӗ, Историпе филологи наукисен уйрӑмӗ [Iisus Hristos Huşamăr pană Şĕnĕ Halal: Raşşejri Naukăsen Akademijĕ, Istoripe Filologi Naukisen Ujrămĕ] = Новый Завет на чувашском языке [Novyj Zavet na čuvašskom jazyke] = New Testament in Chuvash. - Moskau, 2009

NÖ Landesbibliothek, Signatur 138.072 B 


\subsection{Mongolische Sprachen}

An bedeutenden mongolischen Sprachen seien neben dem eigentlichen Mongolisch ${ }^{301}$ (Chalcha-Mongolisch) das Oiratische mit seiner Variante Kalmückisch, der einzigen mongolischen Sprache Europas, ${ }^{302}$ und das nordmongolische Burjatische ${ }^{303}$ erwähnt. Vorherrschende Religion der Mongolen und somit auch der Kalmücken ist der Buddhismus tibetischer Prägung. Wohl in das Reich der Legende gehört hingegen die Herleitung des Kalmuck-Jankers der Donauschiffer oder Donauflößer sowie der Wachauer Winzer vom Stoff der Satteldecken der Kalmücken.

Nach dem Vorbild der uigurischen Schrift, die ihrerseits über die sogdische Schrift von der aramäischen Schrift abstammt, wurde im dreizehnten Jahrhundert eine mongolische Schrift geschaffen, die vertikal nach unten in rechtsläufigen Kolumnen geschrieben wird. Sie dominiert in der Inneren Mongolei (in China), während in der Mongolei und natürlich in Russland die kyrillische Schrift vorherrscht. Als Vertreter der mongolischen Sprachen werden eine Bibel in Mongolisch und ein Neues Testament in Burjatisch vorgestellt, beide in kyrillischer Schrift.

\section{8}

\section{Bibel. Mongolisch. Kyrillische Schrift}

Ариун Библи: Хуучин Гэрээ, Шинэ Гэрээ [Ariun Bibli: Huučin Gẻrė, Šinė Gèrėė] = Mongolian Bible. Ulan Bator, 2004

NÖ Landesbibliothek, Signatur 123.485 B

\section{9}

\section{Bibel. Neues Testament. Burjatisch. Kyrillische Schrift}

Шэнэ хэлсээн [Šėnė hẻlsėėn] = Новый Завет на бурятском языке [Novyj Zavet na burjatskom jazyke] = New Testament in Buryat. - Moskau, 2010

NÖ Landesbibliothek, Signatur 138.064 B

301 In der ( ̈̈ußeren) Mongolei und Inneren Mongolei.

302 Im Nordwesten des Kaspischen Meeres. 


\subsection{Tungusische Sprachen}

$\mathrm{Zu}$ den tungusischen Sprachen ${ }^{304}$ zählen unter anderem das Ewenkische (Tungusische, inklusive Solonisch), das Ewenische (Lamutische), das Nanaiische (Goldische) sowie das vom früheren Jurchenischen abstammende und fast ausgestorbene Mandschurische mit seiner Tochtersprache Xibenisch. Das Mandschurische war die Hofsprache der chinesischen Qing-Dynastie (1644-1911) und wurde in der von der mongolischen Schrift abgeleiteten mandschurischen Schrift geschrieben; im Laufe der Zeit fand ein fast vollständiger Sprachwechsel der Mandschu zum Chinesischen statt.

Von einer Präsentation des Lukasevangeliums in Ewenkisch, Ewenisch und Nanaiisch wird abgesehen, weil in der Niederösterreichischen Landesbibliothek nur gebundene Ausdrucke vorhanden sind. ${ }^{305}$

\subsection{Tschuktschisch-kamtschadalische Sprachen}

Keine Sprachfamilie, sondern lediglich eine Restgruppe bilden die paläosibirischen Sprachen mit Jukagirisch ${ }^{306}$, Ketisch $^{307}$, Niwchisch ${ }^{308}$, Ainu ${ }^{309}$ und den tschuktschisch-kamtschadalischen Sprachen. Zu den heute von lediglich rund 15.000 Menschen gesprochenen tschuktschisch-kamtschadalischen Sprachen zählen das Tschuktschische, das Korjakische (mit dem Aliutorischen) sowie das Itelmenische (Kamtschadalische).

Von einer Präsentation des Lukasevangeliums in Tschuktschisch, Korjakisch und Itelmenisch wird abgesehen, weil in der Niederösterreichischen Landesbibliothek nur gebundene Ausdrucke vorhanden sind. ${ }^{310}$

304 Mit heute weniger als 100.000 Sprechern.

305 Für diese Sprachen siehe https://ibtrussia.org/de/media (9.6.2020).

306 Meist in die Nähe der uralischen Sprachen gestellt.

307 Letzte Überlebende der jenisseischen Sprachen, wird auch Jenissei-Ostjakisch genannt. Die jenisseischen Sprachen werden neuerdings in die Nähe der Na-Dené-Sprachen gestellt.

308 Auch Giljakisch; isolierte Sprache am Amur und auf Sachalin.

309 Nahezu ausgestorbene isolierte Sprache auf Hokkaidō, Sachalin und den Kurilen.

310 Für diese Sprachen siehe https://ibtrussia.org/de/media (9.6.2020). 


\subsection{Nordwestkaukasische Sprachen}

Die nordwestkaukasischen Sprachen ${ }^{311}$ bestehen aus dem Abchasischen und dem Abasinischen einerseits und den tscherkessischen Sprachen Adygeisch ${ }^{312}$ und Kabardinisch ${ }^{313}$ andererseits; das Ubychische ist Ende des zwanzigsten Jahrhunderts ausgestorben. Die vermutete Verwandtschaft des um 1500 vor Christus ausgestorbenen Hattischen in Anatolien ist nicht hinreichend belegt.

Von einer Präsentation des Lukasevangeliums in Kabardinisch wird abgesehen, weil in der Niederösterreichischen Landesbibliothek nur ein gebundener Ausdruck vorhanden ist. ${ }^{314}$

\subsection{Nordostkaukasische Sprachen}

Die nordostkaukasischen Sprachen ${ }^{315}$ bestehen aus den nachischen $\operatorname{Sprachen}^{316}$, den awaro-ando-didoischen Sprachen $^{317}$, Lakkisch (Lakisch) und Darginisch (Dargwa) sowie den lesgischen Sprachen ${ }^{318}$. Traditionell werden die nachischen Sprachen den restlichen Dagestan-Sprachen gegenübergestellt; in neuerer Zeit geht man von einer Zweiteilung Awaro-Ando-Didoisch gegenüber den restlichen Sprachen aus. Hypothetisch bleibt die Annahme einer Verwandtschaft des ausgestorbenen Hurritisch-Urartäischen.

Das Tschetschenische wird anhand eines 2010 in Wien erschienenen Lukasevangeliums vorgestellt; für das Awarische und das zu lesgischen Sprachen zählende Tabassaranische liegt jeweils ein Neues Testament vor, wiederum ein Lukasevangelium für das Lakkische und Darginische, alles in kyrillischer Schrift.

311 Auch Westkaukasisch, Pontisch oder Abchasisch-Adygheisch genannt.

312 Auch Adygejisch, Adygisch, West-Tscherkessisch oder Nieder-Tscherkessisch.

313 Auch Ost-Tscherkessisch oder Ober-Tscherkessisch.

314 Für diese Sprache siehe https://ibtrussia.org/de/media (9.6.2020).

315 Auch Ostkaukasisch, Kaspisch oder Nachisch-Dagestanisch genannt.

316 Tschetschenisch, Inguschisch und Batsisch.

317 Awarisch (nicht verwandt mit dem mittelalterlichen Awarisch, das vielleicht eine oghurische Turksprache war), Andisch, Tsesisch (Didoisch) und weitere, kleinere Sprachen.

318 Lesgisch, Tabassaranisch, Aghulisch (Agulisch), Rutulisch, Tsachurisch, Buduchisch, Krysisch, Artschinisch, Udisch und vielleicht Chinalugisch (Chinalughisch). Als Vorform des Udischen gilt das Alwanische mit eigener alwanischer Schrift. 
150

Bibel. Lukasevangelium. Tschetschenisch. Kyrillische Schrift

Іийсас беана, Лакас дІаязбина болу Хаза Кхаъ [Hijsas beana, Lakas dhajazbina bolu haza khaq]. - Wien, 2010

NÖ Landesbibliothek, Signatur 133.667 B Abb. 41

\section{1}

\section{Bibel. Neues Testament. Awarisch.}

\section{Kyrillische Schrift}

Инжил / Россияльул гІелмабазул академия, Тарихиялгун филологиял гІелмабазул отделение, Дагъистанальул гІелмияб центр, ЦІадаса ХІамзатил цІаралда МацІальул, литератураяльул ва искусствояльул институт [Inžil / Rossijalqul Gḩelmabazul Akademija, Tarihijalgun Filologijal Ghelmabazul Otdelenie, Dagqestanalqul Gḩelmijab Centr, Cḩadasa Hḩamzatil Cḩaralda Bugeb Machalqul, Literaturajalqul va Iskusstvojalqul Institut] = Новый Завет на аварском языке [Novyj Zavet na avarskom jazyke] $=$ New Testament in Avar language. - Moskau, 2008 NÖ Landesbibliothek, Signatur 138.065 B

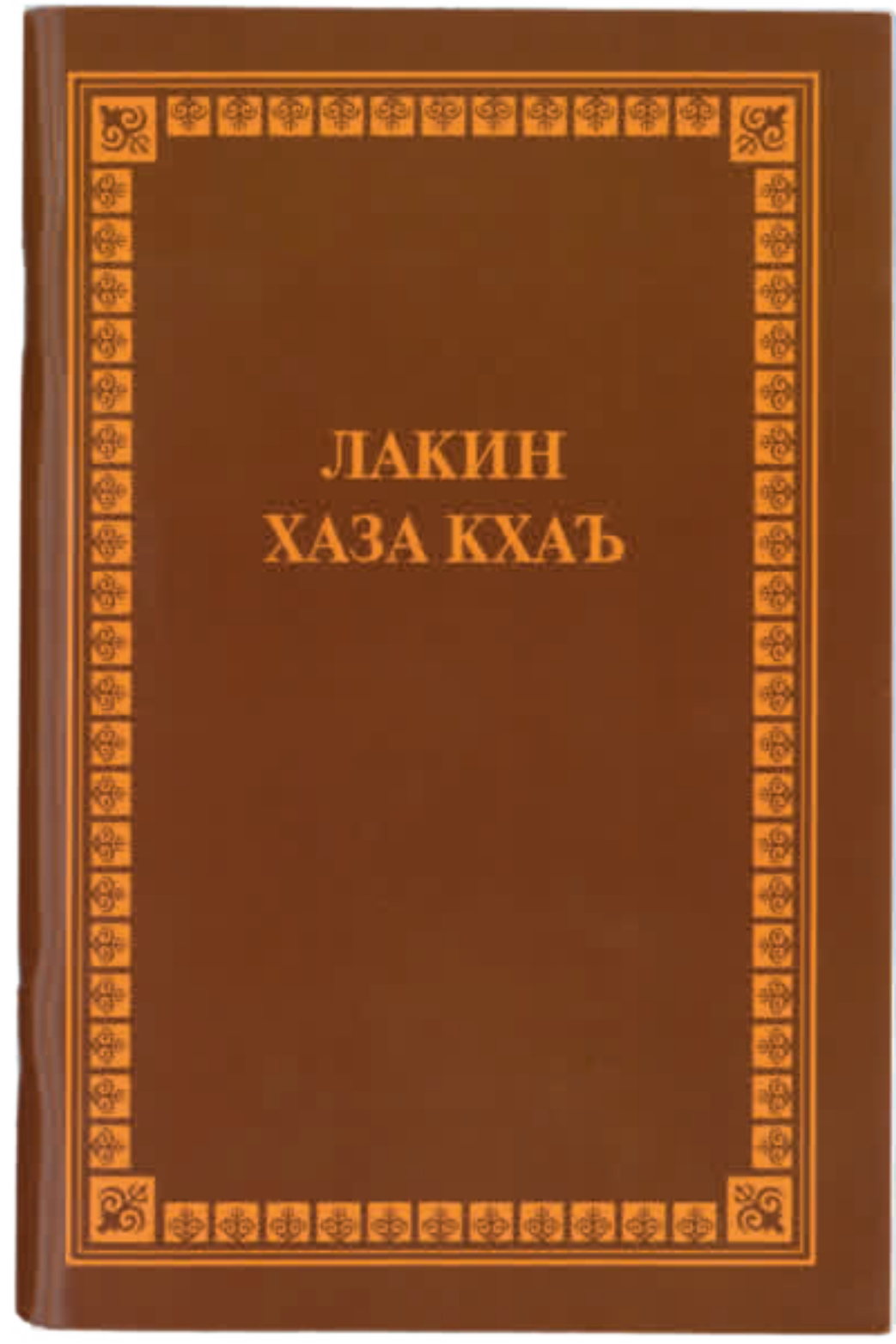

Abb. 41 / Katalog Nr. 150: Лакин Хаза Кхаъ [Lakin Haza Khaq] (Tschetschenisch) (2010). 
Bibel. Neues Testament. Tabassaranisch. Kyrillische Schrift

ЦІийи Йикьрар / Урусатдин илмарин Академия, ЧІалар ахтармиш апІру Институт [Chiji Jikǐrar /

Urusatdin Ilmarin Akademija, Çhalar Ahtarmiš Aphru Institut] = Новый Завет на табасаранском языке [Novyj Zavet na tabasaranskom jazyke] = New Testament in Tabasaran language. - Moskau, 2010

NÖ Landesbibliothek, Signatur 138.071 B

\section{3}

\section{Bibel. Lukasevangelium. Lakkisch. Kyrillische Schrift}

Инжил: Лукал Эса МасихІная чивчусса Ххарисса Хавар / таржумачитал: Явубукухъал Эса, Мазяйхъал Казвек [Inžil: Lukal Ėsa Masihḩnaja čivčussa Hharissa Havar / taržumačital: Javubukuhqal Ėsa, Mazjajhqal Kazbek] = Евангелие от Луки на лакском языке [Evangelie ot Luki na lakskom jazyke]. - Moskau, 2002 NÖ Landesbibliothek, Signatur 138.068 B

\section{4}

\section{Bibel. Lukasevangelium. Darginisch. Kyrillische Schrift}

Инжил: Лукала ГІяхІ хабар / шурбатурти: Ильяс ХІясанов, Хизри Юсупов, Михаил Алексеев [Inžil: Lukala ghjahḩ havar / šurbaturti: Ill̆jas Hḩjasanov, Chizri Jusupov, Michail Alekseev] = Евангелие от Луки на даргинском языке [Evangelie ot Luki na darginskom jazyke] = Gospel of Luke in Dargin. - Moskau, 2010 NÖ Landesbibliothek, Signatur 138.070 B

\subsection{Südkaukasische Sprachen}

Zu den südkaukasischen Sprachen ${ }^{319}$ zählt neben Swanisch und den als Sanisch oder Kolchisch zusammengefassten Sprachen Lasisch und Mingrelisch die alte Schriftsprache Georgisch oder Grusinisch. ${ }^{320}$ Die georgische Schrift, die ähnlich wie die armenische Schrift stark von der griechischen Schrift beeinflusst ist, dürfte von einer Variante der aramäischen Schrift abstammen und spätestens im fünften Jahrhundert nach Christus entstanden sein. Zwischen dem fünften und neunten Jahrhundert wurde die Variante Assomtawruli ${ }^{321}$ verwendet und dann

319 Auch kartwelische Sprachen oder Kartwelsprachen.

320 Georgisch ist eine Split-Ergativsprache; zu ihren Kennzeichen gehört neben dem Vorhandensein von drei Verschlusslautserien (aspiriert, stimmhaft und ejektiv) die Neigung zu Konsonantenanhäufungen, auch im Wortanlaut. Das alte Wanderwort Wein soll dem Georgischen entstammen. Ein bedeutendes Werk der georgischen Literatur ist das Nationalepos „Der Recke im Tigerfell“ von Schota Rustaweli. 
von der kursiven Nuschuri ${ }^{322}$ abgelöst; beide Varianten werden als Chutsuri (Priesterschrift) von der im elften Jahrhundert entstandenen und heute dominierenden Mchedruli (Kriegerschrift) abgegrenzt. Die Mehrheit der Georgier gehört der Georgischen Orthodoxen Kirche an. Das Georgische wird anhand einer Bibel vorgestellt.

\section{5}

Bibel. Georgisch. Georgische Schrift

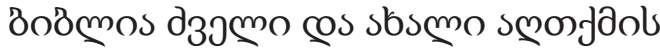
бozбjठ̊o [Biblia żveli da axali agt'k'mis cignebi]. - Tiflis, 2001

NÖ Landesbibliothek, Signatur 119.718 B Abb. 42

\subsection{Koreanisch}

Das durch eine Bibel vorgestellte Koreanisch ist eine isolierte Sprache mit einer eigenen Buchstabenschrift Hangul. Die einzelnen Buchstaben für die Laute einer Silbe werden dabei gruppenweise angeordnet. Die Schrift gilt als Erfindung von König Sejong aus dem fünfzehnten Jahrhundert und soll zumindest teilweise auf der im Auftrag Kublai Khans 1269 nach dem Vorbild der tibetischen Schrift

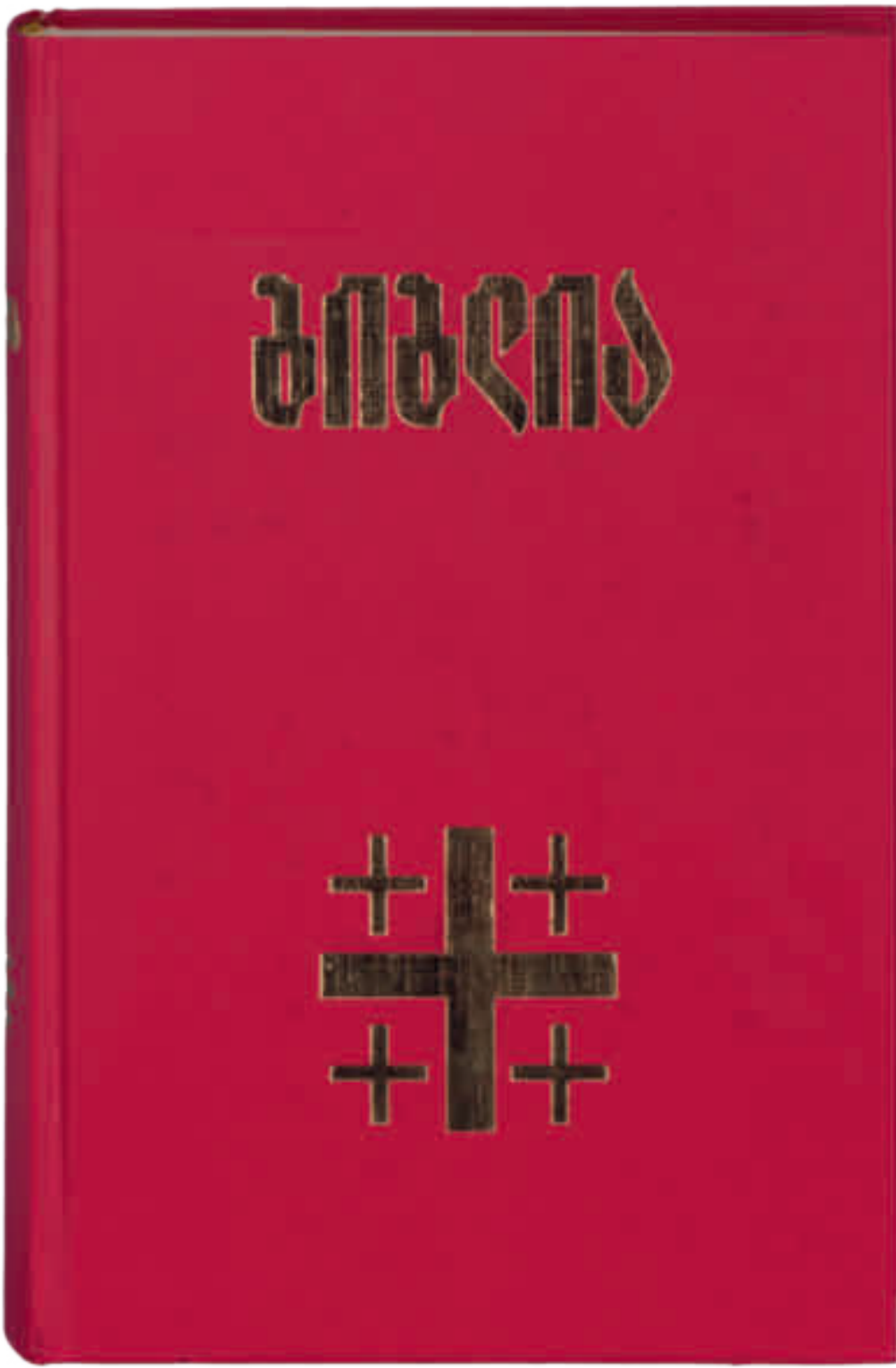

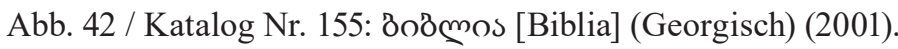


geschaffenen und nach ihrem Erfinder Chögyel Phagpa benannten Phagpa-Schrift beruhen. Nur in Südkorea werden zum Teil noch chinesische Schriftzeichen (Hanja) neben Hangul verwendet.

\section{6}

\section{Bibel. Koreanisch. Hangul}

공동번역성서 [Kongdong pŏnyŏk Sŏngsŏ] = The Holy Bible. - Seoul, 1977

NÖ Landesbibliothek, Signatur 123.486 B

\subsection{Japanisch-Ryūkyū}

Das Japanische ist lediglich mit den Ryūkyū-Sprachen, deren bedeutendste das Okinawa darstellt, verwandt. Sehr komplex ist die japanische Schrift: Sie umfasst Kanji-Zeichen ${ }^{323}$ chinesischen Ursprungs, die als Logogramme für die Wortstämme verwendet werden, und die beiden Silbenschriften Hiragana und Katakana, die im gleichen Text ebenfalls zur Anwendung gelangen. Hiragana wird für grammatische Partikel, Präfixe und Suffixe, japanische Wörter ohne gebräuchliches Kanji sowie als Furigana bei Bedarf zur Erläuterung eines Kanjis eingesetzt, Katakana hauptsächlich für Lehnwörter und Eigennamen. Zu den Kanji-Zeichen ist noch zu bemerken, dass sie entweder in chinesischer bzw. sinojapanischer On-Lesung oder in japanischer Kun-Lesung gelesen werden können.

Die in literarischen Texten wie auch der Bibel verwendete traditionelle Schreibrichtung verläuft in Spalten vertikal von oben nach unten, die Spalten ihrerseits sind linksläufig, das Buch ist also von hinten beginnend zu lesen; nach europäischem Vorbild existiert heute daneben aber auch die normale zeilenweise und rechtsläufige Schreibweise. Die in Japan ebenfalls verwendete lateinische Schrift heißt Rōmaji.

323 Kanji 漢字 [chinesische Kurzschrift: 汉字 Pinyin: hànzi (Mandarin)] „hanchinesisches Zeichen”, vgl. dazu Wiktionary https://en.wiktionary.org/wiki/ 漢字 $=$ https://en.wiktionary.org/wiki/\%E6\%BC\%A2\%E5\%AD\%97. Siehe ebenso seisho 聖書 [Pinyin: shèngshü (Mandarin)] „Bibel”, koreanisch 성서 sŏngsŏ oder seongseo „Bibel“, vgl. dazu Wiktionary https://en.wiktionary.org/wiki/聖書 = https://en.wiktionary.org/wiki/\%E8 \%81 \%96 \%E6 \%9B\%B8. In der Regel führt die Eingabe der Han-Zeichen nebst dem Begriff Wiktionary in der Google-Suche zu diesen Seiten. Durch die Han-Vereinheitlichung in Unicode werden die CJK-Schriften (chinesische Hanzi - Langzeichen und Kurzzeichen, japanische Kanji, koreanische Hanja und die vietnamesische Chũ Nôm) einheitlich codiert. Um ein bestimmtes Zeichen zu finden, muss man zunächst den Radikal (die Grundbedeutung tragende Zeichenkomponente) bestimmen und dort nach dem vollständigen Zeichen weitersuchen; das Ordnungsprinzip ist jeweils die Zahl der enthaltenen Striche. Beispiel 聖書: Zeichen 1 zeigt links oben den Radikal 耳 mit sechs Strichen, das ganze Zeichen 聖hat 13 Striche und den Pinyin-Wert shèng; Zeichen 2 zeigt unten den Radikal 曰 mit vier Strichen, das ganze Zeichen 書 hat zehn Striche und den Pinyin-Wert shü, vgl. dazu z. B. https://www.chinese-tools.com/tools/sinograms.html?r= (alle 31.3.2020). 
NÖ Landesbibliothek, Signatur 123.478 B

\subsection{Sinotibetische Sprachen}

$\mathrm{Zu}$ den sinotibetischen Sprachen zählen die sinitischen (chinesischen) Sprachen einerseits und die tibetobirmanischen Sprachen andererseits. Diese Zweiteilung wurde auch schon angezweifelt, wodurch Sinitisch zu einem Zweig des Tibetobirmanischen und dieses synonym zu Sinotibetisch würde.

Das Sinitische (Chinesisch, Hànyǔ) besteht aus dem nordchinesischen Mandarin (mit dem Standard Hochchinesisch auf Basis des Dialektes von Peking), Jin, Wu (mit dem Shanghai-Dialekt), Min, Gan, Hakka, Yue (Kantonesisch), Xiang, Hui und Pinghua.

Als älteste Form des Chinesischen gelten die „Orakelknocheninschriften“ aus der Zeit der Shang-Dynastie (achtzehntes bis elftes Jahrhundert vor Christus); unter Altchinesisch versteht man die Sprache der folgenden Zhou-Dynastie (bis 256 vor Christus). Die letzte Phase des Altchinesischen bildet das Klassische Chinesisch des fünften bis dritten vorchristlichen Jahrhunderts, das als Literatursprache und somit Schriftsprache bis zum Ende des Kaiserreiches verwendet wurde.

Da sich die Aussprache der toten Sprache Klassisches Chinesisch parallel zur Aussprache der tatsächlich gesprochenen Sprache änderte und die logographische chinesische Schrift nur bedingt lautliche Rückschlüsse erlaubt, ist die ursprüngliche Lautung des Altchinesischen rekonstruktionsabhängig. Sowohl im Anlaut als auch im Auslaut kamen Konsonantenhäufungen vor, deren spätere Vereinfachung durch tonsprachliche Muster der späteren chinesischen Sprachstufen ab dem Mittelchinesischen spezifisch kompensiert wurde. ${ }^{324}$ Altchinesisch steht auch dem Klassischen Tibetisch und Birmanisch deutlich näher als Hochchinesisch. ${ }^{325}$

Mit dem Tibetischen und Birmanischen sind zugleich die beiden wichtigsten Vertreter der tibetobirmanischen Sprachen genannt, die insgesamt rund 330 Sprachen mit allerdings lediglich 70 Mio. Sprechern umfassen; beide Sprachen verfügen über spezifische Schriften aus dem indischen Schriftenkreis, dessen Verbreitung mit der des aus Indien stammenden Buddhismus einhergeht.

324 So steht z. B. rekonstruiertes altchinesisches *mun (hören) und *muns (fragen) hochchinesischem wén bzw. wèn gegenüber. 
Zum chinesischen Schriftenkreis andererseits zählen die japanische Schrift, die koreanische Hanja und die heute weitgehend von der lateinischen Schrift verdrängte vietnamesische Chữ Nôm. Die chinesische Schrift ist in erster Linie eine logographische Schrift oder genauer Morphemschrift ${ }^{326}$ und keine phonographische Schrift. Neben einigen Piktogrammen und einfachen wie zusammengesetzten Ideogrammen bestehen die chinesischen Zeichen allerdings überwiegend aus Phonogrammen, die jeweils zweiteilig aus einem bedeutungstragenden Radikal und einem lauttragenden Phonetikum bestehen. Infolge einer Schriftreform in der Volksrepublik China, der sich Singapur, nicht aber Taiwan, Hongkong, Macau oder Japan angeschlossen hat, entstanden vereinfachte Kurzzeichen anstelle der traditionellen Langzeichen. Zur traditionellen Schreibrichtung, die lediglich bei Langzeichen vorkommt, vergleiche die Beschreibung des Japanischen; dort wird auch das Auffinden eines Zeichens und seiner Lautung anhand des Beispiels seisho (Bibel) erläutert. Als offizielle Umschrift der chinesischen Schrift in die lateinische Schrift gilt der Standard Pinyin. ${ }^{327}$ Ein unbestreitbarer Vorteil der chinesischen Schrift ist gerade der Umstand, dass sie nicht phonographisch funktioniert: Zumindest bei etymologisch zusammengehörigen Morphemen wirkt sie einigend über zeitliche und räumliche Sprachgrenzen hinweg.

Einen Sonderfall stellt das Dunganische dar: Im Zuge der Dunganenaufstände der Jahre 1862-1873 sind die Dunganen, eine muslimische und den Hui-Chinesen nahestehende Gruppe, nach Zentralasien geflohen; ihre Nachkommen siedeln in Kirgistan, aber auch Kasachstan, Tadschikistan, Usbekistan und Turkmenistan. Das dem Hochchinesischen immer noch nahestehende Dunganische ${ }^{328}$ wird in kyrillischer Schrift geschrieben.

Im Zusammenhang mit der Bibel ist auch die Wiedergabe von „Gott“ ein Thema: Während katholische Kreise 天 主 (Pinyin: Tiānzhǔ) bevorzugen, weswegen der Katholizismus auch als 天主教 (Pinyin: Tiānzhǔjiào) bezeichnet wird, ist in protestantischen Kreisen 上帝 (Pinyin: Shàngdì ${ }^{329}$ ) üblich.

Als Beispiele werden chinesische Bibeln in traditionellen Langzeichen (Shangti) und in Kurzzeichen vorgestellt, ebenso ein Neues Testament in Pinyin samt Kurzzeichen; für das Dunganische mit kyrillischer Schrift können die Evangelien mit der Apostelgeschichte als Exempel dienen. Schlussendlich werden Tibetisch und Birmanisch anhand von Bibeln repräsentiert.

326 Morpheme sind im allgemeinen die kleinsten bedeutungstragenden Einheiten einer Sprache; ein oder mehrere Morpheme bilden ein Wort; Menschheit besteht zum Beispiel aus den Morphemen Mensch und -heit. Der Begriff des Morphems deckt sich nicht mit dem Begriff der Silbe: Morpheme können mehrsilbig sein (z. B. Preisel-beere), Silben als bloße Lautgruppen tragen hingegen keine Bedeutung (sofern nicht ein aus einer Silbe bestehendes Morphem vorliegt). Chinesische Schriftzeichen repräsentieren Morpheme und nicht Wörter (soweit diese nicht aus nur einem Morphem bestehen).

327 Ein Beispiel: Běijīng (Peking).

328 Gegenseitige Verständlichkeit ist weitgehend gegeben.

329 Oder Shang Ti (Umschrift nach Wade-Giles). 
Bibel. Chinesisch. Chinesische Schrift (Langzeichen)

新舊約全書. - 和合本 (上帝版) [Xīn jiù yuē quán shū. - Hé hé běn (shàng dì băn)] = The Holy Bible. Chinese Union Version (Shangti-Edition). - Hongkong, 2006

NÖ Landesbibliothek, Signatur 123.479 B

159

Bibel. Chinesisch. Chinesische Schrift (Kurzzeichen)

圣经: (和合本) [Shèng jīng: hé hé běn]

NÖ Landesbibliothek, Signatur 124.963 B

160

Bibel. Neues Testament. Chinesisch. Lateinische Schrift (Pinyin) und chinesische Schrift (Kurzzeichen)

Xīn yuē quán shū: hé hé běn: hàn yù pīn yīn zhù yīn [新约全书: 和合本: 汉语拼音注音]. - 1978

NÖ Landesbibliothek, Signatur 138.099 B

161

Bibel. Evangelien und Bibel. Apostelgeschichte. Dunganisch. Kyrillische Schrift

Инжил: Матфей, Марк, Лука, Йихия щехади Инжил. Апостолму ганхади сычин [Inğil: Matfej, Mark, Luka, Jihija ščehadi Inğil. Apostolmu ganhadi syčin] = Евангелие от Матфея, Марка, Луки, Иоанна и Деяния апостолов на дунганском языке [Evangelie ot Matfeja, Marka, Luki, Ioanna i Dejanija apostolov na dunganskom jazyke]. - Moskau, 2006

NÖ Landesbibliothek, Signatur 138.069 B

162

Bibel. Tibetisch. Tibetische Schrift

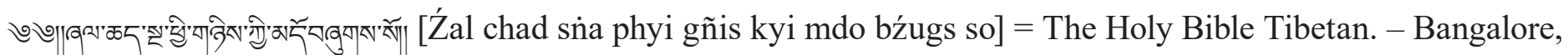
[2004?]

NÖ Landesbibliothek, Signatur 123.484 B

163

Bibel. Birmanisch. Birmanische Schrift

The Holy Bible: containing the Old and New Testaments / translated into the Burmese from the original tongues

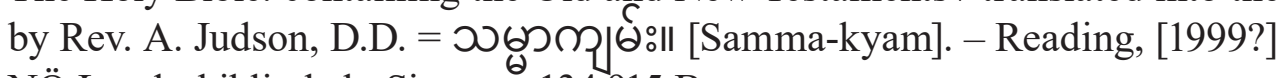

NÖ Landesbibliothek, Signatur 134.915 B 


\subsection{Hmong-Mien-Sprachen}

Die kleine Sprachfamilie der Hmong-Mien-Sprachen oder Miao-Yao-Sprachen aus dem südchinesischvietnamesisch-laotisch-thailändischen Grenzgebiet wird durch eine Bibel in Blue Hmong repräsentiert, die in den Vereinigten Staaten für Hmong-Flüchtlinge des Vietnamkriegs aus Laos gedruckt wurde; in den USA werden heute die beiden Varietäten White Hmong (Hmong Daw) und Blue (Green) Hmong (Hmong Njua) von rund 280.000 Menschen gesprochen.

\section{4}

\section{Bibel. Hmong Njua. Lateinische Schrift}

Txuj Moo Zoo kws Yog Vaajtswv Txujlug: Phoo Txhais Tshab = The Holy Bible in Blue Hmong. - New York, NY, 2000

NÖ Landesbibliothek, Signatur 133.665 B

\subsection{Austroasiatische Sprachen}

Die austroasiatischen Sprachen werden traditionell in die hauptsächlich im Nordosten Indiens gesprochenen Munda-Sprachen, die in Südchina und Südostasien gesprochenen Mon-Khmer-Sprachen und die nikobaresischen Sprachen eingeteilt. Die bedeutendste Munda-Sprache ist Santali mit rund 7 Mio. Sprechern und einer eigenen Schrift, der 1925 entwickelten Ol Chiki, die neben der lateinischen Schrift und Schriften aus dem indischen Schriftenkreis verwendet wird; erwähnenswert sind auch die Sprachen Mundari und Ho. Die Mon-Khmer-Sprachen umfassen neben den namensgebenden Sprachen Mon $^{330}$ und Khmer (Kambodschanisch) ${ }^{331}$ insbesondere die im indischen Bundesstaat Meghalaya gesprochene Sprache Khasi sowie Vietnamesisch ${ }^{332}$ nebst Muong. Das auch sprachlich stark vom Chinesischen beeinflusste Vietnamesische wurde zunächst in chinesischer Schrift bzw. der daraus entwickelten Schrift Chữ Nôm geschrieben; seit 1945 ist die lateinische Schrift unter der Bezeichnung Chữ quốc ngữ die offizielle Schrift. Auffällig sind die Diakritika zur Bezeichnung der sechs verschiedenen Töne: Zahlreiche Vokale weisen gleich zwei Diakritika auf, siehe dazu vor allem den Unicode-Block Latin Extended Additional.

330 In Myanmar (Birma); die Mon-Schrift gilt als Vorläufer der birmanischen Schrift.

331 Mit jeweils eigenen Schriften aus dem indischen Schriftenkreis. 
Als Beispiele dienen Bibeln in den Sprachen Khmer und Vietnamesisch.

165

Bibel. Kambodschanisch. Khmer-Schrift [ต๋ะกิ่ courant $=$ The Bible in today's Khmer version. - Phnom Penh, 1997

NÖ Landesbibliothek, Signatur 133.691 B Abb. 43

166

Bibel. Vietnamesisch. Lateinische Schrift Kinh Thánh: Cựu ước và Tân ước $=$ The Holy Bible in Vietnamese. - Hanoi, 2004 NÖ Landesbibliothek, Signatur 123.482 B

\subsection{Tai-Kadai-Sprachen}

Die Tai-Kadai-Sprachen (Kra-Dai-Sprachen) gliedern sich in die Zweige Hlai (Li), Kadai (Kra, Geyang) und Kam-Tai (Zhuang-Dong); zur letzteren Gruppe gehören unter anderem die Tai-Sprachen (Zhuang-Tai) mit den beiden Sprachen Thailändisch und Laotisch in der südwestlichen Untergruppe. Beide Sprachen werden mit einer jeweils eigenen Schrift aus dem indischen Schriftenkreis geschrieben und sind auch hier vertreten.

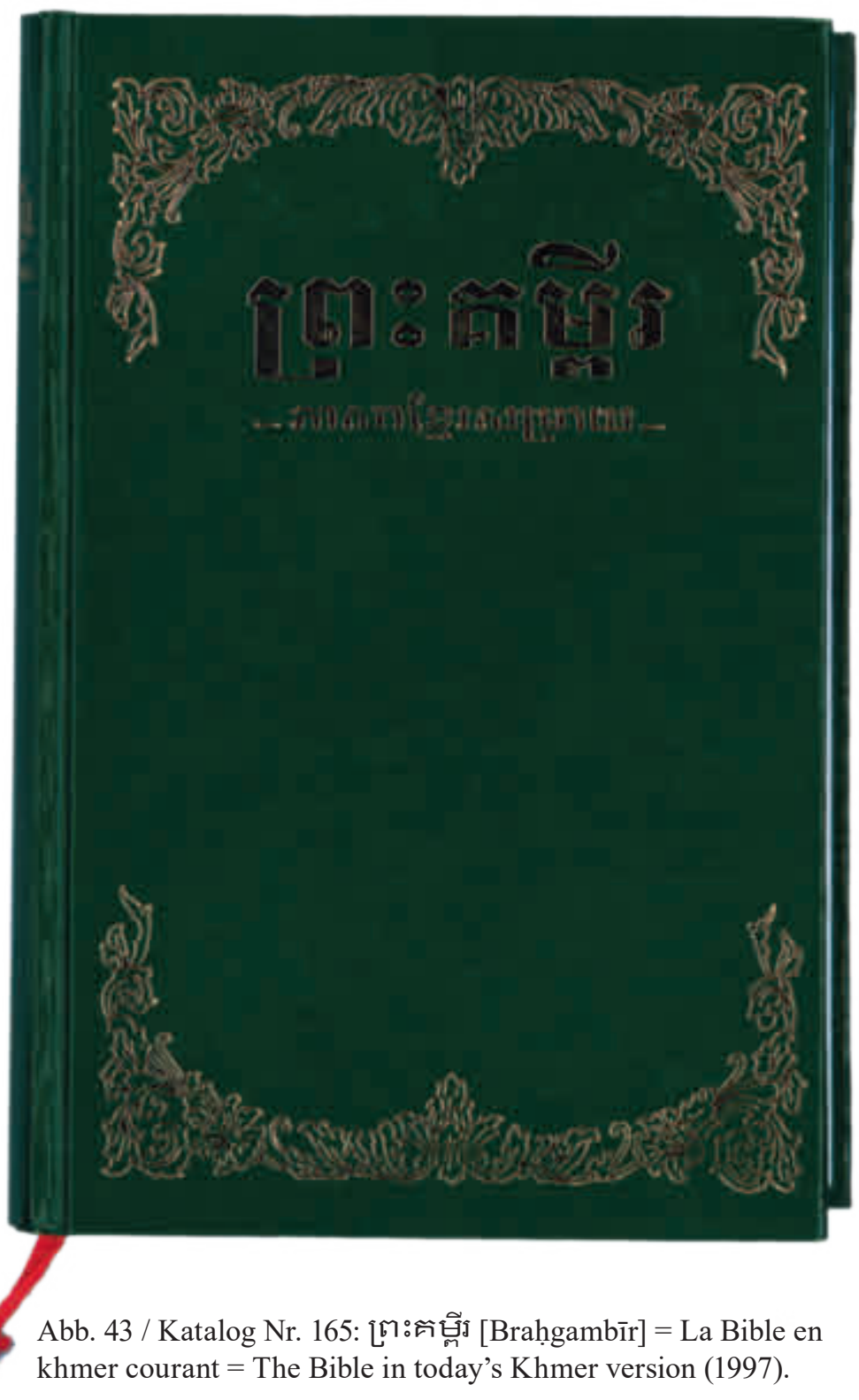




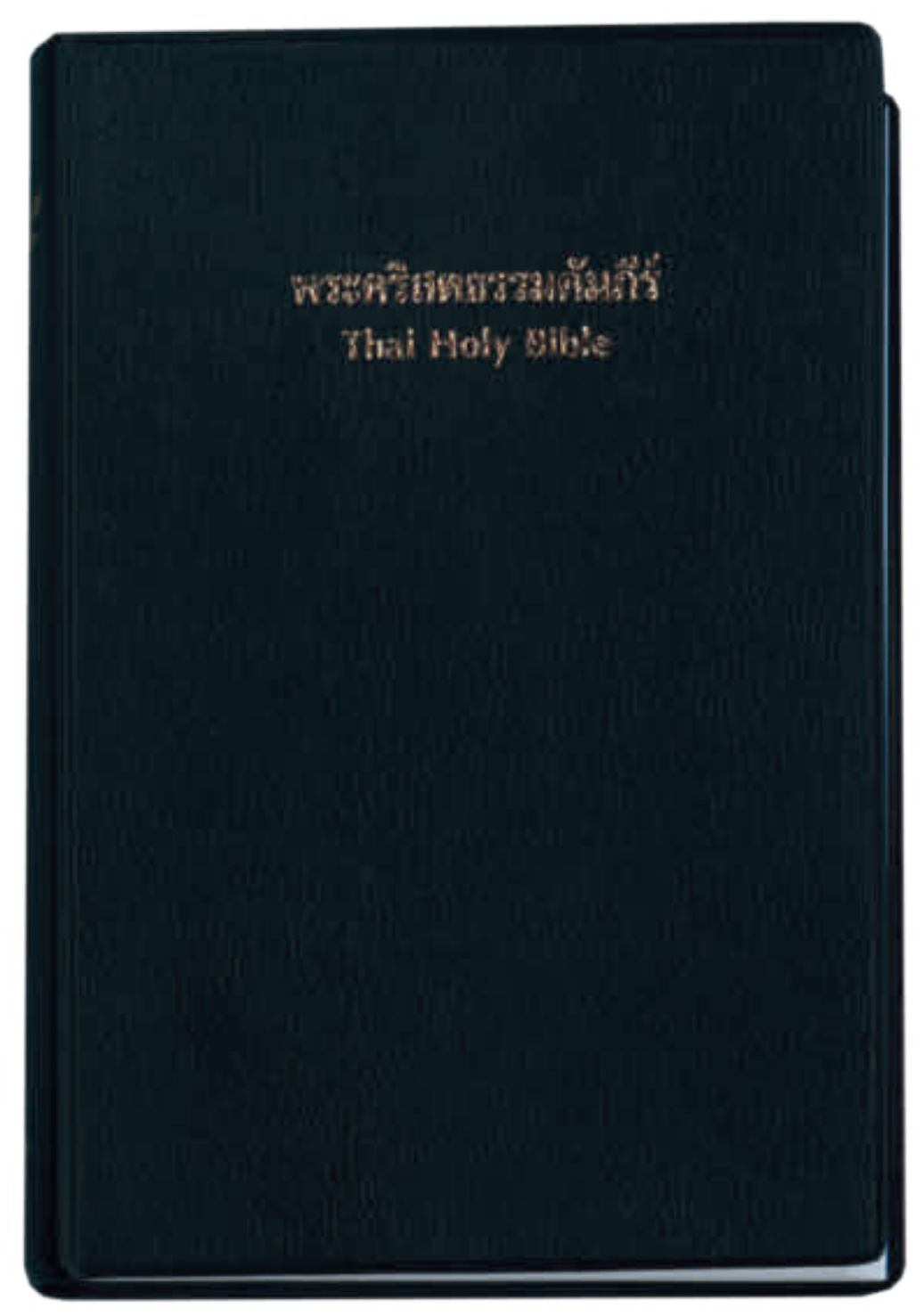

Abb. 44 / Katalog Nr. 167: พระคริสตธรรมคัมภีร์ [Phra khrittham khamphī] $=$ Thai Holy Bible (1998).
167

Bibel. Thailändisch. Thai-Schrift

พระคริสตธรรมคัมภีร์ [Phra khrittham khamphī]

= Thai Holy Bible. - Bangkok, [1998]

NÖ Landesbibliothek, Signatur 123.483 B

Abb. 44

168

Bibel. Laotisch. Laotische Schrift

๒ะถำ๒ [Phakhamphī] = The Holy Bible in Lao common language $=\mathrm{La}$ Bible en laotien courant. - Reading, 2001

NÖ Landesbibliothek, Signatur 135.500 B

\subsection{Austronesische Sprachen}

Bis auf die Untergruppe der malayo-polynesischen Sprachen sind alle anderen Unterzweige der austronesischen Sprachen auf Taiwan ${ }^{333}$ beschränkt, die mutmaßliche Urheimat dieser Sprachen oder zumindest ein Teil dieser Urheimat (bei Einbeziehung benachbarter Festlandregionen in China). Die Ausbreitung des Malayo-Polynesischen ist über die Philippinen, Indonesien und die malaiische Halbinsel sowie Melanesien nach Mikronesien und Polynesien erfolgt; zuletzt wurden Madagaskar und Neuseeland erreicht.

Zum West-Malayo-Polynesischen zählen die meso-philippinischen Sprachen Tagalog (als

333 Man spricht zusammenfassend von Formosa-Sprachen oder Taiwan-Sprachen 
Nationalsprache der Philippinen: Filipino) und Cebuano, das Malaiische mit den beiden Standardvarietäten Bahasa Malaysia ${ }^{334}$ und Bahasa Indonesia ${ }^{335}$ und die damit näher verwandten Sprachen Achinesisch, Sundanesisch, Maduresisch und Balinesisch, das Javanische und das Malagasy auf Madagaskar, dessen nächste Verwandten die Ost-Barito-Sprachen auf Borneo darstellen.

Zum Zentral-Ost-Malyao-Polynesischen gehört zunächst das Zentral-Malayo-Polynesische mit Tetum ${ }^{336}$, der Amtssprache von Osttimor; das Ost-Malayo-Polynesische wiederum wird unterteilt in die Süd-Halmahera-WestNeuguinea-Gruppe und die ozeanischen Sprachen, zu deren Untergruppe Zentral-Ost-Ozeanisch die zentralpazifischen Sprachen mit Fidschi und den polynesischen Sprachen wie Tongaisch, Samoanisch, Hawaiisch, Tahitianisch, Maorisch ${ }^{337}$ und Rapanui ${ }^{338}$ zählen. Durch die Lautwandel k zu ' ('Okina), t zu k, r zu 1, $\Phi$ zu h und y zu n ist Hawaiisch nicht nur zu einer Sprache mit einem äußerst geringen Phoneminventar von nur 13 Phonemen und ohne den Laut $t$ geworden, es unterscheidet sich auch dementsprechend von dem deutlich konservativeren Maorisch; eine Wortgleichung ist z. B. Maorisch tokerau (Nordwind) gegenüber Hawaiisch ko'olau.

Hawaiisch ist mit nur mehr 1.000 Muttersprachlern vom Aussterben bedroht; umso bemerkenswerter ist der Umstand, dass neben Bibeln in Bahasa Malaysia und Bahasa Indonesia und einem Neuen Testament in Tagalog eine Bibel in Maori-Sprache und vor allem auch eine Bibel in Hawaiisch präsentiert werden können.

\section{9}

\section{Bibel. Bahasa Indonesia. Lateinische Schrift}

Alkitab: [yaitu Perjanjian Lama dan Perjanjian Baru dalam Terjemahan Baru, yang diselenggarakan oleh Lembaga Alkitab Indonesia] = Bible in Indonesian (formal translation). - Jakarta, 2001

NÖ Landesbibliothek, Signatur 132.328 B

\section{0}

\section{Bibel. Bahasa Malaysia. Lateinische Schrift}

Alkitab: berita baik: [Penerbitan Kristian; Terjemahan Kitab Suci Jemaah Kristian dalam Bahasa Malaysia] = Old and New Testament (today's Malay version). - Petaling Jaya, 2006

NÖ Landesbibliothek, Signatur 127.580 B

334 1957-1969 und 1986-2007 Bahasa Melayu.

335 Infolge der unterschiedlichen Kolonialvergangenheit ist die Bahasa Malaysia englisch, die Bahasa Indonesia aber niederländisch geprägt, vgl. z. B. Bahasa Malaysia ekzos (Auspuff, aus englisch exhaust) gegenüber Bahasa Indonesia knalpot.

336 Tetum gehört zur Untergruppe der Timor-Flores-Sprachen.

337 Auf Neuseeland.

338 Auf der Osterinsel. 
Bibel. Neues Testament. Tagalog. Lateinische Schrift

Ang Bagong Tipan: ng Magandang Balita Biblia = Tagalog popular version New Testament. - Manila, 2010

NÖ Landesbibliothek, Signatur 134.010 B

\section{2}

\section{Bibel. Maori-Sprache. Lateinische Schrift}

Ko te Paipera Tapu: ara, ko te Kawenata Tawhito me te Kawenata Hou = The Holy Bible in Maori. Wellington, 1991

NÖ Landesbibliothek, Signatur 133.444 B

\section{3}

\section{Bibel. Hawaiisch. Lateinische Schrift}

Ka Baibala hemolele: o ke kauoha kahiko a me ke kauoha hou: i unuhiia mailoko mai o na olelo kahiko, a hooponopono hou ia = Hawaiian Bible. - New York, NY, [Erscheinungsdatum nicht ermittelbar] NÖ Landesbibliothek, Signatur 133.662 B

\subsection{Afroasiatische Sprachen}

Die afroasiatischen Sprachen, auch als afrasische, hamitosemitische oder semitohamitische ${ }^{339}$, erythräische ${ }^{340}$ oder lisramische ${ }^{341}$ Sprachen bezeichnet, umfassen die semitischen Sprachen, das Ägyptische mit dessen jüngster Sprachstufe Koptisch, die Berbersprachen, die tschadischen Sprachen, die kuschitischen Sprachen inklusive Bedscha $^{342}$ und die omotischen Sprachen ${ }^{343}$. Dass bis auf die semitischen Sprachen alle anderen Gruppen in Nordafrika beheimatet sind, erlaubt einen gewissen Rückschluss auf das Ursprungsgebiet dieser Sprachfamilie: Die afroasiatischen Sprachen gelten als eine der großen afrikanischen Sprachfamilien. ${ }^{344}$ Die semitischen Sprachen

339 Heute überholte Bezeichnung, siehe die folgenden Ausführungen zur Hamitentheorie.

340 Unter Bezugnahme auf das Rote Meer von Leo Reinisch geprägt; Christopher Ehret verwendet diese Bezeichnung für das Afroasiatische unter Ausschluss des stark abweichenden Omotischen.

341 Vorgeschlagen von Carlton T. Hodge, nach afroasiatisch-ägyptisch *lis-rāməč (Sprache der Menschen).

342 Auch Beja oder Bedauye; repräsentiert das Nordkuschitische oder einen eigenständigen Zweig des Afroasiatischen.

343 Nach dem Fluss Omo; früher als westkuschitisch, heute als eigenständiger und stark von den anderen Untergruppen abweichender Zweig des Afroasiatischen angesehen.

344 Neben den Niger-Kongo-Sprachen, den nilosaharanischen Sprachen und den Khoisan-Sprachen; letztere bestehen aus den miteinander nicht verwandten Sprachen und Sprachfamilien Hadza, Sandawe, Khoe-Kwadi (Zentral-Khoisan), Tuu (Südkhoisan) und Ju-łHõã (Nordkhoisan). 
kommen außer im Nahen Osten auch in Afrika und Europa vor. ${ }^{345} \mathrm{Zu}$ den afroasiatischen Charakteristika gehört unter anderem eine Maskulin-Feminin-Unterscheidung, wobei das feminine Genus den Marker t aufweist.

Abgelehnt wird heute die seinerzeit vor allem von Carl Meinhof (1857-1944) vertretene „Hamitentheorie“: Zum einen wurden Sprachen wie Fulfulde (Niger-Kongo-Sprachen), Maasai (nilosaharanische Sprachen) und Khoekhoegowab $^{346}$ (Zentral-Khoisan-Sprachen) zu den hamitischen Sprachen gerechnet und die Bantusprachen im Gegensatz zu den sogenannten Sudansprachen wegen ihrer Nominalklassensysteme als Mischung von „hamitischem Vater“" und „nigritischer Mutter“ angesehen, ${ }^{347}$ zum anderen die nichtsemitischen Sprachen innerhalb des Afroasiatischen den semitischen als hamitisch gegenübergestellt.

Zur Herkunft der Begriffe Hamiten und Semiten: Sem, Ham und Japhet waren die drei Söhne Noahs, von denen nach der „Völkertafel“ (Genesis 10) alle Völker abstammen sollen, im Wesentlichen die Asiaten (jedenfalls die Hebräer über Eber) von Sem, die Afrikaner (jedenfalls die Ägypter) von Ham und die Europäer (jedenfalls die Griechen bzw. Ionier über Jawan) von Japhet. Als Merkmale der hamitischen Sprachen galten flektierender Sprachbau und vor allem das Vorhandensein eines grammatischen Genus wie z. B. im Khoekhoegowab oder im nilohamitischen Maasai, was in den Bantusprachen mit ihren Klassenpräfixen als annähernd erfüllt angesehen wurde; zugleich erblickte man in den Hamiten hochgewachsene, eher hellhäutige nomadisierende Rinderhirten gegenüber den dunkelhäutigeren, sesshaften und Ackerbau treibenden Nigritiern; diese hamitischen Eigenschaften wurden insbesondere auch den Sprechern von Fulfulde, Maasai und Khoekhoegowab zugeschrieben.

Man könnte die Bedeutung von hamitisch als afrikanisch und fast-semitisch auffassen; heute wird auch die daraus resultierende Dichotomie semitisch versus hamitisch innerhalb des Afroasiatischen abgelehnt, weil das Semitische lediglich einen von sechs gleichberechtigten Unterzweigen des Afroasiatischen bildet, sodass man die traditionellen Bezeichnungen hamitosemitische oder semitohamitische Sprachen für das Afroasiatische als überholt ansehen muss.

\subsubsection{Semitische Sprachen}

Das Semitische gliedert sich in das ausgestorbene Ostsemitische mit dem Akkadischen inklusive dem Eblaitischen und das Westsemitische mit dem Nordwestsemitischen, Nordarabischen, Altsüdarabischen, Neusüdarabischen und Äthiosemitischen; Nordwestsemitisch, Nordarabisch und Altsüdarabisch werden wegen gemeinsamer

345 In Europa Maltesisch, eine Varietät des Arabischen, sowie die jüdischen Bildungssprachen Hebräisch und Aramäisch, in Afrika neben dem aus Asien stammenden Arabischen die äthiosemitischen Sprachen wie Amharisch und Tigrinya.

346 Nama inklusive Damara, Hai||om und Topnaar, früher auch als Hottentottisch bezeichnet.

347 Tatsächlich bilden die Bantusprachen eine Untereinheit der westlichen Sudansprachen ( Niger-Kongo). 
Neuerungen auch als zentralsemitisch gegenüber den restlichen peripher-semitischen Sprachen zusammengefasst. Das Nordwestsemitische besteht aus dem ausgestorbenen Ugaritisch, den kanaanäischen Sprachen Hebräisch, Ammonitisch $\uparrow$, Moabitisch $\uparrow$, Edomitisch $\uparrow$ und Phönizisch $\uparrow$ inklusive Punisch $\uparrow$ und den aramäischen Sprachen inklusive Syrisch.

Das Akkadische ist seit der Mitte des dritten vorchristlichen Jahrtausends belegt und stark vom Sumerischen, einer seit Mitte des vierten vorchristlichen Jahrtausends in Südmesopotamien gesprochenen isolierten Sprache, beeinflusst; beide Sprachen zusammen bilden den Kernbereich der durch die Verwendung einer Silbenschrift, der Keilschrift, gekennzeichneten Sprachen des Alten Orients. Bereits im dritten Jahrtausend vor Christus treten Eblaitisch $^{348}$, Mariotisch ${ }^{349}$ und der Dialekt von Tell Beydar ${ }^{350}$ als weitere Varietäten des Altakkadischen neben dem Reichsakkadischen der von Sargon von Akkad begründeten Dynastie in Erscheinung; später werden die Dialekte Babylonisch ${ }^{351}$ und Assyrisch ${ }^{352}$ greifbar, die zwar auf das vorangehende Ur-III-Akkadische, nicht aber auf das Reichsakkadische zurückgeführt werden können.

Charakteristisch für das Akkadische ${ }^{353}$ ist die Kategorie des mithilfe der Suffixkonjugation gebildeten Stativs ${ }^{354}$ (anstelle der in den anderen Verbalkategorien üblichen Präfixkonjugation ${ }^{355}$ ). Das Westsemitische bildet hingegen mithilfe der Suffixkonjugation das Perfekt, wohingegen die Präfixkonjugation ${ }^{356}$ für das Imperfekt verwendet wird.

Bis ins vierte nachchristliche Jahrhundert sind Inschriften in verschiedenen frühnordarabischen Dialekten ${ }^{357}$ überliefert; die verwendeten Schriften sind mit der altsüdarabischen Schrift verwandt. Zu den sprachlichen Kennzeichen gegenüber dem Arabischen gehört die Verwendung des Artikels h- statt al-. ${ }^{358}$ Das Altarabische mit dem klassischen Arabisch weist noch die kurzvokalischen Kasusendungen inklusive der Nunation bei unbestimmten Nomina auf, die an die akkadische Mimation erinnert. ${ }^{359}$

348 Nach der Stadt Ebla in Syrien.

349 Nach der Stadt Mari am mittleren Euphrat, in Syrien.

350 Ebenfalls in Syrien.

351 Altbabylonisch ca. 1900-1500 vor Christus, Mittelbabylonisch ca. 1500-1000 vor Christus, Neubabylonisch ca. 1000-626 vor Christus, Spätbabylonisch ab 626 vor Christus; als Jungbabylonisch wird die archaisierende Literatursprache der neubabylonischen Zeit bezeichnet.

352 Altassyrisch, Mittelassyrisch und Neuassyrisch, zeitlich parallel zu den entsprechenden babylonischen Sprachstufen.

353 Neben dem Zusammenfall oder Schwund verschiedener Konsonanten und der Verwendung der sonst nicht belegten Präpositionen ina (in, an, bei) und ana (zu, nach).

354 Siehe beispielsweise paris / pars-at (3. Person Singular maskulin / feminin) zur Wurzel prs (entscheiden).

355 Von derselben Wortwurzel: i-prus (3. Person Singular Präteritum), i-parras (3. Person Singular Präsens) und i-p-ta-ras (3. Person Singular Perfekt).

356 Vgl. arabisch Perfekt katab-a / katab-at (er / sie hat geschrieben) gegenüber Imperfekt ya-ktub-u / ta-ktub-u (er / sie schreibt).

357 Wie z. B. Dadanitisch und Safaitisch.

358 Vgl. den hebräischen Artikel.

359 Arabisch $b \bar{a} b-u-n, b \bar{a} b-i-n, b \bar{a} b-a-n$ gegenüber bestimmtem al-bāb-u (Tür), vgl. akkadisch šarr-um, šarr-im, šarr-am (König). 
Neben der Schriftsprache (modernes) Hocharabisch haben sich zahlreiche gesprochene Varietäten des Arabischen ${ }^{360}$ entwickelt; eine selbständige Schriftsprache hat das in lateinischer Schrift geschriebene Maltesische ausgebildet.

Die arabische Schrift, eine linksläufige Konsonantenschrift (Abdschad), geht über die Zwischenstufe der nabatäischen Schrift auf die aramäische Schrift zurück; typisch ist die unterschiedliche Gestalt der miteinander verbundenen Buchstaben je nach Position im Wort (alleinstehend, am Wortanfang, im Wortinneren oder am Wortende); sechs Buchstaben (Alif, Dāl, D̄āl, Rā, Zāy und Wāw) können allerdings nicht nach links verbunden werden, sodass sie selbst die Endform und der folgende Buchstabe die Anfangsform aufweisen. Entsprechend dem großen Phoneminventar des Arabischen mit 28 erhaltenen von 29 ursemitischen Konsonanten wurden Zeichen in die klassische Alphabet-Abfolge eingefügt, wobei die Übereinstimmung der Zeichenform bis auf die (dem zuvor undifferenzierten Rasm) später hinzugefügten diakritischen Punkte eine Rolle spielte. ${ }^{361}$ Ähnlich wie für die hebräische Schrift gibt es auch für die arabische Schrift (neben der Plene-Schreibung der Langvokale $\bar{a}, \overline{1}, \bar{u}$ durch die Konsonanten Alif, Yā', Wāw) ein Vokalisierungssystem, Taškīl oder Harakāt genannt. Zu den verwendeten Zeichen gehören Šadda oder Tašdīd (Konsonanten-Verdoppelung), Sukūn (Vokallosigkeit), Fatḥa (Kurzvokal a), Kasra (Kurzvokal i), Damma (Kurzvokal u); verdoppelte Vokalzeichen Fathatan, Kasratan, Dammatan dienen zur Wiedergabe der Nunation (-an, -in, -un). Die arabische Kalligrafie brachte verschiedene Schriftstile hervor, als deren für den Druck wichtigster die Nashī-Schrift gilt; erwähnt seien auch die archaische kufische Schrift und die persische Nasta līq-Schrift.

Das Altsüdarabische, das die 29 konsonantischen Phoneme des Ursemitischen vollständig bewahrt hat, ist in tausenden Inschriften vom neunten vorchristlichen bis zum sechsten nachchristlichen Jahrhundert überliefert; es umfasst die Sprachformen Sabäisch ${ }^{362}$ sowie Minäisch ${ }^{363}$, Qatabanisch und Hadramautisch, wobei Sabäisch als h-Sprache den restlichen s-Sprachen gegenüberzustellen ist. ${ }^{364}$ Die altsüdarabische Schrift, zu deren Umfeld auch die frühnordarabischen Inschriften gehören, ist wie die phönizische Schrift und die althebräische Schrift ein Abkömmling der protosinaitischen (protokanaanäischen) Schrift; sie folgt der auch für das Ugaritische belegten besonderen Reihenfolge h, l, h., m ... Diese Reihenfolge bildet übrigens eine der Erklärungen für die Herkunft des Wortes elementum, das somit eine Parallele zu ABC oder Alphabet darstellen würde; dies gilt allerdings auch

360 Maghrebinisches Arabisch (Marokkanisch-Arabisch, Algerisch-Arabisch, Tunesisch-Arabisch, Libysch-Arabisch, Maltesisch), Ägyptisches Arabisch, Sudanesisches Arabisch, Levantinisches Arabisch (Syrisch-Arabisch, Libanesisch-Arabisch, Palästinensisch-Arabisch, Jordanisch-Arabisch, zypriotisches Arabisch), Irakisch-Arabisch, Golf-Arabisch, Jemenitisch-Arabisch, Oman-Arabisch, die Hedschas-Dialekte usw.

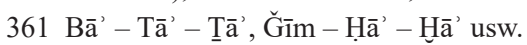

362 Nach dem Reich Saba.

363 Nach dem Reich Ma'in.

364 Vgl. z. B. die suffigierten Personalpronomina der 3. Person Plural sabäisch -hm (maskulin) und -hn (feminin) gegenüber sonstigem - $\mathrm{s}_{1} \mathrm{~m}$ bzw. - $\mathrm{s}_{1} \mathrm{n}$. Vgl. dazu arabisch -humu und -hunna gegenüber akkadisch -šunu und -šina. 
für eine Herleitung von $1-\mathrm{m}-\mathrm{n}$, den ersten drei Buchstaben der zweiten Hälfte des phönizischen Alphabets. Ein Abkömmling der altsüdarabischen Schrift ist die äthiopische Schrift und vielleicht auch die Tifinagh-Schrift.

Die weiter östlich als die altsüdarabischen Sprachen gesprochenen neusüdarabischen Sprachen sind kein Nachfahre derselben; am bekanntesten sind die Sprachen Mehri, Jibbāli (Śḥeri) und Soqotri.

Das Äthiosemitische umfasst neben dem ausgestorbenen Altäthiopischen oder Ge'ez, der Sprache des Aksumitischen Reiches und Liturgiesprache der Äthiopisch-Orthodoxen Tewahedo-Kirche ${ }^{365}$ und der EritreischOrthodoxen Tewahedo-Kirche ${ }^{366}$, und den damit näher verwandten Sprachen Tigré und Tigrinya vor allem Amharisch, die Amtssprache Äthiopiens, und weitere, zum Teil als Gurage-Sprachen zusammengefasste Idiome.

Die äthiopische Schrift, ein Abkömmling der altsüdarabischen Schrift ${ }^{367}$, ist rechtsläufig und hat sich zu einer Silbenschrift (Abugida) entwickelt: Dem jeweiligen Konsonanten ist der Vokal a (altäthiopisch) bzw. ä (amharisch) inhärent, andere Vokale oder Vokallosigkeit werden durch regelmäßige Modifikationen der Grundbuchstaben ausgedrückt, im Prinzip wie bei den indischen Schriften. Unabhängig von der Frage, ob die äthiosemitischen Sprachen auf eine Einwanderung aus Altsüdarabien über das Rote Meer zurückgehen oder autochthon sind, belegt die äthiopische Schrift den kulturellen Austausch mit dieser Region.

Nach der Stadt Ugarit in Syrien (heute Ra's Schamra) ist das Ugaritische benannt. Die ugaritische Schrift ist eine Alphabetschrift in keilschriftlicher Form und wurde vom Ende des vierzehnten Jahrhunderts bis zum Beginn des zwölften vorchristlichen Jahrhunderts verwendet. Neben den $22 \mathrm{im}$ phönizischen Alphabet üblichen gibt es weitere fünf ( $\left(\underline{\mathrm{d}}, \dot{\mathrm{g}}, \mathrm{h}, \breve{s}\right.$, z) und somit insgesamt 27 Konsonantenzeichen und drei Sonderzeichen ('i, 'u, $\mathrm{s}_{2}$ ), deren erste beide zusammen mit '(a) die Schreibung von Vokalen nach ? erlaubten. Neben der üblichen Reihenfolge '(a), b, g, (h), d ... ist auch die südarabische Reihenfolge h, $1, \mathrm{~h}, \mathrm{~m}$... auf erhaltenen Abecedarien vertreten. Außer der rechtsläufigen Langform kommt aber auch bereits die linksläufige Kurzform mit nur 22 Konsonanten vor. Unklar ist die Beziehung zur Byblos-Schrift (achtzehntes bis vierzehntes vorchristliches Jahrhundert), offenbar eine Silbenschrift, die noch einer zufriedenstellenden Entzifferung harrt.

Beim Hebräischen unterscheidet man die Sprachstufen Althebräisch ${ }^{368}$, Mittelhebräisch ${ }^{369}$, Neuhebräisch und Modernes Hebräisch ${ }^{370}$. Zu den typischen Entwicklungen des Hebräischen gehört die Entstehung der Segolata:

365 Früher Teil der Koptisch-Orthodoxen Kirche, seit 1950 autokephal.

366 Früher Teil der Äthiopisch-Orthodoxen Kirche, 1998 autokephal.

367 Mit der Reihenfolge h, 1, hi, m ...

368 Erstes vorchristliches Jahrtausend, mit dem Biblisch-Hebräischen.

369 Zweites vorchristliches bis fünftes nachchristliches Jahrhundert, mit den literarischen Ergebnissen Mischna und Gemara sowie Midraschim.

370 Ivrit; wiederbelebt als gesprochene Sprache. 
Semitisch *málku (König) wurde nach Abfall der kurzvokalischen Kasusendungen ${ }^{371}$ über *málk durch Epenthese des Vokals Segol zu *mál $k$, durch folgende Assimilation des Stammvokals zu *mélek und durch die abschließende Entwicklung der nicht emphatischen Verschlusslaute nach Vokal zu Reibelauten ${ }^{372}$ zu mélekh; analoger Werdegang bei *kúdshu (Heiligtum) $\rightarrow * k u ́ d s h \rightarrow * k u ́ d_{e} s h \rightarrow k o ́ d e s h$. Unterschiede zum Aramäischen bestehen unter anderem im kanaanäischen Lautwechsel ā zu $\overline{0},{ }^{373} \mathrm{im}$ hebräischen präfigierten Artikel $h a^{374}$ gegenüber aramäischem suffigiertem $\bar{a}$ und beim Wort hebräisch ben (Sohn) gegenüber aramäisch bar.

Hebräisch wurde zunächst in der althebräischen Schrift, einer nahen Verwandten der phönizischen Schrift, geschrieben; später fand eine Wechsel zur aramäischen Schrift statt, die der heutigen hebräischen Schrift zugrunde liegt. Gehalten hat sich die althebräische Schrift lediglich in der heiligen Schrift der Samaritaner, dem „Samaritanischen Pentateuch“. Die hebräische Schrift ist eine linksläufige Konsonantenschrift (Abdschad), in der lediglich die Konsonanten He, Waw und Jod als matres lectionis zur Andeutung der Langvokale a, u/o und i/e verwendet werden konnten (Plene-Schreibung im Unterschied zur defektiven Schreibung). Erst zwischen 700 und 1000 nach Christus entwickelten die Masoreten, am bedeutendsten die Familie Ben-Asher aus Tiberias, ein Punktationssystem zur vollständigen Wiedergabe der gesprochenen Vokale, vor allem in der Heiligen Schrift. Dieser textkritisch bearbeitete Text heißt „Masoretischer Text“" (im Unterschied zum Konsonantentext, der um 100 nach Christus fixiert worden war); die älteste vollständig erhaltene Handschrift ist der „Codex Leningradensis“" von 1008, die Grundlage der heutigen Druckausgaben der hebräischen Bibel.

Vergleichsweise nur spärlich bezeugt sind die transjordanischen Sprachen: Ammonitisch, die Sprache der Ammoniter, die südlich des Landes Gilead ${ }^{375}$ und nördlich von Moab siedelten, mit dem Zentrum Rabbat-Amman, dem heutigen Amman, und dem Hauptgott Milkom, Moabitisch, die Sprache der zwischen den Ammonitern im Norden und den Edomitern im Süden siedelnden Moabiter, ${ }^{376}$ und schließlich Edomitisch ${ }^{377}$.

Das Phönizische, das vor allem im heutigen Libanon in Stadtstaaten wie Byblos, Beirut, Sidon und Tyrus gesprochen wurde, und seine in Karthago gesprochene Tochtersprache Punisch ${ }^{378}$ sind vor allem wegen der mit

371 -u Nominativ, -i Genetiv, -a Akkusativ.

372 Im heutigen Hebräisch entsprechende Aussprache nur mehr bei v statt b, f statt $\mathrm{p}$ und kh statt $\mathrm{k}$.

373 Siehe z. B. die weibliche Pluralendung -ōt in banot (Töchter) zum Singular bat, vgl. arabisch banāt, siehe auch hebräisch shalom gegenüber arabisch salām.

374 Ursprünglich *hal-, vgl. arabisch al-, oder aber *han-.

375 Mit der in Deir Alla aufgefundenen „Bileam-Inschrift“ aus der Zeit um 800 vor Christus, deren Sprache nicht eindeutig als kanaanäisch oder aramäisch einzuordnen ist.

376 Berühmt ist der Fund der „Mescha-Stele“ aus dem neunten vorchristlichen Jahrhundert zum Dank für die Befreiung Moabs von der Herrschaft Israels mithilfe des Gottes Kemosch.

377 Als Stammvater der Edomiter gilt Esau; Hauptgott war Qaus.

378 Mit der bekannten Textstelle in der Komödie „Poenulus“ des Plautus. 
dieser Sprache verbundenen phönizischen Schrift bedeutsam; von dieser linksläufigen Konsonantenschrift (Abdschad) mit 22 Buchstaben in der festgelegten Reihenfolge Palf (Rind), bèt (Haus), gaml (Kamel), delt (Tür) usw. stammen die griechische Schrift und deren Nachfolger ebenso wie die aramäische Schrift und deren Nachfolger ab. Sie rührt ihrerseits wie auch die althebräische Schrift und die altsüdarabische Schrift von der protosinaitischen (protokanaanäischen) Schrift her, als deren Beginn die Wadi-el-Hol-Schrift aus Ägypten (neunzehntes vorchristliches Jahrhundert) gilt. Nach dem Vorbild der Ein-Konsonanten-Zeichen der ägyptischen Hieroglyphen (bzw. der linksläufigen hieratischen Schrift) und unter Anwendung des akrophonen Prinzips wurden den Zeichen die Lautwerte des Anfangskonsonanten der dargestellten Wörter zugeordnet, allerdings in ihrer semitischen statt ihrer überlieferten ägyptischen Lautung.

Das Aramäische gliedert sich in Altaramäisch ${ }^{379}$, Reichsaramäisch ${ }^{380}$, Mittelaramäisch mit dem Biblischen Aramäisch, Nabatäisch und Palmyrenisch, Klassisches Westaramäisch (Jüdisch-Palästinisch, Samaritanisch, Christlich-Palästinisch) und Klassisches Ostaramäisch (Klassisches Syrisch, Klassisches Mandäisch, Babylonisch-Talmudisch), Neuwestaramäisch (Dialekte von Ma' lūla, Bax‘a und Ğubb'adīn in Syrien) und Neuostaramäisch (Turoyo, Assyrisch-Neuaramäisch, Chaldäisch-Neuaramäisch, Neu-Mandäisch und weitere christliche und jüdische Sprachformen).

Die aramäische Schrift, ein Abkömmling der phönizischen Schrift (und somit ebenfalls ein linksläufiges Abdschad), hat die althebräische Schrift (abgesehen vom Samaritanischen) verdrängt und bildet die Grundlage der heutigen hebräischen Schrift. Weitere Abkömmlinge sind die syrische Schrift (Estrangelo, westsyrische oder jakobitische Schrift bzw. Serto, ostsyrische oder nestorianische Schrift) mit der davon abgeleiteten sogdischen Schrift und deren Nachfahren, ${ }^{381}$ die mandäische Schrift, die palmyrenische und die nabatäische Schrift, die ihrerseits zur arabischen Schrift führt. Die indische Kharoșthī-Schrift und wohl auch die Brahmi-Schrift, sicher auch die Pahlavischrift und die awestische Schrift, lassen sich ebenfalls auf die aramäische Schrift zurückführen, die armenische und georgische Schrift sind hingegen nicht ohne gleichzeitige Annahme eines Einflusses der griechischen Schrift erklärbar.

Im Laufe des ersten Jahrtausends war Aramäisch auf Kosten des Akkadischen zur überwiegend gesprochenen Sprache Mesopotamiens geworden; dies betraf infolge der Deportationen letztlich auch das um 720 vor Christus von den Assyrern eroberte Nordreich Israel und das 597 vor Christus von den Babyloniern eroberte Südreich Juda und ist der Grund für den Aufstieg des Aramäischen zur Verwaltungssprache des Perserreiches infolge der Eroberung Babylons 539 vor Christus, die zugleich das Ende des babylonischen Exils markiert. Aramäisch ver-

379 Mit dem Dialekt von Ja'udi.

380 Des Perserreiches. 
drängte nun auch das Hebräische als Alltagssprache; es kam zu Targumim (aramäische Übersetzungen biblischer Texte), bereits zuvor entstanden aber auch einige biblische Textpassagen in aramäischer Sprache.

Die eigentliche aramäische Bibel ist aber die um 400 nach Christus entstandene syrische Peshitta, die vor allem die Evangelienharmonie „Diatessaron“ des Tatian aus dem zweiten nachchristlichen Jahrhundert endgültig verdrängte. Nach den Konzilien von Ephesos 431 und Chalcedon 451, bei denen der Nestorianismus abgelehnt worden war, übernahm das Katholikat Seleukia-Ktesiphon im damaligen Sassanidenreich (und somit außerhalb der Grenzen des Oströmischen Reiches) 484 diese Lehre und begründete damit die ostsyrische Assyrische Kirche des Ostens; zum ostsyrischen Christentum gehören auch die 1968 abgespaltene Alte Kirche des Ostens, die Chaldäisch-Katholische Kirche und die Syro-malabarische Katholische Kirche. Zum westsyrischen Ritus zählen die monophysitische (miaphysitische) bzw. jakobitische Syrisch-Orthodoxe Kirche von Antiochien (mit der Malankara Syrisch-Orthodoxen Kirche) und deren katholische Abspaltungen, die Syrisch-katholische Kirche und die Syrisch-Maronitische Kirche von Antiochien sowie die Syro-Malankara Katholische Kirche, weiters die Griechisch-orthodoxe Kirche von Antiochien bzw. von Jerusalem und die Melkitische Griechisch-katholische Kirche.

Trotz dieser gerade aus christlicher Perspektive großen Bedeutung des Aramäischen bzw. Syrischen befindet sich dieses auf dem ständigen Rückzug vor dem vom Islam getragenen Arabischen, sodass Syrien heute nahezu zur Gänze arabischsprachig ist, so wie auch das Koptische in Ägypten vom Arabischen verdrängt wurde. Nach dem Akkadischen und dem Aramäisch-Syrischen ist also Arabisch die dritte semitische Lingua franca im Nahen Osten.

In dem von Holger Gzella herausgegebenen Buch „Sprachen aus der Welt des Alten Testaments“ werden unter anderem neben der Entwicklung der Alphabetschrift die Sprachen Ugaritisch, Phönizisch, Althebräisch, die transjordanischen Sprachen, Alt- und Reichsaramäisch sowie Altsüdarabisch vorgestellt.

Darüber hinaus werden Bibeln in Maltesisch und Arabisch, Bibeln in westsyrischer und ostsyrischer Tradition, ein neuhebräisches Neues Testament sowie Bibeln in Amharisch und Tigrinya vorgestellt; Hebräisch und Aramäisch-Syrisch sind auch im ersten Bereich vertreten. ${ }^{382}$

Literaturtipps:

Satzinger, Helmut. Antike Buchstabenschriften der arabischen Halbinsel: Herkunft und Fortleben. In: Der Turmbau zu Babel: Ursprung und Vielfalt von Sprache und Schrift / herausgegeben von Wilfried Seipel. Band 3A, Schrift. -2003

Sprachen des Alten Orients / Michael P. Streck (Hrsg.). - 3. Auflage. - Darmstadt, 2007

382 Katalog Nr. 5, 6, 7, 10, 11, 12, 19, 21, 22 und 24. 


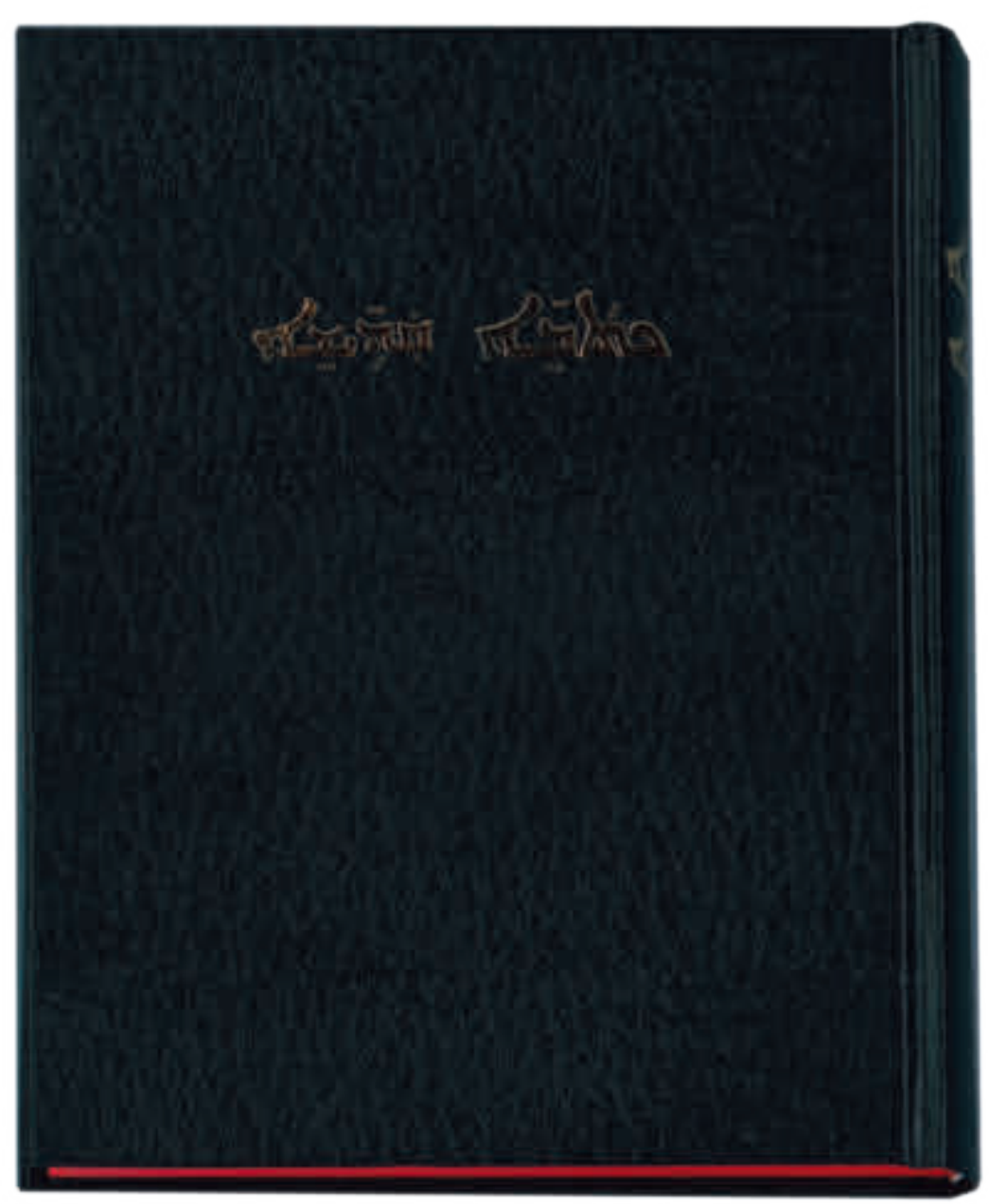

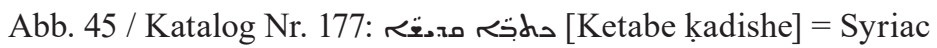
Bible (1979).
Sprachen aus der Welt des Alten Testaments / Holger Gzella (Hrsg.). - Darmstadt, [2009]

Krause, Martin, 1942-. Hebräisch: biblischhebräische Unterrichtsgrammatik / herausgegeben von Michael Pietsch und Martin Rösel. - Berlin; New York, NY, [2008]

Segert, Stanislav, 1921-2005. Altaramäische Grammatik: mit Bibliographie, Chrestomathie und Glossar. 4., unveränderte Auflage. - Leipzig, [1990]

174

Sprachen aus der Welt des Alten

Testaments / Holger Gzella (Hrsg.). Darmstadt, [2009]

NÖ Landesbibliothek, Signatur 132.102 B

\section{5}

Bibel. Maltesisch. Lateinische Schrift

Il- Bibbja mqaddsa: it-testment il-qadim u t-testment il-gdid: skond il-verżjoni awtorizzata: maqluba ghall-malti mill-ingliż $=$ Maltese Bible. - London, 2006 NÖ Landesbibliothek, Signatur 122.130 B

176

Bibel. Arabisch. Arabische Schrift [alKitāb al-muqaddas: ay kutub al-'ahd al-qadīm wa-'1-'ahd al-ğadīd] = Arabic Bible. -1998 NÖ Landesbibliothek, Signatur 119.721 B 
Bibel. Syrisch. Westliche Syrische Schrift (Serto)

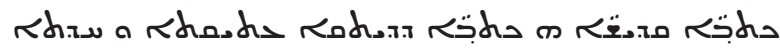
[Ketabe kadishe he ketabe de-diyatiki 'atiḳta wa-hdata $]=$ Syriac Bible - London, 1979 NÖ Landesbibliothek, Signatur 124.406 B Abb. 45

\section{8}

Bibel. Neuostaramäisch. Östliche Syrische Schrift (Nestorianisch)

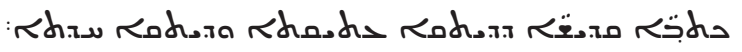
م حס [Ktābe qadíše d-diyatiqi 'atíqtā w-diyatiqi hudatā 'am sahedwātā] = Syriac Modern Bible. - Beirut, 1995

NÖ Landesbibliothek, Signatur 119.719 B

\section{9}

Bibel. Neues Testament. Neuhebräisch. Hebräische Schrift

הברית החדשה [ha- Berit ha-ḥadashah]. Jerusalem, 1991

NÖ Landesbibliothek, Signatur 119.720 B

\section{0}

Bibel. Amharisch. Äthiopische Schrift

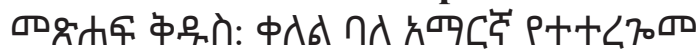
[Maṣhạaf qedus: qalal bāla 'amāreñā yatataragwama] $=$ Amharic Bible - Addis Abeba, 1980

NÖ Landesbibliothek, Signatur 119.723 B Abb. 46

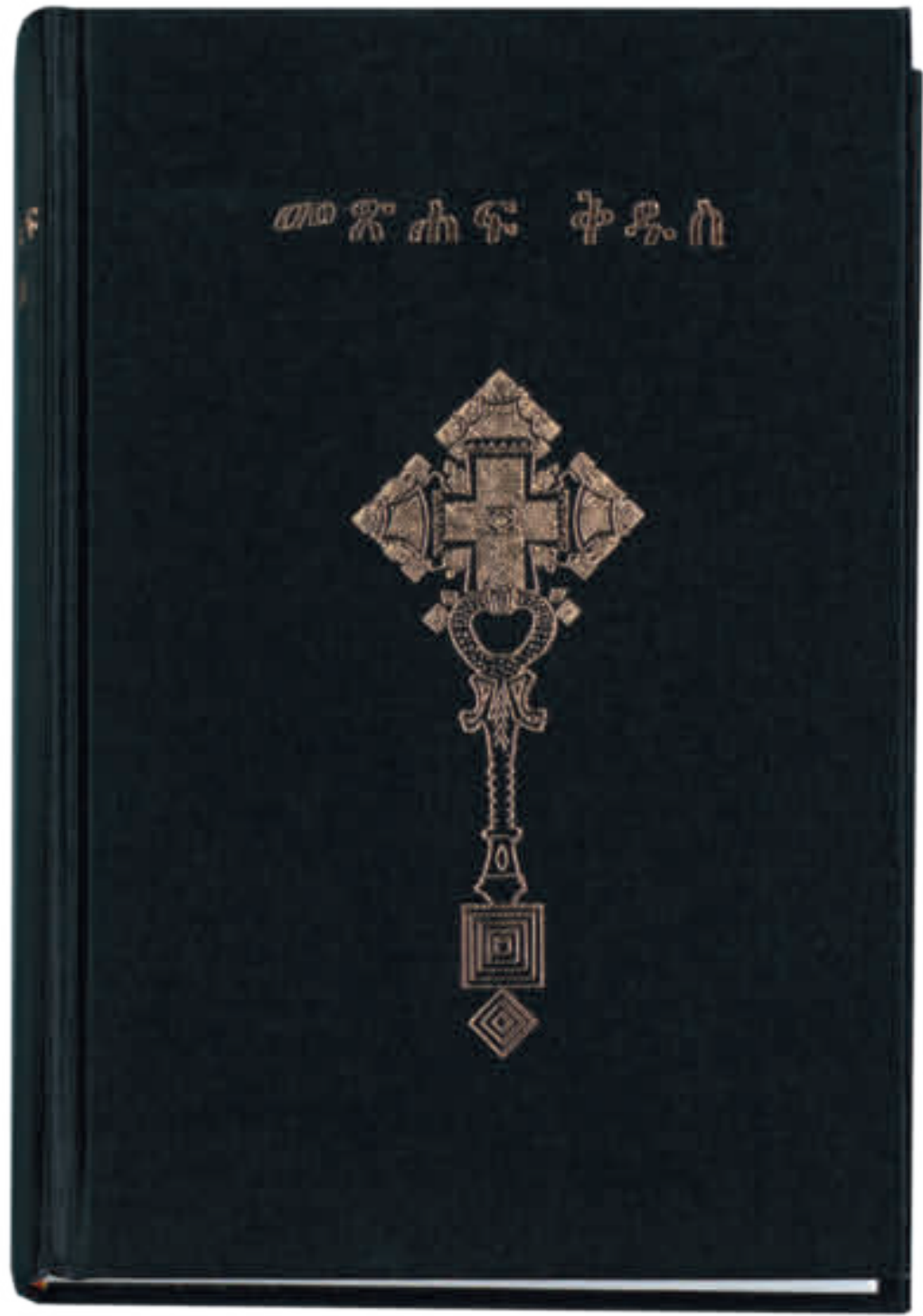

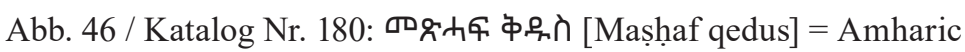
Bible (1980). 


\section{Bibel. Tigrinja. Äthiopische Schrift}

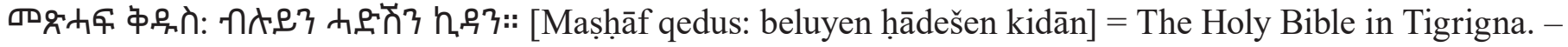

Asmara, 2001

NÖ Landesbibliothek, Signatur 119.722 B

\subsection{2 Ägyptische Sprache (Koptisch)}

Einen eigenständigen, allerdings ausgestorbenen Zweig des Afroasiatischen stellt das Ägyptische ${ }^{383}$ dar, das die afroasiatische Präfixkonjugation schon zu Beginn verloren hat; die stativische Suffixkonjugation ${ }^{384}$ ist in Form des ägyptischen Pseudopartizips (koptischen Qualitativs) erhalten.

An Sprachstufen werden unterschieden:

Frühägyptisch (prädynastische Zeit bis Ende der dritten Dynastie, ca. 3300-2700 vor Christus)

Altägyptisch (Altes Reich, ca. 2700-2200 vor Christus)

Mittelägyptisch (Mittleres Reich, ca. 2200-1500 vor Christus)

Neuägyptisch (Neues Reich, ca. 1500-700 vor Christus)

Demotisch (ca. 700 vor bis 400 nach Christus)

Koptisch (ca. 300-1700 nach Christus, lebt als Liturgiesprache der sich auf den Evangelisten Markus als Gründer berufenden, monophysitischen oder genauer miaphysitischen Koptisch-orthodoxen Kirche weiter).

Im Unterschied zu früheren Sprachstufen des Ägyptischen besteht das Koptische aus mehreren Dialekten mit schriftsprachlichem Charakter; am wichtigsten sind das Sahidische (Thebanische) aus Oberägypten und das Bohairische (Alexandrinische) aus Unterägypten, die heutige Liturgiesprache der Kopten. Die heute vielleicht zehn Prozent der ägyptischen Bevölkerung und damit um zehn Millionen Menschen umfassenden Kopten definieren sich nicht mehr über ihre Sprache, sondern über ihre christliche Religionszugehörigkeit. Das ägyptische Christentum besitzt eine besondere Bedeutung durch die Grundlegung des christlichen Mönchtums: Neben dem heiligen Antonius dem Einsiedler ( $†$ 356), dem Begründer des Eremitentums, und dem heiligen Pachomios ( $†$ 346), dem Begründer des ersten Klosters (mit der „Engelsregel“) und somit des Koinobitentums, ist hier der durch den

383 Altägyptisch wäre missverständlich, weil es eine bestimmte Sprachstufe des Ägyptischen bezeichnet; man muss also Ägyptisch und das heutige Ägyptisch-Arabisch unterscheiden. Unter Einbeziehung der jüngsten Sprachstufe des Ägyptischen, des Koptischen, spricht man auch von Ägyptisch-Koptisch. Die alternative Bezeichnung Kemisch leitet sich vom einheimischen Namen für Ägypten (Kemet, eigentlich Km.t, schwarzes Land bzw. Nilschwemmland, im Unterschied zu Deshret, rotes Land oder Wüste, auch die rote Krone von Unterägypten) her, davon abgeleitet vielleicht auch das Wortfeld Alchimie, Alchemie, Chemie. 
Kirchenvater Hieronymus legendenhaft überlieferte heilige Paulus von Theben $(\dagger 341)$ als erster ägyptischer Einsiedler und Wüstenvater erwähnenswert; genannt sei auch noch der spätere Schenute von Atripe († 466), ein Archimandrit. Vom koptischen Schrifttum sind vor allem die „Nag-Hammadi-Texte“ (mit dem „Thomasevangelium“) zu nennen.

Die koptische Schrift, die seit dem zweiten nachchristlichen Jahrhundert verwendet wurde, basiert auf der griechischen Schrift, die um acht Zeichen demotischen Ursprungs vermehrt wurde. Diese Alphabetschrift verdrängte die demotische Schrift (siebentes vorchristliches bis fünftes nachchristliches Jahrhundert), die ihrerseits eine Weiterentwicklung der hieratischen Schrift, der zeitlich parallelen kursiven Ausprägung der monumentalen ägyptischen Hieroglyphen, bildete. Dieses neben der mesopotamischen Keilschrift älteste Schriftsystem mit bis 3200 vor Christus zurückreichenden Schriftfunden besaß ein Zeicheninventar von Logogrammen und Ideogrammen neben Phonogrammen (Ein-, Zwei- und Drei-Konsonanten-Zeichen); Vokale wurden wie in verschiedenen semitischen Schriften nicht geschrieben und sind daher nicht bekannt ${ }^{385}$ oder allenfalls durch Nennungen in anderen Sprachen oder Rückschlüsse aus dem Koptischen erschließbar.

Vorangestellt wird dem Bereich die lateinische Dissertation von Mathias Fuhrmann (1690-1773) über den heiligen Paulus von Theben, verfasst 1759 im Paulinerkloster Wiener Neustadt (gegründet 1476 durch Kaiser Friedrich III., aufgehoben 1783 durch Kaiser Joseph II.). Damit ist ein niederösterreichischer Anknüpfungspunkt zum koptischen Christentum gegeben.

Als wissenschaftlich einführende Literatur in das Thema Koptisch dient die „Einführung in die koptische Sprache“ von Uwe-Karsten Plisch, der als Herausgeber auch für die Ausgabe des „Thomasevangeliums“ verantwortlich zeichnet.

Der Brite George William Horner (1849-1930) veröffentlichte 1898-1905 das koptische Neue Testament im bohairischen Dialekt in vier Bänden und 1911-1924 das koptische Neue Testament im sahidischen Dialekt in sieben Bänden; von beiden Ausgaben wird ein Reprint des jeweils dritten Bandes präsentiert.

\section{2}

Fuhrmann, Mathias, 1690-1773. Acta sincera Sancti Pauli Thebaei cognomento primi Eremitae GraecoLatina: cum variantibus lectionibus \& notis variorum. - Dissertation, Paulinerkloster Wiener Neustadt, 1759 NÖ Landesbibliothek, Signatur 53.043 B 


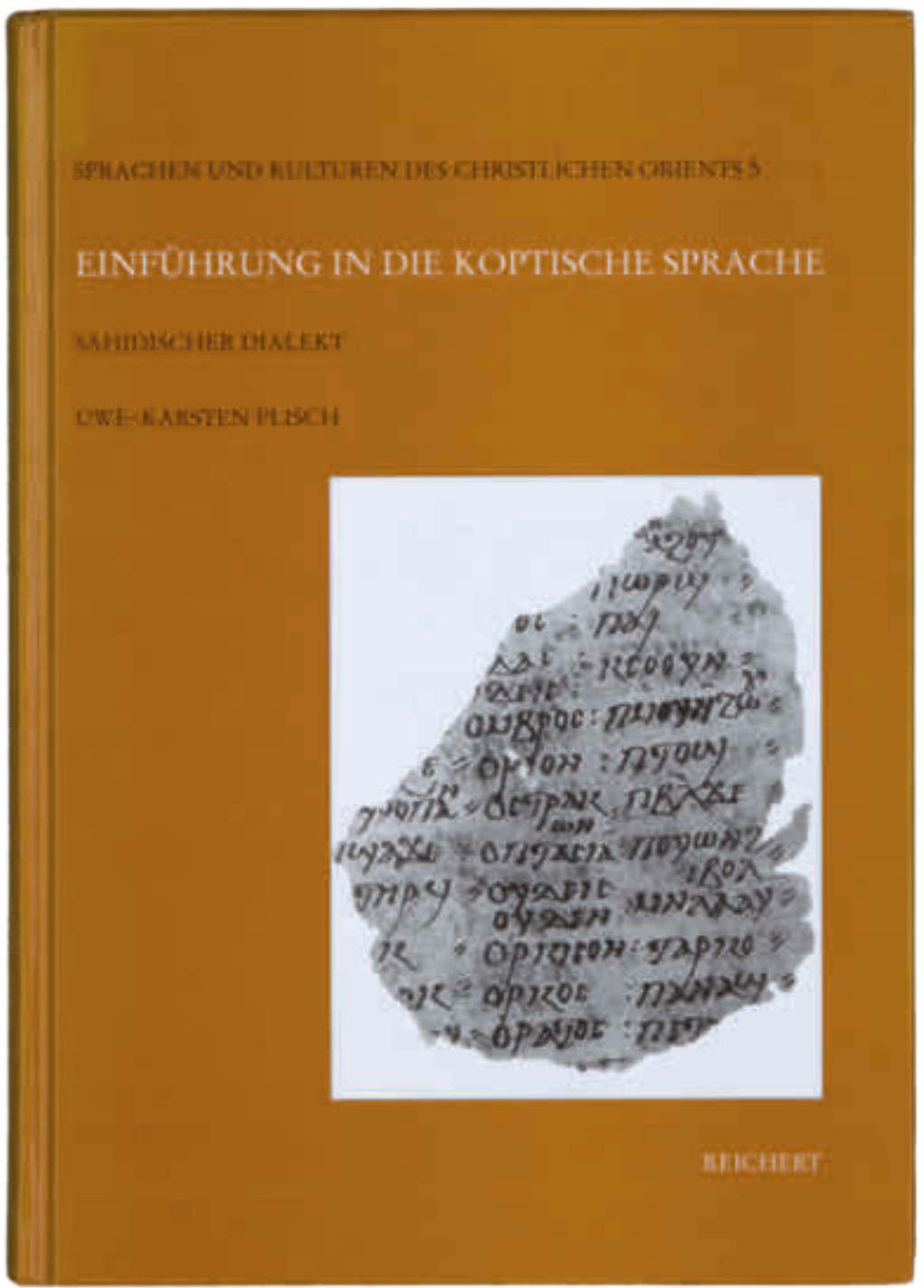

Abb. 47 / Katalog Nr. 183: Uwe-Karsten Plisch, Einführung in die koptische Sprache: Sahidischer Dialekt (1999).
183

Plisch, Uwe-Karsten, 1965-. Einführung in die koptische Sprache: Sahidischer Dialekt.

- Wiesbaden, 1999. - (Sprachen und Kulturen des christlichen Orients; Band 5)

NÖ Landesbibliothek, Signatur 118.383 B 5

Abb. 47

\section{4}

Evangelium Thomae

Das Thomasevangelium: Originaltext mit Kommentar / Uwe-Karsten Plisch. Stuttgart, 2007

NÖ Landesbibliothek, Signatur 118.737 B Abb. 48

185

Bibel. Johannesevangelium. Sahidisch. Koptische Schrift

The gospel of S. John: register of fragments, etc.: facsimiles. - Milton Keynes, 2010. (The Coptic version of the New Testament in the southern dialect: otherwise called Sahidic and Thebaic: with critical apparatus, literal English translation, register of fragments and estimate of the version / George William Horner; 3)

NÖ Landesbibliothek, Signatur 132.607 B 
186

Bibel. Paulinische Briefe. Bohairisch.

Koptische Schrift

The epistles of S. Paul: edited from Ms. Oriental 424 in the British Museum. -

Charleston, SC, 2010. - (The Coptic version

of the New Testament in the northern dialect:

[otherwise called Memphitic and Bohairic:

with introduction, critical apparatus, and

literal English translation] / George William

Horner; 3)

NÖ Landesbibliothek, Signatur 132.593 B

\subsubsection{Kuschitische Sprachen}

Die kuschitischen Sprachen $^{386}$ umfassen nach Abtrennung der früher als westkuschitisch klassifizierten omotischen Sprachen das nordkuschitische Bedscha ${ }^{387}$,

386 Nach Kusch, dem ältesten Sohn Hams. Das danach benannte antike Reich von Kusch mit dem anfänglichen Zentrum Napata und dem späteren Zentrum Meroe (in Nubien, d. h. im nördlichen Sudan) existierte vom achten vorchristlichen bis zum vierten nachchristlichen Jahrhundert; das in der meroitischen Schrift geschriebene und derzeit noch weitgehend unverständliche Meroitische war die Sprache des Reiches von Kusch und wird heute meist mit dem Nilosaharanischen in Verbindung gebracht.

387 Auch Beja oder Bedauye, möglicherweise ein eigenständiger Zweig des Afroasiatischen.

\section{Uwe-Karsten Plisch}

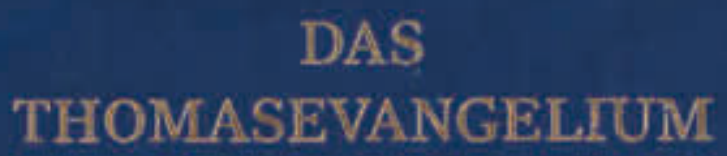

Originaltext mit Kommentar
Abb. 48 / Katalog Nr. 184: Uwe-Karsten Plisch, Das Thomasevangelium: Originaltext mit Kommentar (2007). 


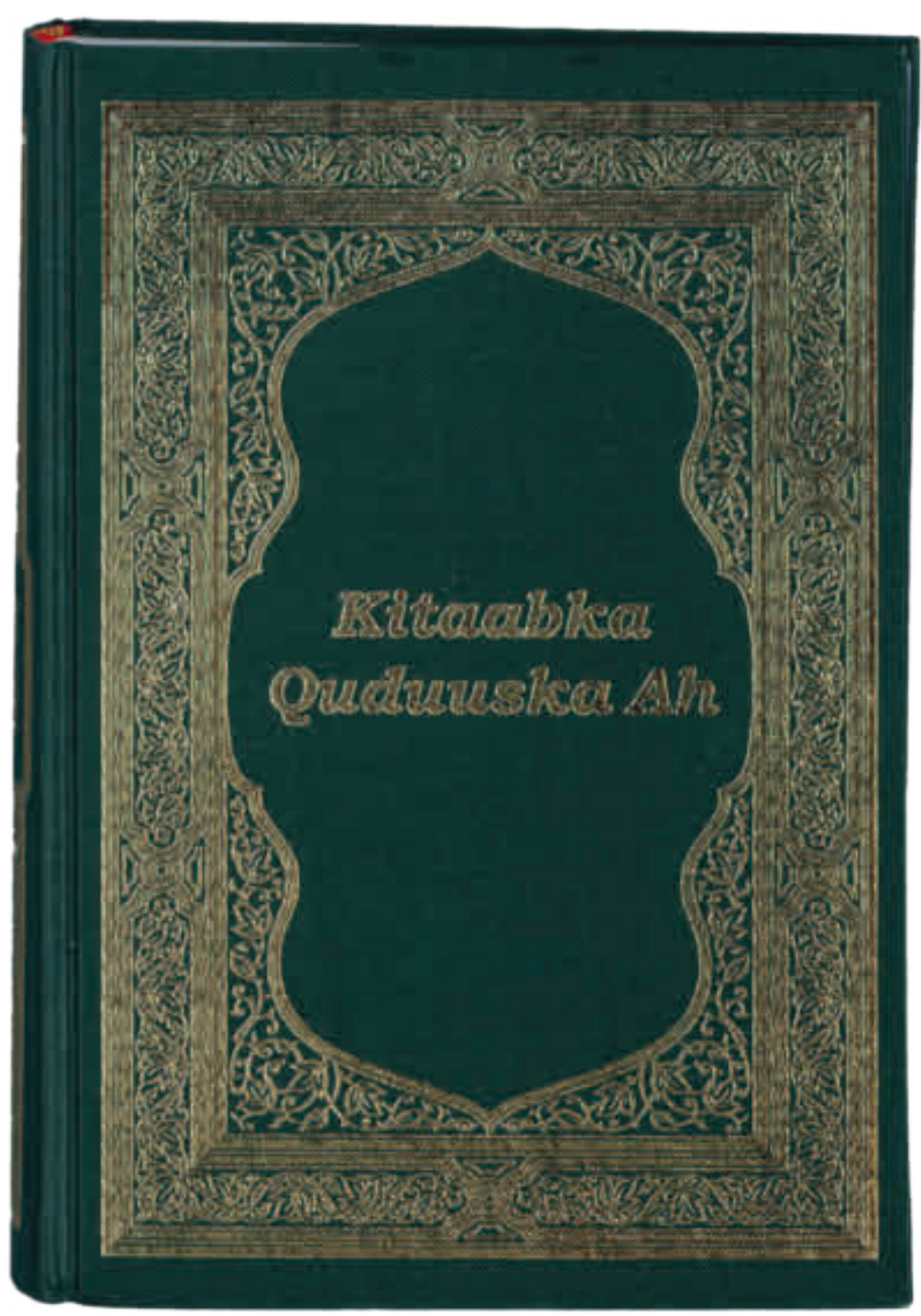

Abb. 49 / Katalog Nr. 187: Kitaabka Quduuska Ah = The Bible in Somali language (2008). die zentralkuschitischen Agaw-Sprachen ${ }^{388}$, die ostkuschitischen Sprachen mit dem Hochlandostkuschitischen ${ }^{389}$ und Tieflandostkuschitischen $^{390}$ und die teilweise dem Ostkuschitischen zugerechneten südkuschitischen Sprachen ${ }^{391}$.

Als Beispiel dient eine Bibel in Somali, der Staatssprache in Somalia und mit ca. 12 Mio. Sprechern zweitgrößten kuschitischen Sprache nach dem Oromo mit rund 25 Mio. Sprechern.

187

Bibel. Somali. Lateinische Schrift

Kitaabka Quduuska Ah = The Bible in

Somali language. - Nairobi, 2008

NÖ Landesbibliothek, Signatur 123.487 B

Abb. 49
388 Auch Agau-Sprachen; Bilen (oder Bilin), Xamtanga (auch Xamir, Xamta, Khamtanga, Khamir, Khamta, Chamtanga, Chamir, Chamta), Kemant (oder Qimant, mit den praktisch ausgestorbenen Dialekten Kwara oder Qwara und Kayla) sowie Awngi (Awiya) inklusive Kunfäl. Kwara und Kayla waren die wichtigsten Sprachen der Falasha (heute Beta Israel), der äthiopischen Juden, die im Zuge der Operationen Moses und Joshua (1984-1985), Salomon (1991) und Taubenflügel (2011-2013) größtenteils nach Israel ausgeflogen wurden und das sogenannte Haymanot-Judentum praktizierten.

389 Sidamo, Darasa, Hadiyya, Kambata (mit Alaba) und das stärker abweichende Burji.

390 Vor allem Saho und Afar (Danakil), Somali und Oromo (Galla).

391 Mit den Rift-Sprachen, vor allem Iraqw (in Tansania). Die vom Aussterben bedrohte Sprache Dahalo besitzt zwei dentale Schnalzlaute. 


\subsubsection{Berbersprachen}

Die Berbersprachen gliedern sich in eine nördliche Gruppe mit dem Atlas-Berberischen ${ }^{392}$, Kabylischen ${ }^{393}$ und Zenati ${ }^{394}$, eine östliche Gruppe mit Siwi ${ }^{395}$, die Tuareg-Sprachen ${ }^{396}$ und Zenaga ${ }^{397}$; ausgestorben sind das Guanche der kanarischen Inseln und das antike Libysch ${ }^{398}$.

Eine althergebrachte Schrift der Tuareg ist die Tifinagh-Schrift ${ }^{399}$, eine Weiterentwicklung der libyschen (altlibyschen, numidischen) Schrift. Es handelt sich um eine Konsonantenschrift (Abdschad) ohne festgelegte Schreibrichtung, die lediglich für die Abfassung sehr kurzer Texte (Inschriften, Graffiti und dergleichen) Verwendung fand. Ungefähr ab 1980 wurde allerdings die rechtsläufige Neo-Tifinagh-Schrift mit Vokalschreibung, also eine Alphabetschrift, entwickelt, die für die in Marokko gesprochenen Berbersprachen Taschelhit, Tamazight und Tarifit ab 2003 offiziellen Status erlangte und somit nicht auf die Tuareg-Sprachen beschränkt ist; sie steht in Konkurrenz mit der lateinischen Schrift und der arabischen Schrift.

Als Beispiel dient ein Neues Testament in Tawallammat, der größten Tuareg-Sprache, in Neo-Tifinagh-Schrift. Der Text ist auch als kostenlose App unter der Bezeichnung „Linjil Twlmt" ${ }^{“ 400}$ für iOS und Android verfügbar, und zwar in den Versionen „Latine“ (lateinische Schrift), „Ajami“401 (arabische Schrift), „Shifinagh“ (Neo-TifinaghSchrift) und „Multi“ (alle drei Versionen zusammen).

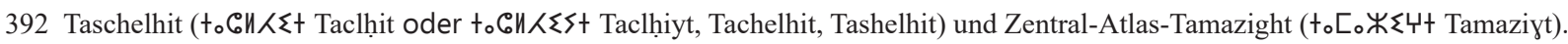

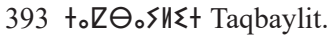

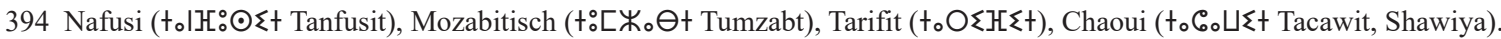

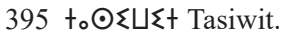

396 t॰_॰\#。:: Tamazaq mit den Varianten Tamahaq (Tahaggart der Kel Ahaggar, Ajjer der Kel Ajjer, Ghat), Tamasheq (der Kel Adrar), Tayị̣t (der Kel Aïr, Aïr Tamajaq) und Tawallammat (Tawellemmet, Tamajaq Tawallammat).

397 Im Südwesten Mauretaniens.

398 Auch Altlibysch oder Numidisch mit einer ebenso genannten Schrift, der Vorläuferin der Tifinagh-Schrift.

399 Wird etymologisch mit lateinisch punica sowie griechisch pinax in Verbindung gebracht; Helmut Satzinger (vgl. semitische Sprachen, Literaturtipps), vermutet eine Herkunft der vorangegangenen libyschen Schrift aus dem Umfeld der altsüdarabischen Schrift, ebenso wie allgemein für die äthiopische Schrift angenommen.

400 Zum Titel vgl. den Hinweis auf Al-Inğĭl (das Evangelium, auch: das Neue Testament) und 'ísā al-Masĭh (Jesus der Messias) zur türkischen Bibel.

401 Unter Adschami (Ajami, 'Ağamī) versteht man die Verwendung der arabischen Schrift für andere, besonders afrikanische Sprachen (oft traditionell und heute in Konkurrenz zur lateinischen Schrift). 


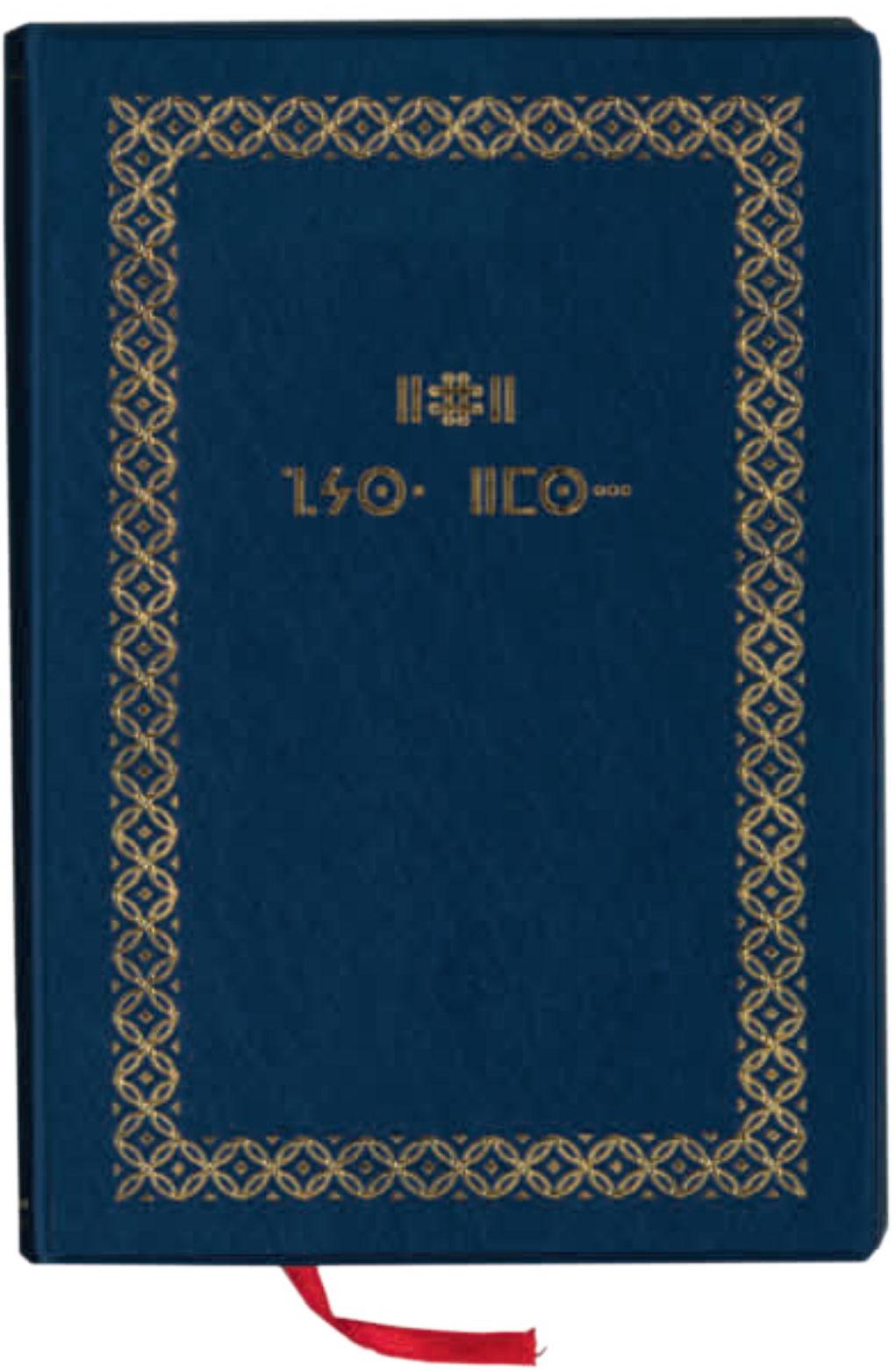

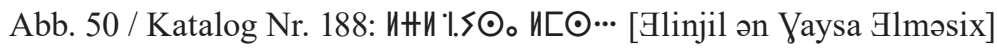
$=$ Le Nouveau Testament en tamajaq tawallammat, écriture shifinagh (2015).
188

Bibel. Neues Testament. Tawallammat. Tifinagh-Schrift

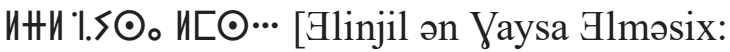
Itawann-as dey Arkawal wa Aynayan] = Le Nouveau Testament en tamajaq tawallammat, écriture shifinagh. - Préverenges, [2015] NÖ Landesbibliothek, Signatur 203.050 B Abb. 50

\subsubsection{Tschadische Sprachen}

Die tschadischen Sprachen $^{402}$ umfassen die westtschadischen Sprachen mit Hausa (Haussa), die Biu-Mandara-Sprachen ${ }^{403}$, Masa und die osttschadischen Sprachen ${ }^{404}$.

Die mit Abstand bedeutendste tschadische Sprache Hausa, die vor allem in Nigeria und Niger ${ }^{405}$ gesprochen wird, darf hier natürlich nicht fehlen. Eine kleine Anekdote aus der Studienzeit des Verfassers: Bei seiner Abschluss-Prüfung im Fach Afrikanistik wurde er mit der Übersetzung der Fabel von den zwei Fröschen im Milchtopf aus dem Hausa konfrontiert.

402 Inklusive der früher als tschadohamitisch bezeichneten Sprachen

403 Unter anderem mit Margi, Mandara, Matakam, Kotoko, Logone, Buduma, Musgu und Gidar.

404 Unter anderem mit Somrai und Sokoro.

405 Wegen der unterschiedlichen Kolonialvergangenheit - Nigeria englisch, Niger französisch - gibt es zwei unterschiedliche Orthografien, wozu als dritte Variante auch noch die Adschami-Schreibung kommt. 
Bibel. Hausa-Sprache. Lateinische Schrift

Littafi Mai Tsarki = The Holy Bible in Hausa. - Lagos, [2007]

NÖ Landesbibliothek, Signatur 136.621 B

\subsection{Niger-Kongo-Sprachen}

Den Niger-Kongo-Sprachen, zeitweilig auch niger-kordofanische Sprachen genannt, liegt die bereits von Diedrich Westermann vertretene und später von Joseph Greenberg etablierte Zusammenfassung der westlichen Sudansprachen und der Bantusprachen zugrunde. Sie bestehen aus den Zweigen Kordofanisch ${ }^{406}$, Mande ${ }^{407}$, Atlantisch, Dogon $^{408}$, Jjoid $^{409}$ und Volta-Kongo.

Die atlantischen Sprachen ${ }^{410}$ umfassen eine Nordgruppe mit den Senegal-Sprachen (Fulfulde oder kurz Ful, Wolof, Serer oder genauer Serer-Sine) und weiteren, kleineren Untergruppen wie den Cangin-Sprachen ${ }^{411}$ und Bak-Sprachen ${ }^{412}$ sowie eine Südgruppe mit den Mel-Sprachen, zu denen das Temne und das Kissi zählen.

Die größte Sprache Fulfulde ist vielleicht auch die komplexeste: Zunächst ist die Anlautpermutation ${ }^{413}$ zu nennen, ein regelmäßiger Wechsel des Anlautkonsonanten in den drei Stufen Reibelaut - oraler Verschlusslaut - pränasalierter Verschlusslaut, also $\mathrm{f}, \mathrm{s}, \mathrm{h}, \mathrm{r}, \mathrm{w}, \mathrm{\prime} / \mathrm{w}_{2} / \mathrm{y}_{2}, \mathrm{y} \rightarrow \mathrm{p}, \mathrm{c}, \mathrm{k}, \mathrm{d}, \mathrm{b}, \mathrm{g}, \mathrm{j} \rightarrow \mathrm{p}, \mathrm{c}, \mathrm{k}, \mathrm{nd}, \mathrm{mb}, \mathrm{ng}, \mathrm{nj}$. Beim Verbum wird im Plural regelmäßig die dritte Anlautstufe (mit pränasalierten Verschlusslauten) verwendet; beim Nomen ist die Anlautstufe vom jeweiligen Klassensuffix der zahlreichen Nominalklassen ${ }^{414}$ abhängig. Die Klasse der Personen im Singular (-'o, Objektspronomen: mo) verlangt die zweite Anlautstufe, die Klasse der Personen im

406 Im Gebiet der Nuba-Berge im Sudan, mit den Untergruppen Heiban, Talodi, Rashad und Katla; die Kadugli-Sprachen werden heute zum Nilosaharanischen gerechnet.

407 Die Mande-Sprachen bestehen aus einem Westzweig, dessen zentraler Gruppe außer Susu die Manding-Sprachen (Mandingo, Mandingue, Mandé-kan) Bambara (Bamanakan), Dioula (Dyula, Jula), Maninka (Malinke), Mandinka, Vai usw. angehören; zur südwestlichen Gruppe zählen u. a. Kpelle und Mende, zur nordwestlichen Gruppe das Soninke. Die einzige größere Sprache des Ostzweiges ist Dan (Yakuba). Mangels eines Nominalklassensystems wurde die Zugehörigkeit der Mande-Sprachen zum Niger-Kongo auch schon angezweifelt. Für Vai wurde schon in der ersten Hälfte des neunzehnten Jahrhunderts eine eigene Schrift entwickelt; später kamen die Kpelle-Schrift, die Mende-Schrift und schließlich die N'Ko-Schrift (für Bambara, Dioula und Maninka) hinzu. Mit dem Namen der Malinke verbunden ist das mittelalterliche Reich Mali mit dem sagenhaft reichen König Mansa Musa.

408 Einzelsprache in Mali und Burkina Faso.

409 Ijo oder Ijaw, Dialektkontinuum im Süden Nigerias; am bedeutendsten ist die Varietät İzọn.

410 Früher auch: westatlantische Sprachen.

411 Saafi oder Serer-Safen, Lehar oder Serer-Lehar, Noon oder Serer-Noon, Palor oder Serer-Palor, Ndut oder Serer-Ndut.

412 Mit Balanta und Diola bzw. Jola.

413 Wie in den heutigen keltischen Sprachen.

414 Im Maasina-Fulfulde beispielsweise 22 an der Zahl. 
Plural (-be) die erste Anlautstufe, viele Singular-Sachenklassen (-nde, -ndu, -nge, -ngo, -ko) verlangen die erste Anlautstufe, die beiden Plural-Sachenklassen (-de und -di) die zweite Anlautstufe. ${ }^{415}$ Damit nicht genug: Auch die Klassensuffixe kommen in vier Stufen vor: Vokal - Reibelaut - oraler Verschlusslaut - pränasalierter Verschlusslaut, z. B. -e $\rightarrow$-we $\rightarrow$-ge $\rightarrow$-nge oder -o $\rightarrow$-jo (-wo) $\rightarrow$-do (-ko) $\rightarrow$-do (-ko); -be ändert sich naturgemäß nicht. Beispiele: Pullo - Fulbe (Ful), gorko (Mann) - worbe (Männer), debbo (Frau) - rewbe (Frauen), raneewe (weißes Rind) - daneeji (weiße Rinder).

$\mathrm{Zu}$ den Dialekten des Fulfulde, das sich nicht zuletzt infolge von Reichsgründungen unter Anführern wie Osman dan Fodio (1754-1817, Begründer des Kalifats von Sokoto in Nigeria) oder El Hadj Omar (1797-1864, Begründer des Staates Segu Tukulor) über weite Teile Westafrikas verbreitet hat, zählen unter anderem Pulaar, Fuuta Tooro, Fuuta Jaloo, Maasina, Liptaako, Borgu, Sokoto, Gombe, Adamawa und Bagirmi.

\section{Literaturtipp:}

Gajdos, Martina. Fulfulde: Lehrbuch einer westafrikanischen Sprache. - Wien, [2004]. - (Edition Praesens Studienbücher; Band 11)

Die Volta-Kongo-Sprachen bestehen aus den nördlichen Zweigen Kru, Gur ${ }^{416}$, Senufo ${ }^{417}$ und Adamawa-Ubangi ${ }^{418}$ und den südlichen Zweigen Kwa ${ }^{419}$ und Benue-Kongo. Die Kwa-Sprachen waren früher weiter und die BenueKongo-Sprachen enger gefasst; die östlichen Kwa-Sprachen gelten heute als die westlichen Benue-KongoSprachen ${ }^{420}$; auch Ijo und die Kru-Sprachen gelten heute nicht mehr als Bestandteil der Kwa-Sprachen. Zu den

415 Zusammengefasst ergibt sich also das Anlautmuster Verschlusslaut (Singular) gegenüber Reibelaut (Plural) bei Personen und Reibelaut (Singular) gegenüber Verschlusslaut (Plural) bei Sachen.

416 Gur-Sprachen oder Volta-Sprachen; erwähnt seien Mòoré (Mossi) in Burkina Faso, Frafra (Farefare, Gurenne) im Norden Ghanas und in Burkina Faso sowie Dagaare (Dagaari) und Dagbane (Dagbani, Dagomba) in Ghana.

417 Im Dreiländereck Mali, Elfenbeinküste und Burkina Faso; früher zu den Gur-Sprachen gerechnet.

418 Die Adamaua-Ubangi-Sprachen, früher auch Adamaua-Ost genannt, bestehen aus den Adamaua-Sprachen (nach dem hauptsächlich im Norden Kameruns gelegenen Hochland von Adamaua, dessen Name sich von dem von Adama gegründeten Emirat Adamaua im Kalifat Sokoto ableitet) und den UbangiSprachen (nach dem Ubangi, einem Nebenfluss des Kongo in Zentralafrika); zu letzteren gehören das vorwiegend in der Demokratischen Republik Kongo gesprochene Azande (Zande) und Ngbandi mit seiner Tochtersprache Sango (Sangho), heute Amtssprache der Zentralafrikanischen Republik. Auch einige Pygmäen-Völker sprechen Ubangi-Sprachen.

419 Bedeutend sind zunächst die Akan-Sprachen Twi (Asante-Twi oder Aschanti-Twi und Akwapem-Twi oder Akuapem-Twi) und Fante sowie in einem weiteren Sinn auch Anyin und Baule, dann die Sprachen Ga und Dangme in Ghana und schließlich die Gbe-Sprachen Ewe (Evegbe) und Fon (Fongbè); die Untergruppen Na-Togo und Ka-Togo beinhalten die früher sogenannten Togo-Restsprachen.

420 Mit den wichtigen Untergruppen Yoruboid (mit Yoruba und Igala), Edoid (mit Edo oder Bini, der Sprache des ehemaligen Königreiches Benin), Igboid (mit Igbo oder Ibo; die Igbo im südöstlichen Nigeria gründeten 1967 die Republik Biafra, die aber nach dem Bürgerkrieg mit Hungerblockade 1970 wieder nach Nigeria eingegliedert wurde), Nupoid (mit Nupe und Igbira oder Ebira) und Idomoid (mit Idoma), alle überwiegend im eher christlich geprägten südlichen Nigeria gesprochen. 
östlichen Benue-Kongo-Sprachen ${ }^{421}$ zählen neben mehreren kleinen Sprachgruppen in Nigeria und Kamerun die Bantu-Sprachen als Teil des südlichen Zweiges der bantoiden Sprachen.

Kennzeichnend für die relativ eng verwandten Bantu-Sprachen, so genannt nach dem Wort ba-ntu (Menschen) zu mu-ntu (Mensch) ${ }^{422}$, sind die zahlreichen Nominalklassen, ${ }^{423}$ die durch Präfixe angezeigt werden, siehe das zuvor erwähnte Beispielwort Menschen ${ }^{424}$. Die bedeutendste Bantu-Sprache ist Swahili oder Kiswahili (früher auch Suaheli oder Kisuaheli) ${ }^{425}$, Amtssprache in Tansania, Kenia und Uganda und eine der Nationalsprachen der Demokratischen Republik Kongo; erwähnt seien darüber hinaus: Beti, Ewondo (Jaunde) und Fang; Lingala; Gikuyu; Kikongo mit Kituba; Luganda, Rwanda und Rundi; Lunda; Chiluba und Kiluba; Bemba; Nyanja (Chichewa); Umbundu, Oshivambo, Herero; Shona; Venda; Pedi, Sotho und Tswana; Zulu, Xhosa, Swati, Nord-Ndebele, Süd-Ndebele; Tsonga. Einige Bantusprachen wie z. B. Zulu und Xhosa weisen übrigens Schnalzlaute auf.

Neben Neuen Testamenten in Maasina-Fulfulde und Wolof werden Bibeln in Aschanti-Twi, Ewe, Ga, Yoruba, Igbo, Edo und Swahili vorgestellt.

\subsubsection{Atlantische Sprachen}

\section{0}

\section{Bibel. Neues Testament. Maasina-Fulfulde. Lateinische Schrift}

Aadi keyri: linjiila iisaa almasiihu = Maasina Fulfulde New Testament. - Conroe, Tex., [2005]

NÖ Landesbibliothek, Signatur 202.987 B

421 Mit den Untergruppen Platoid (Kainji, Nordwest-Plateau, Zentral-Plateau, Südost-Plateau, Süd-Plateau, Tarokoid und Jukunoid), den Cross-River-Sprachen (mit den Sprachen Efik, Ibibio und Anaang innerhalb der Untergruppe Lower Delta Cross) und den damit näher verwandten bantoiden Sprachen (mit Sprachen wie Tiv und vor allem den weitverzweigten Bantusprachen in der südlichen Untergruppe).

422 Kikongo, Zulu; die Swahili-Entsprechung lautet wa-tu bzw. $m$-tu.

42315 im Swahili.

424 Präfixe m(u)- und ba- bzw. wa- für die Personenklasse Singular bzw. Plural. Noch eine weitere kleine Anekdote aus der Studienzeit des Verfassers: Er erinnert sich noch gut an das Wort Warumi (Römer), auf das er im Rahmen einer Prüfung stieß, bei der er Shakespeares Julius Caesar auf Swahili vorgesetzt bekam.

425 Von arabisch sāhil, Plural sawāḥil (Küste, Rand); gemeint sind also die Küstenleute der ostafrikanischen Küste, vgl. Sahel (Südrand der Sahara und zugleich Nordrand der Savannenlandschaft des Sudan). 


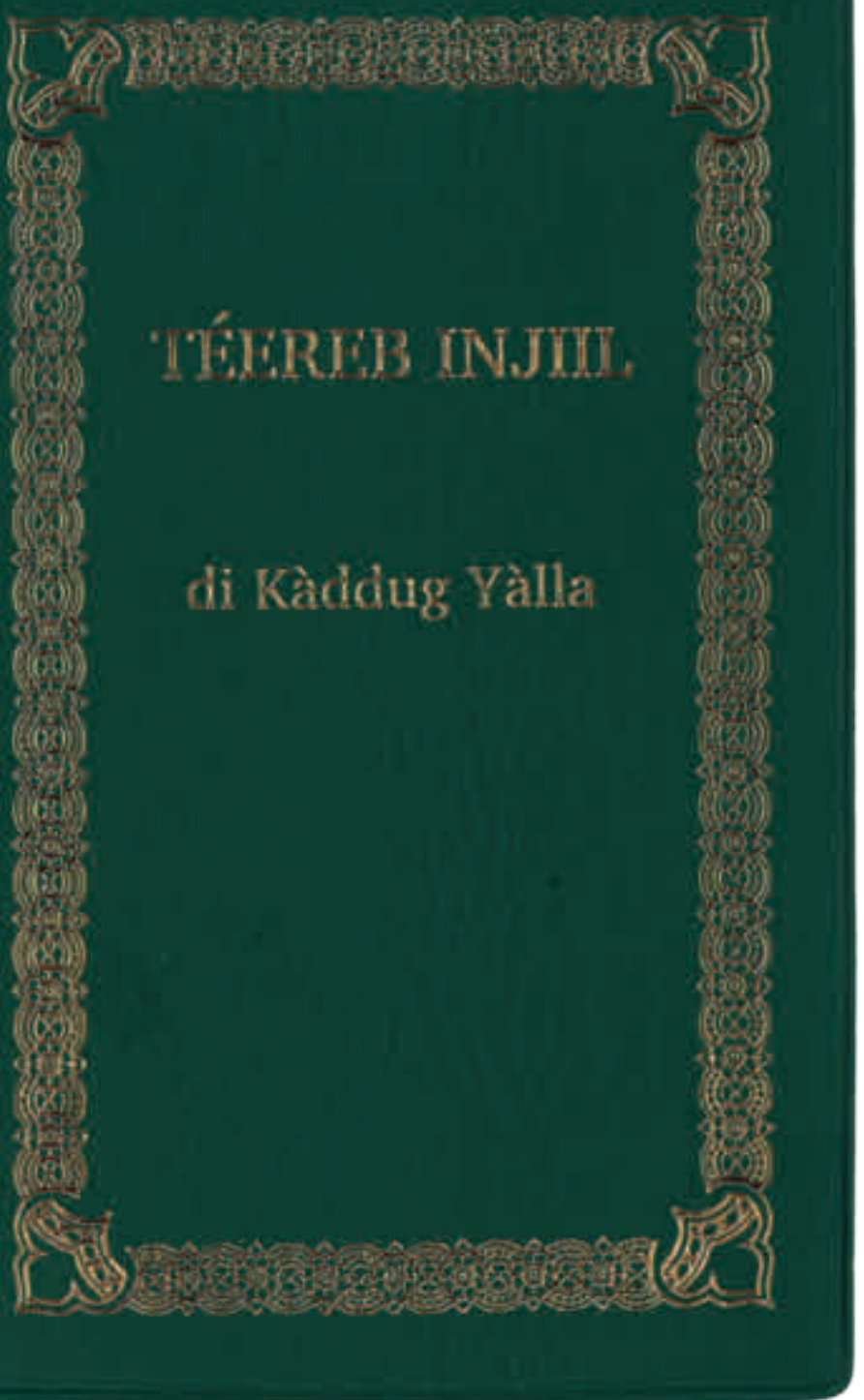

Abb. 51 / Katalog Nr. 191: Téereb Injiil di Kàddug Yàlla = Le nouveau testament en wolof (2004).

\section{1}

Bibel. Neues Testament. Wolof. Lateinische Schrift

Téereb Injiil di Kàddug Yàlla: Kóllëre gi Yàlla fas ak nit ñi, jaarale ko ci Almasi bi Yeesu, te ñudi ko wax: Kóllëre gu bees gi $=$ Le nouveau testament en wolof. - Dakar, 2004

NÖ Landesbibliothek, Signatur 164.381 B

Abb. 51

\subsubsection{Volta-Kongo-Sprachen}

\subsubsection{Kwa-Sprachen}

\section{2}

Bibel. Aschanti-Sprache. Lateinische Schrift Anyamescm anaa twere kronkron akan kasa mu $=$ The Holy Bible in Twi: Asante. - Accra, 2008 NÖ Landesbibliothek, Signatur 133.661 B

\section{3}

Bibel. Ewe-Sprache. Lateinische Schrift Biblia: alo yonlo kokse la le evegbe $\mathrm{me}=$ The Bible in Ewe. - Accra, 2008

NÖ Landesbibliothek, Signatur 133.300 B

\section{4}

Bibel. Ga-Sprache. Lateinische Schrift Biblia alo ṅmãle kronkkron̉ lẹ: kpãṅmo momo kẹ kpãnmo hē le ye Gã wiemo mli [Biblia alo

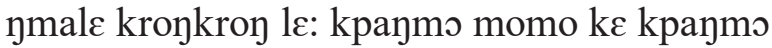
hee $1 \varepsilon$ y $\varepsilon$ Ga wiemo mli] = The Bible in Ga. Accra, 1997

NÖ Landesbibliothek, Signatur 123.492 B 


\subsubsection{Benue-Kongo-Sprachen}

\section{5}

Bibel. Yoruba-Sprache. Lateinische Schrift

Bibeli mimọ $=$ The Holy Bible in Yoruba. - Lagos, 2004

NÖ Landesbibliothek, Signatur 123.481 B

\section{6}

Bibel. Ibo-Sprache. Lateinische Schrift

Bible nsọ: nke nãnagide Testament Ochie na Testament Ohu = The Holy Bible in Igbo (Union version). - Lagos, 2003

NÖ Landesbibliothek, Signatur 123.480 B

\section{7}

Bibel. Edo-Sprache. Lateinische Schrift

E Baibol Edo = The Holy Bible in Edo language. - Lagos, 1996

NÖ Landesbibliothek, Signatur 136.620 B

\subsection{Bantusprachen}

198

Bibel. Swahili. Lateinische Schrift

Biblia: Maandiko Matakatifu ya Mungu Yaitwayo: yaani Agano la Kale na Agano Jipya = The Holy Bible in Kiswahili, Union version. - Nairobi, 2004

NÖ Landesbibliothek, Signatur 120.539 B

\subsection{Nilosaharanische Sprachen (Ostsudanische Sprachen, Nilotische Sprachen)}

$\mathrm{Zu}$ den nilosaharanischen Sprachen zählen zunächst die ostsudanischen Sprachen, zu denen einerseits die nubischen Sprachen nebst kleineren Sprachen wie Nera (Barea) oder Nyimang, andererseits die nilotischen Sprachen 
nebst den surmischen Sprachen ${ }^{426}$, Ingassana und anderen zählen; unklar ist dabei die Stellung des ausgestorbenen Meroitischen (mit der ihm eigenen meroitischen Schrift) im Verhältnis zum Nubischen.

Die nubischen Sprachen bestehen aus dem Nobiin, dem Midob (in Darfur) sowie Kenzi (in Unternubien), Dongolawi (in Obernubien) und den bergnubischen Sprachen (in Kordofan); die Zusammenfassung von Kenzi, Nobiin und Dongolawi als Nilnubisch widerspricht dem Umstand, dass Kenzi und Dongolawi näher mit dem Bergnubischen als mit dem Nobiin verwandt sind. Dem Nobiin steht hingegen das Altnubische nahe, welches die Sprache der drei nördlich des Aksumitischen Reiches gelegenen christlichen nubischen Königreiche des Mittelalters (Nobatia, Makuria und Alodia) war; die altnubische Schrift ist ein um meroitische Zusatzzeichen erweiterter Ableger der koptischen Schrift.

Die nilotischen Sprachen bestehen aus den westnilotischen Sprachen Nuer-Dinka und Luo ${ }^{427}$, den ostnilotischen Sprachen Bari, Teso und Turkana ${ }^{428}$, Lotuko ${ }^{429}$ und $\mathrm{Maa}^{430}$ und den südnilotischen Sprachen Kalendjin ${ }^{431}$, Omotik und Datooga.

$\mathrm{Zu}$ den zentralsudanischen Sprachen zählen die Bongo-Bagirmi-Sprachen oder Sara-Bongo-Bagirmi-Sprachen ${ }^{432}$, die Moru-Ma'di-Sprachen ${ }^{433}$, die Mangbutu-Lese-Sprachen ${ }^{434}$, Mangbetu, Lendu oder Bale und Kresh.

Abgesehen vom Gumuz, den Koma-Sprachen, den aus den kordofanischen Sprachen ausgesonderten KadugliSprachen, den Kuliak-Sprachen oder Rub-Sprachen und den Einzelsprachen Kunama und Berta sind noch folgende Untergruppen des Nilosaharanischen hervorzuheben: die Fur-Sprachen ${ }^{435}$, die Maba-Sprachen ${ }^{436}$, die saharanischen Sprachen ${ }^{437}$ und die Songhai-Sprachen ${ }^{438}$.

Die ostsudanischen und zentralsudanischen Sprachen sind bereits früher mit Kunama und Berta als Schari-NilSprachen zusammengefasst worden.

Als Vertreterin für die nilosaharanischen Sprachen dient eine Bibel im ostnilotischen Maa (Maasai-Sprache).

426 Auch: Didinga-Murle-Sprachen.

427 Vor allem Schilluk bzw. Chollo, Anuak; Adhola; Kumam; Luo, Alur, Lango, Acholi.

428 Mit Karamojong, Toposa und Nyangatom.

429 Mit einigen kleineren Verwandten.

430 Maasai, Samburu und Chamus.

431 Eigentlich eine Sprachgruppe.

432 Mit Ngambay; Bagirmi oder Barma war die Sprache des Sultanats Bagirmi.

433 Mit Lugbara und Aringa.

434 Mit der Sprache der Efe-Bambuti, einem Dialekt des Lese.

435 Mit der Sprache Fur in Darfur.

436 Mit Masalit und Maba, der Sprache des Reiches Wadai.

437 Kanuri inklusive Kanembu, die Sprache des Reiches Kanem-Bornu (im Tschadbecken); Tibu oder Tibbu (auch Tubu bzw. Tebu; der Name hängt mit dem in ihrem Gebiet gelegenen Tibesti zusammen) mit den Varianten Teda oder Tedaga und Daza oder Dazaga; Zaghawa und das ausgestorbene Berti. 


\section{9}

\section{Bibel. Maasai-Sprache. Lateinische Schrift}

Biblia Sinyati: te nkutuk oo Lmaasai: o Sotua Musana o Sotua Ng'ejuk = The Bible in Maasai. - Nairobi und Dodoma, [1991]

NÖ Landesbibliothek, Signatur 203.200 B

\subsection{Zentral-Khoisan-Sprachen (Khoe-Kwadi)}

Schnalzlaute (auch Injektive oder Klicks) ${ }^{439}$ gelten als das Kennzeichen der Khoisan-Sprachen, die aber keine Sprachfamilie bilden, sondern nur durch dieses typologische Merkmal untereinander verbunden sind. Außerhalb der Khoisan-Sprachen kommen Schnalzlaute nur in einigen Bantusprachen sowie der südkuschitischen Sprache Dahalo vor, was auf eine Beeinflussung durch benachbarte Khoisan-Sprachen zurückgeführt wird. Die größte Sprachfamilie im Khoisan-Komplex sind die Zentral-Khoisan-Sprachen, auch Khoe-Kwadi genannt, die aus dem früher in Angola gesprochenen Kwadi und dem Khoe-Zweig bestehen; zu diesen gehört neben Khoekhoegowab ${ }^{440}$ und dem aussterbenden Süd-Khoekhoe ${ }^{441}$ das Tshu-Khwe oder Kalahari ${ }^{442}$. Von den restlichen Khoisan-Sprachen ist vielleicht noch das ansonsten als isoliert geltende Sandawe in Tansania mit dem Khoe-Kwadi verwandt; sicher isoliert ist das ebenfalls in Tansania gesprochene Hadza ${ }^{443}$. Keine Verwandtschaft mit dem Khoe-Kwadi oder untereinander besteht auch für die Süd-Khoisan-Sprachen oder Tuu-Sprachen ${ }^{444}$ und Nord-Khoisan-Sprachen oder Ju-łHõã(n)-Sprachen ${ }^{445}$. Die mit Abstand vitalste aller Khoisan-Sprachen ist mit rund 300.000 Sprechern das Khoekhoegowab, welches auch durch eine Bibel vertreten ist.

439 Es handelt sich um Obstruenten mit einem doppelten Verschluss, deren vorderer (im Gegensatz zum hinteren velaren) durch eine Einsaugbewegung der Zunge gelöst wird; die infolge des aufgebauten Unterdrucks nunmehr einströmende Luft erzeugt den Schnalz. Schnalzlaute sind also Ingressive (wie auch die im Unterschied zu den postglottalisierten Ejektiven p', t', k' usw. präglottalisierten Implosive 6, d, $g$ usw.). Schnalzlaute und ihre Notation im Khoekhoegowab (der mögliche bilabiale Schnalz $\odot$ kommt in dieser Sprache nicht vor): dentaler Schnalz I, palataler Schnalz $\neq$, alveolarer (lateraler) Schnalz $\|$

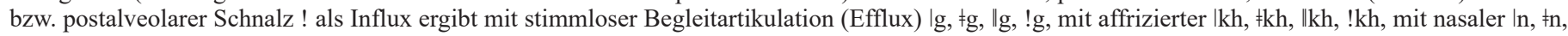

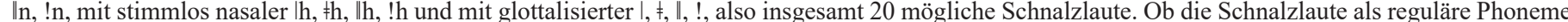
ein Relikt der Sprachentstehung darstellen, ist eine offene Frage; immerhin handelt es sich um Laute, die ohne Beteiligung des Kehlkopfes auskommen; die Hadza gelten überdies als Kandidaten für eine der ältesten DNA-Lineages des modernen Menschen. Eine mögliche Quelle für die Schnalzlaute dürften allerdings infolge Vokalschwunds entstandene initiale Konsonantencluster sein.

440 Auch Khoekhoe, Nama, Nama-Damara oder Hottentottisch; mit Nama, Dama und Haillom.

441 Korana (Kora, !Ora, Kap-Hottentottisch) bzw. Griqua (Xiri).

442 Ost-Kalahari: Shua, Tsoa; West-Kalahari: Kxoe, Naro, Gllana inklusive Glui.

443 Früher auch: Hatsa.

444 Taa-Sprachen mit !Xóõ als letztem Vertreter und !Wi-Sprachen mit dem aussterbenden Nllng als letztem Vertreter.

445 Auch: Kx’a-Sprachen; mit Ju bzw. !Kung oder !Xun und ¥’Amkoe oder ¥Hõã(n). 
Bibel. Nama-Sprache (Khoekhoegowab).

\section{Lateinische Schrift}

Elobmîs: |Asa Xoalgaub !nâ = The Bible in Khoekhoegowab. - Windhuk, [2013]

NÖ Landesbibliothek, Signatur 203.997 B

Abb. 52

\subsection{Eskimo-aleutische Sprachen}

Neben dem Aleutischen besteht diese Sprachfamilie $^{46}$ aus der westlichen Eskimo-Sprache Yupik mit den Varietäten Alaska-Yupik (Zentral-Alaska-Yupik und Pazifik-Golf-Yupik) sowie Sibirisch-Yupik (Chaplino, Naukan und das ausgestorbene Serenik) und der östlichen Eskimo-Sprache Inupiaq-Inuktitut mit dem Grönländischen (Kalaallisut), dem Inuktitut in Ostkanada, dem Inuvialuktun (mit dem Inuinnaqtun) in Westkanada und dem Inupiaq in Nordalaska. Die größte Sprache Grönländisch, deren Standardform auf dem ZentralWestgrönländischen basiert, umfasst neben dem Westgrönländischen (Kitaamiusut) das Ostgrönländische (Tunumiisut) und das nordgrönländische Inuktun (Avanersuarmiusut). Wie die anderen Eskimosprachen kann man es typologisch als polysynthetische Ergativ-

Abb. 52 / Katalog Nr. 200: Elobmîs (Khoekhoegowab) (2013). 
sprache einstufen. Abgesehen vom Inuktun findet eine Assimilation von Konsonantengruppen statt, sodass z. B. iglu (Haus) auf grönländisch illu lautet.

Eine von der dänischen Königin Margrethe II. autorisierte grönländische Bibel darf hier natürlich nicht fehlen.

\section{1}

\section{Bibel. Grönländisch. Lateinische Schrift}

Biibili: allakkat illernartut: atortussanngortitaq: ataqqinartorsuarmit Dronningimit Margrethe II-mit. Kopenhagen, 2005

NÖ Landesbibliothek, Signatur 126.755 B

\subsection{Haida}

Die vom Aussterben bedrohte Sprache Haida wird auf den kanadischen Haida Gwaii (Queen Charlotte Islands) und auf der zu Alaska gehörenden Prince of Wales Island gesprochen. Früher wurde Haida zu den Na-DenéSprachen gezählt, ${ }^{447}$ gilt aber heute als isolierte Sprache. Dass von dieser Sprache ein Lukasevangelium aus dem Jahr 1899 den Weg in unsere Zusammenstellung gefunden hat, ist jedenfalls bemerkenswert.

202

Bibel. Lukasevangelium. Haida-Sprache. Lateinische Schrift

The gospel according to Saint Luke in Haida / [transl. by J. H. Keen]. - London, 1899

NÖ Landesbibliothek, Signatur 146.634 B

\subsection{Na-Dené-Sprachen (Athapaskische Sprachen, Apache-Sprachen)}

Nach Ausschluss des Haida bestehen die Na-Dené-Sprachen aus Tlingit, dem ausgestorbenen Eyak und den Athapaskischen (Athabaskischen) Sprachen. Neuerdings wird eine Verwandtschaft der Na-Dené-Sprachen und der jenisseischen Sprachen ${ }^{48}$ postuliert. Die Athapaskensprachen bestehen aus den nördlichen Athapaskensprachen in Alaska und Nordwestkanada, zu denen die offiziellen Sprachen Gwich'in (Kutchin), Chipewyan,

447 Siehe den folgenden Abschnitt 3.26 (zu Katalog Nr. 203).

448 Mit dem Ketischen als letztem Überlebenden. 


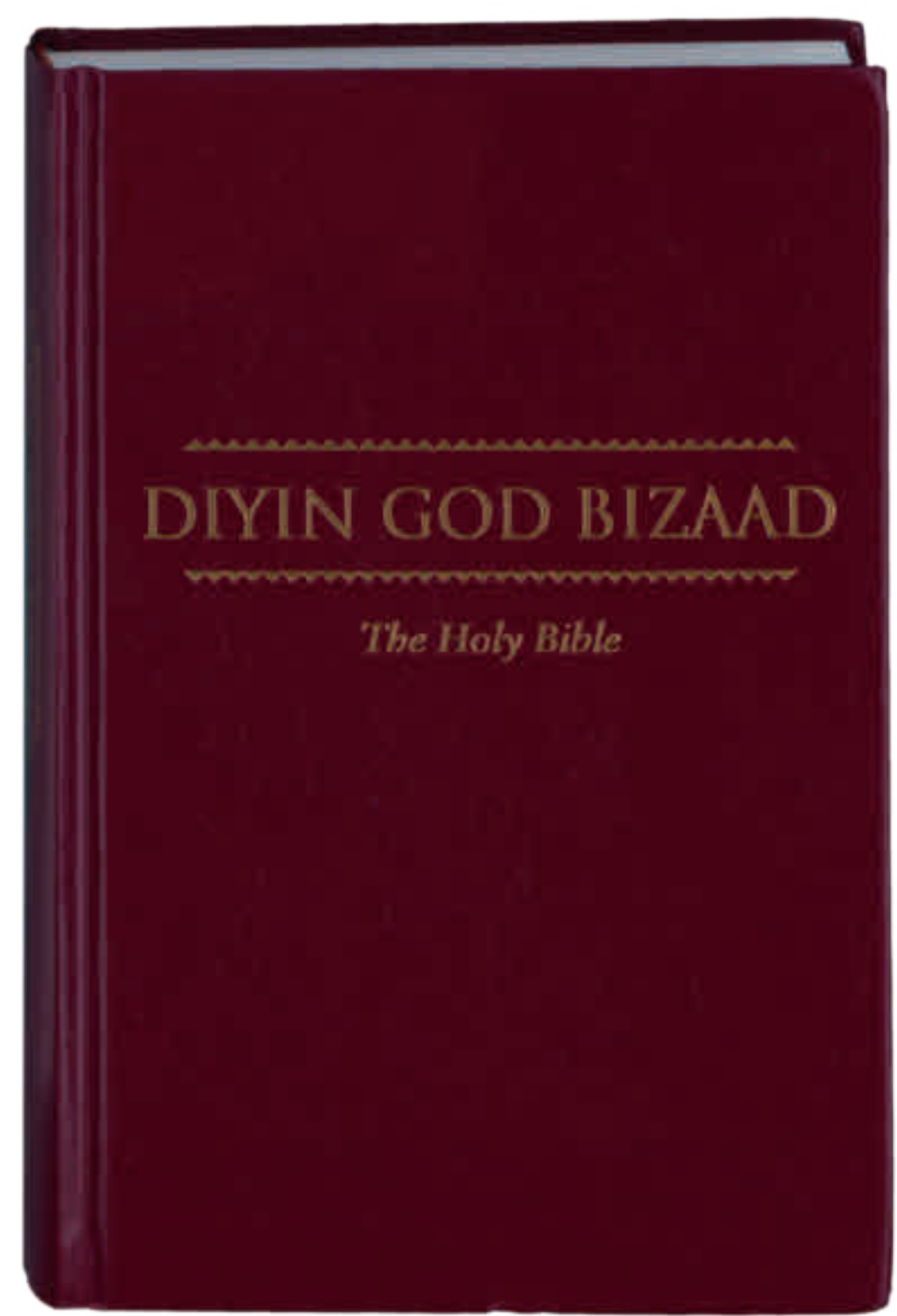

Abb. 53 / Katalog Nr. 203: Diyin God bizaad = The Holy Bible in Navajo (2000).
Dogrib und nördliches bzw. südliches Slavey zählen, den fast ausgestorbenen PazifikKüsten-Athapaskensprachen und den südlichen Athapaskensprachen oder ApacheSprachen. Die westlichen Apachensprachen bestehen aus dem Western Apache ${ }^{44}$, dem Navajo und den untereinander enger verwandten Mescalero und Chiricahua ${ }^{450}$, zu den östlichen zählen Plains Apache (Kiowa Apache), Jicarilla und Lipan. Ein intensiver Kulturkontakt und infolge Zweisprachigkeit wechselseitiger Spracheinfluss fand zwischen dem Western Apache und der Yuma-Sprache Yavapai statt. Aus kultureller Sicht werden die Sprecher des Plains Apache zu den Kiowa gerechnet und die des Navajo als eigenständige Gruppe betrachtet, gelten also nicht als Apachen. Kein historischer Apache war auch Winnetou, der diese ethnische Zuordnung übrigens einer Umkehrung der Verhältnisse in dem vom französischen Schriftsteller Gabriel Ferry (1809-1852) verfassten und von Karl May (1842-1912) bearbeiteten Roman „Der Waldläufer" mit positiv gezeichneten Comanchen und negativ gezeichneten Apachen verdankt. Überraschend ist auch der Umstand, dass nach der umstrittenen Dreiteilung der indigenen Sprachen Amerikas in Eskimo-Aleutisch,

449 Coyotero Apache, mit dem nördlichen und südlichen Tonto, White Mountain, San Carlos und Cibecue.

450 In kultureller Hinsicht werden die Chiricahua und Mescalero allerdings zu den östlichen Apachen gerechnet. 
Na-Dené und Amerind ${ }^{451}$ die Apachen sozusagen keine Indianer sind. Navajo ist nicht nur die größte lebende NaDené-Sprache, sondern auch die größte indigene Sprache der Vereinigten Staaten, berühmt ist auch ihr Einsatz zu Verschlüsselungszwecken im Zweiten Weltkrieg (Navajo-Code). Vielleicht hätte ja eine Bibel in Navajo bei der Entschlüsselung helfen können ...

\section{3}

\section{Bibel. Navajo-Sprache. Lateinische Schrift}

Diyin God bizaad $=$ The Holy Bible in Navajo. - New York, NY, 2000

NÖ Landesbibliothek, Signatur 128.412 B

Abb. 53

\subsection{Algonkin-Sprachen}

Die südöstlich der nördlichen Athapaskensprachen beheimateten Algonkin-Sprachen ${ }^{452}$ werden üblicherweise wie folgt eingeteilt: Plains-Algonkin-Sprachen: Blackfoot, Arapaho, Gros Ventre † und Cheyenne; Zentral-Algonkin-Sprachen: Cree-Montagnais-Naskapi, Ojibwa-Potawatomi, Fox-Sauk-Kickapoo, Menomini, Shawnee ${ }^{453}$, Miami-Illinois †; Ost-Algonkin-Sprachen: Mi'kmaq, Abenaki, Maliseet-Passamaquoddy, Massachusett $\dagger$, Narragansett $\dagger$, Mohegan-Pequot $\dagger$, Mahican $\dagger^{454}$, Delaware (Munsee und Unami $\dagger$ ), Carolina-Algonkin (Pamlico) $\dagger$, Virginia-Algonkin (Powhatan) $\uparrow^{455}$ und weitere ausgestorbene Sprachen; unklar ist die Zugehörigkeit des ausgestorbenen Beothuk auf Neufundland. Zu den bekannten Fremdwörtern aus Algonkin-Sprachen zählen etwa Eskimo, Manitu, Mokassin, Opossum, Skunk, Squaw, Tomahawk, Totem und Wigwam.

Das Dialektkontinuum Cree-Montagnais-Naskapi umfasst Plains Cree, Woods Cree, Swampy Cree, Moose Cree, Atikamekw, Eastern Cree (James Bay Cree), Naskapi und Montagnais (Innu). Eine Mischsprache von Cree und Französisch ist das Michif (Mitchif), von Cree und Gälisch-Schottisch das Bungee. Zum Ojibwa-Potawatomi-

451 Nach Joseph H. Greenberg. Das umstrittene Amerind umfasst das Nord-Amerind mit Almosan-Keres (Almosan = Algisch bzw. Algonkin-Ritwan + Kutenai + Mosanisch bzw. Chimakum-Salish-Wakash; Keresiouanisch $=$ Caddo + Irokesisch + Keres + Sioux + Yuchi) und Penuti-Hoka (zum Penuti werden unter anderen Zuñi und die Maya-Sprachen gerechnet; zum Hoka zählen unter anderem die Yuma-Sprachen; Keres und Zuñi gehören so wie das uto-aztekische Hopi und die Kiowa-Tano-Sprachen Tiwa, Tewa und Towa zu den Sprachen der Pueblo-Indianer), das Zentral-Amerind mit den Kiowa-Tano-Sprachen, uto-aztekischen Sprachen und Oto-Mangue-Sprachen sowie das Süd-Amerind mit den Chibcha-Paez-Sprachen, andischen Sprachen (mit Aymara und Quechua), Äquatorial-Tucano-Sprachen (mit den Tupí-Sprachen wie z. B. Guaraní) und Ge-Pano-Carib-Sprachen.

452 Mit den Ritwan-Sprachen Yurok und Wiyot † im Nordwesten Kaliforniens zusammen als Algisch bezeichnet.

453 Ein berühmter Shawnee war Tecumseh, dem eine Romanreihe von Fritz Steuben gewidmet ist.

454 Die Mohikaner in James Fenimore Coopers Roman „Der letzte Mohikaner“ beruhen offenbar auf einer Vermengung der Mahican und Mohegan.

455 Die Sprache von Pocahontas. 


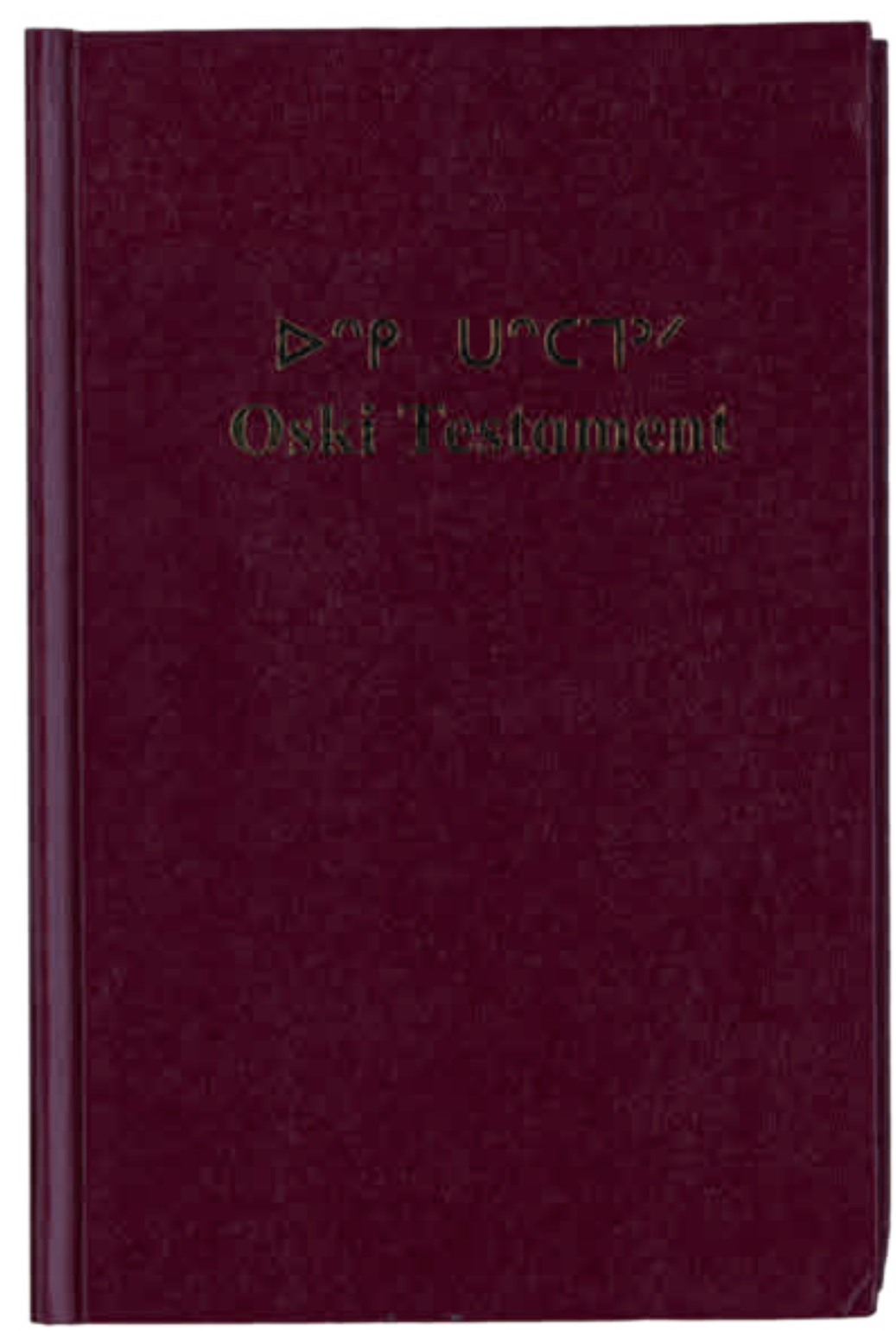

Abb. 54 / Katalog Nr. 204: $\triangleright^{n} p \cup^{n} \subset^{J \prime}$ [Oski Testament] = The New Testament in Western Cree (2000).
Dialektkontinuum zählen Algonkin, Oji-Cree (Severn Ojibwe), Saulteaux (Plains Ojibwe, Western Ojibwe, West-Ojibwe), NordwestOjibwe, Chippewa (Südwest-Ojibwe), Zentral-Ojibwe, Ottawa (Odawa), Ost-Ojibwe (Mississauga Ojibwa) und Potawatomi. Cree und Ojibwe sind die beiden bedeutendsten Algonkin-Sprachen Kanadas. Auf der Mitte des neunzehnten Jahrhunderts entwickelten Cree-Schrift basiert die kanadische Silbenschrift, eine Abugida, bei der die (den Konsonanten inhärenten) Vokale durch Drehungen des Grundzeichens um jeweils 90 Grad angezeigt werden, z. B. $\vee$ pe, $\wedge$ pi, > po, < pa; am Silbenschluss werden eigene Zeichen für finale Konsonanten verwendet, z. B. ${ }^{n}$ für $-\mathrm{s}$

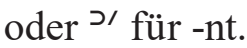

Sowohl ein Neues Testament in Plains Cree wie auch eine Kurzbibel (mit auszugsweisem Alten Testament) in Saulteaux können hier vorgestellt werden, beide Bücher in kanadischer Silbenschrift und lateinischer Schrift.

\section{4}

Bibel. Neues Testament. Plains-CreeSprache. Kanadische Silbenschrift und lateinische Schrift

$\left.\triangleright^{n} p \cup^{n} \subset\right\rceil^{\prime \prime}$ [Oski Testament] $=$ The New Testament in Western Cree. - Toronto, [2000] NÖ Landesbibliothek, Signatur 134.918 B Abb. 54 
$=$ Bible in Ojibwe/Saulteaux [Ojibwe Short

Bible]. - Toronto, [2008]

NÖ Landesbibliothek, Signatur 134.917 B

Abb. 55

\subsection{Sioux-Sprachen}

$\mathrm{Zu}$ den Zentral-Sioux-Sprachen gehören Lakota $^{456}$, Dakota ${ }^{457}$ und die beiden Nakota-Sprachen Assiniboine und Stoney, weiters Chiwere und Winnebago und die Dhegiha-Gruppe mit Omaha-Ponca, Kansa †, Osage $\dagger$ und Quapaw. Weitere westliche Sioux-Sprachen sind Mandan †, Crow und Hidatsa; gänzlich ausgestorben sind das Virginia-Sioux mit Tutelo und Moneton, das Mississippi-Sioux mit Biloxi und Oto und die östlichen Sioux-Sprachen Catawba und Woccon.

Diese klassische indianische Sprachfamilie wird durch ein Neues Testament in DakotaSprache repräsentiert.

456 Auch Lakhota; Sprache der Teton, deren bekanntesten Stamm die Oglala bilden.

457 Auch Dakhota; mit den westlichen, fälschlich als Nakota bezeichneten Yankton und Yanktonai und den östlichen Santee und Sisseton.

Abb. 55 / Katalog Nr. 205: $\triangleright \Gamma \cdot V$ P Lra $\Delta b^{\circ}$ [Ojibwe Kihcimasina'ikan] = Bible in Ojibwe/Saulteaux (2008). 


\section{Bibel. Neues Testament. Dakota-Sprache. Lateinische Schrift}

Dakota wowapi wakan kin / translated from the original Greek by Stephen R. Riggs = The New Testament, in the Dakota language. - Reprint der Ausgabe 1871. - 2012

NÖ Landesbibliothek, Signatur 144.082 B

\subsection{Irokesische Sprachen}

$\mathrm{Zu}$ den Irokesensprachen zählen die Sprachen der Five Nations der Irokesenliga: Seneca, Cayuga, Onondaga, Mohawk und Oneida, zu denen 1722 die Tuscarora als sechste Nation stießen.

Außerhalb der Irokesenliga standen die historischen Konföderationen der Huronen, Petun, Neutral, Wenro, Erie und Susquehannock, die von der Irokesenliga in den Biberkriegen des siebzehnten Jahrhunderts vernichtet wurden; aus ihren Resten entstand das Wyandot, eine erst im zwanzigsten Jahrhundert ausgestorbene weitere Irokesensprache. Bereits im sechzehnten Jahrhundert ist hingegen das Laurentische ausgestorben.

Am bedeutendsten ist allerdings die südliche Irokesensprache Cherokee (Tsalagi), für die Sequoyah 1821 eine eigene Cherokee-Silbenschrift entwickelte. Zusammen mit den Chickasaws, Choctaws, Muskogee (Creek) und Seminolen ${ }^{458}$ gehörten sie 1820 zu den Fünf Zivilisierten Stämmen. Dessen ungeachtet wurden die Cherokee, nachdem die westlichen Cherokee bereits 1828 einer Umsiedlung nach Oklahoma zugestimmt hatten, infolge des von Andrew Jackson 1830 unterzeichneten „Indian Removal Act“ in den Jahren 1838-1839 zwangsumgesiedelt. Bei diesem „Trail of tears“ kamen rund 4.000 Cherokee ums Leben; die Umsiedlungsaktionen betrafen auch die anderen Zivilisierten Stämme.

In diesem Zusammenhang wird eine Ausgabe der Evangelien und des Psalters in Cherokee-Sprache vorgestellt; bis auf eine Cherokee-Schrifttafel und eine Wiedergabe des Vaterunsers in Cherokee-Schrift im Rahmen der Einleitung ist diese Ausgabe allerdings in lateinischer Schrift gedruckt.

458 Chickasaw, Choctaw und Maskoki (Creek) inklusive Seminolisch bilden gemeinsam mit Hitchiti-Mikasuki, Apalachee †, Alabama und Koasati die Muskogee-Sprachfamilie. Die Muskogee-Sprachen ihrerseits werden mit Natchez, Tunica, Atakapa und Chitimacha zu den Golf-Sprachen zusammengefasst, die wiederum mit Yuki und Wappo zum Penuti innerhalb des Amerind gerechnet werden, was insgesamt als hypothetisch gelten muss. 
Bibel. Evangelien und Bibel. Psalmen.

Cherokee-Sprache. Lateinische Schrift Nvgi Dikanoheda ale Hilvsgi Dinetlvtanvhi Dewi Dikanogidv Tsalagiya: Tsutloya Digohweli Tsalagi Ditse Dikanoheda $=$ The four gospels and selected psalms in Cherokee / Ruth Bradley Holmes. - Norman, Okla., [2004]

NÖ Landesbibliothek, Signatur 134.916 B Abb. 56

\subsection{Uto-aztekische Sprachen}

Die uto-aztekischen Sprachen bestehen aus den Numic-Sprachen (Shoshoni, Comanche, Panamint, Mono, nördliches Paiute, Kawaiisu, südliches Paiute und Ute), Hopi, den Takic-Sprachen (Serrano und Kitanemuk $\dagger$, Cahuilla und Cupeño $\dagger$, Luiseño-Juaneño, Gabrieleño-Fernandeño $\dagger$ ), Tübatulabal, O'odham (Pima-Papago), Pima Bajo und Tepehuán, Tarahumara und Huarijío, Yaqui und Mayo, Opata †, Cora und Huichol, Pochutec $\dagger$ und Nahuatl nebst Nawat (Pipil).

Wenn auch Schoschonen, Komantschen, die für Utah namensgebenden Ute, Pima und Papago bekannte Indianerstämme verkörpern und die nicht zuletzt durch die „Sapir-WhorfHypothese" bekannt gewordene Pueblo-Sprache Hopi von entsprechender Bedeutung ist,

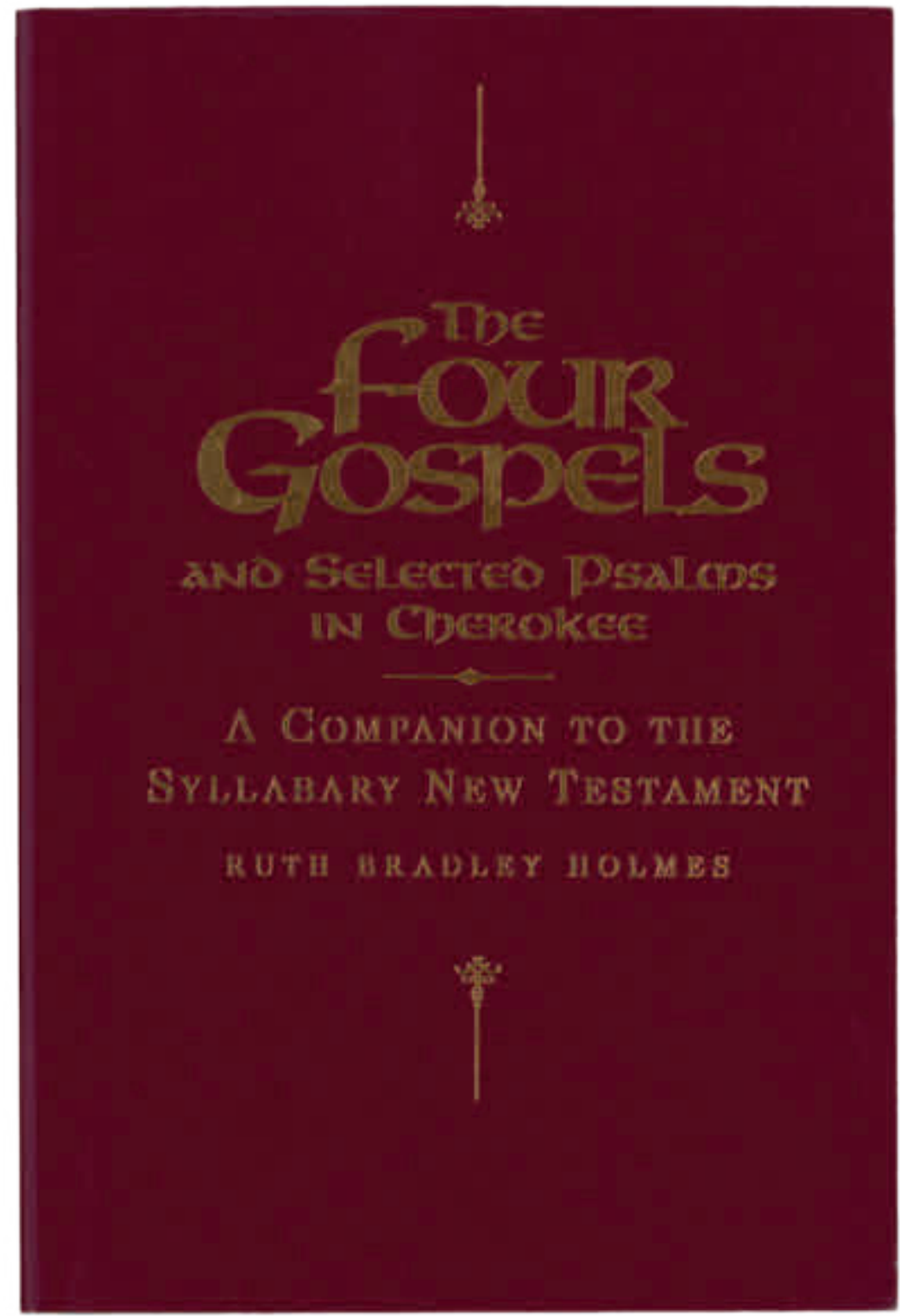

Abb. 56 / Katalog Nr. 207: The four gospels and selected psalms in Cherokee (2004). 
muss dennoch Nahuatl mit der Sprachform Klassisches Nahuatl (Aztekisch, Mēxihcatlahtōlli) und den von rund 1,5 Mio. Menschen gesprochenen heutigen Varianten als mit Abstand wichtigste Sprache der gesamten Sprachfamilie gelten; zu den geläufigen Fremdwörtern aus dem Nahuatl zählen unter anderem Avocado, Tomate, Chili, Kakao und Schokolade. Außer den Azteken werden übrigens auch die Tolteken als eines der historischen NahuaVölker betrachtet.

Die heutigen Nahuatl-Varianten werden in Zentral-Nahuatl, West-Nahuatl, Ost-Nahuatl und Huasteca-Nahuatl gegliedert; zu den sprecherreichsten Varianten zählen westliches und östliches Huasteca-Nahuatl sowie das zum Zentral-Nahuatl gehörende Guerrero Nahuatl, die alle drei durch ein Neues Testament vertreten sind.

208

Bibel. Neues Testament. Nahuatl (Huasteca Occidental). Lateinische Schrift

Nopa yancuic camanali catli toteco techtlajtolcahuilijtoc $=$ El Nuevo Testamento de Nuestro Señor Jesucristo en el náhuatl de la Huasteca Occidental. - 2009

NÖ Landesbibliothek, Signatur 134.806 B

209

Bibel. Neues Testament. Nahuatl (Huasteca Oriental). Lateinische Schrift

Ya ni nopa yancuic tlajtoli tlen toteco toca mocajtoc $=$ El Nuevo Testamento de nuestro Señor Jesucristo en el náhuatl de la Huasteca Oriental. - 2009

NÖ Landesbibliothek, Signatur 134.808 B

210

Bibel. Neues Testament. Nahuatl (Guerrero). Lateinische Schrift

In yencuic iyectlajtoltzin dios: itech ica toTeco Jesucristo $=$ El Nuevo Testamento de nuestro Señor Jesucristo en el náhuatl de Guerrero. - 2009

NÖ Landesbibliothek, Signatur 134.804 B

\subsection{Oto-Mangue-Sprachen}

Die Oto-Mangue-Sprachen umfassen unter anderem Otomi, Mazahua, Chinantekisch, Pame, Tlapanekisch, Popoloca, Mazatekisch, Zapotekisch, Chatino, Amuzgo und Mixtekisch; am bedeutendsten sind mit jeweils mehr als 500.000 Sprechern Zapotekisch und Mixtekisch, deren zahlreiche Varianten vor allem im mexikanischen Bundes- 
staat Oaxaca gesprochen werden. Beide Sprachen verfügten wie die Maya über ein Schriftsystem; ein Zeugnis des Mixtekischen bildet der „Codex Vindobonensis Mexicanus I“, eine Bilderhandschrift aus dem vierzehnten Jahrhundert. ${ }^{459}$ Mit den Zapoteken und Mixteken in Zusammenhang stehen die archäologischen Stätten Monte Albán und Mitla; ein berühmter Zapoteke war der bekannte mexikanische Politiker Benito Juárez (1806-1872). ${ }^{460}$

Das Zapotekische (Dialekt von Rincón) und das Mixtekische (Dialekt von Chayuco) sind jeweils durch ein Neues Testament vertreten.

\section{1}

\section{Bibel. Neues Testament. Rincon-} Zapotekisch. Lateinische Schrift Didza' cubi rucá'ana tsahui' $=$ El Nuevo Testamento en el zapoteco del Rincón. - 2009 NÖ Landesbibliothek, Signatur 134.810 B Abb. 57

212

Bibel. Neues Testament. ChayucoMixtekisch. Lateinische Schrift Tuhun ndyoo sihin tyehen $\tilde{n} i=$ El Nuevo Testamento en el mixteco de Chayuco. 2009

NÖ Landesbibliothek, Signatur 134.809 B

459 Der Codex beinhaltet mythologische Genealogien und Listen von Herrschern sowie Priestern.

460 Ab 1858 mexikanischer Staatspräsident und somit 1864 1867 letztlich siegreicher Gegenspieler Kaiser Maximilians von Mexiko.

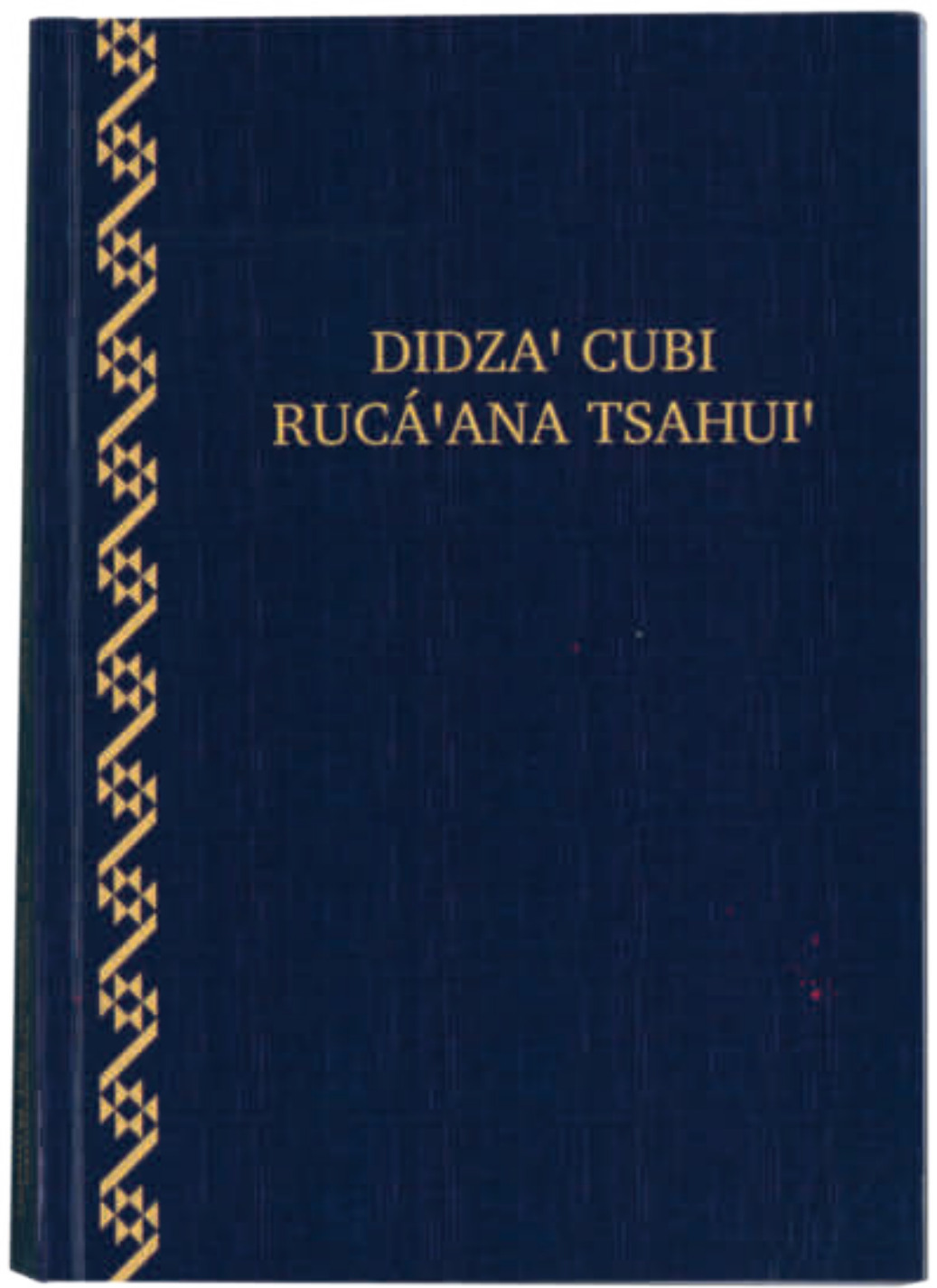

Abb. 57 / Katalog Nr. 211: Didza' cubi rucá’ana tsahui' = El Nuevo Testamento en el zapoteco del Rincón (2009). 


\subsection{Maya-Sprachen}

Die Maya sprechen über dreißig verschiedene Sprachen; ${ }^{461}$ die überwiegend epigraphisch überlieferte und in Maya-Schrift aufgezeichnete klassische Maya-Sprache dürfte eine literarische Form des Ch'olti', eines ausgestorbenen engen Verwandten des heutigen Ch'orti', gewesen sein. Das bekannte „Popol Vuh” ist allerdings in Quiché (K'iche') überliefert. Die Maya-Sprachen, deren Untergruppen jeweils in den Fußnoten näher beschrieben werden, gliedern sich in: Huastekisch, Yucatecan ${ }^{462}$, Cholan-Tzeltalan ${ }^{463}$, Chujean-Q'anjob'alan ${ }^{464}$ und QuicheanMamean ${ }^{465}$.

Von besonderem Interesse ist das Lakandonische, eine Abspaltung vom Yukatekischen Maya, das in der Selva Lacandona im südlichsten mexikanischen Bundesstaat Chiapas von rund 700 Menschen gesprochen wird. Im Unterschied zu den in der zweiten Hälfte des zwanzigsten Jahrhunderts christianisierten südlichen Lakandonen (im Gebiet des Sees von Lacanjá in der Nähe der Ruinenstadt Bonampak) wurden die nördlichen Lakandonen (im Gebiet des Sees von Najá, südöstlich von Palenque) nie christianisiert.

Neben dem Neuen Testament in Lakandonisch sind eine Apostelgeschichte in Yukatekischem Maya und ein Neues Testament in südlichem Mam zu sehen; die beiden letzteren Bücher sind jeweils zweisprachig MayaSprache und Spanisch.

213

Bibel. Apostelgeschichte. Maya-Sprache und Spanisch. Lateinische Schrift

Le Baaxoob tu Betajoob le Aj-tuchi'ob = Los hechos de los apostoles. - Mexiko (Stadt), 1958

NÖ Landesbibliothek, Signatur 146.630 B

214

Bibel. Neues Testament. Lakandonisch. Lateinische Schrift

A quet u t'Ano' a ric'beno' = El Nuevo Testamento en el lacandón de Lacanjá. - 2009

NÖ Landesbibliothek, Signatur 134.805 B

461 Im Rahmen des Amerind werden die Maya-Sprachen zusammen mit Huave, Mixe-Zoque und Totonakisch in die mexikanische Untergruppe des Penuti eingeordnet.

462 Yukatekisches Maya und Lakandonisch; Itza' und Mopan.

463 Ch'ol, Chontal und Ch'orti sowie Ch'olti' †; Tzeltal und Tzotzil.

464 Chuj und Tojolab'al; Q'anjob'al, Jakaltekisch und Akatekisch; Mocho'.

465 Mam und Tektitekisch; Ixil und Awakatekisch; Uspantekisch; Kaqchikel und Tz'utujil; K'iche' und Achí; Sakapultekisch und Sipakapensisch; Poqomchi' und Poqomam; Q'eqchi'. 
Bibel. Neues Testament. Quetzaltenango Mam und Spanisch. Lateinische Schrift

Ju' Ac'a'j Tu'jil Tu’n Kajau Jesucrist = El Nuevo Testamento de Nuestro Señor Jesucristo en Mam de Ostuncalco y Español (versión popular). - Guatemala (Stadt), 1980

NÖ Landesbibliothek, Signatur 134.805 B

\subsection{Aymara-Sprachen}

Die einzigen näheren Verwandten des Aymara sind Jaqaru und das fast ausgestorbene Kawki; die früher angenommene nähere Verbindung zum Quechua dürfte auf Lehnbeziehungen ${ }^{466}$ beruhen. Aymara war neben Quechua, Puquina (Pukina) $†$ und Muchik (Mochica) $†$ eine der vier großen Sprachen des Inka-Reichs und wird auf dem Altiplano im Südosten Perus und Westen Boliviens gesprochen. Die Hochkultur von Tiahuanaco (Tiwanaku) ca. 16 km südöstlich des Titicacasees im heutigen Aymara-Verbreitungsgebiet dürfte allerdings eher den Sprechern des ausgestorbenen Puquina zuzurechnen sein. Am Titicacasee wurde bis ins zwanzigste Jahrhundert auch die mit Chipaya verwandte Sprache Uru † gesprochen.

216

Bibel. Aymará-Sprache. Lateinische Schrift

Qullan Arunaka = Biblia Aymara. - Cochabamba, 2013

NÖ Landesbibliothek, Signatur 164.382 B

\subsection{Quechua-Sprachen}

Quechua, auch Ketschua, Qichwa, Qhichwa, Kichwa, Qheswa oder Runa Simi (Runa Shimi), ist eine Gruppe mehrerer Sprachen oder Dialekte, die hauptsächlich in Ecuador, Peru und Bolivien gesprochen werden. Man unterscheidet Waywash mit den Teilgruppen Wanka-Quechua (Huanca-Quechua), Ancash-Quechua, HuánucoQuechua (mit der Variante Huallaga-Quechua oder Wallaqa Runashimi) und Yaru-Quechua von Wampuy mit den Teilgruppen Yunkay, Chinchay (Kichwa) und Südliches Quechua. Waywash wird im zentralen Peru gesprochen, Südliches Quechua südlich davon, Yunkay nördlich davon, Kichwa noch weiter nördlich (hauptsächlich in Ecuador). Südliches Quechua mit den als Klassisches Quechua bezeichneten älteren Sprachstufen besteht aus Chanka-

466 Im Wortschatz, aber auch in phonologischer Hinsicht: Das Vorkommen ejektiver und aspirierter Plosive in der südlichen Quechua-Variante Qusqu-Qullaw (Cusco-Quechua und bolivianisches Quechua) wird als Aymara-Einfluss gedeutet. 
Quechua (Ayacucho-Quechua), Qusqu-Qullaw (Cusco-Quechua, nordbolivianisches Quechua, südbolivianisches Quechua) und dem argentinischen Quechua von Santiago del Estero; Qusqu-Qullaw ist phonologisch vom Aymara beeinflusst und weist als einzige Quechua-Varietät aspirierte und ejektive Plosive auf. Der schriftsprachliche Standard Südliches Quechua, der in Peru und Bolivien verwendet wird, orientiert sich am Chanka-Quechua, gibt aber die dem Qusqu-Qullaw eigenen aspirierten und ejektiven Plosive, denen im Chanka-Quechua einfache Plosive entsprechen, wieder; in Bolivien wird $\mathrm{j}$ statt $\mathrm{h}$ geschrieben. $\mathrm{Zu}$ den Fremdwörtern aus dem Quechua zählen Chinin, Guanako, Guano, Inka, Koka und Kokain, Kondor, Lama, Pampa, Puma, Quinoa und Vikunja.

Vorgestellt werden Bibeln in Cusco-Quechua, Ayacucho-Quechua und südbolivianischem Quechua; bereits 1923 ist die zweisprachige Ausgabe der Evangelien in Huánuco-Quechua (Huallaga-Quechua) und Spanisch als erste Bibelübersetzung in eine Waywash-Mundart erschienen.

\section{7}

\section{Bibel. Cusco-Quechua. Lateinische Schrift}

Diospa Simin Qelqa: Hebreo, Arameo, Griego rimaymanta Perú suyuq uray hap'iyninpi qheswa simiman t'ikrasqa $=$ Santa Biblia. - Lima, 2004

NÖ Landesbibliothek, Signatur 143.350 B

218

Bibel. Ayacucho-Quechua. Lateinische Schrift

Chuya Qellqa = La Biblia en Quechua Ayacuchano: traducción directa de los textos originales: hebreo, arameo y griego. - Lima, 1987

NÖ Landesbibliothek, Signatur 141.480 B

219

Bibel. Quechua (Südbolivien). Lateinische Schrift

Qheshwa Biblia. - Cochabamba, 1986

NÖ Landesbibliothek, Signatur 146.635 B

220

\section{Bibel. Evangelien. Huanuco-Quechua und Spanisch. Lateinische Schrift}

Apunchic Jesucristoc Chuscu Evangeliocuna o sea los cuatro evangelios = The four gospels in QuechuaHuanuco and Spanish. - London, 1923 


\subsection{Tupí-Sprachen}

Zum Tupí-Guaraní-Zweig der Tupí-Sprachen gehören unter anderem die Untergruppen Guaraní, Guarayu und Tupí ${ }^{467}$; Guaraní wiederum besteht neben dem paraguayanischen Guaraní aus dem ostbolivianischen Chiriguano, dem westbolivianischen Simba, Mbyá Guaraní, Chiripá Guaraní, Kaiwá, Aché und Xetá. Mit dem Guaraní verbunden sind die Jesuitenreduktionen ${ }^{468}$ des sechzehnten und siebzehnten Jahrhunderts in Paraguay und angrenzenden Ländern. Das heutige paraguayische Guaraní ist aber kein direkter Nachfolger der Sprache in diesen Reduktionen, die nach deren Schließung in demselben aufgegangen ist. Diese Volkssprache ist weniger puristisch und stärker von Hispanismen durchsetzt als die frühere Missionssprache. Zu den Fremdwörtern aus den Tupí-Sprachen zählen Cashew, Capybara, Jaguar, Jaguarundi, Maracas, Maniok, Petunie, Piranha, Seriema, Tapioka, Tapir und Tukan.

Hier wird eine Bibel in ostbolivianischem Guaraní (auch Chiriguano oder Ava Guaraní) vorgestellt. Die Chiriguanos, die die Sprecher des Chané ${ }^{469}$ absorbiert haben, wurden erst ab Mitte des neunzehnten Jahrhunderts erfolgreich christianisiert; ihr letzter kriegerischer Aufstand wurde 1892 niedergeschlagen.

\section{1}

Bibel. Guaraní (Chiriguano). Lateinische Schrift

Tumpa Iñee = Biblia Guaraní. - Cochabamba, 2001

NÖ Landesbibliothek, Signatur 143.641 B

\subsection{Trans-Neuguinea-Sprachen (Ost-Neuguinea-Hochland-Sprachen)}

Die nicht zum Austronesischen gehörenden Sprachen auf Neuguinea und weiteren Inseln in deren Umgebung (vor allem Halmahera, Timor, Neuirland, Neubritannien, Bougainville) werden als Papua-Sprachen bezeichnet; die rund 800 Papua-Sprachen gehören einer Reihe wahrscheinlich untereinander nicht verwandter Sprachfamilien an. Als größte Sprachfamilie gelten die Trans-Neuguinea-Sprachen; zu diesen zählen die Ost-Neuguinea-Hochland-Sprachen mit Enga und weiteren Sprachen im West-Zentral-Unterzweig, was aber nicht unwidersprochen ist. Enga ist mit über 200.000 Sprechern die zahlenmäßig bedeutendste Papua-Sprache, die daher in vorliegende Zusammenstellung mit eingeschlossen wird.

467 Mit Nheengatu, zurückgehend auf die vom Tupinambá abstammende Língua geral amazônica.

468 Von der Jesuitenmission errichtete Siedlungen für die indigene Bevölkerung.

469 Wie auch Guaná eine ausgestorbene Variante der Arawak-Sprache Terena. 
Bibel. Neues Testament. Enga-Sprache. Lateinische Schrift

Enga Nutesamene Baipolo = Enga New Testament. - Conroe, Tex., 1988

NÖ Landesbibliothek, Signatur 202.986 B

\subsection{Pama-Nyunga-Sprachen}

Abgesehen von den zahlreichen kleineren Sprachfamilien im Norden Australiens wird der Kontinent von den Pama-Nyunga-Sprachen dominiert, die aber Robert M.W. Dixon (*1939) nur als Sprachbund und nicht als Sprachfamilie gelten lassen will, ${ }^{470}$ unklar bleibt die Einordnung der ausgestorbenen tasmanischen Sprachen in die australischen Sprachen.

Die Bibel oder Teile der Bibel können in folgenden Sprachen präsentiert werden: Kala Lagaw Ya (bzw. deren Dialekt Kala Kawaw Ya), die Sprache der westlichen Torres-Strait-Inseln, die aber deutlich von der Sprache der östlichen Torres-Strait-Inseln Meriam Mir beeinflusst ist; Meriam Mir gehört zu den Östlichen Trans-FlySprachen und ist somit eine Papua-Sprache. Eine der größten australischen Sprachen ist Walbiri (Warlpiri) aus der Ngarrka-Untergruppe der Ngumpin-Yapa-Sprachen im Northern Territory (Northern Desert Fringe Area languages), noch bedeutender ist Pitjantjatjara (Wati-Sprachen bzw. Western Desert languages), das im Zentralraum des Kontinents (sowohl im Northern Territory als auch in Westaustralien und Südaustralien) gesprochen wird. Auf dem Gebiet der Pitjantjatjara (Anangu) liegt der Uluru-Kata-Tjuta-Nationalpark, in dessen Verwaltung sie eingebunden sind. Zu den Arandic languages gehört schließlich Alyawarr (Alyawarre), der wichtigste Dialekt des (Upper) Arrernte nach dem weiter südlich im Raum Alice Springs gesprochenen östlichen bzw. zentralen Arrernte.

\section{3}

Bibel. Genesis, Evangelien, Römerbrief, 1. und 2. Timotheusbrief. Kala Lagaw Ya (Kala Kawaw Ya). Lateinische Schrift

Minar Poelayzimayl = Genesis, Matthew, Mark, Luke, John, Romans, 1 \& 2 Timothy in Kalaw Kawaw dialect of the Kala Lagaw language, Torres Strait, Australia. - Minto (New South Wales), 2014

NÖ Landesbibliothek, Signatur 203.405 B

Abb. 58

470 Vgl. Nicholas Evans, Australian languages reconsidered: a review of Dixon (2002). In: Oceanic linguistics 44 (2005) 242-286, online unter: https://www. researchgate.net/publication/236719294_Australian_Languages_Reconsidered_A_Review_of_Dixon_2002 (10.6.2020). 


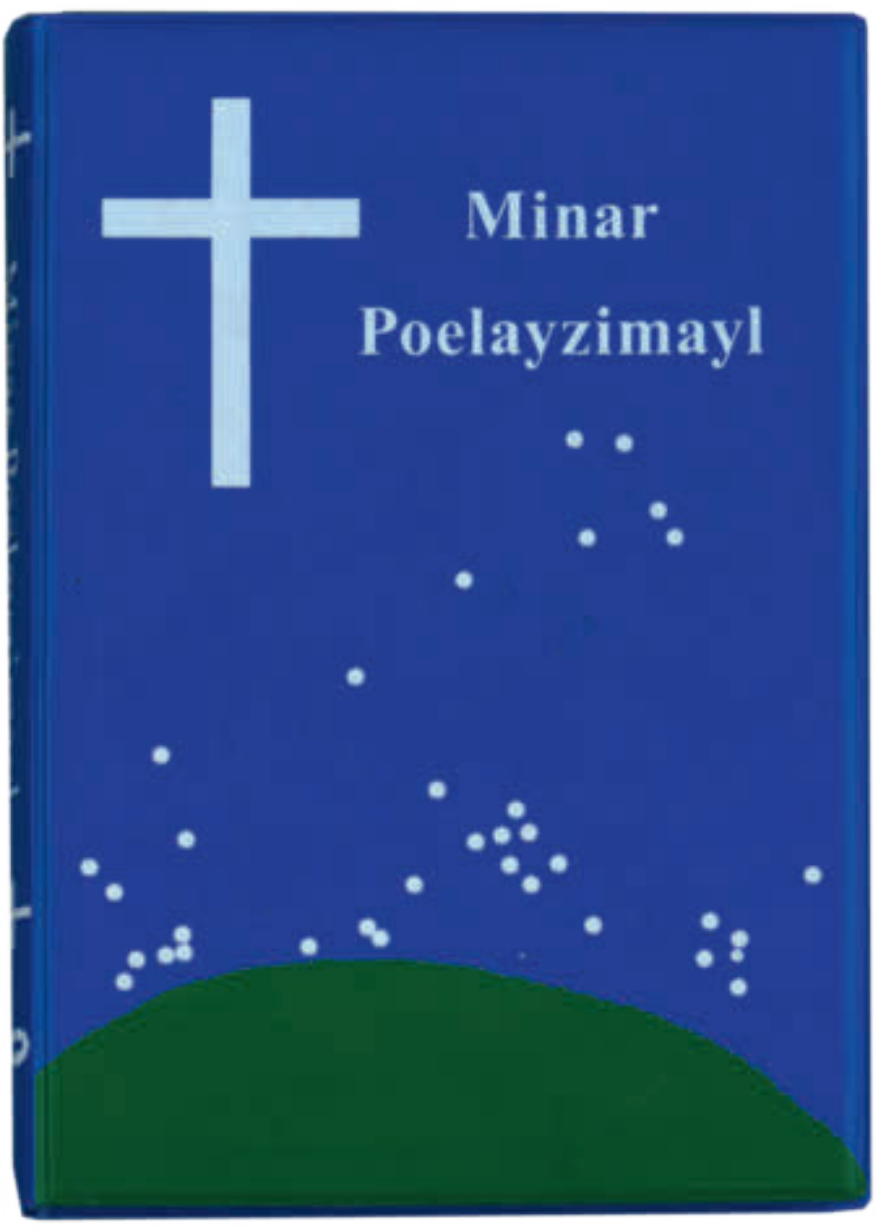

Abb. 58 / Katalog Nr. 223: Minar Poelayzimayl = Genesis, Matthew, Mark, Luke, John, Romans, 1 \& 2 Timothy in Kalaw Kawaw dialect of the Kala Lagaw language, Torres Strait, Australia (2014).

\section{YIMI-NYAYAIRNI-WANGU KAATU-KURULANGU}

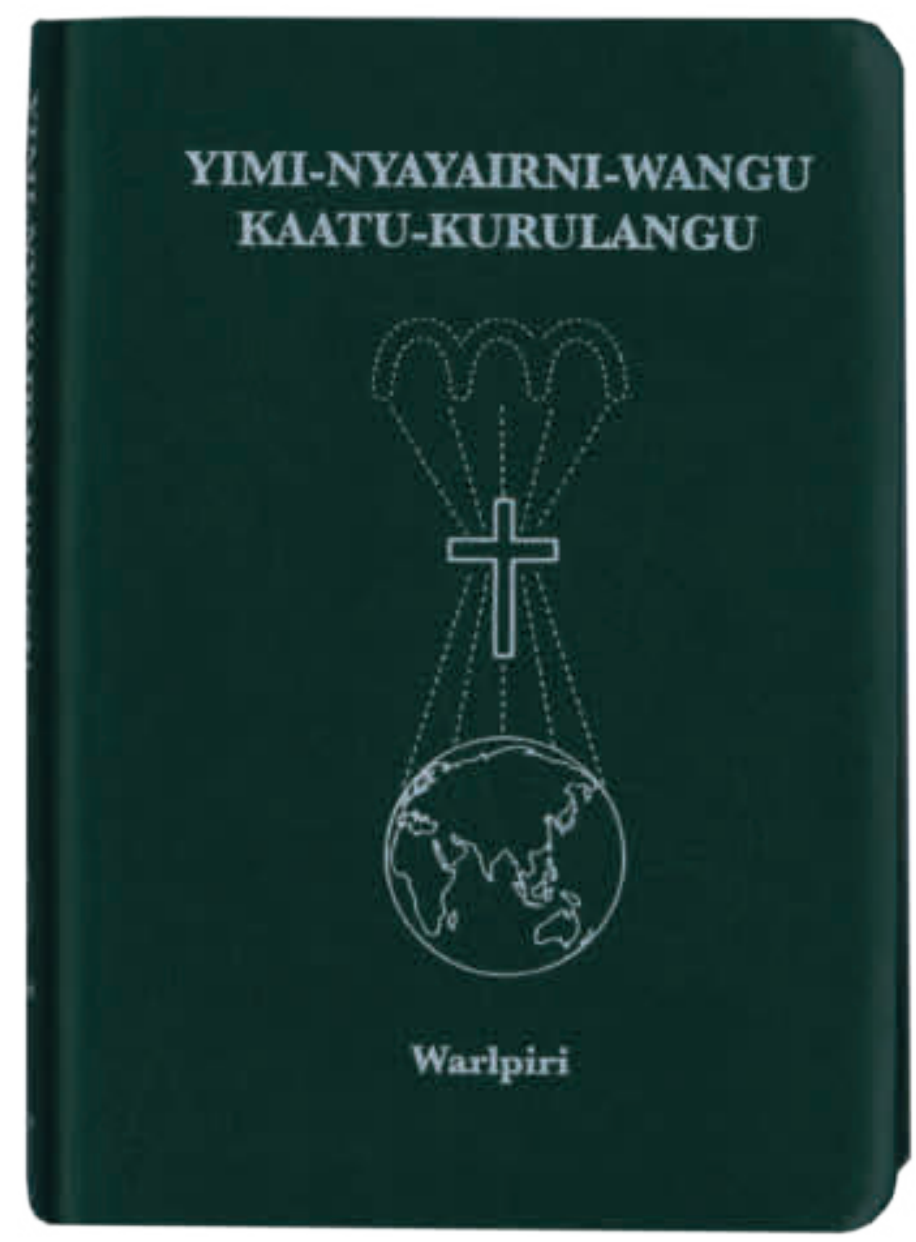

Abb. 59 / Katalog Nr. 224: Yimi-Nyayirni-Wangu KaatuKurlangui: Warlpiri $=$ The Bible in Warlpiri, Central Australia (2014). 


\section{4}

\section{Bibel. Walbiri-Sprache. Lateinische Schrift}

Yimi-Nyayirni-Wangu Kaatu-Kurlangu: Warlpiri = The Bible in Warlpiri, Central Australia: containing the Old Testament books of Genesis, Ruth, Jonah and selections from Exodus, Numbers, Deuteronomy, Joshua, Judges $\&$ Psalms and the complete New Testament [God's Sacred Story in the Warlpiri Language]. - Minto (New South Wales), 2014

NÖ Landesbibliothek, Signatur 203.407 C

Abb. 59

\section{5}

\section{Bibel. Alyawarra-Sprache und Englisch. Lateinische Schrift}

Angka Mwerr-angker $=$ Good News: Alyawarr, Northern edition [Portions of the Old Testament in Alyawarr together with portions of the New Testament in Alyawarr and English, Northern edition]. - Sydney, 2017 NÖ Landesbibliothek, Signatur 203.406 B

\section{6}

\section{Bibel. Pitjantjatjara-Sprache. Lateinische Schrift}

Tjukurpa Palya $=$ The Bible in Pitjantjatjara, the language of Central Australia: (containing Old Testament portions and the full New Testament). - Sydney, 2019

NÖ Landesbibliothek, Signatur 103.408 B

\subsection{Braille-Schrift}

Nach einem linguistischen Streifzug von Europa ausgehend rund um den Globus bis nach Australien folgt eine Rückkehr zu Menschen, die noch nicht berücksichtigt wurden: Zu Menschen mit besonderen Bedürfnissen gehören blinde und taube Menschen, was Auswirkungen auf Präsentationsformen (auch biblischer Texte) hat. Eine Möglichkeit der Expression besteht in der Form des Hörbuches (gesprochenes Wort), wozu wir auch AudioStreamingdienste zählen. Dann gibt es die Gebärdensprachen, die als unabhängig von der Lautsprache ihrer Umgebung und somit als eigenständige Sprachen anzusehen sind und sich auch in Sprachfamilien gliedern lassen: Zu den französischen Gebärdensprachen gehören neben der Langue des signes française (LSF) von 1752 unter anderem die daraus entwickelte Österreichische Gebärdensprache (ÖGS) und die American Sign Language (ASL), nicht aber die Deutsche Gebärdensprache (DGS). Druckausgaben biblischer Texte in Gebärdensprache 


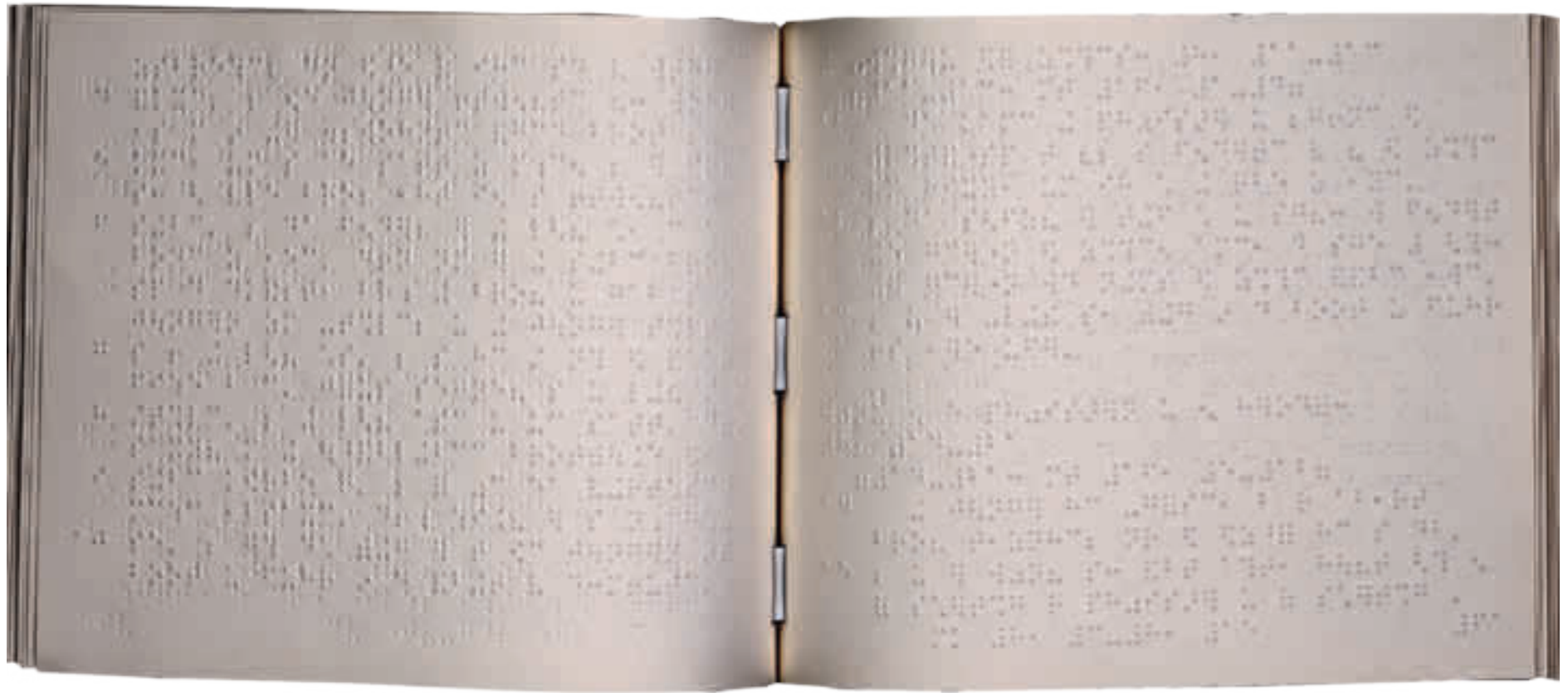

Abb. 60 / Katalog Nr. 227: : $: \because: .:^{\bullet}=$ Markus (Markusevangelium, Braille-Schrift), aufgeschlagen (o. J.).

besitzt die Niederösterreichische Landesbibliothek keine; einen Eindruck vermitteln aber die unter www.bible-lsf. org abrufbaren Videosequenzen von Teilen der Bibel in LSF.

Was demonstriert werden kann, ist das Markusevangelium in der 1825 erfundenen Brailleschrift mit einer taktilen 6-Punkte-Kodierung für jeden Buchstaben.

\section{7}

Bibel. Markusevangelium. Deutsch. Brailleschrift

$$
\because \because \because \therefore:^{\circ}=\text { Markus }
$$

NÖ Landesbibliothek, Signatur 203.277 C

Abb. 60 


\section{REGISTER DER VERTRETENEN SPRACHEN UND SCHRIFTEN}

A

Afrikaans 91, 92, 93

Albanisch 6, 88, 109

Althochdeutsch 5, 45, 51, 91, 92

Altkirchenslawisch 104

Altpreußisch 99

Altsächsisch 5, 51, 52, 92

Alyawarra-Sprache 180

Amharisch 141, 144, 147, 149

Arabisch 142, 143, 147, 148, 150

Arabische Schrift 113, 115, 118, 148

Armenisch 6, 88, 110

Armenische Schrift 111

Aschanti-Sprache 160

Aserbaidschanisch 124, 125

Äthiopische Schrift 149, 150

Awarisch (Kaukasus) 128, 129

Aymará-Sprache 175

B

Bahasa Indonesia 139

Bahasa Malaysia 139

Baskisch 6,87

Bengali 116, 117, 119

Bengalische Schrift 119

Birmanisch 133, 134, 135

Birmanische Schrift 135

Brailleschrift 181

I82

Bretonisch 88, 89
Bulgarisch 101, 102, 103, 107

Burgenlandkroatisch 105

Burgenland-Romani 117

Burjatisch 126

C

Cherokee-Schrift 170

Cherokee-Sprache 170, 171

Chinesisch 117, 133, 135

Chinesische Schrift 135

Chinesische Schrift (Kurzzeichen) 135

Chinesische Schrift (Langzeichen) 135

\section{D}

Dakota-Sprache 169, 170

Dänisch 90, 92, 95

Darginisch 128, 130

Deutsch 23, 24, 36, 37, 44, 45, 48, 52, 54, 56, 57, 59, $60,61,62,68,72,73,76,77,91,92,181$

Devanagari-Schrift 118

Dunganisch 135

$\mathbf{E}$

Edo-Sprache (Bini) 161

Enga-Sprache 178

Englisch 66, 90, 91, 92, 94, 117, 180

Esperanto 6, 87

Estnisch 122, 123

Ewenisch (Lamutisch) 127 
Ewenkisch (Tungusisch) 127

Ewe-Sprache 160

F

Färöisch 90, 92, 94

Fārsī Siehe Persisch

Finnisch 122

Französisch 96, 97, 98, 167

Fulfulde 85, 141, 157, 158, 159

Fulfulde (Maasina) 159

G

Gagausisch 123

Gälisch-Schottisch 88, 89, 90, 167

Ga-Sprache 160

Georgisch 130, 131

Georgische Schrift 131

Gotisch 5, 49, 50, 90, 92

Griechisch $6,22,23,24,36,44,45,50,88,107,110$, 147

Griechische Schrift 23, 24, 36, 45, 50, 109

Grönländisch 164, 165

Guaraní (Chiriguano) 177

\section{H}

Haida-Sprache 165

Hausa-Sprache 157

Hawaiisch 139, 140

Hebräisch 20, 23, 27, 35, 44, 66, 141, 142, 144, 145, 147, 148

Hebräische Schrift 20, 23, 27, 37, 44, 66, 149

Hindi 116, 117, 118

Hmong Njua (Blue Hmong) 136
Igbo-Sprache 161

Irisch 88

Isländisch 90, 92, 94

Italienisch 96, 97, 98

Itelmenisch (Kamtschadalisch) 127

J

Jakutisch 124, 125

Japanisch 6, 132, 133

Japanische Schrift (Kanji+Hiragana+Katakana)

$132,133,134$

Jiddisch 63, 66, 92

K

Kabardinisch 128

Kala Kawaw Ya Siehe Kala Lagaw Ya

Kala Lagaw Ya 178

Kalmückisch 126

Kambodschanisch 136, 137

Kanadische Silbenschrift 168, 169

Katalanisch 96, 97

Khmer-Schrift 116, 137

Khoekhoegowab 141, 163, 164

Koptisch 7, 42, 140, 144, 150, 151

Koptisch (Bohairisch) 150, 151, 153

Koptische Schrift 152, 153

Koptisch (Sahidisch) 150, 151, 152

Koreanisch 6, 131, 132

Koreanische Schrift (Hangul) 131, 132

Korjakisch 127

Kroatisch 101, 103, 106

Kurdisch (Kurmandschi) 113, 115

Kurdisch (Soranī) 113 
Kymrisch 88, 89, 90

Kyrillische (kirchenslawische) Schrift 104

Kyrillische Schrift 104, 106, 107, 125, 126, 129,

130,135

L

Ladinisch 96, 97, 98

Lakandonisch 174

Lakkisch 128, 130

Laotisch 137, 138

Laotische Schrift 138

Latein Siehe Lateinisch

Lateinisch $16,19,36,37,49,51,56$

Lateinische Schrift 16, 17, 19, 24, 36, 37, 44, 45, $50,56,57,59-62,64,66,72,73,76,77,87,90$, 93-95, 97, 98, 100, 104-106, 109, 115, 119, 122-124, 135-137, 139, 140, 148, 154, 157, 159-161, 163-165, $167-178,180$

Lettisch 99, 100

Litauisch 99, 100

Lovari (Lovara-Romani) 117

M

Maasai-Sprache 162, 163

Malayalam 116, 120, 121

Malayalam-Schrift 116, 121

Maltesisch 141, 143, 147, 148

Mam (Quetzaltenango) 175

Maori-Sprache 139, 140

Maya-Sprache 174

Mazedonisch 101, 103, 106

Mennonitendeutsch 64, 92

Mittelhochdeutsch 17, 67, 91, 92

I84 Mixtekisch 172, 173
Mixtekisch (Chayuco) 173

Mongolisch 126

$\mathbf{N}$

Nahuatl 171, 172

Nama-Sprache Siehe Khoekhoegowab

Nanaiisch (Goldisch) 127

Navajo-Sprache 167

Nenzisch 122

Neugriechisch 21, 108, 109

Neuhebräisch 36, 37, 144, 149

Neuostaramäisch 146, 149

Niederdeutsch 64, 92

Niederländisch 91, 92, 93

Niedersorbisch 102,104

Nordsaamisch 122,123

Norwegisch (Bokmål) 90, 92, 95

Norwegisch (Nynorsk) 90, 92, 95

O

Obersorbisch 102, 105

Ostarmenisch 110, 111

$\mathbf{P}$

Pennsylvaniadeutsch 66,92

Persisch 113

Pitjantjatjara-Sprache 180

Plains-Cree-Sprache 168

Plautdietsch Siehe Mennonitendeutsch

Polnisch 101, 103, 105

Portugiesisch 96, 97

Q

Quechua 7, 167, 175, 176 
Quechua (Ayacucho) 176

Quechua (Cusco) 175, 176

Quechua (Huanuco) 176

$\mathbf{R}$

Rumänisch 96, 97, 98, 117

Russisch 101, 103, 104

Russisch-Kirchenslawisch 104

S

Sanskrit $88,112,115,116,117,118,120$

Saterfriesisch 92, 93

Saulteaux-Sprache (Western Ojibwe, Plains

Ojibwe) 168, 169

Schwedisch 90, 92, 95

Serbisch 101, 103, 106

Slowakisch 101, 103, 106

Slowenisch 101, 103, 106

Somali 154

Spanisch 96, 97, 174, 175, 176

Swahili 159, 161

Sylter Friesisch (Sölring) 91, 92, 94

Syrisch 35, 37, 121, 142, 143, 146, 147, 149

Syrische Schrift 149

T

Tabassaranisch 128,130

Tagalog 138, 139, 140

Tamaschek Siehe Tuareg-Sprache

Tamil 116, 120, 121

Tamil-Schrift 116, 121

Thailändisch 137, 138

Thai-Schrift 138

Tibetisch 133, 134, 135
Tibetische Schrift 135

Tifinagh-Schrift (Tuareg-Schrift) 144, 155, 156

Tigrinja 150

Tschechisch 101, 103, 105

Tschetschenisch 128, 129

Tschuktschisch 6, 127

Tschuwaschisch 123, 124, 125

Tuareg-Sprache 155

Tuareg-Sprache (Tawallammat) 155, 156

Türkisch 123, 124

$\mathbf{U}$

Uigurisch 124,125

Ukrainisch 101, 103, 107

Ungarisch 122, 123

Urdu 116, 117, 118

V

Vietnamesisch 136, 137

W

Walbiri-Sprache (Warlpiri-Sprache) 178, 180

Walisisch Siehe Kymrisch

Westarmenisch 110, 111

Westfriesisch 92, 93

Wolof 157, 159, 160

Y

Yoruba-Sprache 161

Z

Zapotekisch 172, 173

Zapotekisch (Rincon) 173 


\section{ABBILDUNGSVERZEICHNIS}

Abb. 1 / Katalog Nr. 1: Handschrift 54 der Diözesanbibliothek St. Pölten (um 1230), Blatt 5r, bewohnte Initiale mit dem Hexaemeron (Sechstagewerk).

Abb. 2 / Katalog Nr. 2: Codex 4 der Stiftsbibliothek Klosterneuburg (um 1410), Blatt 10r, bewohnte Initiale mit dem Evangelisten Johannes und seinem Adler (siehe auch Umschlagbild).

Abb. 3 / Katalog Nr. 3: Albrecht Dürer, Hieronymus im Gehäus, Kupferstich 1514 (SLUB Dresden / Deutsche Fotothek / Hans Loos).

Abb. 4 / Katalog Nr. 4: Johannes Franciscus de Pavinis, Oratio in laudem Leopoldi Marchionis Austriae (1485?), Einband mit Pergamentmakulatur. NÖ Landesbibliothek 139.394 B.

Abb. 5 / Katalog Nr. 5: Fragment der Megillat Ester (1400-1420). NÖ Landesarchiv Varia 012.

Abb. 6 / Katalog Nr. 17: Sixto-Clementina mit deutscher Übersetzung von Joseph Franz Allioli (1874). NÖ Landesbibliothek 147.543 B 1.

Abb. 7 / Katalog Nr. 19: The New Covenant commonly called The New Testament: Peshitta Aramaic text with a Hebrew translation (2005). NÖ Landesbibliothek 119.545 B.

Abb. 8 / Katalog Nr. 23: Nag Hammadi deutsch (2013). NÖ Landesbibliothek 164.879 B.

Abb. 9 / Katalog Nr. 29: Die Feier der Heiligen Messe. Die Sonn- und Festtage im Lesejahr A (2019). NÖ Landesbibliothek 196.785 C 1.

Abb. 10 / Katalog Nr. 35: Wilhelm Streitberg (Hg.), Die gotische Bibel. Band 1, Der gotische Text und seine griechische Vorlage (2000). NÖ Landesbibliothek 109.817 B 3.

Abb. 11 / Katalog Nr. 38: Die Gutenberg-Bibel von 1454: Faksimile-Ausgabe. Band 1 (2018). NÖ Landesbibliothek $198.463 \mathrm{C} 1$.

Abb. 12 / Katalog Nr. 39: Biblia, beider Allt vnnd Newen Testamenten. Durch D. Johan Dietenberger new verdeutscht (1534). Sammlung Gerhard Sarman.

Abb. 13 / Katalog Nr. 40: Das New Testament durch den hochgelehrten Herrn Hieronymum Emser (1626), Einband. NÖ Landesbibliothek 22.785 B.

Abb. 14 / Katalog Nr. 40: Das New Testament durch den hochgelehrten Herrn Hieronymum Emser (1626), Titelseite. NÖ Landesbibliothek 22.785 B. 
Abb. 15 / Katalog Nr. 41: Bibel von 1534 (Luther): vollständiger Nachdruck. 1, Das Alte Testament (2002). NÖ Landesbibliothek 101.291 C 1.

Abb. 16 / Katalog Nr. 43: Die Bibel oder die ganze heilige Schrift des Alten und Neuen Testaments nach der deutschen Übersetzung D. Martin Luthers (1894). NÖ Landesbibliothek 197.210 B.

Abb. 17 / Katalog Nr. 58: Dat Ole un dat Nie Testament in unse Moderspraak (Johannes Jessen, Niederdeutsch, 2006). NÖ Landesbibliothek 134.169 B.

Abb. 18 / Katalog Nr. 59: Daut Niehe Tastament (J.J. Neufeld, Plautdietsch, 1987). NÖ Landesbibliothek $134.427 \mathrm{~B}$.

Abb. 19 / Katalog Nr. 60: Es Nei Teshtament: Pennsylvania Deitsh un English (1993). NÖ Landesbibliothek $134.424 \mathrm{~B}$.

Abb. 20 / Katalog Nr. 63: Signiertes Porträtfoto Dr. Nivard Schlögl von Hans Saitz (1867-1944).

Abb. 21 / Katalog Nr. 63: Porträtfoto Nivard Schlögl von Fritz Knozer (1853-1923).

Abb. 22 / Katalog Nr. 66: Die heiligen Schriften des Alten Bundes. Aus dem kritisch wiederhergestellten hebräischen Urtexte übersetzt und kurz erläutert von Nivard Schlögl. Band 1, Das Buch Mosche, Jehoschua und Schophetim (1922). Mit Index-Hinweis. NÖ Landesbibliothek 32.255 B 1.

Abb. 23 / Katalog Nr. 68: Die Heilige Schrift des Alten Bundes. Herausgegeben von Pius Parsch (Klosterneuburg 1934). NÖ Landesbibliothek 127.508 B.

Abb. 24 / Katalog Nr. 69: Die Heilige Schrift des Neuen Bundes. Herausgegeben von Pius Parsch (Klosterneuburg 1934). NÖ Landesbibliothek 147.557 B.

Abb. 25 / Katalog Nr. 70: Pius Parsch, Laien-Rituale - das Buch des Lebens (2016) (Pius-Parsch-Studien; Band 13). NÖ Landesbibliothek 202.989 B.

Abb. 26 / Katalog Nr. 70: Porträtfoto Pius Parsch (Stift Klosterneuburg).

Abb. 27 / Katalog Nr. 71: Pius Parsch, Laien-Rituale - das Buch des Lebens (1939), Cover. NÖ Landesbibliothek $184.250 \mathrm{~B}$.

Abb. 28 / Katalog Nr. 71: Pius Parsch, Laien-Rituale - das Buch des Lebens (1939), Widmung für Alois Mock und Firmenstempel. NÖ Landesbibliothek 184.250 B.

Abb. 29 / Katalog Nr. 72: Missionshaus St. Gabriel (Verlag Missionshaus St. Gabriel), Druck nach koloriertem Schwarzweiß-Lichtbild, gelaufen 1930, Vorderseite. NÖ Landesbibliothek PK 785/1,86.

Abb. 30 / Katalog Nr. 72: Missionshaus St. Gabriel (Verlag Missionshaus St. Gabriel), Druck nach koloriertem Schwarzweiß-Lichtbild, gelaufen 1930, Rückseite. NÖ Landesbibliothek PK 785/1,86.

Abb. 31 / Katalog Nr. 73: Paul Schebesta, Baba wa Bambuti: vier Fahrten zu den Ituri-Pygmäen (1957). NÖ Landesbibliothek 21.923 B 1.

Abb. 32 / Katalog Nr. 74: P. W. Schmidt SVD, Die Sprachfamilien und Sprachenkreise der Erde. Atlas (1977). NÖ Landesbibliothek 44.660 D. 
Abb. 33 / Katalog Nr. 89: New American Standard Bible (1975). Mit Widmung für Alois Mock. NÖ Landesbibliothek $202.990 \mathrm{~B}$.

Abb. 34 / Katalog Nr. 102: Bibia (Ladinisch). Nuef Testamënt (2005). NÖ Landesbibliothek 134.007 B

Abb. 35 / Katalog Nr. 112: Biblija na gradišćanskohrvatskom jeziku (Stefan Geosits). Band 1 (2014). NÖ Landesbibliothek 202.662 C 1.

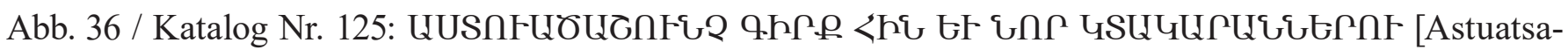
shunch' girk' hin ew nor ktakaranneru] = Western Armenian Bible (1981). NÖ Landesbibliothek 119.716 B.

Abb. 37 / Katalog Nr. 126: كتاب مُقدّس [Kitāb-i Muqaddas] = The Holy Bible, Today’s Persian Version (2007). NÖ Landesbibliothek 123.490 B.

Abb. 38 / Katalog Nr. 127: آيين قربانى مقدس [Āȳ̄n-i qurbān̄̄ muqaddas] = Die Heilige Messe in persischer Sprache mit deutscher Umschrift (übersetzt von Mag. theol. Jalalifar N. Anna Maria, 2018). NÖ Landesbibliothek 192.729 B.

Abb. 39 / Katalog Nr. 134: Biblia: Dulmutano thaj Nyevoteshtamenticko Suntoiskiripe (boldasles:VeshoFarkas Zoltán) = Ó- és Újszövetségi Szentírás (Lovari, 2008). NÖ Landesbibliothek 137.085 B.

Abb. 40 / Katalog Nr. 135: Eleonore Beck, O Del use pre fatschuvtscha vakerel: pisintschago andar i Biblina (Burgenland-Roman, 2008). NÖ Landesbibliothek 131.072 B.

Abb. 41 / Katalog Nr. 150: Лакин Хаза Кхаъ [Lakin Haza Khaq] (Tschetschenisch, Wien 2010). NÖ Landesbibliothek 133.667 B.

Abb. 42 / Katalog Nr. 155: 8o8mos [Biblia] (Georgisch, 2001). NÖ Landesbibliothek 119.718 B.

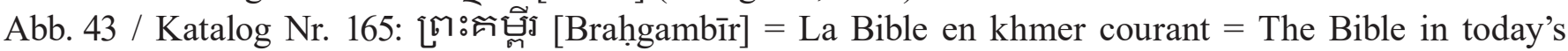
Khmer version (1997). NÖ Landesbibliothek 133.691 B.

Abb. 44 / Katalog Nr. 167: พระคริสตธรรมคัมภีร์ [Phra khrittham khamphī] = Thai Holy Bible (1998). NÖ Landesbibliothek 123.483 B.

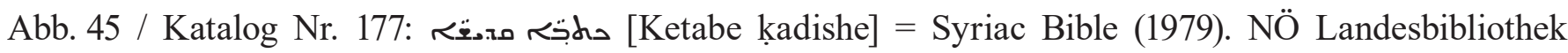
$124.406 \mathrm{~B}$.

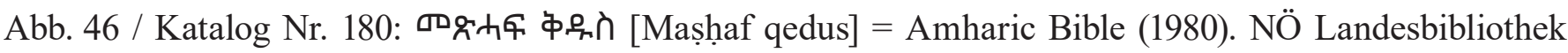
119.723 B.

Abb. 47 / Katalog Nr. 183: Uwe-Karsten Plisch, Einführung in die koptische Sprache: Sahidischer Dialekt (1999). NÖ Landesbibliothek 118.383 B 5.

Abb. 48 / Katalog Nr. 184: Das Thomasevangelium: Originaltext mit Kommentar (Uwe-Karsten Plisch, 2007). NÖ Landesbibliothek 118.737 B.

Abb. 49 / Katalog Nr. 187: Kitaabka Quduuska $\mathrm{Ah}=$ The Bible in Somali language (2008). NÖ Landesbibliothek $123.487 \mathrm{~B}$. 


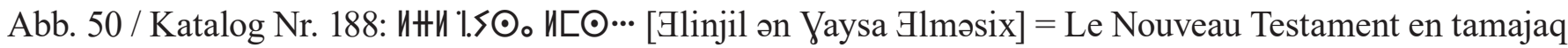
tawallammat, écriture shifinagh (2015). NÖ Landesbibliothek 203.050 B.

Abb. 51 / Katalog Nr. 191: Téereb Injiil di Kàddug Yàlla = Le nouveau testament en wolof (2004). NÖ Landesbibliothek $164.381 \mathrm{~B}$.

Abb. 52 / Katalog Nr. 200: Elobmîs (Khoekhoegowab, 2013). NÖ Landesbibliothek 203.997 B.

Abb. 53 / Katalog Nr. 203: Diyin God bizaad = The Holy Bible in Navajo (2000). NÖ Landesbibliothek 128.412 B.

Abb. 54 / Katalog Nr. 204: $\left.\nabla^{n} p \cup^{n} \subset\right\rceil^{\text {I }}$ [Oski Testament] = The New Testament in Western Cree (2000). NÖ Landesbibliothek 134.918 B.

Abb. 55 / Katalog Nr. 205: $\triangleright \Gamma \cdot V$ P L $\longleftrightarrow \propto \Delta b^{\circ}$ [Ojibwe Kihcimasina'ikan] = Bible in Ojibwe/Saulteaux (2008). NÖ Landesbibliothek 134.917 B.

Abb. 56 / Katalog Nr. 207: The four gospels and selected psalms in Cherokee (2004). NÖ Landesbibliothek $134.916 \mathrm{~B}$.

Abb. 57 / Katalog Nr. 211: Didza' cubi rucá'ana tsahui’ = El Nuevo Testamento en el zapoteco del Rincón (2009). NÖ Landesbibliothek 134.810 B.

Abb. 58 / Katalog Nr. 223: Minar Poelayzimayl = Genesis, Matthew, Mark, Luke, John, Romans, 1 \& 2 Timothy in Kalaw Kawaw dialect of the Kala Lagaw language, Torres Strait, Australia (2014). NÖ Landesbibliothek 203.405 B.

Abb. 59 / Katalog Nr. 224: Yimi-Nyayirni-Wangu Kaatu-Kurlangui: Warlpiri = The Bible in Warlpiri, Central Australia (2014). NÖ Landesbibliothek 203.407 C.

Abb. 60 / Katalog Nr. 227: : ‘ ::.: = Markus (Markusevangelium, Braille-Schrift), aufgeschlagen (o.J.). NÖ Landesbibliothek 203.277 C. 


\section{BILDNACHWEIS}

Abb. 1: Diözesanbibliothek St. Pölten.

Abb. 2: Stiftsbibliothek Klosterneuburg.

Abb. 3: SLUB Dresden / Deutsche Fotothek / Hans Loos.

Abb. 4, 29, 30: NÖ Landesbibliothek.

Abb. 5: NÖ Landesarchiv.

Abb. 12: Gerhard Sarman.

Abb. 20: Stift Heiligenkreuz (Fotograf Hans Saitz, 1867-1944).

Abb. 21: Stift Heiligenkreuz (Fotograf Fritz Knozer, 1853-1923).

Abb. 26: Stift Klosterneuburg.

Alle anderen Abbildungen: Wolfgang Kunerth (NÖLA).

Umschlagbild mit Detail (Initiale) aus Abb. 2. 


